Danilo Hernane Spatti

\title{
Automatização de Processos de Detecção de Faltas em Linhas de Distribuição Utilizando Sistemas Especialistas Híbridos
}

São Carlos 



\section{Automatização de Processos de Detecção de Faltas em Linhas de Distribuição Utilizando Sistemas Especialistas Híbridos}

Tese apresentada à Escola de Engenharia de São Carlos da Universidade de São Paulo, sendo parte dos requisitos para obtenção do título de Doutor em Ciências, Programa de Engenharia Elétrica, Área de Concentração em Sistemas Dinâmicos.

Orientador: Prof. Dr. Ivan Nunes da Silva 
AUTORIZO A REPRODUÇÃO E DIVULGAÇ̃̃O TOTAL OU PARCIAL DESTE TRABALHO, POR QUALQUER MEIO CONVENCIONAL OU ELETRÔNICO, PARA FINS DE ESTUDO E PESQUISA, DESDE QUE CITADA A FONTE.

Ficha catalográfica preparada pela Seção de Tratamento da Informação do Serviço de Biblioteca - EESC/USP

$\mathrm{S} 738 \mathrm{a}$

Spatti, Danilo Hernane.

Automatização de processos de detecção de faltas em linhas de distribuição utilizando sistemas especialistas híbridos / Danilo Hernane Spatti; orientador Ivan Nunes da Silva. São Carlos, 2011.

Tese (Doutorado - Programa de Pós-Graduação em Engenharia Elétrica e Área de Concentração em Sistemas Dinâmicos) - - Escola de Engenharia de São Carlos da Universidade de São Paulo, 2011.

1. Proteção de sistemas elétricos. 2. Sistemas de distribuição. 3. Detecção de faltas. 4. Sistemas híbridos. 5. Sistemas inteligentes. I. Título. 
FOLHA DE JULGAMENTO

Candidato(a): Engenheiro DANILO HERNANE SPATTI.

Tese defendida e julgada em 15/06/2011 perante a Comissão Julgadora:
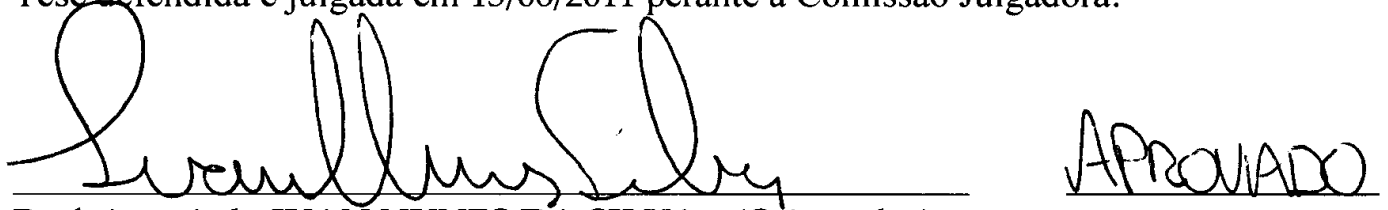

Prof. Associado IVAN NUNES DA SILVA - (Orientador)

(Escola de Engenharia de São Carlos/USP)

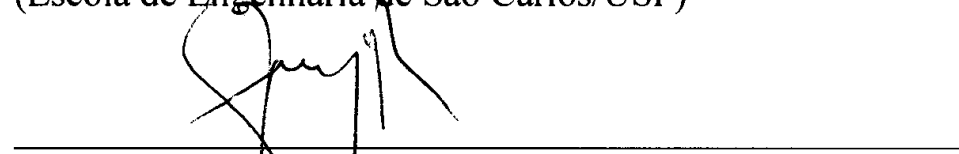

AROVADO

Prof. Titular JOSE PISSOLATO FILHO

(Universidade Estadual de Campinas/UNICAMP)

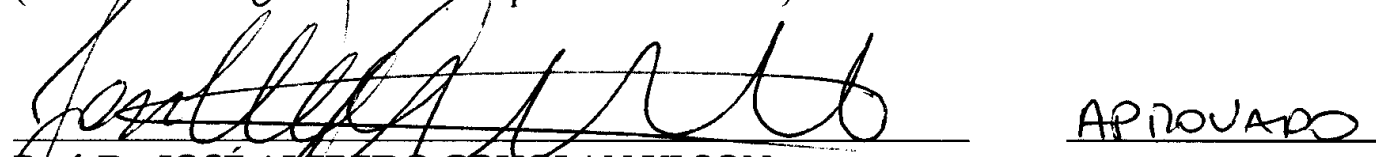

Ptof. Dr. JOSÉ AICREDQCovolan ULSON

UUniversidade Estadual Paulista "Júlio de Mesquita Filho"/UNESP/Campus de Bauru)

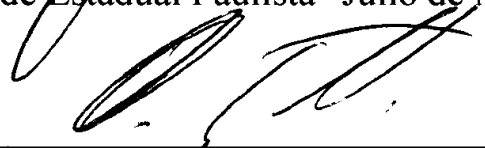

Prof. Dr. CLAUDIONORFRANCISCO DO NASCIMENTO

Arroundo

(Universidade Federal do ABC/ UFABC)

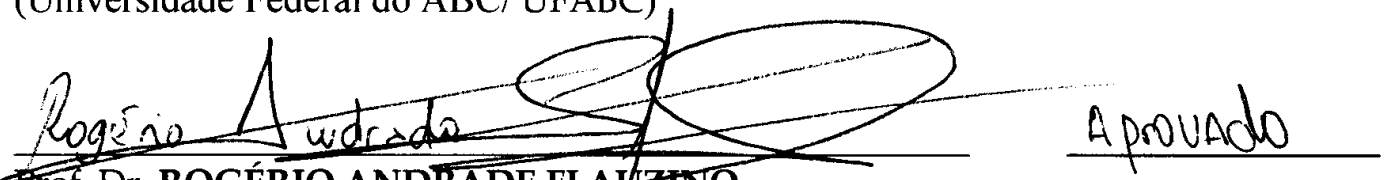

Trof. Dr. ROGÉRIO ANDRADE FLAYZTNO

(Escola de Engenharia de São Carlos/USP)

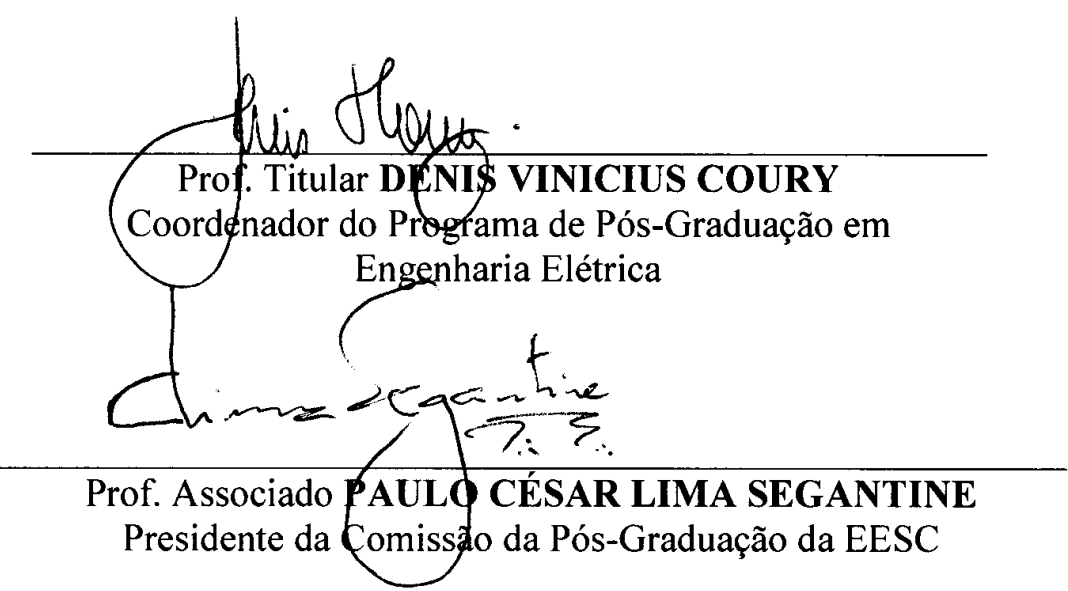



"Nós somos aquilo que fazemos repetidamente. Excelência, então, não é um modo de agir, mas um hábito"

Aristóteles 



\section{Agradecimentos}

Gostaria de agradecer à minha família, sobretudo pela paciência dedicada nas horas em que mais houve necessidade e em especial à Maria Fernanda pelo companheirismo e compreensão.

Ao Prof.Dr. Ivan Nunes da Silva pelo total apoio e ensinamentos nessa etapa de minha carreira.

Ao Prof.Dr. Rogério Andrade Flauzino pelos conselhos acadêmicos e pessoais que sempre atenciosamente ofereceu.

Ao Eng. ${ }^{\circ}$ MSc. Wesley Fernando Usida pela colaboração neste projeto de doutorado.

Aos funcionários da companhia ELEKTRO, em especial ao Eng. ${ }^{\circ} \mathrm{MSc}$. Valmir Ziolkowski e Enga ${ }^{a}$. MSc. Débora M.B.S Souza, por toda assistência e dedicação, sem os quais não seria possível a realização de parte deste trabalho.

Aos funcionários da USP de São Carlos, sempre disponíveis às necessidades dos alunos, em especial à Rosane Aranda, Marisa Helena R.Vicente Fortulan, Jussara Ramos Zoia, João Paulo Brognoni Casati e Roseli Ribeiro.

À FAPESP - Fundação de Amparo à Pesquisa do Estado de São Paulo, pelo auxílio financeiro concedido no período de realização deste trabalho (Processo 2007/03389-5). 



\section{Resumo}

SPATTI, D.H. (2011). Automatização de Processos de Detecção de Faltas em Linhas de Distribuição Utilizando Sistemas Especialistas Híbridos. Tese (Doutorado) - Escola de Engenharia de São Carlos, Universidade de São Paulo, 2011.

Identificar e localizar faltas em alimentadores de distribuição representa um passo importante para a melhoria da qualidade de energia, pois proporciona impactos diretos sobre o tempo de inspeção. Na verdade, a duração da inspeção implica consideravelmente no intervalo em que os consumidores estão sem energia elétrica, quando ocorre uma interrupção não programada. O objetivo deste trabalho é fornecer um sistema de detecção automática de curtos-circuitos, permitindo aos profissionais das companhias de distribuição acompanhar e monitorar de maneira on-line a ocorrência de possíveis faltas e transitórios eletromagnéticos observados na rede primária de distribuição. A abordagem de detecção utiliza um sistema híbrido que combina ferramentas inteligentes e convencionais para identificar e localizar faltas em redes primárias. Os resultados que foram compilados demonstram grande potencialidade de aplicação da proposta em sistemas de distribuição.

Palavras chave: Sistemas de Distribuição, Deteç̧ão de Faltas, Sistemas Híbridos, Sistemas Inteligentes. 



\section{Abstract}

SPATTI, D.H. (2011). Fault Detection Process Automation in Distribution Lines Using Hybrid Expert Systems (Doctor's Degree) - Escola de Engenharia de São Carlos, Universidade de São Paulo, 2011.

Efficient faults identification and location in power distribution lines constitute an important step for power quality improvement, since they provide direct impacts on the inspection time. In fact, the duration of inspection implies directly in the time interval where consumers are without power, considering here the occurrence of a non-programmed interruption. The objective of this work is to provide an automated fault detection system, allowing to the power companies engineers to online track and monitor the possible occurrence of faults and electromagnetic transients observed in the primary network for the distribution circuits. The detection approach uses a hybrid system, which combines a set of intelligent and conventional tools to identify and locate faults in the primary networks. Validation results show great application potential in distribution systems.

Keywords: Distribution Systems, Fault Detection, Hybrid Systems, Intelligent Systems. 



\section{Lista de Siglas e Abreviaturas}

ANEEL Agência nacional de energia elétrica

ANFIS Adaptive neuro-fuzzy inference system (sistema neuro-fuzzy adaptativo)

CFAR Constant false alarm rate (constante de falso alarme)

COD Centro de operação da distribuição

CTW Coeficientes da transformada wavelet

DEC Duração equivalente de interrupção por unidade consumidora

DFT Discrete fourier transform (transformada discreta de fourier)

DSP Digital signal processing (processamento digital de sinais)

ECG Eletro-cardiograma

EPRI Electric Power Research Institute

FEC Freqüência equivalente de interrupção por unidade consumidora

FFT Fast fourier transform (transformada rápida de fourier)

GSM Global system for mobile communications (sistema global para comunicação móvel)

MVD Mean value deviation (desvio do valor médio)

PCA Principal component analysis (análise por componentes principais)

RMS Root mean square (valor quadrático médio)

ROP Relation of power (relação de potência)

SCADA Supervisory control and data acquisition (sistemas de supervisão e aquisição de dados)

SGD Sistema de gestão de base de dados

SQL Structured query language (linguagem de consulta estruturada) 



\section{Lista de Figuras}

Figura 2.1 - Classes de conjuntos na lógica clássica. .......................................20

Figura 2.2 - Função de pertinência da lógica fuzzy. .............................................21

Figura 2.3 - Conjuntos de funções de pertinência da lógica fuzzy...........................22

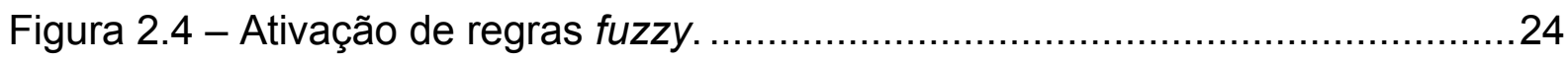

Figura 2.5 - Entrada do sistema fuzzy de exemplo..........................................25

Figura 2.6 - Saída do sistema fuzzy de exemplo.............................................25

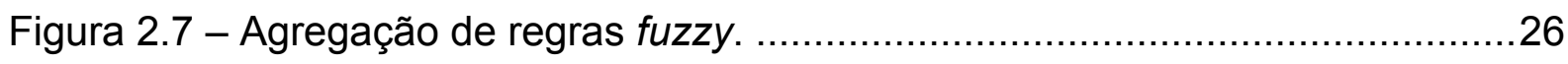

Figura 2.8 - Método de defuzzificação através do centro de área..........................27

Figura 2.9 - Representação do neurônio artificial.............................................28

Figura 2.10 - Representação das camadas de uma rede neural artificial.................30

Figura 2.11 - Modelo neural perceptron multicamadas. ......................................... 32

Figura 2.12 - Representação da aplicação da transformada wavelet........................34

Figura 2.13 - Aplicação da transformada wavelet em um sinal no tempo. ................35

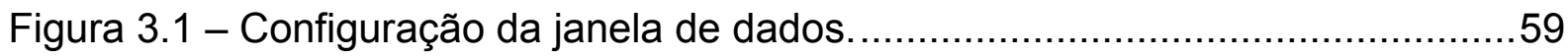

Figura 3.2 - Formas de onda de corrente e tensão para uma falta fase terra com

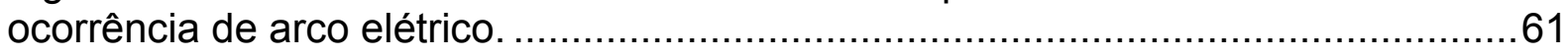

Figura 3.3 - Diagrama de blocos do método de diagnóstico de faltas baseado em características estatísticas das correntes de falta. .................................................62

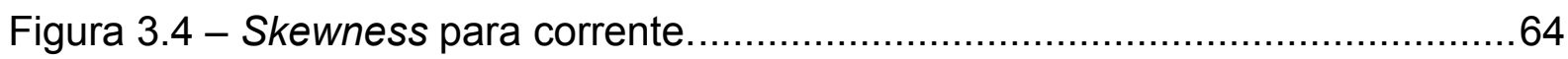

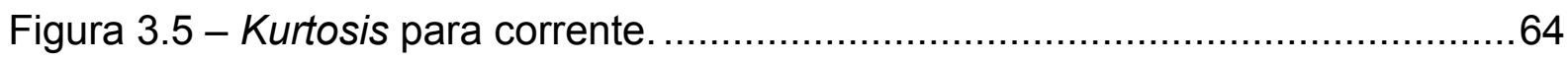

Figura 3.6 - Estrutura do sistema de diagnóstico de falta proposto..........................67

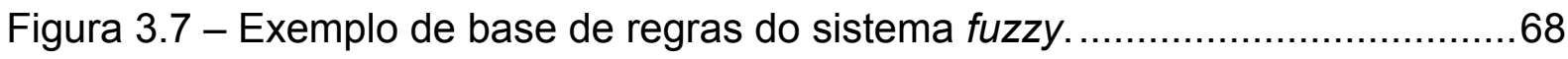

Figura 3.8 - Procedimentos para estimação de faltas para o sistema de inferência

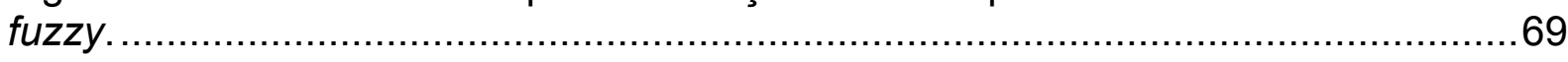

Figura 3.9 - Fluxograma do algoritmo de localização de falta proposto. ..................70

Figura 3.10 - Classificação de perturbações no domínio wavelet..............................73

Figura 3.11 - llustração de um sinal composto por diversas perturbações e sua representação no domínio wavelet. 
Figura 3.12 - Diagrama de blocos do esquema de detecção proposto.................. 75

Figura 3.13 - Diagrama de blocos representando o filtro adaptativo..................... 76

Figura 3.14 - Diagrama de blocos de modelo da falta de alta impedância. ............ 78

Figura 3.15 - Diagrama esquemático do sistema de localização de faltas por meio de redes neurais artificiais.

Figura 3.16 - Distância de falta em função dos autovalores. .............................. 82

Figura 3.17 - Modelo computacional para automatização do tratamento de faltas em sistemas de distribuição.

Figura 4.1 - Estatística RMS para correntes e tensões (ensaio I) ....................... 97

Figura 4.2 - Estatística CFAR para correntes e tensões (ensaio I). ...................... 98

Figura 4.3 - Estatística MVD para correntes e tensões (ensaio I) ......................... 99

Figura 4.4 - Estatística ROP para as correntes e tensões (ensaio I). .................. 100

Figura 4.5 - Estatística Autocorrelação para correntes e tensões (ensaio I).......... 100

Figura 4.6 - Estatística Kurtosis para correntes e tensões (ensaio I)................... 101

Figura 4.7 - Estatística Skewness para correntes e tensões (ensaio I). ................ 102

Figura 4.8 - Estatística RMS para correntes e tensões (ensaio II)...................... 103

Figura 4.9 - Estatística CFAR para correntes e tensões (ensaio II). ..................... 104

Figura 4.10 - Estatística MVD para correntes e tensões (ensaio II) . .................... 104

Figura 4.11 - Estatística ROP para correntes e tensões (ensaio II) ..................... 105

Figura 4.12 - Estatística Autocorrelação para correntes e tensões (ensaio II)....... 106

Figura 4.13 - Estatística Kurtosis para correntes e tensões (ensaio II)................ 106

Figura 4.14 - Estatística Skewness para correntes e tensões (ensaio II). ............ 107

Figura 4.15 - Desempenho das estatísticas na detecção de transitórios de corrente.

Figura 4.16 - Desempenho das estatísticas na detecção de transitórios de tensão. 108

Figura 4.17 - Representação esquemática do sistema de identificação de faltas.. 110

Figura 4.18 - Conexões de tensão e corrente para medição com oscilógrafo. ....... 111

Figura 4.19 - Oscilógrafo utilizado na leitura das variáveis elétricas.................... 112

Figura 4.20 - Diagrama do módulo de identificação de transitórios. .................... 113

Figura 4.21 - Diagrama do módulo Discriminador de faltas. ........................... 113 
Figura 4.22 - Diagrama do módulo identificador de fase.

Figura 4.23 - Mapa dos trechos primários do alimentador piloto modelado.

Figura 4.24 - Diagrama de blocos da modelagem no Matlab/Simulink do alimentador piloto.

Figura 4.25 - Falta fase-terra na fase B com uma resistência de falta de 9877 $\Omega$ : (a)

Tensões no início da falta; (b) Correntes no início da falta.

Figura 4.26 - Falta fase-terra na fase B com uma resistência de falta de $2714 \Omega$ : (a)

Tensões no início da falta; (b) Correntes no início da falta.

Figura 4.27 - Falta fase-terra na fase C com uma resistência de falta de $5149 \Omega$ : (a)

Tensões no início da falta; (b) Correntes no início da falta.

Figura 4.28 - Falta fase-terra na fase C com uma resistência de falta de $1170 \Omega$ : (a)

Tensões no início da falta; (b) Correntes no início da falta.

Figura 4.29 - Falta fase-terra na fase A com uma resistência de falta de $8847 \Omega$ : (a)

Tensões no início da falta; (b) Correntes no início da falta.

Figura 4.30 - Falta fase-fase entre a fase B e a fase C: (a) Tensões no início da falta; (b) Correntes no início da falta.

Figura 4.31 - Falta fase-fase entre a fase A e a fase B: (a) Tensões no início da falta;

(b) Correntes no início da falta.

Figura 4.32 - Falta fase-fase entre a fase B e a fase C: (a) Tensões no término da falta; (b) Correntes no término da falta.

Figura 4.33 - Falta fase-fase entre a fase A e a fase C: (a) Tensões no início da falta; (b) Correntes no início da falta.

Figura 4.34 - Falta fase-fase entre a fase A e a fase C: (a) Tensões no início da falta; (b) Correntes no início da falta.

Figura 4.35 - Falta trifásica próxima à subestação: (a) Tensões no início da falta; (b) Correntes no início da falta.

Figura 4.36 - Falta trifásica próxima ao meio do alimentador: (a) Tensões no início da falta; (b) Correntes no início da falta.

Figura 4.37 - Falta trifásica próxima ao término do alimentador: (a) Tensões no início da falta; (b) Correntes no início da falta.

Figura 4.38 - Falta trifásica próxima ao centro do alimentador: (a) Tensões no término da falta; (b) Correntes no término da falta.

Figura 4.39 - Falta trifásica de curta duração: (a) Tensões no término da falta; (b)

Correntes no término da falta.

Figura 4.40 - Falta fase-fase ao terra próximo à subestação entre as fases B e C: (a) Tensões no início da falta; (b) Correntes no início da falta. 129 
Figura 4.41 - Falta fase-fase ao terra próximo ao centro do alimentador entre as fases A e C: (a) Tensões no início da falta; (b) Correntes no início da falta. 130

Figura 4.42 - Falta fase-fase ao terra próximo ao centro do alimentador entre as fases B e C: (a) Tensões no início da falta; (b) Correntes no início da falta.

Figura 4.43 - Saída de carga próxima à subestação: (a) Tensões no instante de saída de carga; (b) Correntes no instante de saída da carga.

Figura 4.44 - Saída de carga próxima ao centro do alimentador: (a) Tensões no instante de saída de carga; (b) Correntes no instante de saída da carga.

Figura 4.45 - Saída de carga próxima ao fim do alimentador: (a) Tensões no instante de saída de carga; (b) Correntes no instante de saída da carga.

Figura 4.46 - Entrada de carga próxima à subestação: (a) Tensões no instante de entrada de carga; (b) Correntes no instante de entrada da carga.

Figura 4.47 - Entrada de carga próxima ao centro do alimentador: (a) Tensões no instante de entrada de carga; (b) Correntes no instante de entrada da carga........ 135

Figura 4.48 - Entrada de carga próxima ao fim do alimentador: (a) Tensões no instante de entrada de carga; (b) Correntes no instante de entrada da carga

Figura 4.49 - Erro quadrático médio ao longo do treinamento do módulo de identificação de transitório.

Figura 4.50 - Identificação de condições normais de operação e condições transitórias: (a) Resultados fornecidos pela rede neural; (b) Resultados desejados obtidos por meio de simulações do alimentador padrão

Figura 4.51 - Erro quadrático médio ao longo do treinamento do módulo discriminador de faltas.

Figura 4.52 - Discriminador de transitórios: (a) Resultados fornecidos pela rede neural; (b) Resultados desejados obtidos por meio de simulações do alimentador padrão.

Figura 4.53 - Erro quadrático médio ao longo do treinamento do módulo identificador de fase.

Figura 4.54 - Sistema identificador das fases participantes da falta com relação à Fase A: (a) Resultados fornecidos pela rede neural; (b) Resultados desejados obtidos por meio de meio de simulações do alimentador padrão.

Figura 4.55 - Sistema identificador das fases participantes da falta com relação à Fase B: (a) Resultados fornecidos pela rede neural; (b) Resultados desejados obtidos por meio de simulações do alimentador padrão.

Figura 4.56 - Sistema identificador das fases participantes da falta com relação à Fase C: (a) Resultados fornecidos pela rede neural; (b) Resultados desejados obtidos por meio de simulações do alimentador padrão. 
Figura 4.57 - Sistema identificador das fases participantes da falta com relação ao Terra: (a) Resultados fornecidos pela rede neural; (b) Resultados desejados obtidos por meio de meio de simulações do alimentador padrão.

Figura 5.1 - Diagrama esquemático do sistema de localização de faltas. 146

Figura 5.2 - Diagrama de funcionamento do Módulo 1 para localização de faltas.

Figura 5.3 - Diagrama do Módulo 2 para localização de faltas. 149

Figura 5.4 - Diagrama do Módulo 3 para localização de faltas. 151

Figura 5.5 - Diagrama do Módulo 4 de localização de faltas.

Figura 5.6 - Erro relativo médio das redes treinadas para o primeiro submódulo.

Figura 5.7 - Erro relativo médio das redes treinadas para o Módulo 1: (a) Submódulo 2; (b) Submódulo 3. 155

Figura 5.8 - Erro relativo médio das redes treinadas para o Módulo 1: (a) Submódulo 4; (b) Submódulo 5. 155

Figura 5.9 - Erro relativo médio das redes treinadas para o Módulo 1: (a) Submódulo 6; (b) Submódulo 7. 156

Figura 5.10 - Erro relativo médio das redes treinadas para o primeiro submódulo do módulo 2. 158

Figura 5.11 - Erro relativo médio das redes treinadas para o primeiro submódulo do Módulo 3. 160

Figura 5.12 - Resultados de simulação para o submódulo 1 do Módulo 1: (a) Resultados fornecidos pelo submódulo; (b) Resultados desejados.

Figura 5.13 - Resultados de simulação para o submódulo 2 do Módulo 1: (a) Resultados fornecidos pelo submódulo; (b) Resultados desejados. 163

Figura 5.14 - Resultados de simulação para o submódulo 3 do Módulo 1: (a) Resultados fornecidos pelo submódulo; (b) Resultados desejados. 164

Figura 5.15 - Resultados de simulação para o submódulo 4 do Módulo 1: (a) Resultados fornecidos pelo submódulo; (b) Resultados desejados. 165

Figura 5.16 - Resultados de simulação para o submódulo 5 do Módulo 1: (a) Resultados fornecidos pelo submódulo; (b) Resultados desejados. 166

Figura 5.17 - Resultados de simulação para o submódulo 6 do Módulo 1: (a) Resultados fornecidos pelo submódulo; (b) Resultados desejados. 167

Figura 5.18 - Resultados de simulação para o submódulo 7 do Módulo 1: (a) Resultados fornecidos pelo submódulo; (b) Resultados desejados. 
Figura 5.19 - Resultados de simulação para o submódulo 8 do Módulo 1: (a)

Resultados fornecidos pelo submódulo; (b) Resultados desejados.

Figura 5.20 - Resultados de simulação para o submódulo 9 do Módulo 1: (a)

Resultados fornecidos pelo submódulo; (b) Resultados desejados. 170

Figura 5.21 - Resultados de simulação para o submódulo 10 do Módulo 1: (a)

Resultados fornecidos pelo submódulo; (b) Resultados desejados.

Figura 5.22 - Resultados de validação do módulo 4 de localização de faltas. 172

Figura 6.1 - Exemplo de dual monitor utilizado pelo operado do COD. 177

Figura 6.2 - Exemplo de base de dados em tabela. 180

Figura 6.3 - Exemplo de relacionamento entre tabelas. 181

Figura 6.4 - Exemplo de relacionamento entre tabelas com massivas conexões.

Figura 6.5 - Exemplo de cláusulas $S Q L$. 182

Figura 6.6 - Exemplo de rede ethernet com diversos hosts. 185

Figura 6.7 - Exemplo de comunicação via satélite. 186

Figura 6.8 - Sistema de localização de faltas instalado na subestação. 189

Figura 6.9 - Exemplo de base de dados contendo registros de faltas. 190

Figura 6.10 - Tela do software MySQL Front contendo as conexões para as bases de dados.

Figura 6.11 - Tela do software MySQL Front precedente ao sincronismo. 193

Figura 6.12 - Tela do software MySQL contendo as configurações avançadas de sincronismo.

Figura 6.13 - Tela do software MySQL contendo a conclusão do sincronismo...... 194

Figura 6.14 - Comparativo entre bases sincronizadas. 195 


\section{Lista de Tabelas}

Tabela 4.1 - Resultados para a identificação de condições normais de operação e de transitórios para redes neurais com diferentes números de neurônios na camada oculta...

Tabela 5.1 - Redes neurais treinadas para submódulos do Módulo 1 de localização de faltas.

Tabela 5.2 - Redes neurais treinadas para submódulos do Módulo 2 de localização de faltas.

Tabela 5.3 - Redes neurais treinadas para submódulos do Módulo 3 de localização de faltas. 



\section{SUMÁRIO}

Resumo iii
Abstract. .
Lista de Siglas e Abreviaturas vii
Lista de Figuras. .ix
Lista de Tabelas .$x V$

1 Objetivos e introdução ..............................................................................1

1.1 Sistemas inteligentes aplicados nos processos de detecção de falhas ......7

1.2 Motivação e relevância do trabalho ............................................... 9

1.3 Objetivos e contribuições da pesquisa .......................................... 10

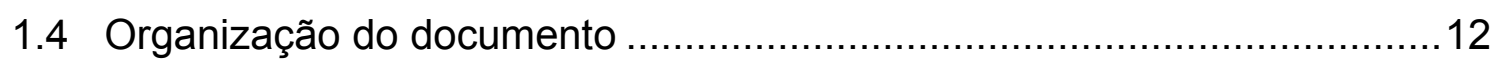

2 Aspectos fundamentais de ferramentas utilizadas em detecção de faltas...........................................................................................................17

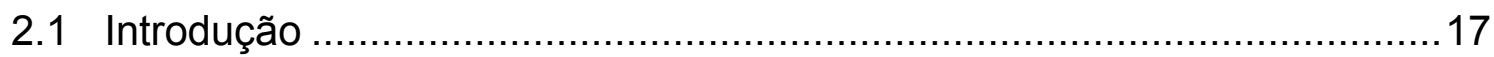

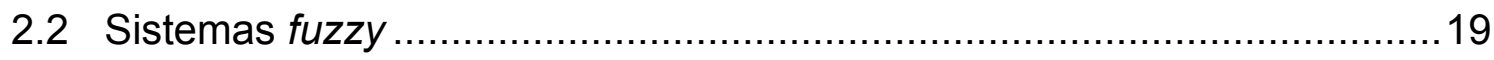

2.2.1 Funções de pertinência ...................................................20

2.2.2 Regras fuzzy............................................................... 22

2.2.3 Agregação de regras fuzzy ............................................ 24

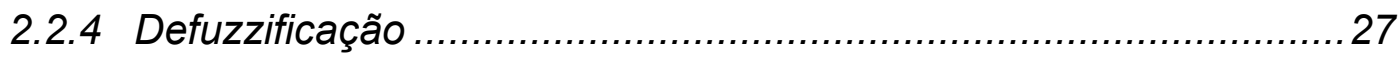

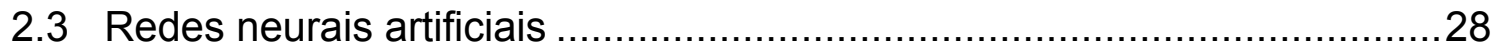

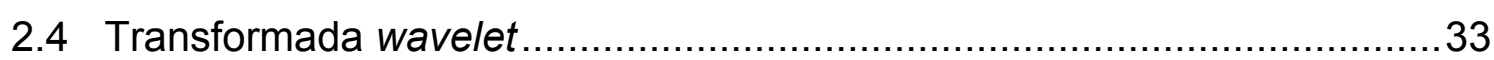

2.5 Ferramentas estatísticas e de processamento digital de sinais .................36

2.5.1 Introdução ao processamento digital de sinais......................... 36

2.5.2 Transformada discreta de Fourier ........................................40 40

2.5.3 Valor médio quadrático (RMS) .......................................... 41

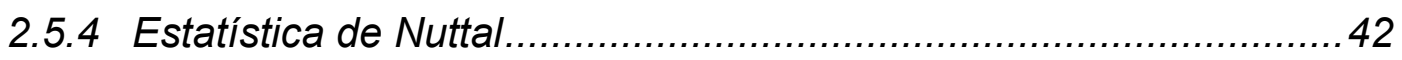

2.5.5 Taxa constante de falso alarme (CFAR) .................................43

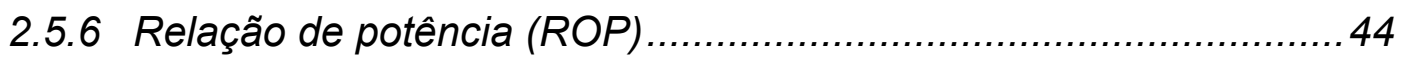

2.5.7 Desvio do valor médio (MVD) ........................................ 45

2.5.8 Kurtosis e Skewness no domínio do tempo..............................46 


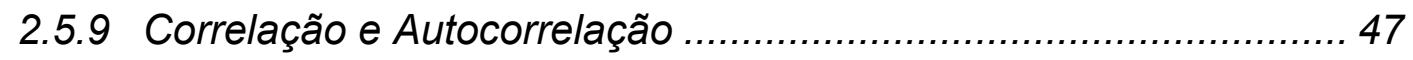

2.5.10 Análise por componentes principais (PCA) ............................... 49

3 Principais metodologias empregadas na detecção de faltas em sistemas de distribuição

3.1 Detecção de faltas de alta impedância em alimentadores de sistema de distribuição utilizando redes neurais artificiais

3.2 Técnicas de identificação de faltas de alta impedância utilizando redes neurais artificiais e transformada de Fourier.

3.3 Abordagem neural utilizando características estatísticas das correntes de falta

3.4 Modelagem fuzzy aplicada na identificação de faltas de alta impedância com característica passiva.

3.5 Método para diagnóstico de faltas em subestações de distribuição utilizando sistemas fuzzy e redes de causa e efeito

3.6 Técnicas de localização de faltas baseadas em sinais de alta freqüência e transformada wavelet

3.7 Classificação e medição dos níveis de perturbação em sistema de potência por meio de wavelet

3.8 Detecção de distúrbios em sistemas de distribuição utilizando wavelet ... 74

3.9 Modelagem de faltas de alta impedância baseada na teoria de arcos elétricos

3.10 Localização de faltas por meio de redes neurais artificiais e da transformada de Clarke-Concórdia.

3.11 Tratamento automatizado de faltas em linhas de distribuição

3.12 Metodologia de localização de faltas fundamentada no modelo do alimentador e medidas tomadas na subestação de distribuição. 86

3.13 Localização de faltas utilizando sistemas inteligentes híbridos ............... 88

3.14 Considerações parciais 89

4 Confecção de sistemas inteligentes para identificação e localização de faltas

4.1 Aplicação de processamento digital de sinais em transitórios de faltas ... 97

4.2 Aspectos metodológicos para identificação de faltas em sistemas de distribuição de energia elétrica

4.3 Sistema de aquisição de dados ....................................................... 111

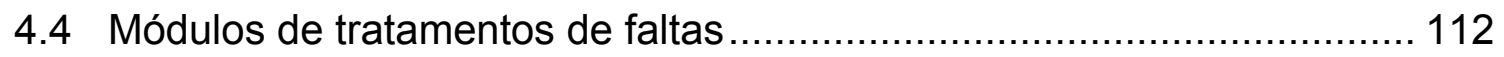

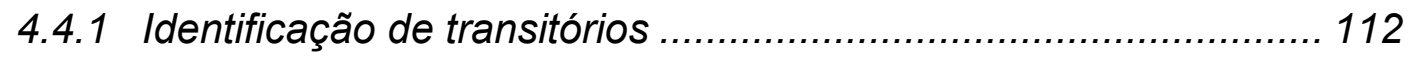

4.4.2 Discriminador de faltas......................................................... 113

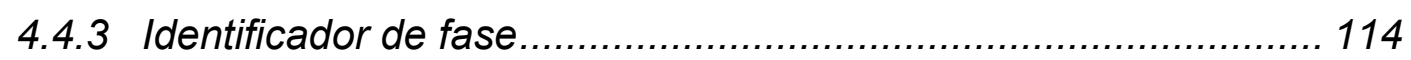

4.5 Resultados de Simulações computacionais no alimentador piloto .......... 114 
4.5.1 Simulações de faltas fase-terra de alta impedância 117

4.5.2 Simulações computacionais referentes às faltas fase-fase 121

4.5.3 Simulações computacionais referentes às faltas trifásicas 125

4.5.4 Simulações computacionais referentes às faltas fase-fase com participação do terra.

4.5.5 Simulações computacionais referentes à entrada e saída de cargas

4.5.6 Resultados de simulação para o módulo de identificação de transitório

4.5.7 Resultados de simulação para o módulo discriminador de faltas

4.5.8 Resultados de simulação para o módulo identificador de fase.....141

5 Validação experimental das ferramentas de localização de faltas 145

5.1 Módulos para localização de faltas 147

5.1.1 Módulo 1 para localização de faltas 147

5.1.2 Módulo 2 para localização de faltas 148

5.1.3 Módulo 3 para localização de faltas 150

5.1.4 Módulo 4 para localização de faltas 151

5.2 Resultados computacionais para treinamento das redes neurais dos módulos de localização de faltas. 152

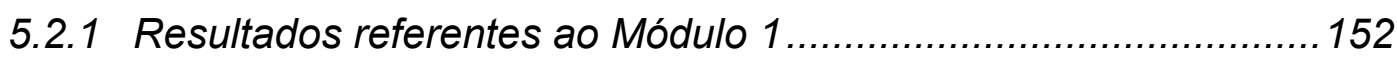

5.2.2 Resultados referentes ao Módulo 2....................................... 157

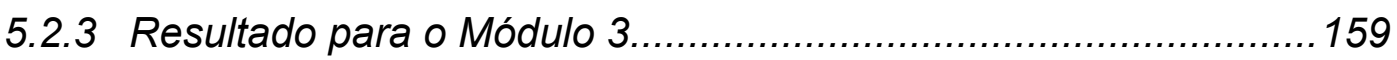

5.2.4 Resultados do sistema especialista para localização de faltas .... 160

6 Monitoramento à distância do alimentador piloto .175

6.1 Procedimento para tratamento de faltas em sistemas de distribuição ....175

6.2 Sistema de bases de dados SQL 179

6.3 Modelo de comunicação fundamentado em redes ethernet. 184

6.4 Estratégia de comunicação à distância do alimentador piloto 188

7 Conclusões e trabalhos futuros. 197

Referências bibliográficas 



\section{Objetivos e introdução}

Atualmente, verifica-se junto ao setor elétrico brasileiro uma constante busca pela melhoria dos serviços prestados pelas companhias de distribuição de energia elétrica aos seus clientes. A excelência nos indicadores de qualidade é traduzida na forma de intervalos e freqüências das interrupções do fornecimento de energia, cujos níveis são considerados adequados pela comunidade técnica internacional e pelos órgãos reguladores do setor de energia.

Tais anseios decorrem do fato de que a continuidade no fornecimento de energia elétrica pelas concessionárias distribuidoras pode ser fragilizada devido à faltas causadas por uma variedade de situações, tais como condições climáticas, contatos de árvores, falhas de equipamentos, acidentes, etc. Se houverem informações sobre a falta, mais rápido é o processo de manutenção e, conseqüentemente, mais rápido é o restabelecimento da energia elétrica [1].

Assim, o progresso dos sistemas elétricos de potência está intimamente ligado com o progresso de sua proteção. A localização rápida e precisa de uma falta é imprescindível para uma operação segura e econômica em um sistema elétrico de potência [2].

As interrupções a que os consumidores são submetidos se enquadram, dentro da área de qualidade da energia elétrica, no tema denominado qualidade do serviço, que pode ser traduzida pelos índices que contabilizam o tempo e a freqüência em que o consumidor fica interrompido [3]. 
Além disso, existem índices que avaliam a continuidade no fornecimento de energia como o DEC e FEC, conforme descrito pela Resolução $n^{\circ}$ 024/2000 da ANEEL [4].

Esta preocupação cresce proporcionalmente ao nível de industrialização da nação, pois eventuais estanques não-programados do sistema acarretam prejuízos econômicos a todos os seus setores dependentes. De maneira ampla, pode-se caracterizar todo este empenho tendo como objetivo geral a melhoria da robustez dos sistemas de distribuição de energia elétrica.

Dentro desse contexto, destaca-se o desenvolvimento sempre crescente de técnicas e metodologias para identificação, classificação e localização de faltas em alimentadores responsáveis pela distribuição de energia elétrica. O aporte conferido a este desenvolvimento se fundamenta na constatação de que grande parte das interrupções não programadas no fornecimento de energia elétrica pelo sistema de distribuição provém da ocorrência de faltas ao longo da extensão dos seus alimentadores.

Desta forma, técnicas modernas e eficientes para identificação, localização e classificação de faltas têm sido desenvolvidas a fim de auxiliar na tomada de decisão dos centros de operações das concessionárias de distribuição. Como benefício direto da aplicação de tais técnicas, pode-se constatar o aumento da eficiência das equipes de manutenção quando da extinção de faltas nos sistemas de distribuição, pois tais equipes serão despachadas para o local bem provável da ocorrência da falta, minimizando, portanto, o tempo de restabelecimento do serviço.

A identificação, localização e classificação de faltas, as quais podem ser coletivamente chamadas de processos de detecção de faltas, constituíram-se, ao longo dos anos, em metas almejadas por diversos setores do sistema elétrico de 
potência, tais como aquele de transmissão e de distribuição de energia elétrica, destacando-se aqui três principais linhas de pesquisa: i) estudo das formas de onda fundamentais de corrente e tensão, principalmente por medições de impedâncias; ii) estudo de ondas viajantes e componentes de alta freqüência; iii) aplicação de sistemas inteligentes [5].

Assim, em função da declarada demanda por sistemas automáticos capazes de identificarem, classificarem e localizarem faltas em sistemas de energia elétrica, diversas proposições de trabalhos que fazem uso das mais distintas ferramentas são observados junto à literatura correlata, nas mais variadas conjunções, com o intuito de contribuírem à concretização das bases envolvidas com o trinômio identificaçãoclassificação-localização de faltas.

Em [6], por exemplo, os autores propõem o emprego de algoritmos computacionais, baseados na análise da hexa-decomposição dos fasores de tensão e de corrente do sistema elétrico sob falta, com o objetivo de determinar sua localização, ou seja, determinar o quão distante da fonte a falta ocorreu. Essa metodologia foi proposta inicialmente para elaboração de algoritmos específicos à proteção de sistemas de energia elétrica, conforme delineado em [7]. No entanto, de acordo com aquilo apresentado nas discussões de [6], a grande limitação da abordagem proposta é a necessidade de se efetuar medição em pelo menos dois pontos do sistema, ou seja, essa metodologia se torna mais adequada à localização de faltas em sistemas de transmissão de energia elétrica do que em sistemas de distribuição.

Contornando o inconveniente da exigência de se realizar medições das tensões e correntes trifásicas em pelo menos dois pontos do sistema de energia elétrica, verifica-se em [8] uma proposição para a identificação de faltas se 
empregando apenas um conjunto de medições. Desta forma, os autores desenvolvem um novo sistema de localização de falta para sistemas de distribuição, o qual se baseia na arquitetura do alimentador e nas medidas de tensão e corrente realizadas na subestação. O algoritmo proposto determina a localização precisa da falta, levando-se em consideração a característica de variação do carregamento da rede, condição de desbalanceamento e a natureza assimétrica do alimentador. Os autores mostram aqui que a variação do carregamento da rede afeta significativamente a precisão do sistema de localização de falta. De forma a contornar tal problema, realiza-se a estimação do carregamento em tempo-real a fim de garantir uma minimização do erro entre a localização da falta calculada e a localização real da falta (valor de referência). Conforme mostrado pelos autores, os resultados somente serão satisfatórios se for possível a obtenção dos valores de carregamento no momento pré-falta. Tal constatação decorre da necessidade em se calcular a impedância do sistema no momento que precede a falta, o que pode prejudicar o algoritmo de localização, caso se apresente valores incoerentes.

Nesta mesma linha de pesquisa, o trabalho apresentado em [9] procura não apenas se valer de impedâncias calculadas a partir da topologia física da rede, mas também de seus valores obtidos por meio das medidas de tensão e de corrente constantemente oscilografados na subestação de origem do alimentador sob monitoramento. No referido estudo, resultados de simulações computacionais são destacados e a qualidade das respostas são superiores àqueles obtidos por técnicas convencionais. Porém, limitações quanto à localização de faltas em sistemas de distribuição com correntes desbalanceadas são pontuadas, podendo-se o erro de estimação ser de até $25 \%$. 
Contornando as limitações das técnicas convencionais, os sistemas inteligentes surgem como uma proposta promissora à tratabilidade de problemas cujas soluções são intrinsecamente complexas. Esse é o caso da identificação, classificação e localização de faltas em sistemas de distribuição de energia elétrica, onde em virtude do número e da não-linearidade das variáveis envolvidas, a precisão, a robustez e a eficácia de um sistema dedicado a essas finalidades podem ser bem afetadas quando constituídas unicamente por ferramentas consideradas convencionais.

Um exemplo dessa nova tendência é o trabalho apresentado em [10], em que técnicas correlatas aos espaços esparsos e algoritmos genéticos são combinadas de maneira a constituir um sistema capaz de localizar faltas em sistemas de energia elétrica. Assim, o referido estudo buscou contornar a problemática do mal condicionamento das matrizes de admitância do sistema por intermédio de técnicas convencionais, sendo que o problema da localização de faltas é tratado por meio dos algoritmos genéticos, os quais possuem destacada eficiência quando da busca por soluções otimizadas.

Outro exemplo de convergência de técnicas convencionais e de sistemas inteligentes é o trabalho destacado em [11]. O objetivo de seu desenvolvimento foi a classificação de faltas em sistemas de energia elétrica por meio de análise multinível fornecida pela decomposição wavelet das formas de onda de tensão e de corrente. Esse tipo de ferramenta fornece informações sobre distúrbios em sistemas elétricos de potência e possui ampla aplicabilidade no contexto da qualidade de energia, uma vez que permite uma análise no domínio do tempo e da freqüência simultaneamente. No entanto, a análise dos resultados oriundos de tal ferramenta para processamento de sinais não se procede de forma natural e é necessária 
grande experiência para que as conclusões alcançadas sejam factíveis aos fatos reais.

Por outro lado, os sistemas de inferência fuzzy possuem a meta de emularem a forma aproximada do raciocínio humano. Desta forma, em [12], o autor mostra como se pode implementar, por meio das ferramentas de processamento de sinais empregados e por intermédio dos sistemas fuzzy, um método para localização de faltas em linhas de transmissão de energia elétrica com habilidades para distinguir as faltas reais frente às situações de manobras programadas no sistema. Destaca-se aqui que a combinação de ferramentas fornece bons resultados, porém aplicados em linhas de transmissão.

Além dos algoritmos genéticos e dos sistemas de inferência fuzzy, outra ferramenta advinda da inteligência computacional são as redes neurais artificiais. Como exemplo de sua aplicação no contexto da localização de faltas em sistemas de distribuição, destaca-se o trabalho relatado em [13], em que os autores conduzem sua pesquisa empregando decomposições vetoriais das formas de onda de tensão e de corrente, sendo que redes neurais artificiais são empregadas para a determinação do local de ocorrência da falta no referido sistema.

No entanto, mesmo diante do emprego de sistemas inteligentes, os resultados comprobatórios podem não possuir todos os requisitos almejados, ou ainda, tais resultados são dignos de melhorias. Tendo tais aspectos como premissa, ultimamente, torna-se cada vez mais comum o desenvolvimento de sistemas para a identificação, classificação e localização de faltas que fazem uso não de apenas um sistema especialista, mas sim de vários deles alinhados de maneira ordenada. Esse é o caso da abordagem proposta em [14], em que os autores empregam redes 
neurais artificiais dispostas em paralelo, cada qual sendo responsável por indicar qual fora o tipo e local da falta.

Outro aspecto fundamental para o alcance de sucessos nos processos de detecção de faltas consiste da integração desses sistemas especialistas junto aos sistemas de comunicação dos centros de operação das concessionárias, sendo esta uma das tônicas mundiais desde meados dos anos 70 , conforme historicamente relatado em [15]. É certo, porém, que nesses mais de 30 anos de evolução dos sistemas de controle e monitoramento muitos conceitos foram criados, bem como novas alternativas para redução de custos foram implementadas, destacando-se a presença crescente da comunicação [16].

De fato, a introdução da comunicação entre os dispositivos e também dos relés numéricos permitiu melhorar a resposta do sistema frente a uma falta, como pode ser observado em [17], em que os autores adotaram uma postura totalmente automatizada para o tratamento de curto-circuitos. Esta linha de pesquisa fornece subsídios ao debate a partir do momento em que há ainda uma grande dificuldade em se adaptar os sistemas automatizados de tratamento de faltas às condições peculiares de cada circuito de distribuição.

\subsection{Sistemas inteligentes aplicados nos processos de detecção de falhas}

Diversas pesquisas têm sido realizadas objetivando o desenvolvimento de esquemas de automatização eficientes para processos envolvidos com a detecção de faltas em sistemas de distribuição. A utilização recente de técnicas de sistemas inteligentes visando tratar tanto o problema de identificação de faltas, assim como a 
sua classificação e localização, têm sido uma tônica nos processos investigativos desses problemas. Os resultados já advindos da aplicação dessas técnicas têm proporcionado a confecção de sistemas de detecção que são eficientes e robustos. Complementarmente, as pesquisas envolvendo a proposição de sistemas automatizados para os processos envolvidos com a detecção de faltas, baseados em sistemas inteligentes, têm despertado a atenção da comunidade técnicocientífica que lida com o assunto. Como exemplo, pesquisas desenvolvidas nos Estados Unidos [18] mostram a utilização desses sistemas para detectarem faltas de alta impedância, cujos resultados foram bastante satisfatórios, obtendo-se taxas de acerto superiores a $90 \%$. Estudos semelhantes a esses foram também realizados no Iran, conforme relatado em [19].

Ainda, em pesquisas realizadas na "Pacific Gas \& Electrical Company" da Califórnia [20], esquemas que utilizam os sinais referentes à ocorrência de uma falta, os quais foram integrados com resultados obtidos de simulação de situações de falta, foi desenvolvido com bastante sucesso. Os resultados finais alcançados pelos sistemas inteligentes foram melhores que aqueles previamente fornecidos por técnicas convencionais, cujos modelos foram desenvolvidos utilizando apenas dados registrados por dispositivos de proteção. Outro método semelhante a este é proposto em [21].

Mais recentemente, uma pesquisa desenvolvida pela Universidade do Texas [22], denominada HiZ e fomentada em parte pelo Electric Power Research Institute $(E P R I)$, utiliza um sistema especialista de reconhecimento de padrões dos níveis harmônicos para detectarem faltas de alta impedância. O sistema HiZ utiliza uma taxa de amostragem de 64 amostras/ciclo nas entradas de corrente AC visando fornecer o padrão espectral usado nas análises das assinaturas. 
Assim, observa-se que esses tipos de abordagens, empregando técnicas inteligentes e técnicas convencionais para tratamento de faltas, são bem promissores e que já vêm proporcionando resultados expressivos aos processos envolvidos com a detecção das mesmas. Tais estratégias são denominadas híbridas, pois combinam uma ou mais ferramentas inteligentes com outras que possuem habilidades para tratamento de sinais. Este é o caso também da abordagem apresentada em [23], em que o processamento de sinais proporcionado pela transformada wavelet é empregado na extração das características dos sinais de tensão e corrente que, em seguida, são apresentadas para um sistema fuzzy com o intuito de se inferir o local da falta.

\subsection{Motivação e relevância do trabalho}

As investigações que levem a esquemas eficientes que permitam a identificação e localização de faltas de forma rápida e confiável são assuntos de suma importância para as concessionárias de distribuição de energia elétrica, tendose em vista que os resultados decorrentes podem implicar em incrementos substantivos dos índices de qualidade e confiabilidade dos serviços oferecidos aos seus clientes.

A adoção de tais práticas que levem então a incrementar esses índices tem sido também incentivada pelos agentes da atual legislação que rege o setor elétrico brasileiro, os quais tem constantemente acompanhado a qualidade dos serviços fornecidos pelas concessionárias de distribuição por meio da avaliação mensal dos indicadores DEC, FEC, DIC, FIC e DMIC.

Diante deste panorama, o efetivo projeto de esquemas que levem à identificação e localização de faltas de forma rápida e eficiente deve levar em 
consideração dois aspectos fundamentais. O primeiro aspecto se refere à definição de técnicas e metodologias de processamento de sinais que objetivam discriminar as características dos diversos tipos de faltas que podem incidir no sistema de distribuição, tendo-se em vista a grande dificuldade em se identificar e localizar curto-circuitos. Já o segundo aspecto a ser tratado tem como foco principal o desenvolvimento de ferramentas que serão responsáveis pela automatização em tempo real de todo o processo de tomada de decisão por parte do centro de operação do sistema de distribuição, as quais serão baseadas nas técnicas e metodologias que serão desenvolvidas para o primeiro aspecto.

\subsection{Objetivos e contribuições da pesquisa}

O objetivo desta pesquisa de doutorado consiste em confeccionar um sistema automatizado de tratamento de faltas que permita monitorar e acompanhar on-line as eventuais ocorrências de faltas e transitórios eletromagnéticos observados na rede primária de distribuição de energia elétrica.

Por intermédio da interligação deste sistema automatizado ao centro de operação da concessionária, tornar-se-á então possível a disponibilização de um ferramental eficiente que auxiliará nas suas tomadas de decisões.

Em suma, o objetivo final da pesquisa consiste em disponibilizar as ferramentas necessárias que visam identificar, quase instantaneamente, a ocorrência de faltas e transitórios no sistema primário de distribuição, bem como determinar a respectiva origem e sua provável localização. 
Dessa forma, procura-se por meio desse trabalho a sistematização de metodologias que auxiliem não apenas a operação do sistema, mas também a área de engenharia e de manutenção das empresas de distribuição como um todo.

Mais especificamente, o desenvolvimento da pesquisa possui como meta principal os seguintes objetivos:

1. Definição dos sistemas especialistas híbridos visando tratar todos os aspectos relacionados aos processos de identificação, classificação e localização de faltas em linhas de distribuição.

2. Proposição de procedimentos de modelagem computacional de alimentadores reais a fim de se obter as características discriminantes que indiquem os seus comportamentos em condições de falta.

3. Desenvolvimento das plataformas computacionais referentes ao sistema automático para identificação, classificação e localização das faltas em tempo real.

5. Definição e investigação de estratégias para monitoramento à distância das subestações, visando a transmissão e incorporação de dados adquiridos ao sistema de monitoramento de faltas.

6. Validação das plataformas de identificação e localização automática de faltas por intermédio de ensaios em laboratório e testes em alimentadores reais.

As principais contribuições da tese podem ser pontuadas como se segue:

- Proposição de um sistema completo para detecção de faltas em alimentadores de distribuição de energia elétrica, contemplando desde 
detalhes da aquisição de dados até os mecanismos para monitoramento à distância do alimentador piloto.

- Formulação dos sistemas especialistas híbridos que permitem realizar a análise integrada de diversas ferramentas que foram desenvolvidas para o propósito de detecção de faltas, ao invés de se utilizar apenas uma única abordagem específica.

- Elaboração de sistema de monitoramento à distância de alimentadores pilotos, o qual proporciona um link de comunicação direto por meio da família de protocolos TCP/IP.

\subsection{Organização do documento}

Uma breve introdução envolvendo os aspectos de regulamentações para os níveis operativos de tensão e, também, a proposta de trabalho encontram-se registrados neste capítulo. No Capítulo 2 serão apresentados os aspectos principais envolvendo as ferramentas comumente encontradas em sistemas de detecção de faltas.

No Capítulo 3 será apresentado o estudo bibliográfico relacionado às ferramentas modernas para detecção de faltas, dando-se um enfoque especial aos trabalhos envolvendo sistemas inteligentes.

No Capítulo 4 encontram-se as principais características do sistema inteligente proposto neste trabalho, destacando-se os fundamentos teóricos e as variáveis de entrada/saída.

No Capítulo 5 serão apresentados e discutidos os resultados obtidos da validação experimental das ferramentas apresentadas no Capítulo 4. 
No Capítulo 6 são apresentados os conceitos envolvendo comunicação à distância do alimentador piloto e, finalmente, no Capítulo 7 serão feitas as considerações a respeito deste trabalho, denotando-se aqui quais os ganhos da pesquisa para os sistemas de distribuição estudados.

Como informação complementar, diversas publicações foram realizadas ao longo do programa de doutorado, tais como as seguintes:

Artigos em periódicos:

1. SPATTI, D.H.; SILVA, I.N.; USIDA, W.F.; FLAUZINO, R.A., "Sistema de Controle Fuzzy Para Regulação de Tensão em Transformadores de Subestação". Revista IEEE América Latina, v. 8, p. 51-57, 2010.

2. SPATTI, D.H.; SILVA, I.N.; USIDA, W.F.; FLAUZINO, R.A., "Real-Time Voltage Regulation in Power Distribution System Using Fuzzy Control". IEEE Transactions on Power Delivery, v. 25, p. 1112-1123, 2009.

3. SILVA, I.N.; FLAUZINO, R.A.; SPATTI, D.H., "An Efficient Hopfield Network to Solve a DC Optimal Power Flow Model". International Journal on Power System Optimization, v. 1, p. 17-25, 2009.

4. SPATTI, D.H.; SILVA, I.N.; FLAUZINO, R.A.; USIDA, W.F., "Fuzzy Control Approaches to On-line Voltage Optimized Regulation in Power Distribution Systems". International Journal on Power System Optimization, v. 1, p. 27-39, 2009.

Livro publicado:

5. SILVA, I.N.; SPATTI, D.H.; FLAUZINO, R.A., "Redes Neurais Artificiais para engenharia e ciências aplicadas: curso prático". São Paulo: Artliber Editora, 2010. 400 p. 
Artigos em congressos:

6. SPATTI, D.H.; SILVA, I.N.; FLAUZINO, R.A., "Automatização de Processos de Detecção de Faltas em Linhas de Distribuição Utilizando Sistemas Híbridos Especialistas". IEEE PES 2010 Transmission \& Distribution Latin America Conference \& Exposition, 6 pp., 2010.

7. SPATTI, D.H.; SILVA, I.N.; SANTOS, N.R.; FLAUZINO, R.A., "Increasing Safety and Reliability in Power Distribution Systems from Optimized Selection of Protection Devices". IEEE International Energy Conference and Exhibition, 6 pp, 2010.

8. SPATTI, D.H.; FLAUZINO, R.A.; ULSON, J.A.C, "Hardware de Controlador Inteligente Para Regulação Automática de Tensão em Sistemas de Distribuição". INDUSCON 2010 - IX IEEE/IAS International Conference on Industry Applications, 6 pp., 2010.

9. SANTOS, N.R.; SILVA, I.N.; FLAUZINO, R.A.; SPATTI, D.H., "Optimized Selection Approach of Transformer Protection Devices against Atmospheric Discharges Using Expert System". 2009 IEEE PES General Meeting, 6 pp., 2009.

10. SPATTI, D.H.; SILVA, I.N., "Recurrent Neural Approach for Solving Economic Dispatch Problems in Power Systems". EuroPES 2008 Eighth IASTED International Conference on POWER AND ENERGY SYSTEMS, 6 pp., 2008.

11. ZIOLKOWSKI, V.; SILVA, I.N.; FLAUZINO, R.A.; SPATTI, D.H., "Technical Strategies for High-Impedance Fault Experiments in Power Distribution System". IEEE PES Transmission and Distribution Conference and Exposition: Latin America, 5 pp., 2008. 
12. SPATTI, D.H.; USIDA, W.F.; SILVA, I.N.; FLAUZINO, R.A., "Controle Fuzzy Para Regulação de Tensão em Transformadores de Potência”. XVII Congresso Brasileiro de Automática, 6 pp., 2008.

13. SPATTI, D.H.; SILVA, I.N.; BENICHIO, V.M.; ALVES, M.E.G., "Estratégia Fuzzy Para Controle de Tensão em Sistemas de Distribuição". VIII Simpósio Brasileiro de Automação Inteligente, 6 pp., 2007.

14. SPATTI, D.H.; SILVA, I.N.; GOEDTEL, A.; VIZOTTO, L., "Análise de Complexidade de Modelos Neurais Aplicados no Despacho de Potência em Sistemas de Energia Elétrica". 7th Latin-American Congress: Electricity Generation and Transmission, 6pp., 2007.

15. SPATTI, D.H.; SILVA, I.N.; USIDA, W.F.; BENICHIO, V.M., "Sistema Inteligente Para Controle Automático de Relés Reguladores de Tensão". VII Conferência Brasileira Sobre Qualidade da Energia Elétrica, 6pp., 2007. 



\section{Aspectos fundamentais de ferramentas}

\section{utilizadas em detecção de faltas}

\subsection{Introdução}

Diversas tentativas têm sido propostas na literatura com o intuito de identificar e localizar de forma eficiente e veloz o ponto de falta em sistemas de distribuição de energia elétrica. A maioria dessas abordagens estima a distância relativa à falta em função dos dados aquisitados pelos dispositivos de proteção. A precisão desses métodos pode ser bem afetada em virtude de algumas características próprias do respectivo sistema, tais como desbalanceamento, condutores não homogêneos, sistemas com alto grau de ramificação, etc.

Ultimamente, a aplicação crescente de técnicas de sistemas inteligentes agregadas às técnicas convencionais, juntamente com ferramentas promissoras de processamento de sinais, nos processos de identificação e localização de faltas têm gerado resultados eficientes e cada vez mais convincentes, pois o objetivo de destaque da aplicação dessas técnicas consiste no alcance de tratabilidade, robustez, baixo custo e altas taxas de eficiência.

Mais especificamente, a utilização de sistemas inteligentes, notadamente aqueles baseados nas redes neurais artificiais $[18,19]$ e em sistemas e controladores fuzzy [20,21], já têm sido aplicados com sucesso na solução de problemas envolvidos com a identificação e localização de faltas. As características mais 
atrativas desses sistemas consistem em sua habilidade em mapear sistemas nãolineares e em tratar as eventuais incertezas associadas ao processo.

A composição de sistemas inteligentes, tais como redes neurais artificiais e sistemas fuzzy, juntamente com ferramentas de processamento de sinais, permite agregar ainda mais funcionalidades e potencialidades aos localizadores de faltas, explorando melhor as características de cada tipo de ferramenta. Destaca-se a utilização de transformada wavelet combinada à sistemas inteligentes, por esta apresentar características de processamento digital de sinais que podem ser facilmente implementadas em conjunto. Nas Seções 2.2 e 2.3 serão apresentadas as principais características envolvendo sistemas fuzzy e redes neurais artificiais, pois tais ferramentas foram efetivamente empregadas no desenvolvimento desta pesquisa de doutorado, sendo também uma presença marcante nos trabalhos mais promissores encontrados em literatura da área.

Na seção 2.4 será apresentada, de forma breve, uma das mais promissoras ferramentas de processamento de sinal para a área de identificação e localização de faltas, ou seja, a transformada wavelet. Ela se faz presente nos trabalhos técnicocientíficos com as contribuições mais relevantes.

Na Seção 2.5 serão apresentados detalhes envolvendo o processamento digital de sinais, destacando-se as ferramentas com grande potencial de aplicação no processo de detecção de transitórios.

Apesar da transformada wavelet ser destacada nesta pesquisa de doutorado, principalmente devido à sua forte presença no pré-processamento de sinais elétricos em termos de componentes de freqüência, ela não foi efetivamente empregada nos processos de detecção faltas. 
Esta postura foi adotada tendo em vista que a maioria das ferramentas que são abordadas na Seção 2.5, e que foram de fato empregadas nos processos de detecção de faltas, utilizam análises de Fourier, especialmente a transformada rápida de Fourier (FFT) para seus cálculos. A adaptação de tais técnicas para a utilização de wavelets representa um grande desafio e não faria parte dos objetivos desta pesquisa. Assim, optou-se por adotar as abordagens convencionais de processamento de sinais, com a análise em freqüência obtida por técnicas de Fourier.

\subsection{Sistemas fuzzy}

Modelagem e controle fuzzy de sistemas são técnicas para o tratamento de informações qualitativas de uma forma rigorosa, sendo capazes de tomar decisões racionais mesmo estando em um ambiente de incertezas e imprecisões [24,25]. Por meio da lógica fuzzy, um sistema pode ser representado através de conceitos imprecisos tais como "rápido", "baixo" e "pequeno". Essas propriedades são responsáveis, entre outras, pela facilidade na extração do conhecimento de um sistema a partir de observações realizadas sobre este.

Em um sistema de inferência fuzzy, os valores de entrada são normalizados e convertidos para uma representação fuzzy. Este processo é denominado de fuzzificação das variáveis de entrada. As regras do sistema fuzzy serão executadas em paralelo; conseqüentemente, uma região fuzzy será produzida para cada variável. A criação desta região fuzzy por intermédio das regras ativas do sistema é conhecida por agregação. Depois do processamento das regras de inferência, as regiões fuzzy são convertidas em valores não fuzzy, também conhecidos como 
valores crisp, determinando assim, o valor de cada variável de saída do sistema. O processo de se converter tal região fuzzy em um valor real é conhecido por defuzzificação.

\subsubsection{Funções de pertinência}

Na teoria de conjuntos clássica, um elemento pertence ou não a uma classe. Isso pode ser evidenciado na Figura 2.1 que mostra a classificação das velocidades de um determinado automóvel, quanto a pertencer à classe de Velocidade Alta.

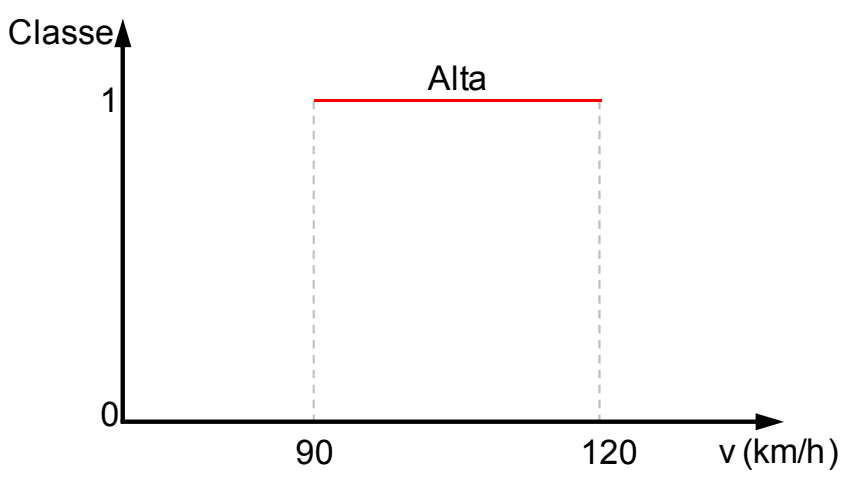

Figura 2.1 - Classes de conjuntos na lógica clássica.

Tomando-se dois exemplos de valores de velocidades, sendo eles $90 \mathrm{~km} / \mathrm{h}$ e 120 km/h, fica evidenciado na Figura 2.1 que valores menores, mas muito próximos de $90 \mathrm{~km} / \mathrm{h}$, não pertencem à classe de Velocidade Alta. O mesmo ocorre para velocidades maiores, mas muito próximas a $120 \mathrm{~km} / \mathrm{h}$. Este tipo de raciocínio da lógica clássica não permite identificar o quão incluído a uma classe de velocidades um determinado valor estaria.

Zadeh propôs uma caracterização mais ampla, na medida em que sugere que alguns elementos são mais membros de um conjunto do que outros. O grau de 
pertinência pode então assumir qualquer valor entre o intervalo $[0,1]$, sendo que o valor 0 indica uma completa exclusão e um valor 1 representa completa pertinência. Esta abordagem pode ser mais bem compreendida por meio das funções de pertinência da lógica fuzzy, como aquela ilustrada na Figura 2.2.

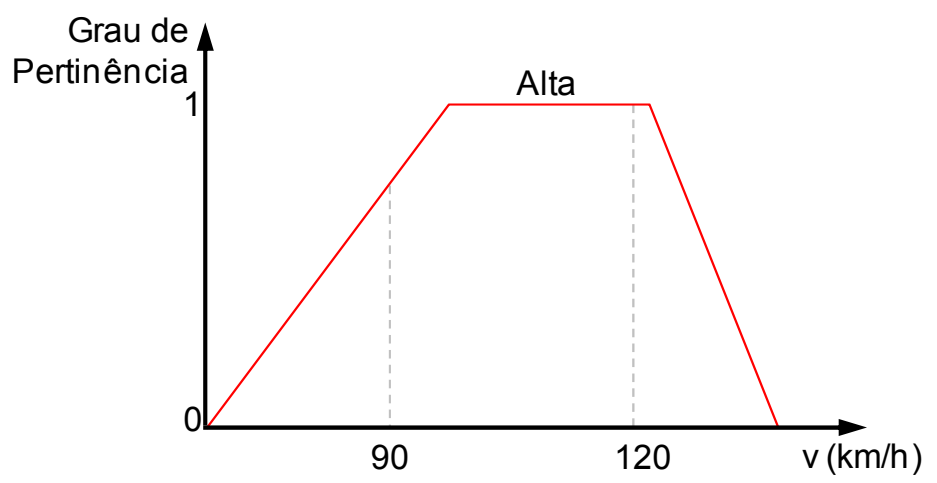

Figura 2.2 - Função de pertinência da lógica fuzzy.

Na Figura 2.2 pode-se observar que a velocidade de $120 \mathrm{~km} / \mathrm{h}$ possui um grau de pertinência na classe de Velocidade Alta maior que a velocidade de 90 $\mathrm{km} / \mathrm{h}$. Desta forma, valores próximos a $120 \mathrm{~km} / \mathrm{h}$ ou $90 \mathrm{~km} / \mathrm{h}$ também pertencem a classe de Velocidade Alta, mas com diferentes graus de inclusão na classe.

Utiliza-se então de conjuntos de funções de pertinência que permitem mapear o universo de discurso em que se deseja atuar, representando-se os diferentes graus de inclusão, como pode ser observado na Figura 2.3. Cada função de pertinência recebe o nome de Termo Lingüístico, pois irá mapear um evento qualitativo, descrito por meio de linguagem natural. 


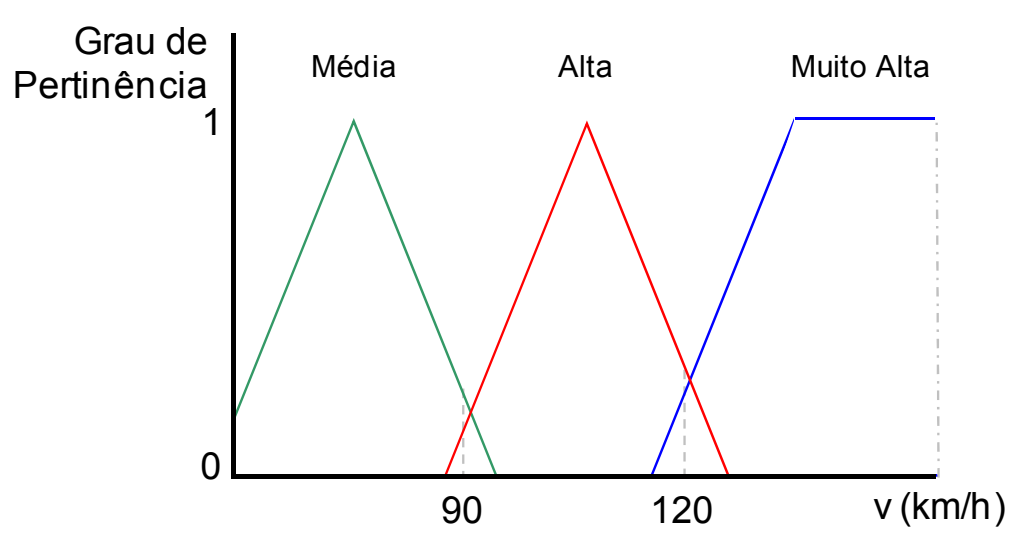

Figura 2.3 - Conjuntos de funções de pertinência da lógica fuzzy.

Com este tipo de tratativa, a velocidade de $90 \mathrm{~km} / \mathrm{h}$ pode ser Média e Alta ao mesmo tempo, mas com diferentes graus de inclusão nestas classes. O mesmo se aplica a velocidade de $120 \mathrm{~km} / \mathrm{h}$, que pode ser Alta e Muito Alta ao mesmo tempo.

Dentre os principais formatos de funções de pertinência utilizados na lógica fuzzy se destacam as triangulares, trapezoidais e gaussianas.

\subsubsection{Regras fuzzy}

Para expressar conceitos ou relacionamentos mediante elementos da linguagem natural é muito comum o uso de elementos qualitativos ao invés de valores quantitativos. Elementos lingüísticos típicos incluem expressões do tipo "mais ou menos", "alto", "não muitos", "médios", etc. Estas idéias são capturadas pela definição de variáveis lingüísticas.

Uma variável lingüística tem por característica assumir valores dentro de um conjunto de Termos Lingüísticos, ou seja, palavras ou frases. Assim, ao invés de assumir instâncias numéricas, estas variáveis assumem instâncias lingüísticas. Por exemplo, uma variável lingüística Velocidade poderá assumir como valor um dos termos do conjunto \{"Média", "Alta", "Muito Alta"\}. 
Para se atribuir um significado aos termos lingüísticos, associa-se a cada um destes termos um conjunto fuzzy definido sobre um universo de discurso comum.

A forma mais comum de expressar o conhecimento é por meio de regras do tipo "Se-Então". Neste tipo de regra, um conjunto de condições descrevendo o comportamento das entradas do sistema é associado com uma ação de saída que irá manter ou levar o sistema às condições desejadas, ou ainda, expressar o conhecimento especialista envolvido em um sistema e permitir que a modelagem seja mais flexível e comporte informações qualitativas do processo.

A idéia embutida junto às regras fuzzy de representar o conhecimento por meio de um conjunto de termos lingüísticos associados às variáveis de saída e entrada do processo é absorvida pelos sistemas de inferência fuzzy. São exemplos de regras fuzzy:

1. Se Velocidade é Alta então Pressão no Freio é Grande;

2. Se Velocidade é Muito Alta então Pressão no Freio é Muito Grande;

3. (..)

Quando a entrada de dados sensibilizar mais de um Termo Lingüístico, ou seja, mais de uma regra estando ativa, a ação de controle consistirá da união de todas as funções fuzzy ativadas. Para uma velocidade de $90 \mathrm{~km} / \mathrm{h}$, observa-se na Figura 2.4 que as funções de pertinência Velocidade Média e Velocidade Alta estarão ativas ao mesmo tempo. 


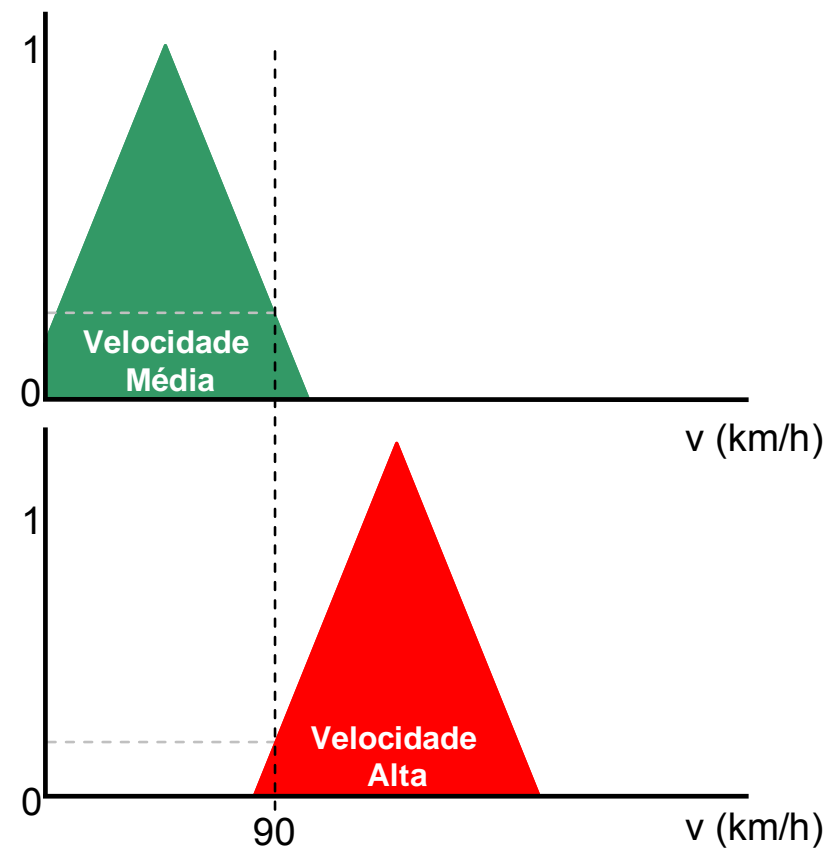

Figura 2.4 - Ativação de regras fuzzy.

Desta forma, faz-se necessário o uso de uma operação de agregação de regras.

\subsubsection{Agregação de regras fuzzy}

Em uma base de regras, quando mais de uma regra é acionada, as contribuições das diversas regras após a inferência são combinadas pelo operador de agregação. Como exemplo, tem-se na Figura 2.5 a representação da entrada de um sistema fuzzy responsável por mapear a velocidade de um automóvel.

O universo de discurso da variável Velocidade foi mapeado com três termos lingüísticos: \{Média, Alta, Muito Alta\}. A saída deste sistema fuzzy pode ser visualizada na Figura 2.6. 


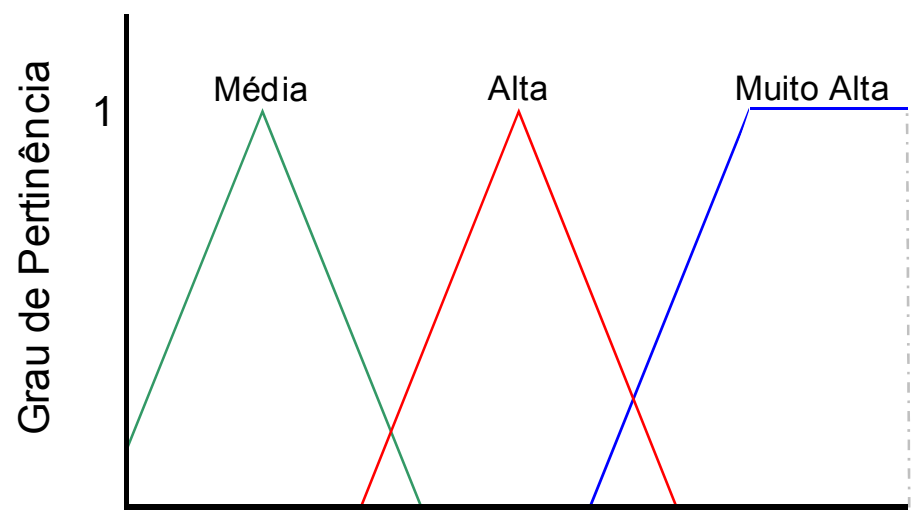

Entrada - Velocidade $(\mathrm{km} / \mathrm{h})$

Figura 2.5 - Entrada do sistema fuzzy de exemplo.

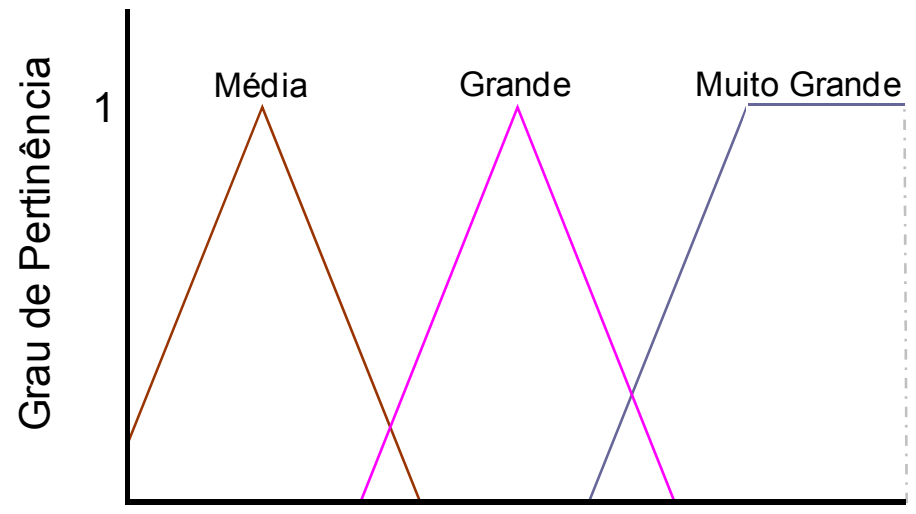

Saída - Pressão no freio $(\mathrm{kPa})$

Figura 2.6 - Saída do sistema fuzzy de exemplo.

A Pressão no Freio foi mapeada também com três termos lingüísticos triangulares: $\{$ Média, Grande, Muito Grande\}. Para este exemplo, adotou-se o seguinte conjunto de regras fuzzy:

Regra 1 - Se Velocidade é Média então Pressão no Freio é Média;

Regra 2 - Se Velocidade é Alta então Pressão no Freio é Grande;

Regra 3 - Se Velocidade é Muito Alta então Pressão no Freio é Muito Grande. 
Supondo-se que uma velocidade de $90 \mathrm{~km} / \mathrm{h}$ ative as Regras 1 e 2, pois essa velocidade é Média e Alta ao mesmo tempo, teríamos 2 regras ativas, cada uma inferindo uma região de saída.

Assim, a Regra 1 ativa teria uma região fuzzy de saída Média e a Regra 2 ativa teria uma região de saída Grande. O processo de agregação das regras para a formação de uma única região fuzzy de saída pode ser visualizado na Figura 2.7.

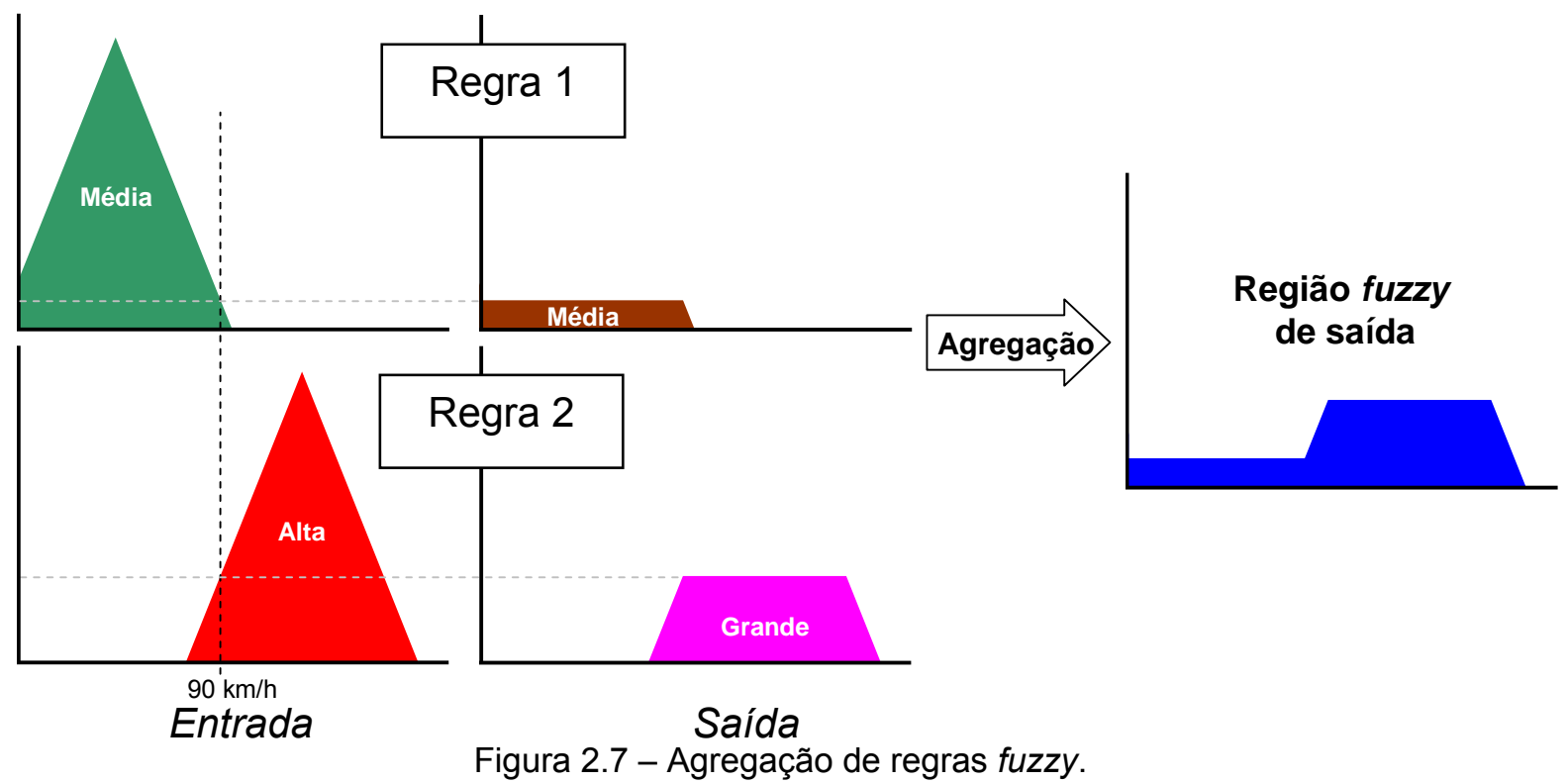

Cada regra gera então uma região de saída que, após a agregação, resultam em uma única região fuzzy de saída.

Essa região fuzzy de saída ainda não pode ser empregada em um sistema de controle, pois é necessário o processo de defuzzificação para se encontrar o valor de saída crisp que representa a região fuzzy de saída. 


\subsubsection{Defuzzificação}

O processo de defuzzificação é responsável por atribuir à região fuzzy de saída um valor numérico crisp que represente quantitativamente aquilo que o sistema fuzzy inferiu de forma qualitativa.

O valor real então obtido após o processo de defuzzificação pode ser utilizado no sistema de controle ou para propósitos de estimação.

Dentre os métodos existentes para o processo de defuzzificação se pode empregar o do centro de área, que consiste em encontrar a coordenada abscissa do centro de área da região fuzzy de saída, como pode ser contemplado na Figura 2.8.

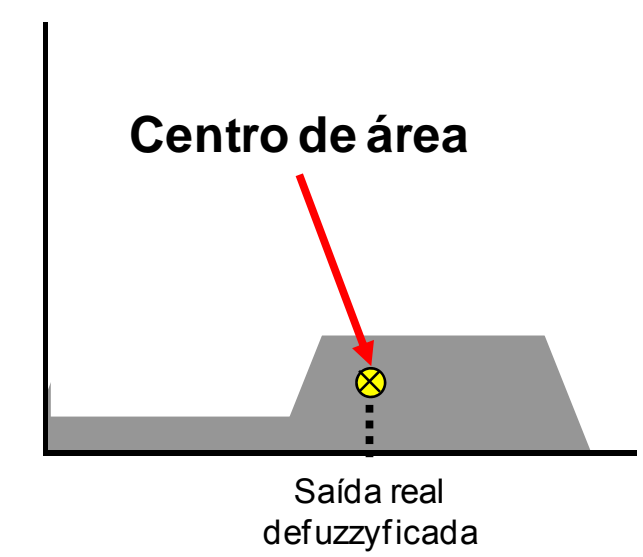

Figura 2.8 - Método de defuzzificação através do centro de área.

O método de defuzzificação por meio do centro de área permite se contabilizar de maneira proporcional as contribuições obtidas para a região fuzzy de saída.

Aspectos mais detalhados a respeito da técnica envolvendo os sistemas de inferência fuzzy podem ser encontrados em [24,25]. 


\subsection{Redes neurais artificiais}

A primeira publicação relacionada à neuro-computação é datada de 1943, através do artigo de McCulloch e Pitts [26]. Neste trabalho, McCulloch e Pitts realizaram o primeiro modelamento matemático inspirado no neurônio biológico, resultando assim na constituição do neurônio artificial.

A descrição matemática resultou em um modelo com $n$ terminais de entrada, ou seja, $x_{1}, x_{2}, \ldots, x_{n}$ (que representam os dendritos), e apenas um terminal de saída y (que representa o axônio). Para simular o comportamento das sinapses, os terminais de entrada do neurônio são influenciados por pesos sinápticos dados por $w_{1}, w_{2}, \ldots, w_{N}$, cujos valores podem ser positivos ou negativos. O efeito de uma sinapse particular $i$ no neurônio é dado pela multiplicação de $x_{i}$ por $w_{i}$. Portanto, cada neurônio da rede pode ser modelado conforme mostra a Figura 2.9.

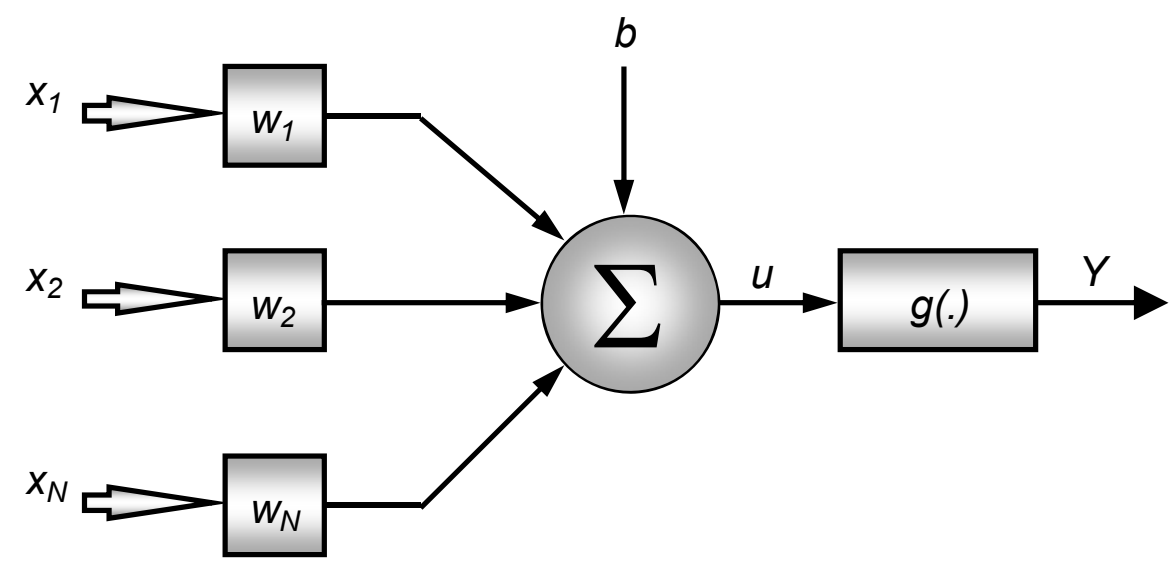

Figura 2.9 - Representação do neurônio artificial.

O modelo matemático que descreve o comportamento do neurônio artificial é expresso pela seguinte equação: 


$$
y=g\left(\sum_{i=1}^{n} w_{i} \cdot x_{i}+b\right)
$$

onde:

$n$ é o número de entradas do neurônio;

$w_{i}$ é o peso associado com a i-ésima entrada;

$b$ é o limiar associado ao neurônio;

$x_{i}$ é a $i$-ésima entrada do neurônio;

$g($.) é a função de ativação do neurônio;

y é a saída do neurônio.

Assim, um neurônio artificial opera da seguinte forma:

i) Os sinais são apresentados à entrada;

ii) Cada sinal é multiplicado por um peso que representa o seu nível de relevância na saída da unidade;

iii) É feita uma soma ponderada dos sinais, resultando assim em um nível de atividade;

iv) Caso este nível de atividade exceda um certo limite (threshold), então a unidade produz uma saída.

A função de ativação é a responsável pelo processamento do conjunto de informações recebidas. É também a função de ativação que é incumbida pela saída do neurônio, podendo assumir valores do tipo binários (0 ou 1), bipolares (1 e -1) ou reais. 
Outro fator muito importante na utilização de redes neurais artificiais é a escolha da topologia da rede, pois está diretamente relacionada à configuração das interligações entre os neurônios. A topologia também está intimamente ligada ao algoritmo de treinamento. Basicamente, a estrutura de uma rede neural artificial se divide em três partes:

I. Camada de entrada: responsável pelo recebimento das informações e é onde os padrões são inicialmente apresentados à rede.

II. Camadas neurais intermediárias ou escondidas: responsáveis pela extração das características do processo ou sistema ao qual se está inferindo. Quase todo o processamento da rede é realizado nestas camadas.

III. Camada neural de saída: responsável pela apresentação do resultado alcançado.

A Figura 2.10 mostra uma representação das camadas de uma rede neural artificial.

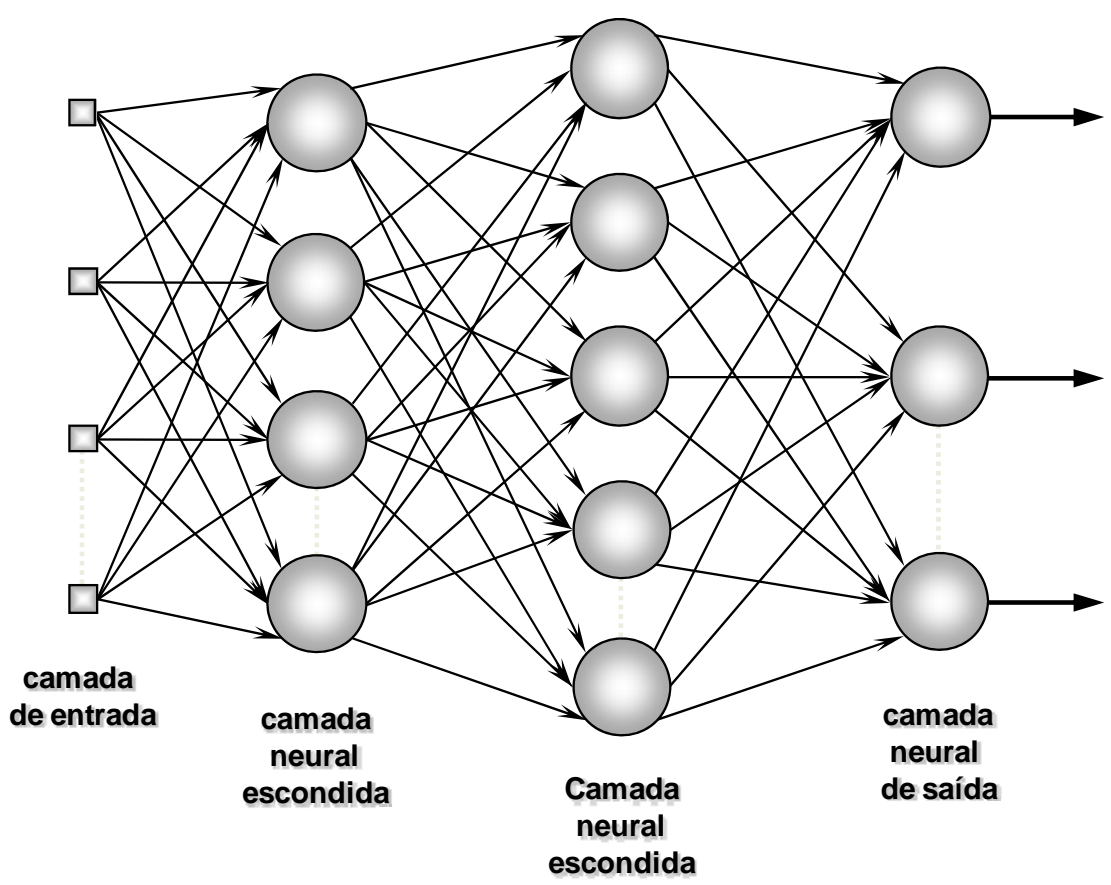

Figura 2.10 - Representação das camadas de uma rede neural artificial. 
As topologias de redes neurais artificiais se dividem em:

- $\quad$ Redes FeedForward (Camada Única): Esta topologia caracteriza-se por ter uma camada de entrada e uma única camada de neurônios que é a própria camada de saída. Esta é a configuração utilizada pelo perceptron e ADALINE. Estas redes são aplicadas, principalmente, em reconhecimento de padrões e em memórias associativas.

- Redes FeedForward (Multicamadas): Esta rede se diferencia da anterior por possuir uma ou mais camadas escondidas ou intermediárias. Nesta rede, as informações são recebidas pela camada de entrada, processadas pela camada escondida, e apresentadas pela camada de saída. Geralmente, esta topologia é aplicada em reconhecimento de padrões e como aproximador universal de funções, uma vez que se pode aproximar funções não-lineares. As principais redes que usam esta topologia são o perceptron multicamadas e a de Função Base Radial.

- Redes Recorrentes: As redes recorrentes se diferenciam por terem realimentação entre neurônios de camadas diferentes. Estas redes têm capacidade de "lembrar" seu comportamento com relação aos padrões anteriormente apresentados e, desta forma, processar seqüência de informações. São aplicadas em sistemas dinâmicos, séries temporais, previsões, identificação e controle. Este tipo de topologia é utilizado principalmente pelas redes perceptron com realimentação e redes de Hopfield. 
As redes perceptrons multicamadas são os tipos de redes mais usados em problemas envolvendo sistemas de distribuição de energia elétrica, sendo que sua topologia é similar àquelas apresentada na Figura 2.11.

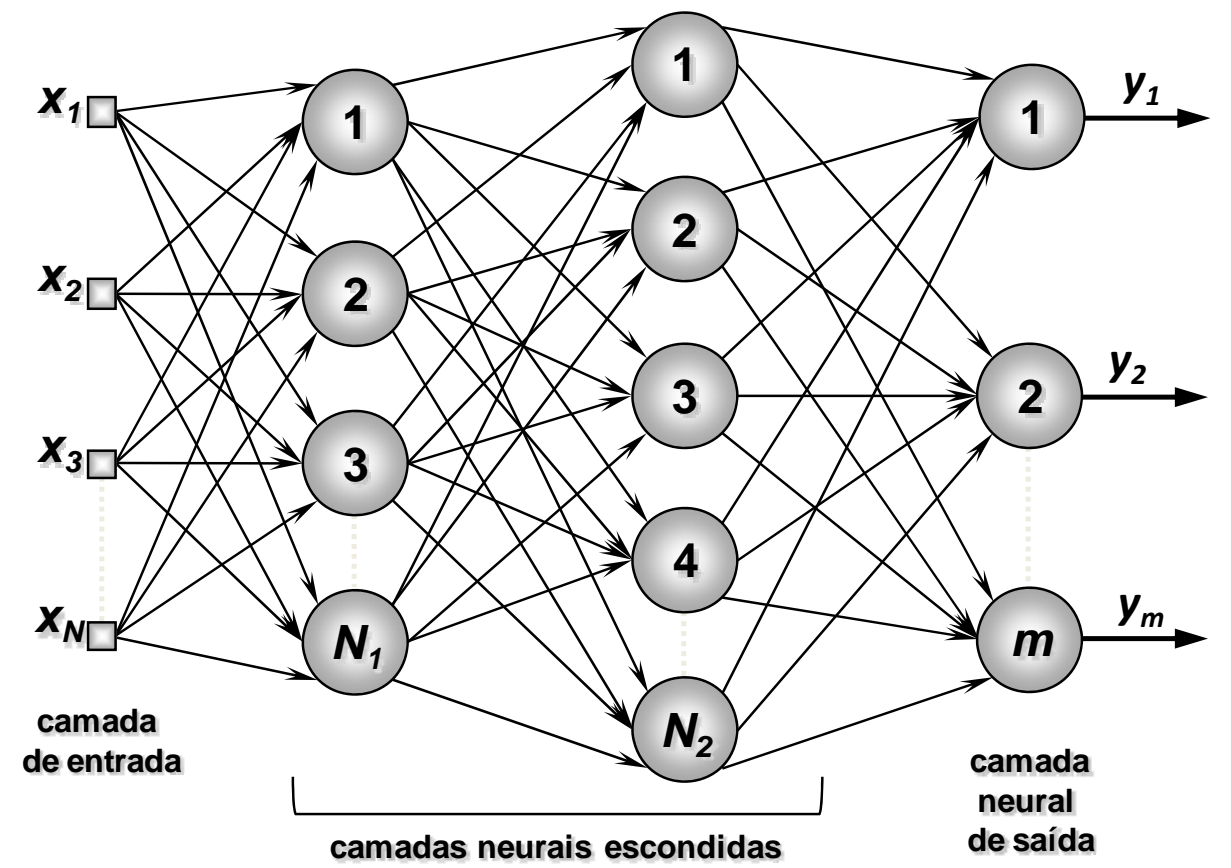

Figura 2.11 - Modelo neural perceptron multicamadas.

Em redes perceptrons multicamadas, as "tarefas" são distribuídas através das camadas. Os estímulos ou sinais são apresentados à rede na camada de entrada. A camada intermediária extrai as informações e as codificam por meio dos pesos sinápticos, formando assim uma representação própria do ambiente externo. Finalmente, a camada de saída recebe os estímulos da camada intermediária, mapeando o padrão de resposta que será a saída da rede. O sucesso desta rede em resolver problemas em sistemas de distribuição de energia elétrica se deve ao fato da mesma operar como um aproximador universal de funções, podendo mapear praticamente todos os tipos de não linearidades.

Aspectos detalhados da teoria envolvendo as redes neurais artificiais podem ser encontrados em [26-35]. 


\subsection{Transformada wavelet}

A teoria da transformada wavelet foi inicialmente proposta na década de 1980, destacando-se os trabalhos de Grossmann [36], Mallat [37] e Daubechies [38].

Desde então, a teoria de wavelet tem atraído a atenção de diversos pesquisadores, encontrando-se aplicações em diferentes áreas, particularmente em processamento de sinais e de imagens. O termo wavelet foi originariamente introduzido por J. Morlet, sendo a base matemática de suas idéias formalizada pelo físico teórico Alex Grossmann.

A transformada wavelet difere da Fourier principalmente na capacidade de identificar no tempo e na freqüência as componentes em análise de um sinal. Eventos que venham a ocorrer em intervalos de tempos distintos, e mesmo bastante remotos, contribuem de maneira global para a transformada, afetando a representação como um todo. Morlet introduziu uma nova transformada, denominada transformada de wavelet, na qual o tamanho da janela varia com a freqüência, permitindo que eventos de alta freqüência possam ser localizados com uma maior resolução temporal, ao passo que componentes de baixa freqüência possam ser analisados com maior resolução no domínio de Fourier. Intuitivamente, um evento de baixa freqüência precisa de uma janela maior no domínio do tempo para ser observado.

Em termos discretos, a transformada wavelet pode ser mais bem compreendida através da Figura 2.12. 


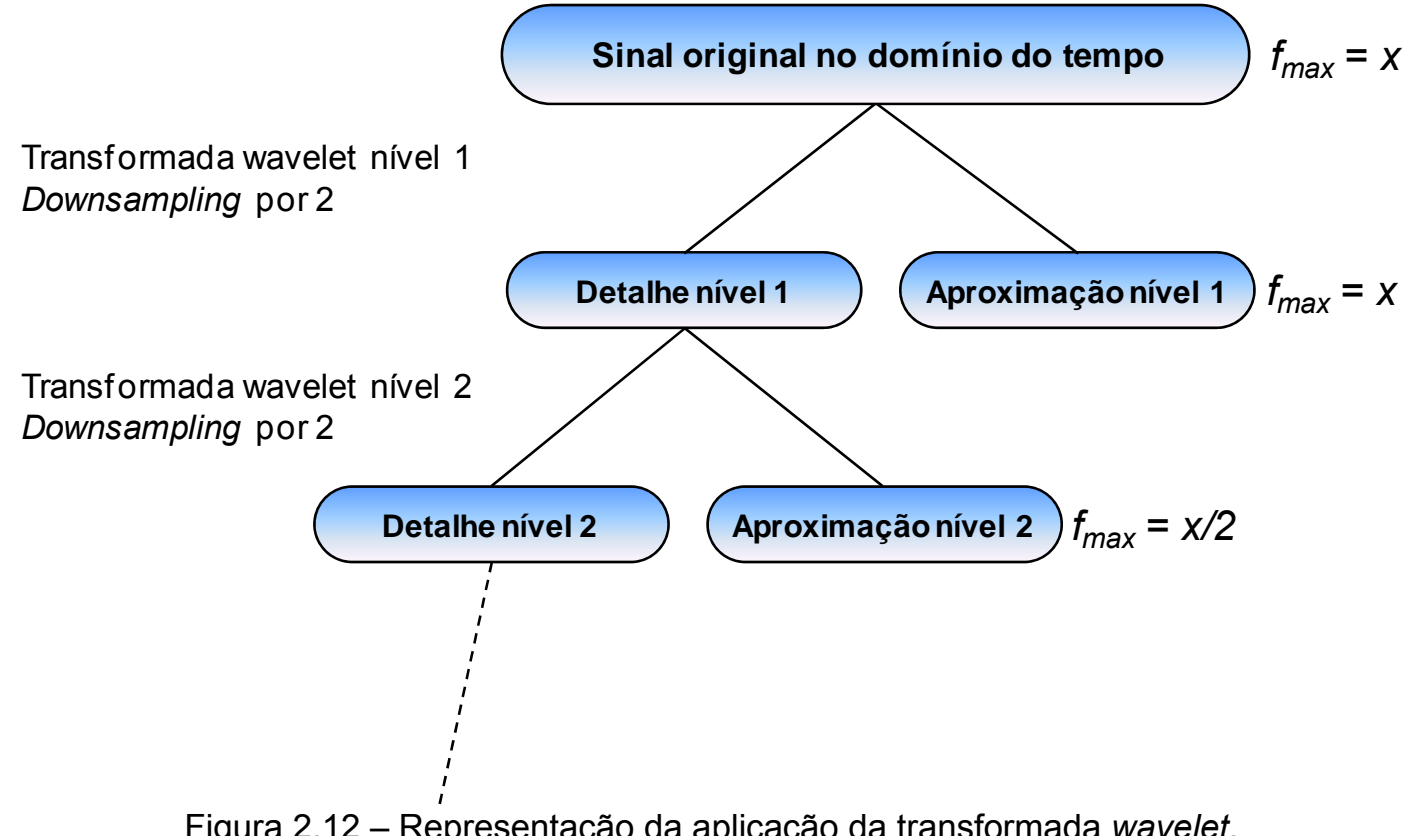

A transformada wavelet permite a decomposição de um sinal discretizado no tempo em dois níveis, denominados de detalhe e aproximação. O detalhe armazena as informações referentes às componentes de baixa freqüência, ao passo que a aproximação armazena aquelas de alta freqüência. À medida que a transformada wavelet é aplicada sobre o sinal, o mesmo é decomposto em níveis. Tais níveis são conhecidos como as folhas da árvore de decomposição wavelet.

A partir do nível 1, o sinal filtrado é decomposto em outros níveis a partir da folha de detalhe, acarretando no processo de Downsampling por 2, onde o número de amostras é reduzido à metade da folha mãe, assim como a freqüência.

Este processo permite inferir que à medida que se aumentam os níveis da transformada, aumenta-se a resolução na freqüência, mas perde-se em resolução no tempo.

O termo mais associado às transformadas wavelet é o de análise de multiresolução, definido primeiramente por Mallat. Isto porque um nível wavelet intermediário, geralmente nível 3, permite uma excelente resolução no tempo e 
freqüência, o que possibilita localizar no sinal original, discretizado no tempo, onde se encontram determinados grupos de freqüências.

Uma conseqüência direta desta capacidade de multi análise é a aplicação cada vez mais crescente da Transfromada wavelet em compressão de sinais, principalmente em áudio e vídeo, onde se realiza uma compactação bem eficiente e sem perdas.

Basicamente, a transformada wavelet aplica sobre o sinal no tempo dois filtros, conforme pode ser observado na Figura 2.13.

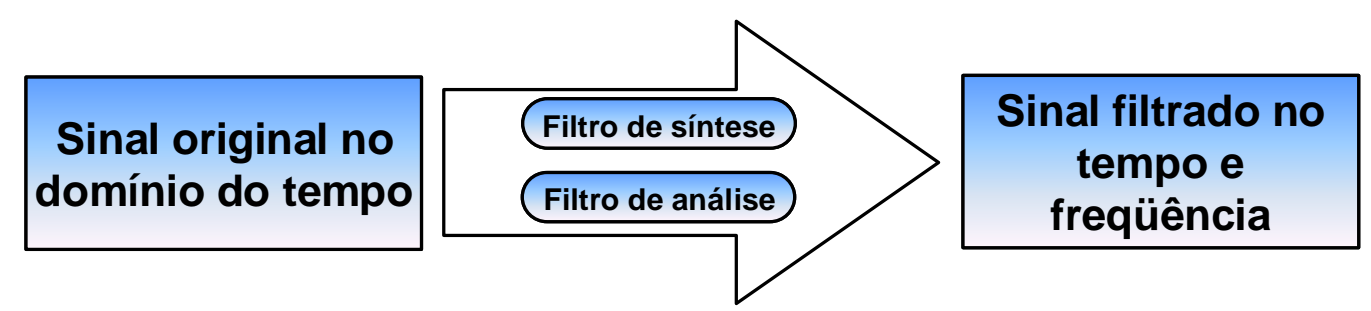

Figura 2.13 - Aplicação da transformada wavelet em um sinal no tempo.

Os dois filtros, de síntese e de análise, são aplicados ainda no domínio do tempo, por meio de convolução dos seus coeficientes com os coeficientes do sinal original. O resultado é um sinal filtrado em nível 1, tanto no domínio do tempo, como da freqüência.

De maneira geral, estes dois filtros podem ser descritos como sendo um passa-altas e outro passa-baixas. Assim, pode-se utilizar uma infinidade de famílias de filtros, desde que os dois sejam ortogonais entre si, para assim caracterizar a transformada wavelet [39].

Quanto mais coeficientes tiverem os filtros, melhor será a resposta, tanto no tempo quanto em freqüência. No entanto, esta quantidade de coeficientes deve respeitar o tamanho do sinal original, para não inserir atrasos na resposta e elevar o tempo de processamento. 
Aspectos mais detalhados sobre a teoria de wavelets podem ser encontrados em [36-39]

\subsection{Ferramentas estatísticas e de processamento digital de sinais}

\subsubsection{Introdução ao processamento digital de sinais}

Diversas são as áreas que se utilizam desta tecnologia, tais como: comunicação, equipamentos médicos, radares e sonares, reprodução de músicas em alta fidelidade, exploração de petróleo, etc. Cada uma dessas áreas tem sua específica funcionalidade $D S P$ desenvolvida, com seus próprios algoritmos, funções matemáticas e técnicas especializadas [40].

Os filtros digitais constituem um tópico muito importante do processamento digital de sinais. Na realidade, sua extraordinária performance é uma das razões chave que levou o DSP a tornar-se tão popular [41].

Os filtros possuem 2 finalidades básicas: separação de sinais e restauração de sinais. A separação de sinais é necessária quando um sinal foi contaminado com uma interferência, ruído ou outra fonte de sinal. Por exemplo, imagina-se um dispositivo para medir a atividade elétrica do coração de um bebê (ECG) enquanto ele ainda está no ventre da sua mãe. O sinal puro será provavelmente corrompido pela respiração e batimento cardíaco da mãe. Portanto, um filtro deve ser usado para separar estes sinais de forma que eles possam ser individualmente analisados [40].

A restauração de sinais é usada quando um sinal foi distorcido de alguma maneira. Por exemplo, uma gravação de áudio feita com um equipamento de baixa 
qualidade deve ser filtrada para melhorar a representação do som, deixando o mais próximo ao original. Outro exemplo é a nitidez de uma imagem adquirida com uma lente fora de foco, ou mesmo um tremor na câmera. Neste caso, filtros também devem ser usados.

Ambos os problemas podem ser combatidos com filtros analógicos ou digitais. A dúvida mais comum é qual o melhor tipo de filtro: o analógico ou o digital? Os filtros analógicos são baratos, rápidos e têm uma grande abrangência em amplitude e freqüência. Os filtros digitais, em comparação, são amplamente superiores em termos de performance que pode ser alcançada. Por exemplo, um filtro digital passa-baixa pode ter um ganho de 1 , mais ou menos 0,0002 para um sinal DC até a sua freqüência de corte $\left(f_{c}=1000 \mathrm{~Hz}\right)$, e um ganho menor que 0,0002 para freqüências de $1 \mathrm{~Hz}$ acima da freqüência de corte $(1001 \mathrm{~Hz})$. Note que é possível construir regiões de corte muito estreitas, nesse caso da ordem de $1 \mathrm{~Hz}$; entretanto, isso não pode ser esperado de um filtro analógico com amplificadores operacionais.

As principais vantagens dos filtros digitais podem ser resumidas por: (a) Eles são programáveis por software e, assim, são fáceis de construir e testar; (b) Requerem apenas operações aritméticas de multiplicação, adição/subtração, e são mais fáceis de implementar; (c) São estáveis (não variam com o tempo ou temperatura) e são previsíveis; (d) Não desajustam com a temperatura ou umidade e não requerem precisão de componentes; (e) Possuem uma relação superior de custo-benefício; (f) Não são afetados por variações de fabricante ou vida útil [42, 43].

Ainda no campo de tratamento digital de sinais, destaca-se a transformada discreta de Fourier (DFT) como uma das mais poderosas ferramentas. A DFT torna possível a análise, manipulação, e a síntese de sinais de uma maneira impossível ao 
processamento analógico de sinais. Embora nos dias de hoje ela seja utilizada em quase todos os campos da engenharia, sua aplicação continua a prosperar quando sua utilidade se torna mais amplamente entendida [42].

A $D F T$ é um procedimento matemático usado para determinar a harmônica, ou freqüência, contida em uma seqüência discreta de um sinal. Embora, um sinal discreto é um conjunto de valores obtidos por uma amostragem periódica de um sinal contínuo no domínio do tempo, pode-se observar que a DFT é útil em analisar qualquer seqüência discreta sem levar em consideração o quê a seqüência de fato representa. A origem da $D F T$, naturalmente, é a transformada de Fourier contínua [43].

A detecção de um transitório ou um sinal de energia finita em conjunto com interferências é um assunto de interesse de muitas áreas, tais como processamento da fala, processamento de sinais sísmicos, processamento de sinais biomédicos, monitoramento das condições de máquinas, dentre outros [44-46].

O emprego de ferramentas estatísticas no processamento de sinais, com finalidade à extração de características de transitórios, vem auxiliando cada vez mais os pesquisadores na busca pela compreensão destes eventos nos sistemas elétricos de potência. Dentre as mais comuns metodologias de extração de informações estatísticas destaca-se o valor RMS, que ainda é bastante utilizado associado a outras ferramentas; porém, devido à sua característica de média estatística, dados relevantes para a utilização na detecção de faltas podem ser descartadados quando empregada esta técnica.

Outra ferramenta de simples implementação e boa performance é a estatística de Nuttal que, sob a hipótese de ausência de sinal (Ho), o dado no domínio do tempo é ruído gaussiano branco complexo, pré-processado pelo 
quadrado da magnitude da transformada discreta de Fourier e produz variáveis exponenciais randômicas independentes e identicamente distribuídas [47]. Sob a hipótese de presença de sinal $(\mathrm{H} 1)$, as observações da transformada discreta de Fourier não são mais exponenciais da população homogênea; assim, supõe-se que os $M$ números de pontos presentes no sinal estejam uniformemente distribuídos entre os $N$ pontos da FFT [48].

A estatística de Nuttal requer dados pré-normalizados, ou seja, a média no modelo deve ser disponível. Assim, como uma extensão à lei de potência de Nuttall, para níveis de ruído desconhecidos, a estatística taxa constante de falso alarme (CFAR) foi introduzida por [49].

Pode-se destacar também o emprego de Correlação e Autocorrelação na busca de semelhanças entre sinais. Como na convolução, duas seqüências são envolvidas na Correlação. Em contraste com a convolução, o objetivo é medir o grau que os dois sinais são semelhantes, e assim extrair alguma informação que dependa de certa forma da aplicação. Correlações de sinais são freqüentemente encontradas em radar, sonar, comunicação digital, geologia, e outras áreas em ciências e engenharia [50].

A seguir serão apresentadas, de forma detalhada, as ferramentas utilizadas no processamento digital dos sinais de tensão e corrente que alimentam os módulos de identificação e localização de faltas desta pesquisa. 


\subsubsection{Transformada discreta de Fourier}

A origem da transformada discreta de Fourier, ou simplesmente DFT, naturalmente, é a transformada de Fourier contínua definida pela expressão (2.2) $[42,43]$ :

$$
X(f)=\int_{-\infty}^{\infty} x(t) e^{-j 2 \pi t t} d t
$$

No campo do processamento de sinais, a expressão (2.2) é usada para transformar uma expressão de uma função $x(t)$ no domínio do tempo contínuo em uma função do domínio da freqüência contínua $X(f)$. Uma posterior avaliação de $X(f)$ torna possível a determinação do conteúdo em freqüência de qualquer sinal prático de interesse, e abre um amplo campo de análise de sinais e possibilidades de processamento nos campos da engenharia e física. Pode-se questionar que a transformada de Fourier é o mecanismo matemático mais dominante e comum disponível para a análise de sistemas físicos.

Com o advento do computador digital, os esforços iniciais dos pioneiros na área de processamento digital levaram ao desenvolvimento da $D F T$ definida como a seqüência discreta no domínio da freqüência $X(m)$, e dada pela expressão (2.3) na forma exponencial [43]:

$$
X(m)=\sum_{n=0}^{N-1} X(n) e^{-j 2 \pi n m / N}
$$

onde $x(n)$ é uma seqüência discreta de valores amostrados no domínio do tempo da variável contínua $x(t)$. O símbolo "e" na expressão (2.3) é, naturalmente, o logaritmo 
natural; $j=\sqrt{-1} ; m=0,1,2,3, \ldots N-1$, é o índice da saída da $D F T$ no domínio da freqüência; $N$ é o número de amostras da seqüência de entrada e o número de pontos de freqüência na saída da DFT [42].

Embora a DFT seja o procedimento matemático mais direto para determinar o conteúdo em freqüência de uma seqüência no domínio do tempo, ela é bem ineficiente. Conforme o número de pontos da DFT aumenta, a quantidade necessária de cálculos se torna excessiva.

Em [51], foi proposto um algoritmo eficiente para implementar a DFT, sendo que este passou a ser conhecido como transformada rápida de Fourier (FFT).

Antes do advento da FFT, centenas de pontos da DFT levavam muito tempo para ser calculados e o seu uso era restrito apenas a grandes centros de pesquisas e universidades. Graças a $F F T$, e a indústria de semicondutores, um cálculo de $D F T$ de 1024 pontos pode ser realizado de forma rápida em computadores pessoais.

Muito se tem reportado sobre a FFT, e diferente de qualquer outra inovação,

o desenvolvimento deste algoritmo abriu muitas possibilidades de aplicação no campo de processamento digital de sinais. Cabe ressaltar que em todos os processos envolvendo a identificação e localização de faltas deste trabalho, serão utilizados apenas os valores reais das respostas produzidas pela FFT.

\subsubsection{Valor médio quadrático (RMS)}

Para um dado tempo $t$, o valor RMS de um sinal $f(t)$ pode ser encontrado pela expressão (2.4). 


$$
F_{r m s}=\sqrt{\frac{1}{T} \int_{t-T}^{t} f^{2}(t) d t}=\sqrt{\frac{1}{N} \sum_{i=1}^{N} f^{2}(i)}
$$

onde $T$ é o tempo de integração e $N$ é o número discreto de dados da função no intervalo de $T$. Em muitos casos, $F_{R M S}$ pode ser obtido através do uso de filtro analógico RMS. No presente trabalho, obteve-se os valores RMS digitalmente onde $T$ foi considerado $16,7 \mathrm{~ms}$.

Devido à sua característica de média estatística, quando empregado, pode eventualmente perder alguma característica do sinal original.

\subsubsection{Estatística de Nuttal}

A suposição básica de Nuttall é de que existem duas populações exponenciais:

$$
\begin{aligned}
& H_{0}: f(X)=\prod_{k=1}^{N} \frac{1}{\mu_{0}} e^{-X_{k} / \mu_{0}} u\left(X_{k}\right) \\
& H_{1}: f(X)=\prod_{k \notin S} \frac{1}{\mu_{0}} e^{-X_{k} / \mu_{0}} u\left(X_{k}\right) \prod_{k \notin S} \frac{1}{\mu_{1}} e^{-X_{k} / \mu_{1}} u\left(X_{k}\right)
\end{aligned}
$$

onde $u(\cdot)$ é a função degrau unitário; $N$ é o número total de pontos da $F F T ; X$ é o quadrado da magnitude dos pontos da FFT; $S$ é o subconjunto com tamanho $M$.

Supõe-se que os $M$ números de pontos presentes no sinal estejam uniformemente distribuídos entre os $N$ pontos da FFT. Pode-se observar claramente que a exata lei de probabilidade sob a hipótese $H_{1}$ depende do sinal transitório em si, e não existe razão particular para levar a expressão (2.5) como verdadeira. No entanto, existe uma flexibilidade considerável em (2.5), e o detector surge dela. 
Considerando o modelo anterior, para qualquer taxa, Nuttall [47] desenvolveu sua estatística como uma aproximação do detector ótimo, cuja forma é descrita pela expressão (2.6).

$$
T_{p l}(X)=\sum_{k=0}^{M-1} X_{k}^{u}
$$

onde $u$ é um expoente ajustável. Na ausência de informação acerca de $M$, o melhor valor de $u$ observado foi 2,5 .

\subsubsection{Taxa constante de falso alarme (CFAR)}

A estatística taxa constante de falso alarme foi introduzida por [49] e pode ser expressa por (2.7).

$$
T_{c p l}(X)=\frac{\sum_{k=1}^{N} X_{k}^{u}}{\left(\sum_{k=1}^{N} X_{k}\right)^{u}}
$$

Como esta estatística é baseada na hipótese que o sinal em questão possui freqüências em todo o espectro, e os sinais analisados em alguns trabalhos não são brancos, uma versão de banda limitada da estatística CFAR foi considerada [48], a qual é expressa pela equação (2.8). 


$$
T_{c p l}(X)=\frac{\sum_{k=n_{1}}^{n_{2}} X_{k}^{u}}{\left(\sum_{k=n_{1}}^{n_{2}} X_{k}\right)^{u}}
$$

onde $T_{c p l}$ não é claramente afetado pela amplitude do sinal.

Para o processamento dos sinais do presente trabalho, foi considerado um bloco de 16,67 ms, ou seja, $M=1667$ (para uma freqüência de amostragem de 100 $\mathrm{kHz}$ ). Procurou-se concentrar uma faixa de freqüência de $50 \mathrm{~Hz}$ a $1 \mathrm{kHz}$ para os sinais coletados, ou seja, $n_{1}=2$ e $n_{2}=33$.

\subsubsection{Relação de potência (ROP)}

O comportamento do espectro do sinal de um transitório indesejável em um dado sistema torna-se no mínimo interessante examinar, pois possivelmente o comportamento em freqüência pode diferir em se ter um sistema operando em uma situação normal e em outra anormal (de falta, por exemplo).

Em [52] utilizou-se a estatística denominada Relação de Potência $(R O P)$ na detecção de fenômenos da manufatura, a qual é expressa pela expressão (2.9).

$$
R O P=\frac{\sum_{k=n_{1}}^{n_{2}}\left|X_{k}\right|^{2}}{\sum_{k=0}^{N-1}\left|X_{k}\right|^{2}}
$$


em que o denominador elimina o efeito local da potência do sinal. Nesta ferramenta, $N$ é escolhido como o comprimento da $F F T, X_{k}$ é a $k$-ésima saída da $D F T$, e a soma é sobre qualquer faixa de freqüência, representada por $n_{1}$ e $n_{2}$.

\subsubsection{Desvio do valor médio (MVD)}

Processada no domínio da freqüência, a estatística de desvio do valor médio $(M V D)$ foi definida por [53] e dada pela expressão (2.10).

$$
T_{m v d}(X)=\frac{1}{M} \sum_{k=0}^{M-1} \log \left[\bar{X} / X_{k}\right]
$$

onde $\bar{X}$ é o valor médio de $\left\{X_{k}\right\}, M$ é o comprimento do bloco da FFT e $X_{k}$ é a $k$ ésima saída da FFT.

Uma vez que esta ferramenta requer que o sinal de entrada seja primeiro processado de tal forma que todos os seus elementos não possuam Correlação e tenha variância unitária (whitening), uma versão de banda limitada foi proposta por [48] e representada pela expressão (2.11).

$$
T_{m v d}(X)=\sum_{k=n_{1}}^{n_{2}} \log \left(\frac{\frac{1}{n_{2}-n_{1}+1} \sum_{l=n_{1}}^{n_{2}} X_{l}}{X_{k}}\right)
$$

A freqüência de preferência é determinada por $n_{1}$ e $n_{2}$. 


\subsubsection{Kurtosis e Skewness no domínio do tempo}

Supõe-se que entre os parâmetros de corrente e tensão, as estatísticas de Kurtosis e Skewness quando do transitório de tais sinais sofram variações significativas, e possam portanto caracterizar de alguma forma o processo.

Seja $x_{i}, i=1, \ldots, n$, representar os dados discretos reais de um dado sinal, e seja $n$ ser o número de pontos de dados de cada bloco. A estatística empírica de Kurtosis é definida por [54] e dada pela expressão (2.12).

$$
K_{t}=\frac{\frac{1}{n} \sum_{i=1}^{N}\left(x_{i}-\bar{x}\right)^{4}}{\left[\frac{1}{n} \sum_{i=1}^{n}\left(x_{i}-\bar{x}\right)^{2}\right]^{2}}
$$

De maneira semelhante, a expressão do cálculo de Skewness é dada pela expressão (2.13) [55].

$$
S=\sum \frac{(x-\mu)^{3}}{N \sigma^{3}}
$$

onde $\mu$ é a média, $N$ é o número de pontos no intervalo considerado e $\sigma$ o desvio padrão. 


\subsubsection{Correlação e Autocorrelação}

Sejam duas seqüências $x(n)$ e $y(n)$ que se deseja comparar. Em aplicações de radar ou sonar, por exemplo, $x(n)$ pode representar o sinal amostrado transmitido e $y(n)$ o sinal amostrado recebido na saída do conversor analógico digital (A/D). Se um alvo é apresentado no espaço sendo pesquisado por um radar ou sonar, o sinal recebido $y(n)$ consiste de um sinal transmitido atrasado, refletido do alvo, e corrompido por um ruído. Pode-se representar o sinal recebido da seqüência representada por (2.14) [50]:

$$
y(n)=\alpha x(n-D)+w(n)
$$

onde $\alpha$ é algum fator atenuante representando a perda do sinal envolvida na transmissão de ida e volta do sinal $x(n)$; $D$ é o atraso de ida e volta, o qual é suposto ser um múltiplo inteiro do intervalo de amostragem; $w(n)$ representa um ruído que é coletado pela antena e qualquer ruído gerado por componentes eletrônicos e amplificadores contidos no receptor. Por outro lado, se não existir alvo no espaço pesquisado pelo radar e sonar, o sinal recebido $y(n)$ consiste apenas de ruído.

Tendo-se os dois sinais $x(n)$, que é chamado de sinal de referência ou sinal transmitido, e $y(n)$ o sinal recebido, o problema de deteç̧ão do radar e sonar é comparar $y(n)$ e $x(n)$ para determinar se um alvo está presente, e no caso afirmativo, determinar o tempo de atraso $D$ e calcular a distância do alvo. Na prática, o sinal $x(n-$ $D)$ é altamente corrompido por ruído até o ponto onde uma inspeção visual de $y(n)$ não revela a presença ou ausência do sinal desejado refletido do alvo. A Correlação fornece um meio de extrair esta importante informação de $y(n)$. 
Assim, supondo-se dois sinais amostrados reais $x(n)$ e $y(n)$ tendo cada um energia finita. A Correlação cruzada de $x(n)$ e $y(n)$ é a seqüência $r_{x y}(I)$ definida por [50].

$$
r_{x y}(I)=\sum_{n=-\infty}^{\infty} x(n) y(n-I) ; \quad I=0, \pm 1, \pm 2, \ldots
$$

O índice I é o parâmetro de deslocamento no tempo e os sub-escritos $x y$ indicam as seqüências sendo correlacionadas. A ordem dos sub-escritos, com $x$ antes do $y$, indica a direção na qual uma seqüência é deslocada em relação à outra.

A semelhança entre o cálculo da Correlação cruzada e a convolução de duas seqüências é evidente. No cálculo da convolução, uma das seqüências é invertida, e então deslocada e, posteriormente, multiplicada pela outra seqüência para formar a seqüência do produto para aquele deslocamento, e finalmente, os valores da seqüência do produto são somados. Exceto para a operação de inversão, o cálculo da seqüência de Correlação cruzada envolve as mesmas operações.

No caso especial onde $y(n)=x(n)$, tem-se a Autocorrelação de $x(n)$, a qual é definida como a seqüência:

$$
r_{x x}(I)=\sum_{n=-\infty}^{\infty} x(n) x(n-I) ; \quad I=0, \pm 1, \pm 2, \ldots
$$

Em se tratando de seqüências de duração finita, é comum expressar a Autocorrelação e a Correlação cruzada em termos de limites finitos na soma. Em particular, se $x(n)$ e $y(n)$ são seqüências causais de comprimento $N$, ou seja, 
$x(n)=y(n)=0$ para $n<0$ e $n \geq N$, a Correlação cruzada e Autocorrelação podem ser expressas por:

$$
\begin{array}{ll}
r_{x y}(I)=\sum_{n=i}^{N-|k|-1} x(n) y(n-I) ; & I=0, \pm 1, \pm 2, \ldots \\
r_{x x}(I)=\sum_{n=i}^{N-|k|-1} x(n) x(n-I) ; \quad I=0, \pm 1, \pm 2, \ldots
\end{array}
$$

onde $i=\mathrm{I}, k=0$ para $l \geq 0$, e $i=0, k=\mid$ para $k$.

\subsubsection{Análise por componentes principais (PCA)}

Os dados aquisitados com o objetivo de identificar e classificar as faltas apresentam grandes quantidades de variáveis. De forma a minimizar o esforço computacional, os dados necessitam ser pré-processados de forma a reduzir a quantidade de variáveis. Nesse contexto, a ferramenta que apresenta tal característica é a análise por componentes principais (PCA).

Análise por componentes principais é um método estatístico que determina uma transformação linear ótima $(y=W x)$ para um vetor de entrada $x$ de um processo estocástico estacionário e uma especificada dimensão do vetor de saída $y$, onde $W$ $\in \mathfrak{R}^{n \times m}$ com $m<n$. O resultado dessa transformação é redução da dimensão dos dados de entrada. Tal redução de dimensão tem importantes benefícios. Primeiro, o esforço computacional de pós-processamento é reduzido de forma significativa. Segundo, o ruído pode ser reduzido, visto que as PCAs contêm as informações desejadas e mantém as características do sinal de entrada, enquanto que as 
componentes menores contêm as estatísticas do sinal aditivo (ruído) que corrompe os sinais de entrada. Terceiro, a projeção em um subespaço de baixa dimensão (por exemplo 2) é útil para a visualização dos dados em análise multivariada.

Em termos estatísticos, o objetivo da análise por componentes principais é encontrar um conjunto de $m$ vetores ortogonais no espaço de entrada que aponte na direção da máxima variância de entrada. Especificamente, a primeira componente principal $y_{1}$ é a combinação linear das componentes dos dados de entrada que tem, em média, a maior variância, ou seja, é a combinação linear das variáveis originais que geram novas variáveis, normalmente de menor dimensão vetorial.

Supondo que $x$ seja o vetor de entrada de dimensão $n$ e $R_{x x}$ sua matriz de Autocorrelação é dada por:

$$
R_{x x}=\frac{1}{N} \sum_{k=1}^{N} x_{k} x_{k}^{T}
$$

e sendo $w_{1}, w_{2}, w_{3}, \ldots, w_{m}$ as linhas da matriz $W$ que são os autovetores da matriz de Correlação $R_{x x}$ correspondendo aos seus maiores autovalores. Então a primeira componente principal é, ao longo da direção do autovetor $w_{1}$ com a máxima variância, igual ao maior autovalor $\lambda_{1}$ de $R_{x x}$. De forma similar, a segunda componente principal tem na média a maior variância (igual ao autovalor $\lambda_{2}$ ) na direção perpendicular ao primeiro autovetor e assim por diante. Em outras palavras, o objetivo da análise de componentes principais é encontrar a direção dos autovetores $w_{1}, w_{2}, w_{3}, \ldots, w_{m}$ tal que a função (2.20) seja maximizada sob a condição de que $w_{i}^{T} w_{j}=0$ para $j<i$ e $w_{i}^{T} w_{i}=1$. 


$$
E_{M}\left\{\left\|x_{k}^{T} x\right\|_{2}^{2}\right\}
$$

onde $E_{M}\{\cdot\}$ representa a média esperada.

Em geral, a primeira componente principal é obtida fazendo-se:

$$
w_{1}=\arg E_{M}\left\{\left(x_{k}^{T} x\right)^{2}\right\}
$$

e a i-ésima componente principal é determinada como o resíduo da primeira componente principal, ou seja:

$$
w_{k}=\arg E_{M}\left\{\left[w^{T}\left(x-\sum_{i=1}^{k-1} w_{i} w_{i}^{T} x\right)^{2}\right]\right\}
$$

onde $w_{i}$ correspondem aos autovetores da matriz de auto-correlação $R_{x x}$ que correspondem aos maiores autovalores. 



\section{Principais metodologias empregadas na}

\section{detecção de faltas em sistemas de}

\section{distribuição}

Um dos requisitos para a operação econômica e confiável de um sistema de potência é a determinação exata, e em tempo hábil, do ponto onde uma falta ocorreu. A localização destas faltas nos sistemas de distribuição de energia elétrica, em geral, é realizada pelo cruzamento das informações fornecidas pelos clientes com a experiência acumulada pelos profissionais da área técnica, os quais são responsáveis pelo despacho das equipes de manutenção aos lugares onde provavelmente a falta ocorreu. Se a estimação inicial estiver incorreta, então novos lugares candidatos deverão ser investigados pelas equipes responsáveis até que o local da falha seja identificado e os procedimentos de reparo possam ser efetuados.

Atualmente, a competição incremental ocasionada pela desregulamentação do setor de energia elétrica, aliada à necessidade crescente em fornecer melhores serviços aos clientes, tem contribuído para que as companhias de distribuição de energia elétrica investiguem novos métodos de localização de faltas que sejam mais rápidos e confiáveis que as abordagens convencionais. Outro aspecto motivador que vem impulsionando o desenvolvimento de novas abordagens para identificação e localização de faltas é a possibilidade de otimização dos recursos técnico-financeiros das companhias, bem como a melhoria dos indicadores de eficiência energética do sistema de distribuição. 
De uma maneira ampla, as faltas observadas junto aos sistemas de distribuição de energia elétrica podem ser classificadas em faltas de alta impedância e em faltas de baixa impedância.

As faltas de baixa impedância passíveis de ocorrência nos sistemas elétricos de distribuição são as faltas fase-fase e as faltas trifásicas. Estes tipos de faltas se caracterizam por provocarem a ocorrência de correntes com magnitudes suficientemente altas para sensibilizar os dispositivos de proteção instalados ao longo do alimentador ou junto à subestação. Além destes dois tipos de faltas, as faltas fase-terra de baixa impedância, num sistema de distribuição estrela aterrada, podem também ser identificadas pelos dispositivos de proteção do sistema de distribuição. Assim, as abordagens referenciadas na bibliografia correlata, relacionadas às faltas de baixa impedância, procuram, mediante a oscilografia do sistema e do estado dos equipamentos seccionalizadores, localizar dentro do segmento faltoso o local de ocorrência da falta para que as medidas corretivas cabíveis sejam providenciadas.

No entanto, dados estatísticos indicam uma maior probabilidade de ocorrência de faltas de alta impedância junto aos sistemas de distribuição de energia elétrica. As faltas de alta impedância se caracterizam por apresentarem magnitudes de corrente de falta menores que a corrente de carga (trabalho) do alimentador. Assim, os sistemas de proteção convencionais são ineficazes na identificação e conseqüente atuação junto ao sistema de distribuição frente à ocorrência deste tipo de falta. Como uma conseqüência direta destas limitações, tem-se que cabos rompidos, encostados no solo, por exemplo, podem permanecer energizados por um longo período. Esta situação ilustrativa pode representar um sério risco, pois pode 
provocar acidentes envolvendo pessoas e animais, ou ainda, desencadear incêndios resultando em danos ao meio ambiente, bem como prejuízos de ordem econômica.

Desta forma, as faltas de alta impedância podem ser definidas como um evento anormal sobre um alimentador de distribuição primário que não pode ser facilmente detectado por dispositivos de proteção modernos. A maioria das faltas de alta impedância envolve níveis de corrente muito menores que aqueles necessários à sensibilização dos dispositivos de proteção de corrente. Essas faltas freqüentemente exibem arcos voltaicos quando nenhum retorno sólido para a corrente é disponível, resultando em correntes de falta com componentes de alta freqüência observáveis. Como decorrência direta destas faltas, este mesmo comportamento pode resultar de outros eventos, tais como o chaveamento de capacitores e mudanças de tap de transformadores.

Basicamente, existem dois tipos de faltas de alta impedância, ou sejam, as faltas ativas e as faltas passivas. Uma falta ativa é caracterizada pela presença de arco elétrico junto ao local de sua ocorrência. A maioria das técnicas propostas na literatura para detectar faltas ativas utiliza inferências que empregam os valores de módulo e ângulo das freqüências harmônicas e não harmônicas geradas pela corrente de arco elétrico.

Uma falta de alta impedância passiva é caracterizada pela ausência do arco elétrico. Este tipo de falta pode representar um risco maior, visto que o condutor não fornece qualquer indicação visual de uma condição de perigo. Além disso, as faltas passivas são mais difíceis de serem detectadas, pois as informações contidas no espectro harmônico da corrente da falta não são tão evidentes quanto aquelas contidas no espectro harmônico das correntes de falta ativas. Uma visão ampla 
sobre os principais aspectos relacionados às faltas de alta impedância passivas é apresentada em [57].

Nas seções seguintes serão apresentadas em detalhes algumas das principais abordagens para identificação e localização de faltas em sistemas de distribuição de energia elétrica por meio de técnicas atuais. Dentre estas técnicas, destaque especial será conferido às redes neurais artificiais, aos sistemas de inferência fuzzy e às abordagens baseadas na transformada wavelet devido aos promissores resultados apresentados por essas abordagens e relatados junto à bibliografia correlata.

\subsection{Detecção de faltas de alta impedância em alimentadores de sistema de distribuição utilizando redes neurais artificiais}

A metodologia proposta em [58] é constituída de três etapas principais, que são utilizadas para o processo de detecção de faltas em sistemas de distribuição. A primeira etapa consiste em se coletar e processar um conjunto de sinais referentes às correntes de linha do alimentador. A segunda etapa é responsável por empregar este conjunto de medidas para treinar a abordagem neural de maneira que a mesma seja capaz de identificar situações de ocorrência de falta ou condições de operação normal do sistema. Finalmente, a terceira etapa é dedicada aos procedimentos envolvidos com a validação da abordagem neural com dados que não pertenceram ao conjunto de treinamento, de forma a comprovar a eficiência da abordagem frente a novas situações.

Tanto os dados de treinamento como os dados de validação da abordagem neural foram gerados utilizando para tal propósito o programa de simulações de 
transientes eletromagnéticos EMTP. Diversas simulações foram executadas envolvendo diferentes situações de transitórios, tais como simulações de acionamento de motores e de energização de capacitores. Quatro tipos de casos foram gerados que podem ser listados da seguinte forma:

- Casos de chaveamento normal de cargas.

- Casos de carga normal com chaveamento de capacitores.

- Casos de falta de alta impedância com chaveamento de cargas.

- Casos de falta de alta impedância com chaveamento de carga e de capacitor.

As amostras de corrente empregadas no treinamento da rede foram inicialmente separadas dentro de conjuntos de um único ciclo cada. Para cada conjunto, 20 parâmetros foram computados para representar a condição do alimentador perante o ciclo de operação. Dentre estes parâmetros, pode-se listar os seguintes:

- O valor de pico da corrente transitória nas três fases.

- O valor da corrente antes e imediatamente após a ocorrência do maior transitório.

- O número de transitórios caindo abaixo de $75 \%$ do valor máximo.

- A magnitude da corrente de seqüência positiva.

- O nível de desbalanço entre as fases.

- As componentes harmônicas de primeira, terceira e quinta ordem da corrente de neutro. 
Vários desses parâmetros, tais como a corrente de seqüência positiva, são somente empregados para propósitos de referência, pois, desta maneira, permite-se que a rede neural possa fazer comparações entre os níveis de corrente transitória e outros parâmetros a fim de que a mesma possa extrair ponderações relativas às perturbações.

\subsection{Técnicas de identificação de faltas de alta impedância utilizando redes neurais artificiais e transformada de Fourier}

Conforme mencionado anteriormente, as faltas de alta impedância são geralmente difíceis ou impossíveis de serem detectadas com dispositivos de proteção de sobrecorrente (relés, elos fusíveis e religadores). Tal fato é constatado pela magnitude da corrente não ser suficientemente alta para ativá-los, dificultando assim a discriminação entre as correntes de carga e correntes de falta de alta impedância, principalmente nos sistemas de distribuição multi-aterrados.

O método proposto em [59] para detecção de faltas de alta impedância consiste também em utilizar redes neurais artificiais do tipo perceptron para identificar a ocorrência ou não de faltas. A metodologia opera dividindo inicialmente um ciclo da forma de onda de corrente e tensão dentro de quatro janelas iguais, sendo duas localizadas em posições contendo os valores mais altos de tensão, e as outras duas estando localizadas junto aos valores mais baixos de tensão. Uma ilustração deste procedimento é apresentada na Figura 3.1. 


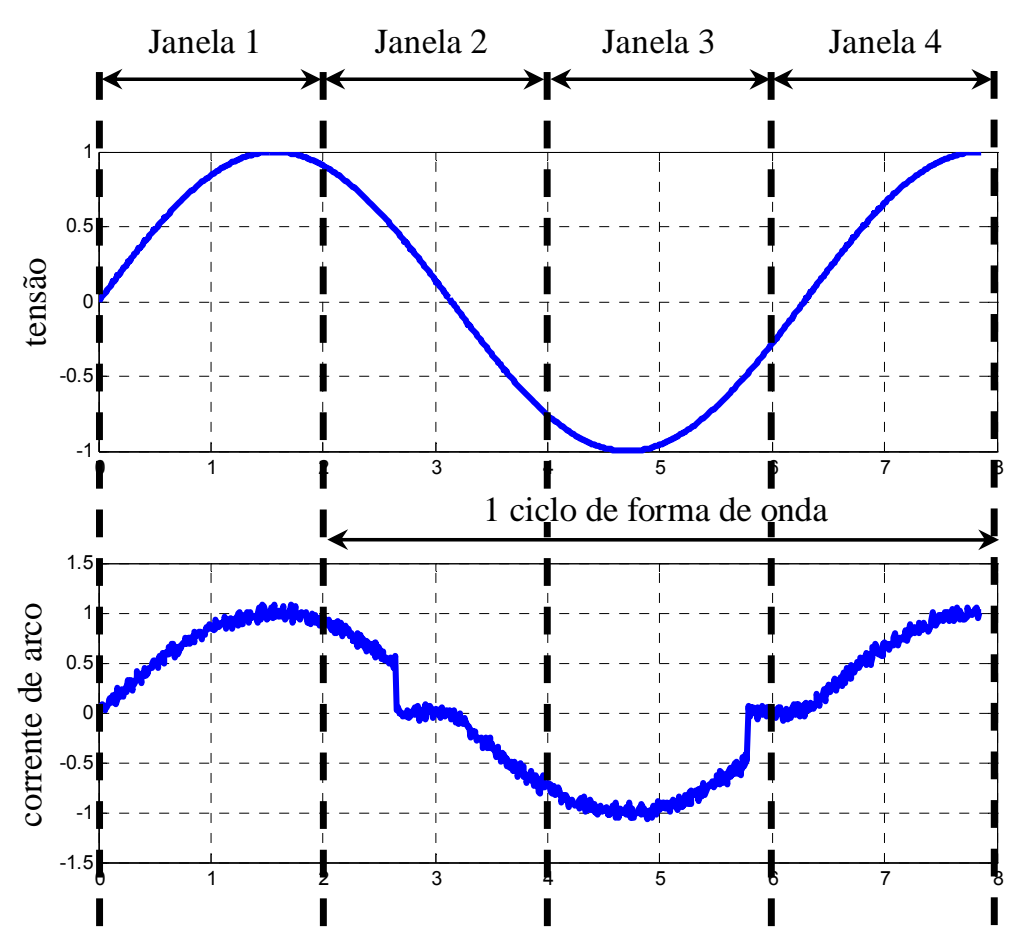

Figura 3.1 - Configuração da janela de dados.

Para detectar as componentes de alta impedância da corrente de falta, aplica-se a transformada rápida de Fourier (Fast Fourier Transform - FFT) nos sinais de corrente em cada uma das quatro janelas. Em seguida, as magnitudes das harmônicas fornecidas pela FFT são utilizadas como variáveis de entradas de uma rede neural do tipo perceptron. Baseado nas informações de entrada, a saída da rede fornece como resultado o valor +1 quando há ocorrência da falta de alta impedância, ao passo que o valor -1 é produzido quando o sistema opera em condições normais.

A rede perceptron utilizada neste método é composta de três camadas neurais, tendo 8 neurônios na primeira camada, 16 neurônios na segunda camada e 1 neurônio na camada de saída. As entradas da rede são as magnitudes das sete primeiras harmônicas do espectro de freqüência, as quais são fornecidas pela aplicação da FFT. O tempo de amostragem dos dados do sinal ficou em $260 \mu$ s (64 pontos por ciclo) ou 3840 amostras por segundo. 


\subsection{Abordagem neural utilizando características estatísticas das correntes de falta}

Um fato observável em faltas que exibem uma baixa corrente é que as mesmas normalmente apresentam grandes magnitudes nos sinais de tensão de fase. Entretanto, há uma alteração destacável no formato de onda da corrente na fase faltosa [60]. Para condições de faltas sem a presença de arco, a amplitude e/ou fase da corrente na fase faltante implica em alterações determinísticas, enquanto que nas condições de falta com presença de arco, distorções aleatórias em intervalos intermitentes podem ser observados na fase ou na amplitude da corrente da fase faltante. Na presença de um distúrbio devido à ocorrência de falta, as formas de onda das correntes de fase e de neutro apresentam-se distorcidas. Assim, a forma de onda de uma corrente faltosa $i_{p}$ pode ser representada pela corrente $i_{p}^{\prime}$ definida em (3.1) em adição ao distúrbio provocado pela falta, ou seja:

$$
i_{p}^{\prime}(t)=i_{p}(t)+n(t)
$$

onde $n(t)$ representa um processo aleatório. No entanto, nas abordagens convencionalmente empregadas, tanto academicamente como tecnicamente, não contemplam os distúrbios gerados na forma de onda de tensão. A fim de garantir uma maior confiabilidade das estimações realizadas, a distorção na forma de onda de tensão será considerada ao longo da apresentação da metodologia proposta em [60]. A Figura 3.2 apresenta formas de onda de tensão e de corrente para um sistema elétrico sob falta fase-terra de alta impedância com presença de arco elétrico. 

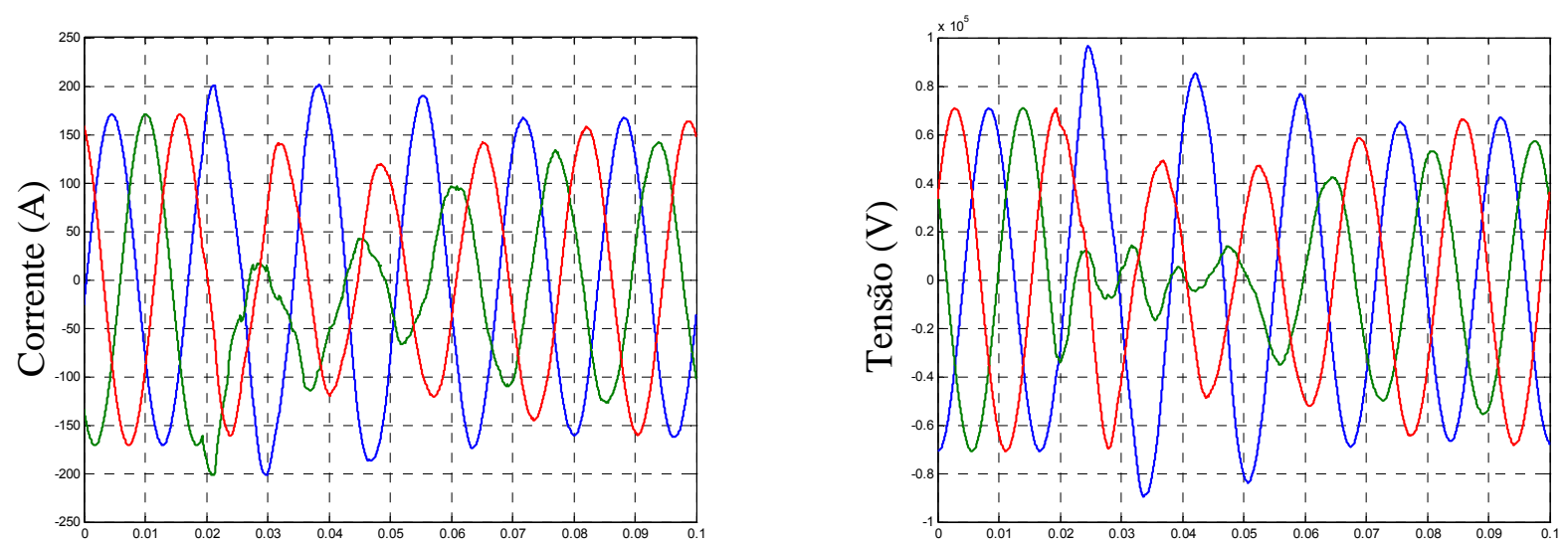

Figura 3.2 - Formas de onda de corrente e tensão para uma falta fase terra com ocorrência de arco elétrico.

Pode-se observar por intermédio dos gráficos da Figura 3.2 a constante alteração de formato de onda a cada ciclo, tanto para as formas de onda de tensão como para as formas de onda de corrente. A assimetria de formato das formas de onda no domínio do tempo torna complexa a tarefa de extração de características que permitam ajustar corretamente o sistema de identificação de faltas. No entanto, quando a análise espectral de freqüência é realizada sob os dados disponíveis, periodicidades ocultas ou pequenos picos de energia em determinadas freqüências podem ser observados. Assim, o levantamento destas peculiaridades do domínio da freqüência pode contribuir positivamente para a detecção de eventuais falhas junto ao sistema de distribuição de energia elétrica.

O método de diagnóstico de falta utilizado nesta abordagem consiste em aplicar as capacidades de reconhecimento de padrões oferecidas pelas redes neurais artificiais para detectar faltas de baixa e alta impedância, na presença de arco, em sistemas aterrados ou não aterrados.

De forma geral, pode-se caracterizar esta abordagem por meio de duas etapas principais. A primeira etapa é responsável por realizar um pré-processamento de sinais e a segunda etapa é constituída por um sistema de diagnóstico baseado em clusterização supervisionada. As entradas do sistema de diagnóstico de faltas 
são as três correntes de fase medidas em cada alimentador. O alimentador da subestação monitora as tensões e correntes fornecidas pelos dispositivos de proteção do sistema. O pré-processador computa as características estatísticas vindas das correntes de fase e as passam para o classificador neural de padrões. A Figura 3.3 ilustra o diagrama de blocos deste método de diagnóstico de faltas.

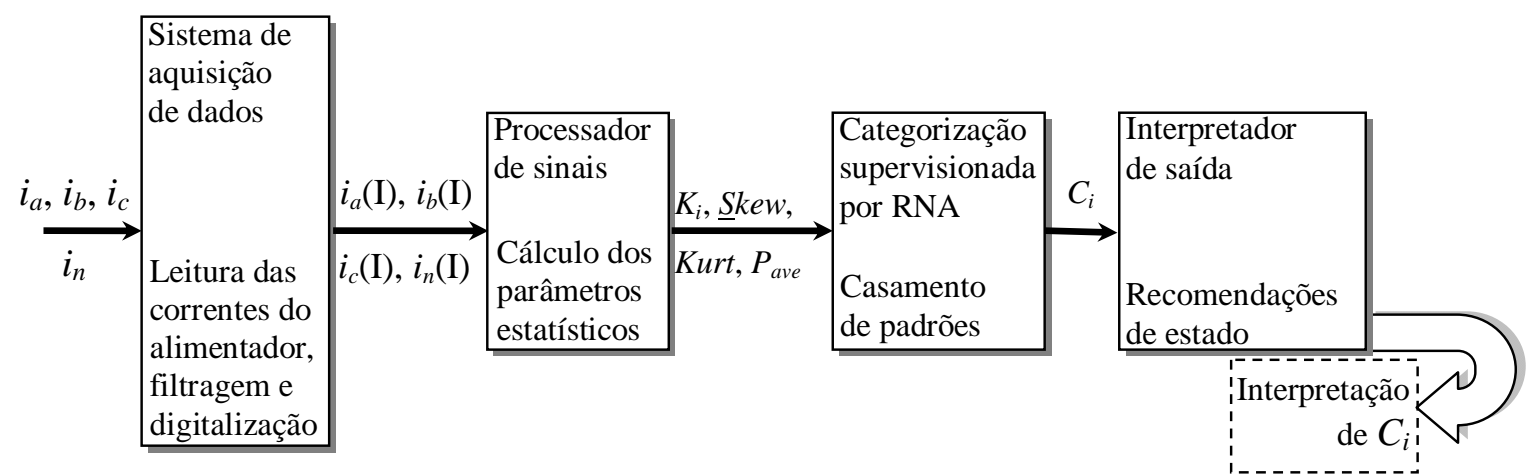

Figura 3.3 - Diagrama de blocos do método de diagnóstico de faltas baseado em características estatísticas das correntes de falta.

As características pertinentes à forma de onda são fundamentais para se determinar o tipo de metodologia a ser empregada na análise em freqüência das formas de onda oscilografadas. Uma vez que os dados obtidos estão comprometidos por um ruído branco, o emprego da transformada de Fourier torna-se inadequada [61]. Desta maneira, o emprego de técnicas de processamento estatístico se configura mais adequada aos propósitos do problema de identificação de faltas em sistemas de distribuição de energia elétrica.

Dentre as diversas metodologias disponíveis para se realizar a análise espectral estatística, os autores optaram pela apresentada em [62,63], em que o conceito de análise espectral pela máxima entropia é formulado. 
Por meio do processamento espectral estatístico das formas de onda, as principais características extraídas pelo pré-processador de sinais e empregadas nesta metodologia são as seguintes:

- Matrizes de coeficientes de reflexão.

- Coeficientes de Skewness.

- Coeficientes de Kurtosis.

- Coeficientes de potência média.

Cada um dos parâmetros estatísticos empregados nesta abordagem representa quantitativamente características inerentes às formas de onda de corrente e tensão. Os coeficientes de Skewness fornecem informações estatísticas de terceira ordem e podem ser interpretados como sendo uma medida da assimetria em torno do valor médio das formas de onda das tensões e correntes faltosas, enquanto que os coeficientes de Kurtosis indicam o quão próximo ou o quão distante a função densidade de probabilidade está de uma distribuição gaussiana. Os coeficientes de reflexão são um indicativo da repetibilidade das formas de onda, enquanto que os coeficientes de potência média fornecem à abordagem um patamar referencial para a correta categorização dos eventos. Para ilustrar como alguns destes parâmetros variam para uma forma de onda de corrente faltosa, as Figuras 3.4 e 3.5 apresentam os valores de Skewness e de kurtosis para uma corrente de falta e para uma corrente normal ao longo de 14 ciclos. 


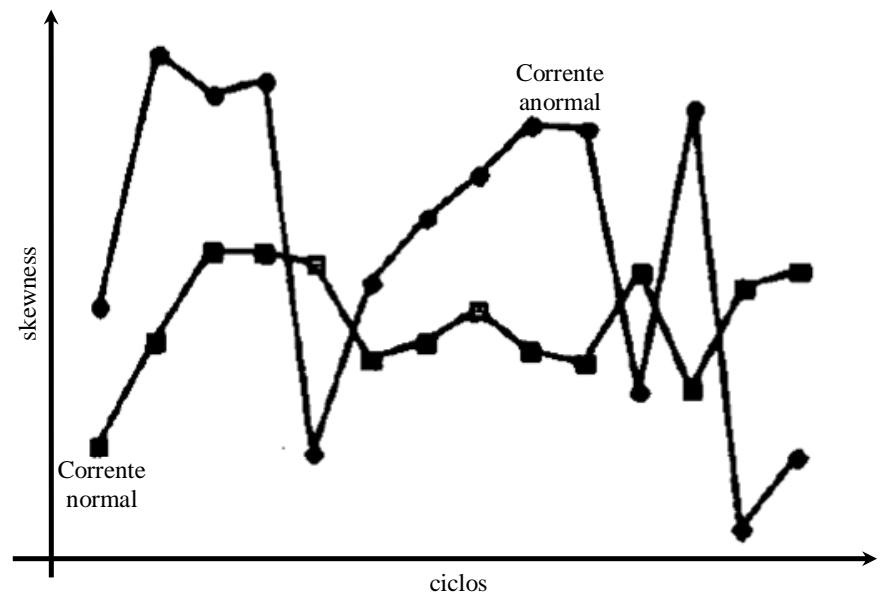

Figura 3.4 - Skewness para corrente.

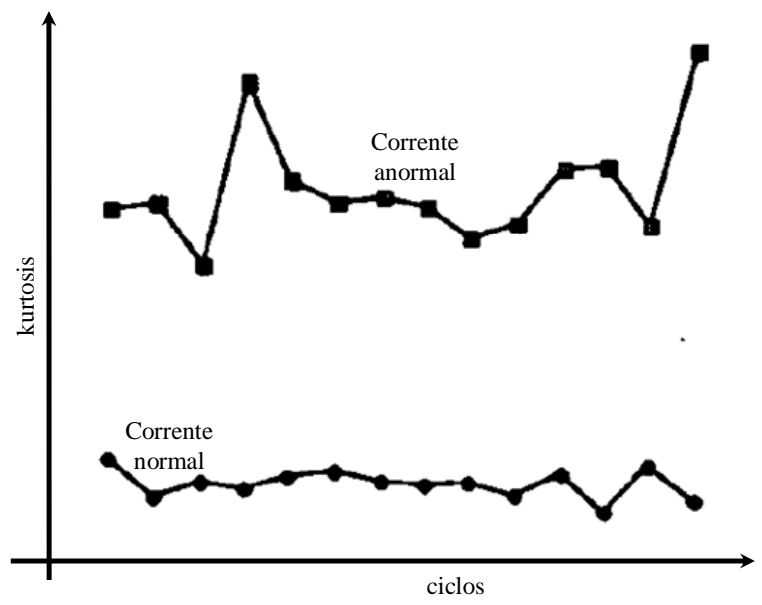

Figura 3.5 - Kurtosis para corrente.

Os resultados fornecidos pela rede neural indicam se um determinado padrão de sinal se deve a uma falta ou não. Se o sinal é detectado como falta, a rede neural adicionalmente classifica o tipo de falta e identifica a fase faltante.

\subsection{Modelagem fuzzy aplicada na identificação de faltas de alta impedância com característica passiva}

Poucas soluções são apresentadas na literatura correlata com o objetivo de identificar as faltas de alta impedância passiva. Verifica-se, ainda, que a maioria das abordagens referenciadas são baseadas na análise do desbalanço de fases dos 
alimentadores do sistema de distribuição. No entanto, em virtude dos sistemas de distribuição apresentarem normalmente um alto nível de correntes desbalanceadas, verificam-se inúmeras limitações destas metodologias quanto da correta identificação de faltas. Um dos principais fatores que contribuem para o desbalanço natural dos sistemas de distribuição é a grande quantidade de cargas monofásicas (fase-terra e fase-fase) instaladas ao longo da extensão dos alimentadores do sistema.

Para contornar esses problemas, o método abordado em [57] consiste no emprego de um sistema fuzzy supervisório que periodicamente monitora as correntes e tensões dos alimentadores do sistema de distribuição. A partir dos valores de tensão e corrente observados, o sistema fuzzy, por meio de comparações e operadores específicos, realiza inferências que fornecem como resultado a indicação de uma ocorrência ou não de falta no sistema.

No entanto, para que o sistema fuzzy opere de maneira a fornecer níveis confiáveis de resposta é necessário que exista um volume adequado de conhecimento acerca do sistema de distribuição, a fim de que as comparações e inferências ocorram dentro de universos de discurso com dados normalmente distribuídos. A base de dados responsável por armazenar este montante de informações pode ser construída por diferentes técnicas. Dentre as técnicas mais usuais, duas merecem destaque especial. Uma dessas técnicas consiste na simulação computacional dos possíveis eventos do alimentador. Por meio de simulações exaustivas uma grande quantidade de informações pode ser computada e, como conseqüência direta, uma consistente base de dados é construída.

A segunda metodologia usualmente empregada é baseada na aplicação de formas de onda impulsivas no início dos alimentadores afim de observar as 
respostas originadas por este procedimento. As ondas impulsivas, que são injetadas no alimentador, viajam ao longo da linha, trazendo informações sobre o status real do alimentador. Após a realização de cada medição, o sinal de resposta é précondicionado, convertido para o domínio da freqüência e então armazenado junto à base de regras correspondente. As componentes complexas dos sinais préprocessados são então calculadas por intermédio da transformada rápida de Fourier.

Na metodologia apresentada nesta seção a base de dados foi constituída por meio da aplicação de formas de onda impulsivas no início dos alimentadores. No entanto, a adoção desta metodologia deve respeitar importantes requisitos como, por exemplo, levar em consideração todas as possíveis configurações operacionais do alimentador. Para tanto, a equipe responsável pelo planejamento, operação e manutenção do sistema deve fornecer informações relevantes sobre as diversas configurações operacionais possíveis do alimentador.

Com relação à operação do sistema, primeiramente, os sinais das respostas impulsivas são comparados com aqueles conhecidos e armazenados junto à base de regras. Na seqüência, o sistema busca por evidências de ocorrências de faltas de alta impedância, considerando-se para tanto o grau de discrepância entre os sinais medidos e as respostas armazenadas na referida base de dados. Como resposta, o sistema fuzzy é responsável por fornecer indicadores de supervisão dos estado do sistema de distribuição.

Análises de respostas típicas têm mostrado que a utilização de 20 freqüências características são suficientes para discriminar satisfatoriamente os sinais medidos. As respostas dos sinais impulsivos (5000 amostras) são descompostas em duas janelas $W_{1}$ e $W_{2}$. Para cada janela, componentes reais e 
imaginárias das 20 freqüências têm sido calculadas, perfazendo assim um total de 80 componentes que serão as entradas do sistema fuzzy.

\subsection{Método para diagnóstico de faltas em subestações de distribuição utilizando sistemas fuzzy e redes de causa e efeito}

A estrutura para o diagnóstico de falta proposto em [64] é compreendida por uma rede de causa e efeito, uma base de regras, uma base de dados fuzzy, um mecanismo de inferência e um processador de dados em tempo real. Um diagrama esquemático do sistema proposto é mostrado na Figura 3.6.

Nesta metodologia, a rede causa e efeito representa a casualidade entre faltas e ações de relés e disjuntores. Para os diversos tipos de faltas, considerando todas as seções possíveis, especificam-se os fluxogramas que representam as seqüências de causa e efeito.

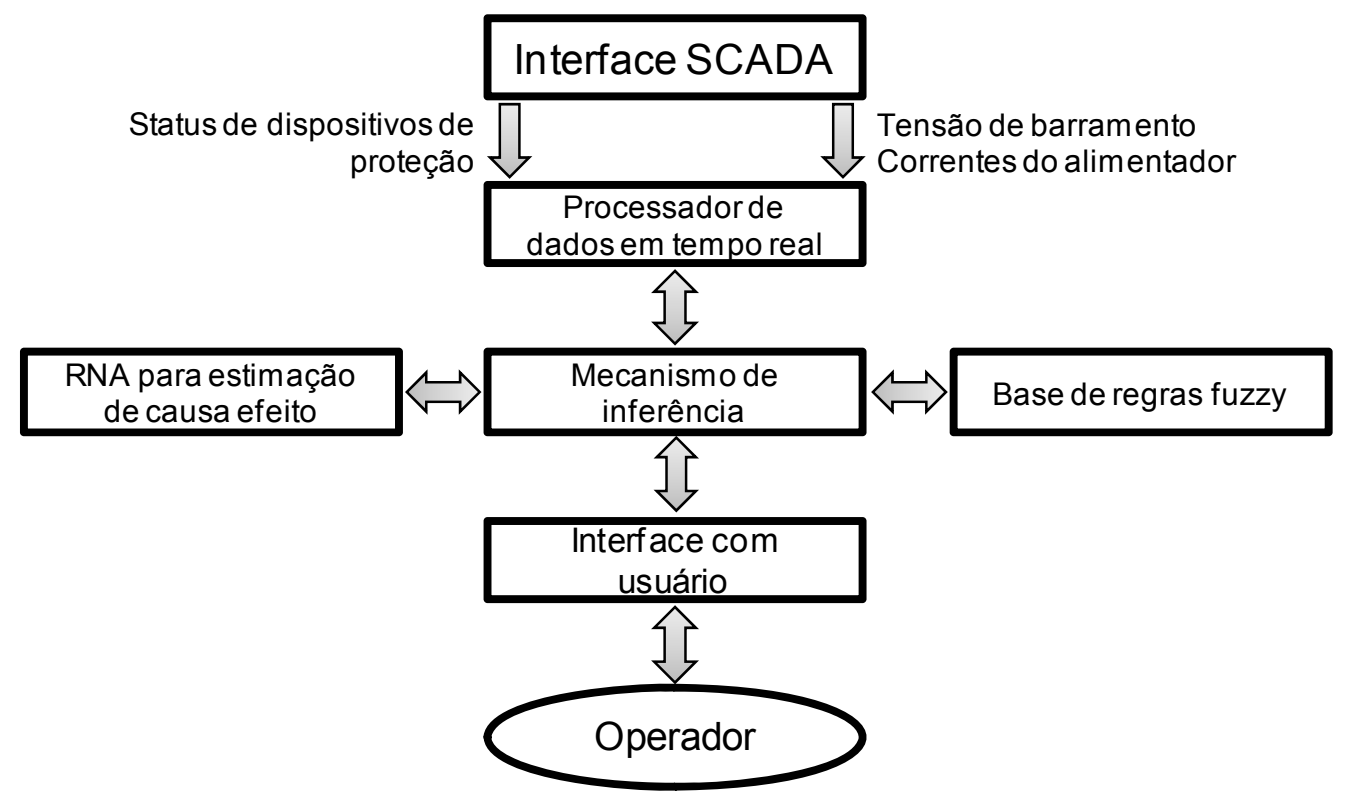

Figura 3.6 - Estrutura do sistema de diagnóstico de falta proposto. 
Outra tarefa do método proposto é classificar os tipos de faltas, levando em consideração as correntes e tensões no alimentador, mediante a utilização de um sistema fuzzy. A base de regras fuzzy é formada por regras que são extraídas a partir de características de todos os tipos de faltas. A definição dessas regras requer um conhecimento detalhado do comportamento dos sinais de corrente e tensão que são gerados durante uma situação de falta. As regras fuzzy desta abordagem são baseadas na premissa de que quando uma falta ocorre, as correntes normalmente aumentam em magnitude e as tensões diminuem. O formato das regras do sistema fuzzy possui o padrão apresentado na Figura 3.7.

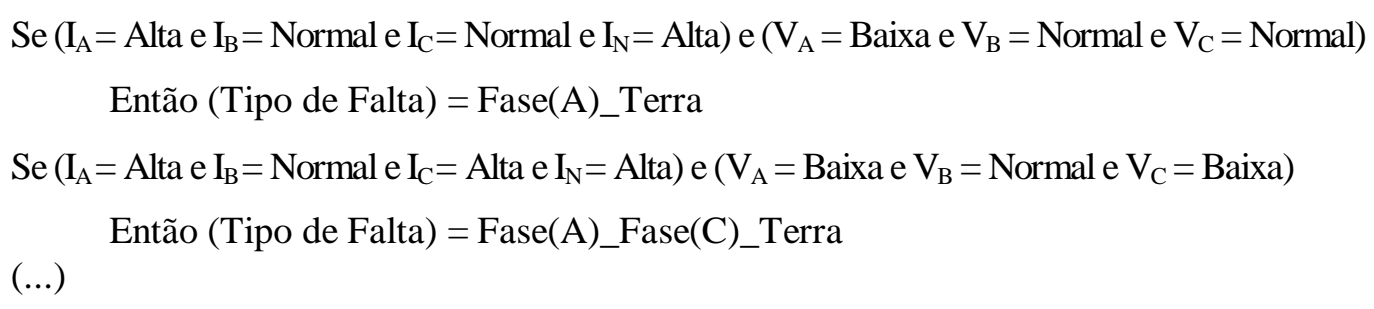

Figura 3.7 - Exemplo de base de regras do sistema fuzzy.

O processo de identificação da falta pelo sistema fuzzy consiste de quatro estágios que podem ser representados esquematicamente conforme apresentado na Figura 3.8. O primeiro passo deste processo é a obtenção das correntes e tensões do alimentador. O segundo passo consiste em converter esses valores para os respectivos termos lingüísticos que são especificados por intermédio de funções de pertinência. Em seguida, esses termos lingüísticos serão empregados na avaliação das regras fuzzy. Finalmente, por meio da aplicação dos procedimentos de inferência, torna-se possível a obtenção dos resultados que permitam identificar o tipo de falta. 


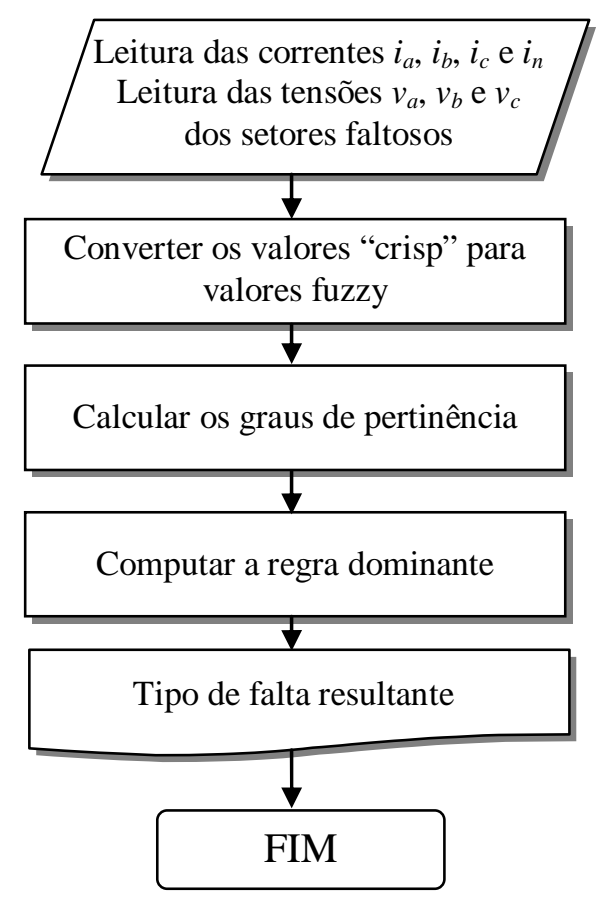

Figura 3.8 - Procedimentos para estimação de faltas para o sistema de inferência fuzzy.

\subsection{Técnicas de localização de faltas baseadas em sinais de alta freqüência e transformada wavelet}

Em [65], a técnica para localização de faltas em alimentadores de distribuição radial é formulada sob as informações fornecidas pelos equipamentos de medição instalados na subestação, levando-se também em consideração detalhes de configuração do alimentador.

método proposto opera identificando o trecho da falta com base nas informações das ondas viajantes fornecidas pelas componentes de alta freqüência, as quais estão intrínsecas nos transitórios dos sinais de faltas que são aquisitados pelos instrumentos de medição. Em seguida, calcula-se, baseado nas potências dos sinais de freqüência, o local exato da falta ao longo do trecho identificado no passo anterior. Para tanto, os sinais transitórios das correntes trifásicas são inicialmente decompostos em suas componentes modais. Em seguida, os sinais modais são 
decompostos em suas componentes wavelet, sendo obtidos então os correspondentes coeficientes wavelet. Esses coeficientes são usados para extrair padrões relevantes dos sinais, os quais são subseqüentemente utilizados para identificar o ramo ou trecho onde a falta está localizada. Finalmente, a distância da falta a partir da subestação principal é calculada utilizando informações baseadas nas potências dos sinais.

A fim de ilustrar esta metodologia, a Figura 3.9 apresenta o diagrama de blocos funcionais da abordagem descrita nesta seção.

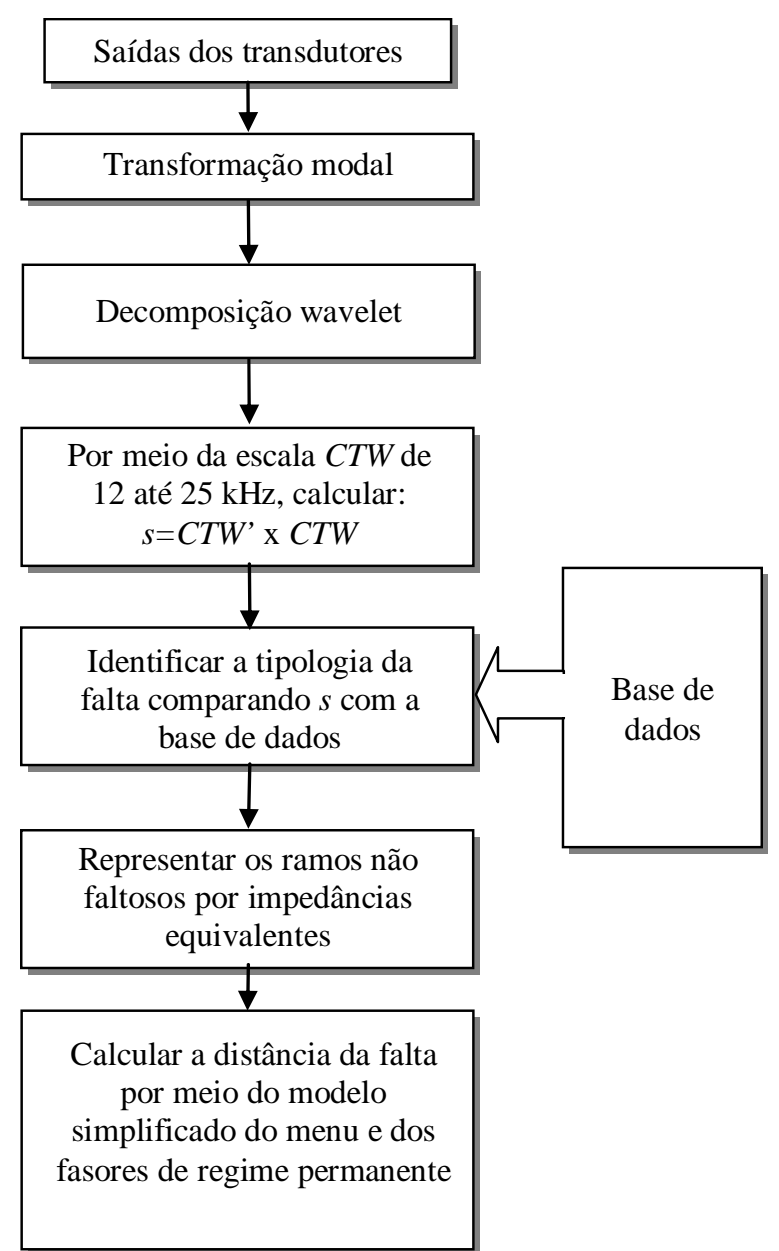

Figura 3.9 - Fluxograma do algoritmo de localização de falta proposto.

Em suma, o procedimento de localização de faltas pode ser descrito da seguinte forma: 
- As tensões e correntes de fase são transformadas para o domínio modal.

- Os sinais modais são decompostos visando obter os coeficientes da transformada wavelet (CTW).

- O trecho e a distância à falta são estimados utilizando informações fornecidas pelos CTW.

Um dos aspectos observados neste método está relacionado à ocorrência de faltas fase-terra. Se a falta é produzida quando a tensão da fase faltante é pequena, isto é, o ângulo de incidência é pequeno, os sinais transitórios produzidos pelas ondas trafegantes também serão pequenos. Entretanto, mesmo para os ângulos de incidência pequenos, os coeficientes da transformada wavelet identificam

o trecho sob falta, pois pôde-se observar que este processo opera sob um mapeamento linear.

\subsection{Classificação e medição dos níveis de perturbação em sistema de potência por meio de wavelet}

O método proposto na abordagem apresentada em [66] consiste em utilizar a técnica de wavelet para detectar, classificar e medir as perturbações que incidem nos sistemas de distribuição.

Um sinal $f_{s}(t)$ de comprimento finito com uma distorção aditiva $s_{d}(t)$ pode ser representado matematicamente por:

$$
f_{s}(t)=f_{p}(t)+s_{d}(t)
$$


onde $f_{p}(t)$ é o sinal puro que está compondo $f_{s}(t)$ e $s_{d}(t)$ representa o sinal de distúrbio inserido ao sinal original.

Aplicando análise multi-resolução é possível decompor o sinal $f_{s}(t)$ em diferentes níveis de resolução e apresentá-lo na forma de uma expansão por série utilizando uma combinação de funções escalas $\varphi_{k}(t)$ e funções wavelet $\psi_{k}(t)$. Se a taxa de amostragem do sinal $f(t)$ estiver acima da taxa de amostragem determinada pelo teorema de Nyquist, então os mesmos são boas aproximações para os coeficientes de escala para uma determinada escala. Isto significa que nenhum coeficiente de escala será necessário.

Assim, quaisquer alterações no sinal $f(t)$ podem ser detectadas e localizadas no tempo devido às mudanças nas magnitudes desses coeficientes. De acordo com o teorema de Parseval, a energia de $f(t)$ poderá ser particionada em diferentes caminhos dependendo do tipo de evento associado à distorção. Portanto, o mapeamento dos dados da distorção $s_{d}(t)$ dentro de um domínio wavelet é o primeiro passo para executar o processo de classificação dos sinais. Em seguida, a distribuição da energia de distorção em diferentes níveis de resolução é computado para gerar um conjunto de características não variantes no que diz respeito à mudança de posição (translação) com baixa dimensionalidade.

A Figura 3.10 apresenta a diferença na distribuição de energia $\Delta E_{d}$, em diferentes níveis de resolução, para 25 sinais distorcidos por diferentes perturbações. 


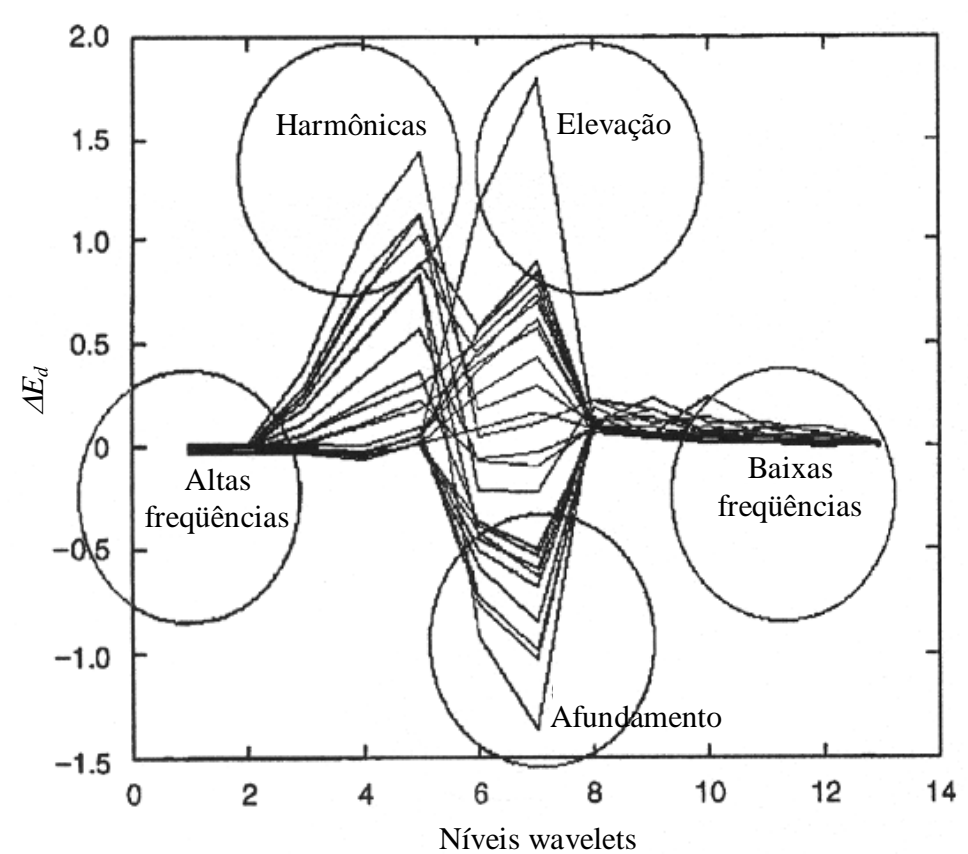

Figura 3.10 - Classificação de perturbações no domínio wavelet.

Pode-se observar por intermédio do gráfico da Figura 3.10 que as características de perturbações envolvendo harmônicas no sistema são melhores identificadas no nível 5, enquanto que afundamento e elevação de tensão são melhores reconhecidos no nível de resolução 7 .

A Figura 3.11 ilustra em detalhes um sinal $f(t)$ constituído de diversas perturbações, ilustrando a decomposição do sinal no primeiro nível $D_{1}$, bem como $\Delta E_{d}$ nos diferentes níveis de resolução.

Portanto, a partir da utilização desta técnica, diversas distorções nos sinais de medição podem ser detectados através da utilização dos coeficientes wavelet em diferentes níveis de resolução. A energia associada à distorção em diferentes níveis de resolução é empregada como um vetor discriminante que pode classificar diferentes perturbações. 

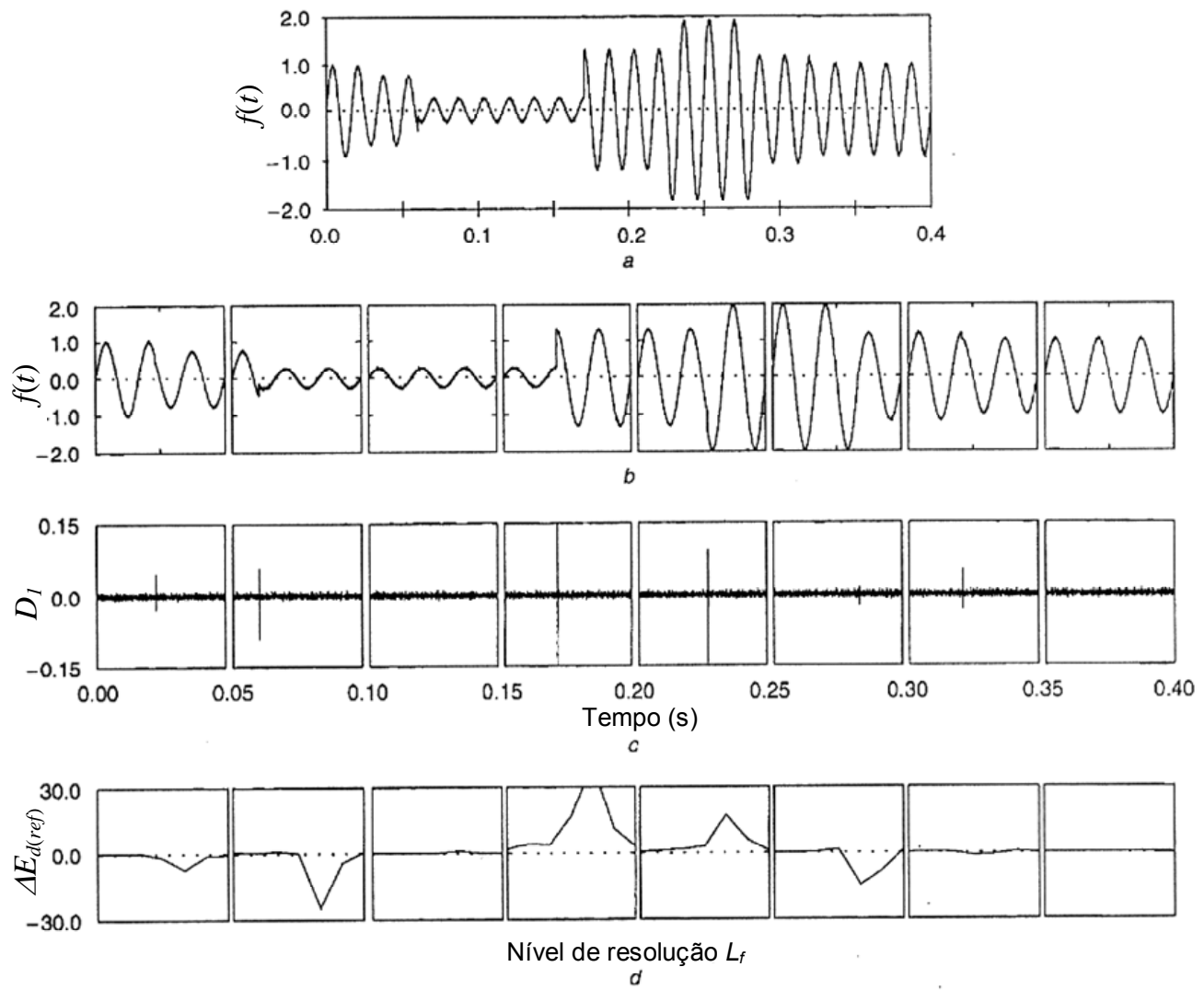

Figura 3.11 - Ilustração de um sinal composto por diversas perturbações e sua representação no domínio wavelet.

\subsection{Detecção de distúrbios em sistemas de distribuição utilizando wavelet}

Existem eventos no sistema de distribuição que geram transitórios que são ocasionados pela energização das próprias cargas instaladas no sistema, como por exemplo, a energização de capacitores e o acionamento de máquinas de elevada potência. Nesses casos, mesmo que os distúrbios de tensão ultrapassem momentaneamente os limites normais que foram pré-estabelecidos para as cargas, nenhuma medida operacional é necessária, pois oscilações são originadas pelas próprias particularidades do sistema.

Contrariamente, no caso de distúrbios de tensão provocados por eventos associados aos diversos tipos de faltas, há então a necessidade de realizar ações 
operacionais que levem às suas isolações. Portanto, a investigação de técnicas que permitam a classificação rápida desses eventos torna-se de suma importância para o incremento da qualidade e confiabilidade do sistema.

O objetivo do método proposto em [67] consiste na aplicação de transformada wavelet para a detecção de distúrbios de tensão em sistemas de distribuição, bem como a identificação do tipo de evento transitório que resultou a respectiva perturbação.

O diagrama de blocos apresentando o esquema de detecção e classificação de distúrbios é ilustrado na Figura 3.12. Esta metodologia é composta por quatro blocos principais, sendo eles a geração do sinal de erro, a análise do sinal de erro usando wavelet, a extração de características e o suporte à decisão.

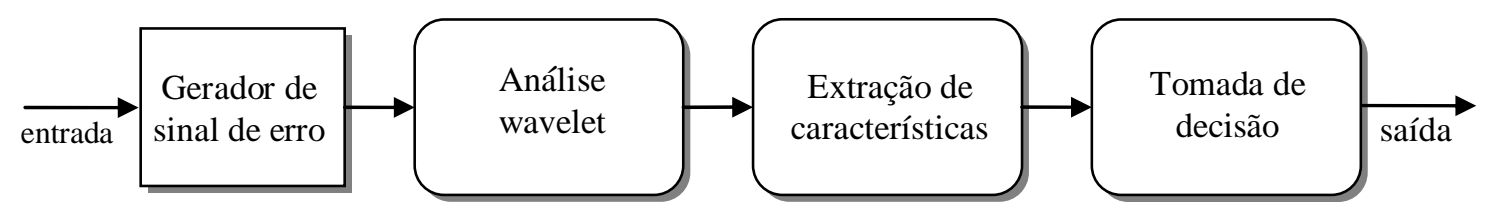

Figura 3.12 - Diagrama de blocos do esquema de detecção proposto.

O bloco dedicado à geração do sinal de erro extrai as distorções superpostas nas tensões medidas, gerando-se um sinal de erro por intermédio de um filtro adaptativo conforme apresentado na Figura 3.13. 


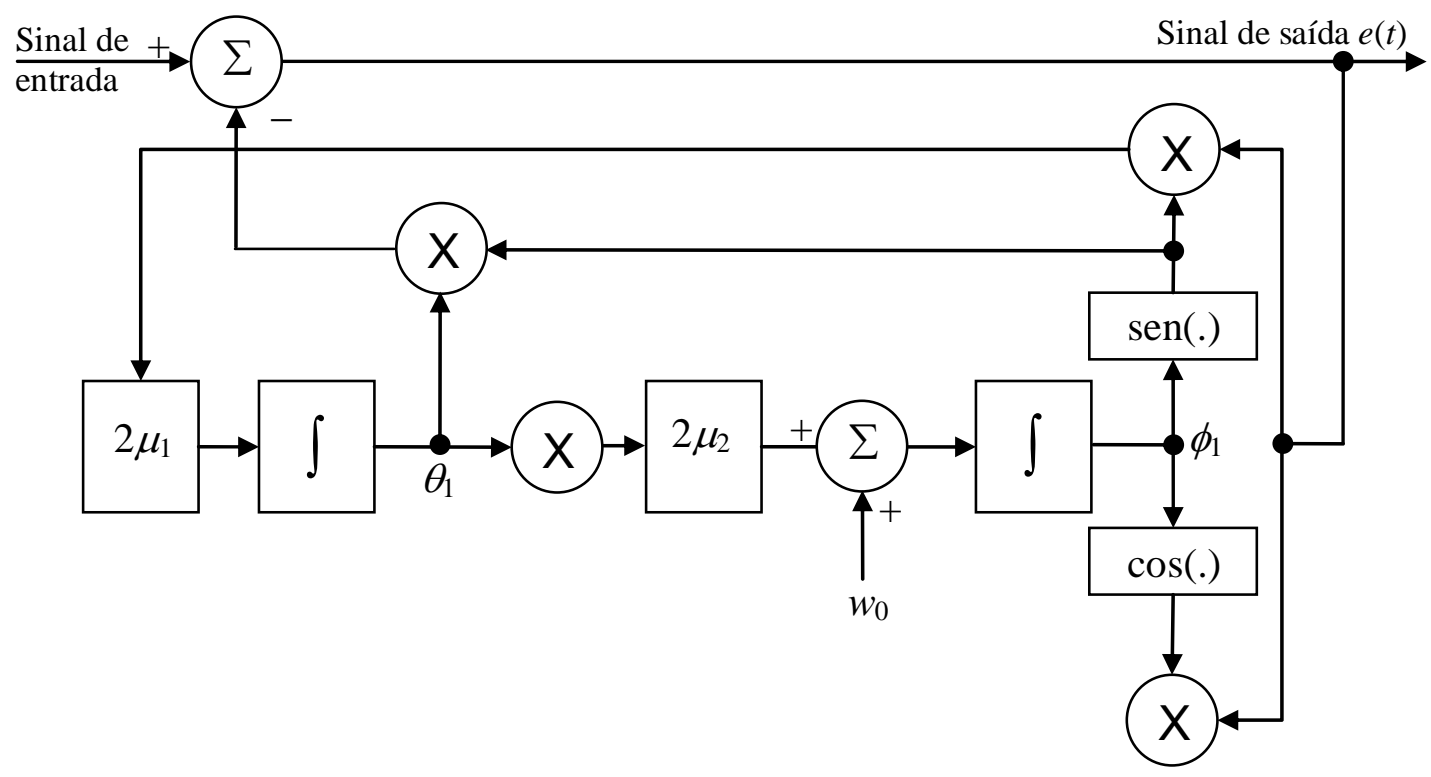

Figura 3.13 - Diagrama de blocos representando o filtro adaptativo.

O filtro rastreia a amplitude $\left(\theta_{1}\right)$ e o ângulo $\left(\phi_{1}\right)$ da componente fundamental do sinal de entrada, sendo que o comportamento dinâmico do filtro é descrito por:

$$
\left\{\begin{array}{l}
\dot{\theta}_{1}=-2 \mu_{1} \cdot \sin \left(\varphi_{1}\right) \cdot e(t) \\
\dot{\varphi}_{1}=-2 \mu_{2} \cdot \theta_{1} \cdot \cos \left(\varphi_{1}\right) \cdot e(t)+w_{0}
\end{array}\right.
$$

O sinal de erro e $(t)$ é obtido subtraindo a componente fundamental do sinal de entrada. Esta é a principal vantagem de usar este filtro no algoritmo.

O bloco responsável pela análise por wavelet transforma o sinal de erro em diferentes escalas no domínio da freqüência. A transformada wavelet fornece informações sobre o conteúdo das freqüências de um sinal de maneira semelhante à transformada de Fourier. Entretanto, diferentemente da transformada de Fourier, a transformada wavelet é capaz de focar componentes de alta freqüência em curtos intervalos de tempo, bem como componentes de baixa freqüência presentes em 
longos intervalos. Portanto, torna-se uma ferramenta adequada para análise de transitórios de alta freqüência na presença de componentes de baixa freqüência.

O objetivo do bloco de extração de características é identificar assinaturas específicas dos diversos tipos de perturbações atuando no sistema. A transformada wavelet decompõe o sinal de erro dentro de diferentes escalas de freqüência. Cada escala representa o sinal de erro na banda correspondente. O conteúdo de energia dos sinais da escala relativo aos sinais de erro se altera dependendo do tipo de perturbação. Portanto, a amplitude relativa dos sinais da escala com relação ao sinal de erro é selecionada como característica discriminante.

Finalmente, a função do bloco de apoio à decisão é discriminar tipos de distúrbios tão precisamente quanto possível. Uma função probabilidade é definida para as características, e a decisão é realizada utilizando o critério de máxima verossimilhança. Este critério é baseado na maximização da função probabilidade das características.

\subsection{Modelagem de faltas de alta impedância baseada na teoria de arcos elétricos}

A simulação de chaveamentos de bancos de capacitores em programas como EMTP e MatLab/SimPowerSystems são bem próximos da realidade e os resultados fornecidos tem um alto grau de precisão quando o sistema é modelado de forma adequada.

No entanto, a modelagem dos fenômenos que simulam o comportamento de faltas de alta impedância é complexa, pois, em função da presença do arco elétrico, 
cuja natureza é bastante complexa e diversa, acarreta em um esforço extra durante a fase de confecção do sistema equivalente.

Desta forma, a investigação de um modelo geral que represente de forma realista a falta de alta impedância é de suma importância para a pesquisa de métodos de detecção de falta de alta impedância, bem como para o projeto de equipamentos de proteção.

Alguns modelos de falta de alta impedância utilizam para propósitos de simulação, a inclusão de uma resistência ou modelo de impedância não linear na rede no ponto de falta. O método proposto em [68] é baseado na teoria de arco voltaico, onde um modelo realista, englobando impedância não linear, fonte de tensão variante no tempo, cujos chaveamentos são controlados por um TACS (Transient Analysis Control System), é empregado com a finalidade de encorpar às simulações um maior grau de fidelidade. A Figura 3.14 ilustra o diagrama esquemático do circuito elétrico dedicado à modelagem física do arco elétrico.

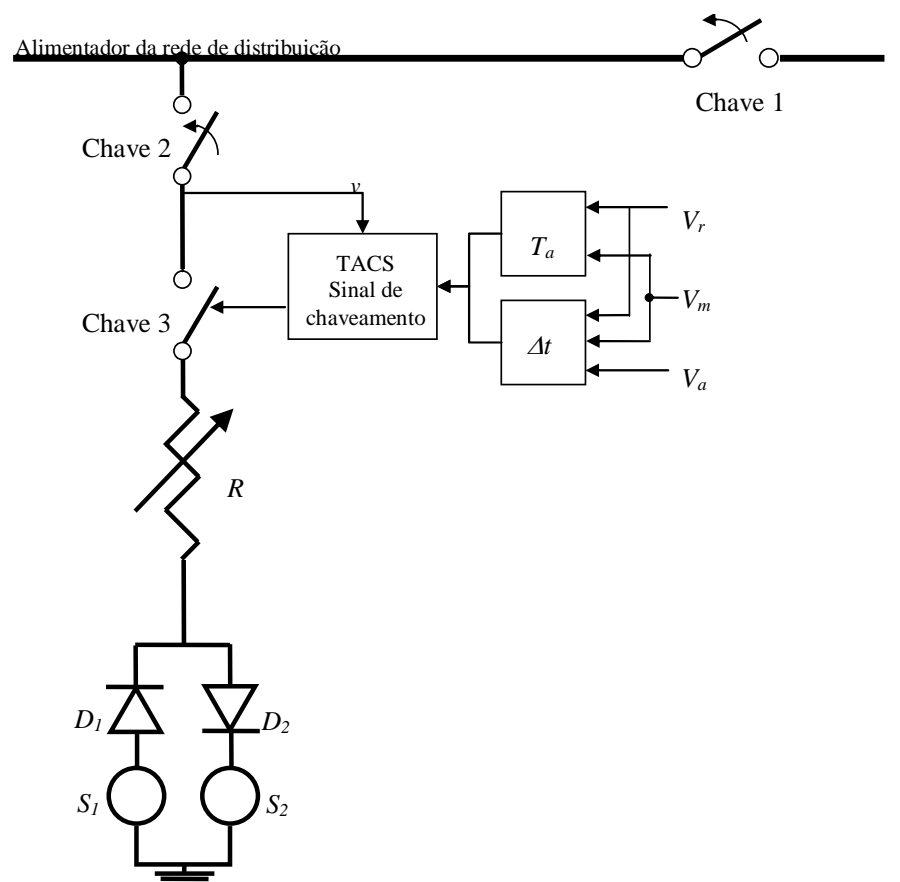

Figura 3.14 - Diagrama de blocos de modelo da falta de alta impedância. 
As chaves 1 e 2 são chaves convencionais com controle temporal que isolam o alimentador da carga, conectando-o ao caminho da falta. A chave 3 é uma chave controlada por um TACS que simula a reignição e extinção do arco.

Sua operação depende da comparação de tempo entre os parâmetros de simulação $T_{a}$ e $\Delta t$. O parâmetro $T_{a}$ é o tempo para a reignição do arco a partir do momento que a tensão aplicada passa por zero, e $\Delta t$ é o tempo de condução do arco em meio ciclo, sendo esses parâmetros dados por:

$$
\begin{aligned}
& T_{a}=\frac{1}{w} \sin ^{-1} \frac{V_{r}}{V_{m}} \\
& \Delta t=\frac{\pi \cdot V_{r}+2 \sqrt{V_{m}^{2}+V_{r}^{2}}}{w \cdot\left(V_{a}+V_{r}\right)}
\end{aligned}
$$

onde $V_{r}$ é a tensão de reignição do arco, $V_{m}$ é o valor de pico da tensão aplicada e $V_{a}$ é a tensão de arco, sendo que a tensão aplicada é assumida como:

$$
V=V_{m} \cdot \sin (w t)
$$

A resistência não linear $R$ controla a magnitude da corrente de falta e é conectada à parte de condução do arco que consiste de dois diodos $D_{1}$ e $D_{2}$ e duas fontes de tensão $S_{1}$ e $S_{2}$. Essas fontes possuem forma de onda dente de serra, com linearidade crescente e decrescente, as quais podem representar a característica dinâmica $v-i$ do arco melhor que fontes DC e ajustar a diferença de fase entre a tensão aplicada e a corrente de falta. 


\subsection{Localização de faltas por meio de redes neurais artificiais e da transformada de Clarke-Concórdia}

A localização de faltas em sistemas de distribuição de energia elétrica diretamente aterrados pode ser realizada de maneira semelhante à localização de faltas em sistemas de distribuição com alta impedância de aterramento. No entanto, devido às peculiaridades das formas de onda de tensão e corrente, novas técnicas de pré-processamento de sinais devem ser incorporadas.

Dentre as técnicas de pré-processamento usualmente empregadas nos diversos trabalhos verificados junto à bibliografia correlata, destaca-se o emprego da análise fasorial dos sinais em conjunto com redes neurais artificiais [69].

No entanto, devido à complexidade do processo de localização de faltas, observa-se a necessidade de se incorporar novas técnicas de processamento às técnicas convencionais. Nesta seção, será apresentada a metodologia de localização de faltas em sistemas de distribuição de energia elétrica diretamente aterrados, empregando-se a transformada de Clarke-Concórdia em conjunto com abordagens que empregam a teoria dos autovalores.

A principal vantagem observada quando da aplicação desta técnica reside no fato de que a mesma é imune às interferências harmônicas e de sinais ruidosos, uma vez que a localização das faltas é realizada com base na comparação de padrões por meio de uma rede neural artificial do tipo perceptron multicamada.

A transformada de Clarke constitui-se em uma metodologia para desacoplamento paramétrico para sistemas trifásicos. As duas componentes estacionárias de corrente são denotadas por $\alpha$ e $\beta$. A terceira variável originada desta transformação é conhecida por componente de seqüência zero. A fim de se 
desenvolver uma metodologia destinada à operação em tempo real de sinais, tornase conveniente uma alteração da transformada original de Clarke. Dentre as possíveis alterações existentes, destaca-se a transformada de Clarke-Concórdia descrita em detalhes em [70]. O desenvolvimento teórico desta modificação é realizado supondo-se que a componente $\alpha$ da transformada original está sobreposta à corrente da primeira fase do sistema trifásico. Desta maneira, verifica-se que a componente $\beta$ estará atrasada em relação à $\alpha$ de $\pi / 2$ radianos. A matriz de transformação proposta pode ser então definida da seguinte forma:

$$
T_{c}=\sqrt{\frac{2}{3}}\left[\begin{array}{ccc}
1 & -\frac{1}{2} & -\frac{1}{2} \\
0 & \frac{\sqrt{3}}{2} & -\frac{\sqrt{3}}{2} \\
\frac{1}{\sqrt{2}} & \frac{1}{\sqrt{2}} & \frac{1}{\sqrt{2}}
\end{array}\right]
$$

Desta maneira, é possível caracterizar cada um dos estágios de falta por meio da análise das componentes de corrente $i_{\alpha}, i_{\beta}$ e $i_{0}$. Essas componentes de corrente podem ser obtidas por meio da seguinte expressão:

$$
\left[\begin{array}{l}
i_{a} \\
i_{b} \\
i_{0}
\end{array}\right]=T_{c}\left[\begin{array}{l}
i_{1} \\
i_{2} \\
i_{3}
\end{array}\right]
$$

onde $i_{1}, i_{2}$ e $i_{3}$ são respectivamente as correntes de cada uma das fases do sistema de distribuição.

Com a finalidade de se extrair as principais características das componentes $i_{\alpha}, i_{\beta}$ e $i_{0}$ é conveniente a análise dos autovetores e autovalores da matriz de correlação de dados. 
A arquitetura neural proposta nesta seção para localização de faltas possui como entradas os autovalores da matriz de correlação, bem como o tipo de falta identificado durante a fase de pré-processamento dos sinais. O diagrama esquemático da estrutura neural sugerida é apresentado na Figura 3.15.

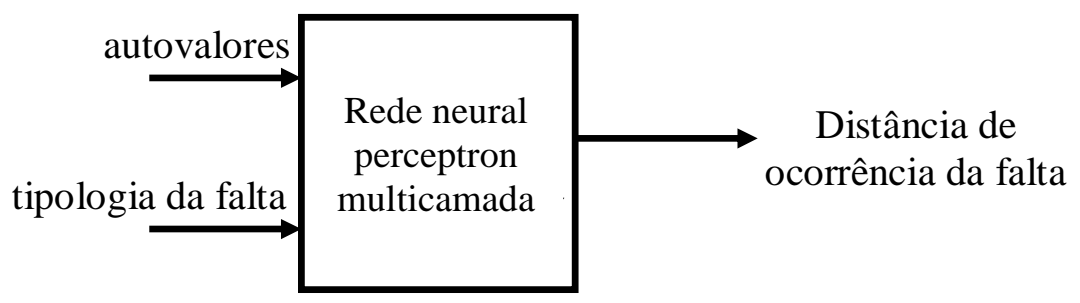

Figura 3.15 - Diagrama esquemático do sistema de localização de faltas por meio de redes neurais artificiais.

Para ilustrar a variação da distância de falta em função dos autovalores para diferentes tipos de falta, apresenta-se na Figura 3.16 o gráfico da distância em função dos autovalores.

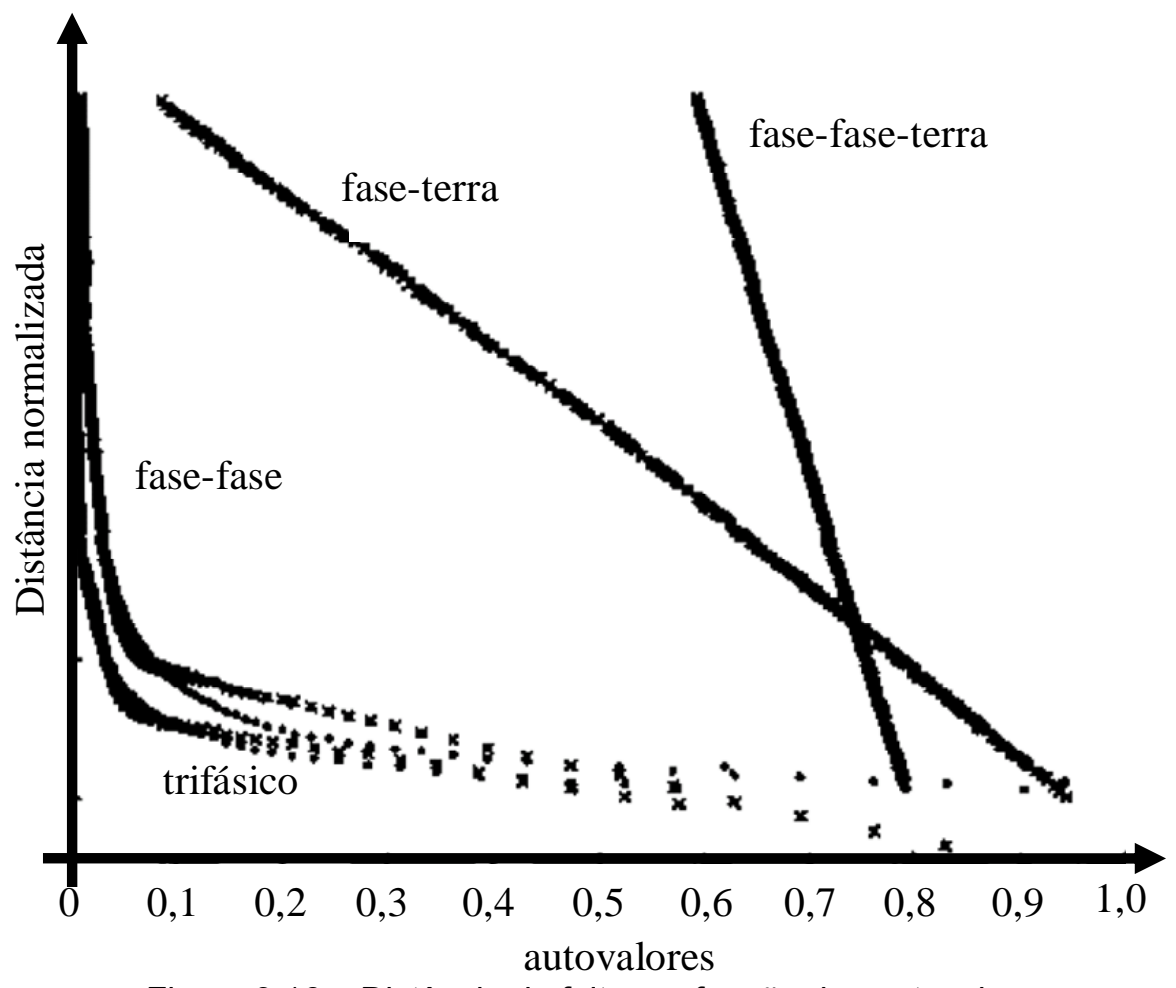

Figura 3.16 - Distância de falta em função dos autovalores. 


\subsection{Tratamento automatizado de faltas em linhas de distribuição}

Nesta seção é apresentado um novo sistema de gerenciamento de faltas em sistemas de distribuição usando informações vindas dos diversos dispositivos instalados no circuito, realizando-se assim uma coordenação entre os mesmos.

O método tradicional para o tratamento de uma falta em uma linha de distribuição é por tentativa e erro, onde as seções dos alimentadores são energizadas uma a uma até que nenhum sinal de falta seja identificado pelos relés. Por meio de disjuntores e chaves seccionadoras consegue-se este tipo de operação que na maioria das vezes ocorre de forma manual. Nestas situações, a localização rápida e precisa da falta diminui o tempo em que o sistema fica desenergizado.

Com a introdução de relés numéricos e também da comunicação entre os dispositivos, tornou-se possível melhorar a resposta do sistema frente a uma falta. No entanto, há uma forte discussão entre os pesquisadores no sentido de que o comando final na proteção dos sistemas de distribuição deve ficar a cargo de um operador especialista ou totalmente automatizado. Tal ceticismo por parte das metodologias totalmente automatizadas se deve à grande dificuldade em se adaptar os diversos sistemas de controle às peculiaridades de cada circuito de distribuição.

modelo de tratamento de faltas investigado em [71] adota uma postura totalmente automatizada para localização de faltas, isolamento dos setores faltosos e restauração do fornecimento de energia. Para tal, o modelo computacional trabalha integrado ao sistema SCADA e também com os dispositivos de automatização de um sistema de distribuição georeferenciado.

O tratamento das faltas neste modelo se inicia pela etapa de sua localização, que é realizada por meio de três técnicas distintas. Após a ocorrência de 
uma falta, valores de correntes medidos são confrontados com valores armazenados para estimar o ponto em que a mesma ocorreu. Em seguida, tais informações são confrontadas com os sinais enviados pelos indicadores de faltas instalados ao longo do alimentador e que possuem capacidade de comunicação. Visando refinar a resposta, utiliza-se aqui das informações estatísticas sobre a ocorrência de faltas nos trechos identificados pelo software de localização e pelos indicadores de faltas.

Os setores faltosos são automaticamente isolados por meio de chaves acionadas por controle remoto. Os setores não afetados pela falta são então energizados. Durante o processo de restabelecimento, cálculos para se determinar a capacidade real de fornecimento do sistema após a falta são efetuados, bem como os limites térmicos das linhas com base no carregamento do circuito. A integração do modelo com o sistema SCADA pode ser observado na Figura 3.17.

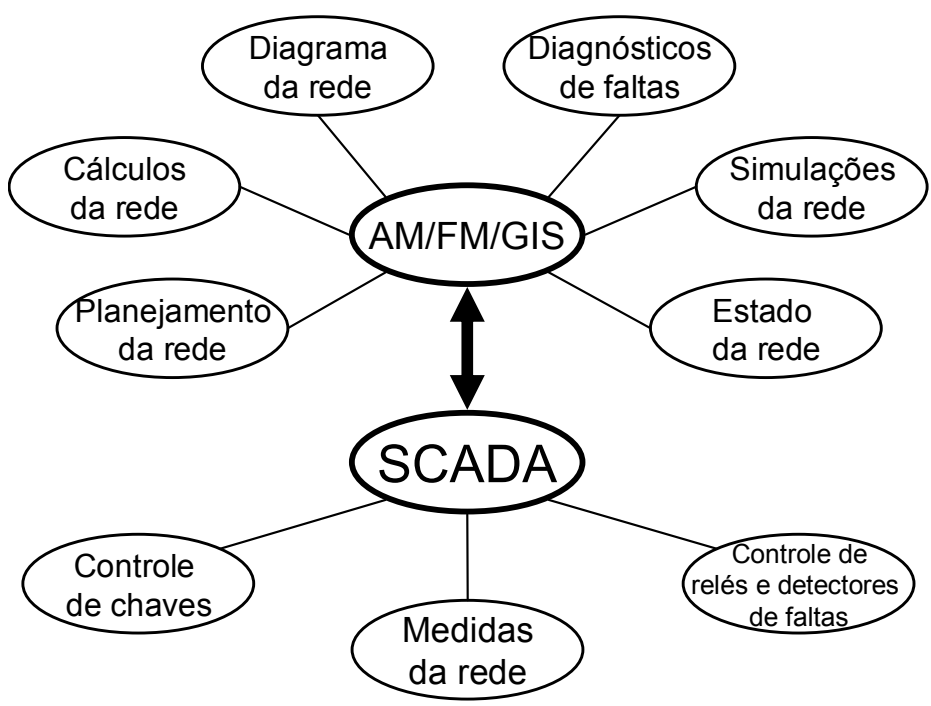

Figura 3.17 - Modelo computacional para automatização do tratamento de faltas em sistemas de distribuição.

O sistema AM/FM/GIS (Automated Mapping, Facilities Management and Geographic Information System) é responsável por realizar diversas tarefas no processo de automatização, indo desde a estimação do estado atual da rede até os 
cálculos envolvendo os diagnósticos das faltas. Este sistema tem comunicação bidirecional com o SCADA, que recolhe informações vindas dos dispositivos, tais como chaves, disjuntores, medidas diversas da rede e o controle sobre os dispositivos que detectam as faltas.

Neste modelo automatizado, até mesmo o fato de parte da linha possuir indicadores de falta e parte não possuir é levado em consideração, modelando-se matematicamente as zonas de atuação. O principal benefício para a automatização da isolação de uma falta é a diminuição de custo ao consumidor, além de reduzir o número de seguidas interrupções em conseqüência da localização errônea de uma falta.

Outra aplicação envolvendo a integração do sistema SCADA para automação do tratamento de faltas pode ser contemplado em [72]. Nesta aplicação é descrito um sistema de distribuição de energia automatizado que adota, dentre outros parâmetros, a utilização de indicadores de faltas instalados em determinados ramos do sistema para tomada de decisão.

Nesta mesma linha de pesquisa é possível encontrar trabalhos que utilizam sistemas computacionais para automatização de procedimentos envolvendo localização de faltas fundamentados em computadores pessoais [73], como é o caso do KODAS (Sistema Automático de Distribuição da Coréia) [74]. 


\subsection{Metodologia de localização de faltas fundamentada no modelo do alimentador e medidas tomadas na subestação de distribuição}

Os autores de [75] desenvolveram um novo sistema de localização de falta para sistemas de distribuição radiais, o qual se baseia na arquitetura do alimentador e nas medidas de tensão e corrente realizadas na subestação. O algoritmo proposto determina a localização precisa da falta, levando-se em consideração a característica de variação do carregamento da rede, a condição de desbalanceamento e a natureza assimétrica do alimentador. Neste trabalho, os autores mostram que a variação do carregamento da rede afeta significativamente a precisão do sistema de localização de falta. De forma a contornar tal problema, realiza-se a estimação do carregamento em tempo-real a fim de garantir uma minimização do erro entre a localização da falta calculada e a localização real da falta (valor de referência).

Com o intuito de mostrar a eficácia da metodologia proposta, os autores realizaram testes sobre dados reais de sistemas de distribuição radiais.

Conforme comentado previamente, a metodologia empregada necessita a priori dos valores de carregamento atual do sistema. Assim, a primeira etapa do método é a estimação do carregamento antes da ocorrência da falta. Portanto, este método deve ser implementado junto ao fluxo de carga do sistema de distribuição, onde são calculadas as variações de carregamento com base nos valores de préfalta e na configuração do alimentador. Desta forma, podem-se calcular também os valores das impedâncias do sistema durante a pré-falta e que será utilizada durante a etapa de localização da falta. 
O carregamento da rede foi considerado como impedância constante e a variação deste carregamento foi calculada por meio da lei de Kirchhoff das tensões. Após esta primeira etapa, deve-se executar então o algoritmo de localização de falta, o qual se baseia no cálculo do funcional (derivadas parciais).

Por meio deste cálculo, obtém-se o valor da distância entre a subestação e a falta. Entretanto, devido ao sistema de distribuição possuir diversos ramos (característica radial do alimentador), o algoritmo de localização de falta pode fornecer como resposta múltiplos ramos como pontos de ocorrência da falta. Com o intuito de sobrepor este problema, realiza-se aqui uma análise da assimetria dos ramos laterais.

Os resultados foram analisados quanto à variação no carregamento do sistema e quanto ao aumento da distância. No caso da variação do carregamento, verificou-se que o erro somente torna-se maior do que $1 \%$ quando o carregamento varia em torno de $100 \%$ de seu valor nominal. Com relação à variação da distância, o erro somente atingiu $1 \%$ após uma distância de $14 \mathrm{~km}$ entre a subestação e o ponto de falta. Conforme mostrado pelos autores, os resultados obtidos com a metodologia proposta são satisfatórios. Entretanto, faz-se extremamente necessária a obtenção dos valores de carregamento no instante pré-falta para que se possa ser calculada a impedância do sistema no momento que precede a falta, o qual pode prejudicar o algoritmo de localização de falta caso apresente valores incoerentes. 


\subsection{Localização de faltas utilizando sistemas inteligentes híbridos}

Para exemplificar todas as imprecisões, incertezas e não linearidades envolvidas com o processo de identificação e localização de faltas, pode-se destacar o trabalho contido em [76]. Isto porque os autores empregaram a ferramenta ANFIS, que é um sistema inteligente híbrido, do tipo incorporado, e que possui redes neurais artificiais e sistemas fuzzy em sua composição.

Além da ferramenta inteligente híbrida, os autores também empregaram ferramentas de processamento de sinais, tais como a transformada wavelet, explorando-se as informações contidas nos sinais de corrente de falta.

A combinação com transformadas wavelet permite realizar análises no tempo e na freqüência simultaneamente, localizando dentro do sinal no tempo, determinados grupos de freqüências. Tal ferramenta permite identificar mudanças abruptas em amplitude e freqüência do sinal de corrente em condições de falta.

Para o processo de aprendizado do sistema ANFIS, dados reais de correntes de faltas são utilizados, sendo que a saída do sistema representa o trecho onde ocorreu a falta. As variáveis de entrada são processadas pela wavelet, buscando-se determinar:

- Relação entre corrente de falta e o tempo de operação da proteção.

- Variação entre corrente na pré-falta e primeiro chaveamento.

- Variação entre corrente na pré-falta e último chaveamento.

- Vetores de tempo de operação da proteção: disjuntores, religadoras e fusíveis.

O sistema investigado consiste de um alimentador que foi dividido em 5 trechos, sendo simuladas faltas com resistências variando entre $0,5 \Omega$ e $40 \Omega$. Os 
autores utilizaram 930 amostras para o aprendizado do sistema ANFIS. A taxa global de acertos verificada pelos autores foi de $99,14 \%$.

Este trabalho apresenta importante contribuição ao constatar o grande relacionamento entre a variação da corrente após o último chaveamento e a préfalta, culminando em eficiência de localização.

\subsection{Considerações parciais}

Ao longo deste capítulo, as principais abordagens para identificação e localização de faltas foram apresentadas. Verifica-se, contudo, a existência de limitações que, sob determinadas condições, podem comprometer a correta estimação desejada aos processos de identificação e localização de faltas.

No entanto, a observância de tais limitações e o levantamento das condições favoráveis para aplicação de cada uma das técnicas pode contribuir para o desenvolvimento de um sistema integrado em que as principais características de cada abordagem podem ser incorporadas. Desta forma, ter-se-á um sistema capaz de identificar e localizar faltas sem que as limitações observadas nas abordagens atuais sejam pertinentes a este sistema.

O foco principal para a utilização dessas abordagens consideradas recentes, principalmente aquelas baseadas em redes neurais artificiais e lógica fuzzy, estão em suas habilidades naturais de poder mapear os relacionamentos existentes entre as entradas e saídas de processos tipicamente não-lineares. Essas ferramentas são normalmente utilizadas em processos onde o comportamento entre as variáveis de entrada e saída não é ainda bem estabelecido, tornando-se assim atrativas para o caso de identificação e localização de faltas. 
Na maioria das abordagens investigadas neste capítulo percebeu-se que as mesmas são altamente dependentes de técnicas de processamento de sinais. Assim, há a necessidade de utilização intensiva de ferramentas que lidam com os problemas envolvendo o processamento e tratamento de sinais. Dentre essas ferramentas, além da transformada de Fourier, a transformada de wavelet tem também se destacado pelo fato de poder tratar de forma eficiente sinais transitórios compostos de altas freqüências.

Algumas abordagens fundamentadas em automatização de equipamentos de redes podem se tornar extremamente difíceis de implementação. Isto porque exige um nível de automação de elementos que não pode apenas ficar restrito às subestações, devendo partir até dos dispositivos mais simples da rede, o que elevaria de forma considerável o custo envolvido com o tratamento de faltas.

Fica então ressaltado que uma ferramenta que possa identificar e localizar uma falta, de forma precisa e ao mesmo tempo que represente uma solução de custo acessível às companhias distribuidoras de energia, deve aproveitar o nível de automatização já empregado pelas empresas, sobretudo aproveitando as facilidades de implementação já disponíveis nas subestações de distribuição, agregando funcionalidades de sistemas inteligentes e também de processamento de sinais. 


\section{Confecção de sistemas inteligentes para}

\section{identificação e localização de faltas}

Um sinal transitório pode ser geralmente definido como aquele cuja duração de tempo é curta comparada com o intervalo de observação. Ele pode ser determinístico ou aleatório, sendo este último não-estacionário [77].

Transitórios em sistemas de potência resultam de uma variedade de distúrbios em linhas de distribuição e transmissão de energia, tal como o chaveamento de capacitores, descargas atmosféricas, tipos diferentes de faltas, e outros eventos. Observa-se, nos últimos anos, um maior interesse sobre tais transitórios, pois a qualidade indesejável de energia acarreta muitos problemas para as cargas, como mau funcionamento, diminuição da vida útil, instabilidade, e mesmo avaria completa.

Portanto, a análise de transitórios em sistemas de potência tem um papel de suma importância. Os registradores digitais de transitórios são capazes de gravar diversos sinais e fornecer assistência básica de informação. No entanto, a análise de transitórios em campo é uma tarefa difícil, devido geralmente a uma quantidade grande de dados gravados por tais registradores.

Uma vez que os registradores de transitórios de corrente não são capazes de classificar os transitórios, existe então a necessidade de se desenvolver sistemas mais sofisticados que tenham a habilidade de classificar diferentes tipos de transitórios, principalmente distinguindo faltas daquelas operações de 
chaveamentos, pois tais operações podem causar transitórios semelhantes àqueles das faltas $[78,79]$.

Além disso, a observação de vários dados ao mesmo tempo exigiria operadores altamente qualificados para tomar decisões importantes baseadas em suas experiências e conhecimentos práticos.

Um dos passos mais relevantes para se desenvolver um sistema de classificação é modelar os transitórios de forma que os computadores possam ser mais eficientes em extrair as características dos transitórios dos sistemas de potência e reconhecê-los automaticamente. Em geral, a classificação de transitórios em tempo real é um desafio, pois muitos sinais transitórios são aperiódicos, nãoestacionários, e de curta duração de tempo [80,81].

Quando uma tensão de linha está sendo monitorada, geralmente existe um número grande de variações acima e abaixo do nível da tensão inicial, que podem ser variações graduais ou bem rápidas. Uma classificação geralmente diferencia entre distúrbios da forma de onda fundamental e distúrbios sobrepostos. Os distúrbios de formas de onda incluem sobretensão e subtensão, queda completa de energia, variações de freqüência, e distorções harmônicas. Distúrbios sobrepostos incluem oscilações persistentes e fenômenos transitórios.

De acordo com [82], sistemas de diagnóstico e monitoramento têm uma grande importância nos processos de controle modernos. Muitos sistemas inteligentes ou baseados em conhecimentos têm sido desenvolvidos com sucesso para diferentes tipos de aplicações. No entanto, o desenvolvimento de um sistema como esse normalmente requer um conhecimento anterior ou dados das condições de faltas ou defeitos. 
O intervalo de tempo de um transitório é geralmente muito curto em comparação ao tempo que ele permanece em estado estacionário ou regime. Ainda, este tempo relativamente curto é muito importante porque é durante este intervalo que os componentes da rede são submetidos a valores extremos das variáveis de circuito. Existem muitos casos de transitórios em sistemas de potência, tais como curto-circuitos, chaveamento de banco de capacitores, chaveamento de grandes cargas indutivas (motores e transformadores), e descargas atmosféricas [83].

Os transitórios dos sistemas de potência são analisados e identificados mediante a comparação das formas de onda no domínio do tempo com as "assinaturas" do domínio do tempo para os diversos eventos transitórios [84].

Em sistemas de distribuição, os quais são normalmente aterrados indiretamente, é comum a ocorrência de faltas de uma fase com a terra. Quando tal falta ocorre, as condições de operação devem ser mantidas por 1 ou 2 segundos, pois não pode ser considerada como um curto-circuito. Porém, se esta condição durar por muito tempo, esta falta pode se tornar facilmente uma falta de duas fases com a terra, e o arco elétrico formado com a terra pode ocasionalmente causar sobretensões no sistema.

Pelo fato de que os sinais transitórios representam mais adequadamente as características de falta do que os sinais estacionários, a utilização de sinais transitórios para identificar uma falta à terra de uma linha possui maior sensibilidade e confiabilidade do que usar os sinais estacionários. Baseado nisto, em [85] empregou-se a teoria de wavelet para analisar e detectar faltas monofásicas à terra em linhas de distribuição. Análises teóricas e resultados de simulações mostraram que o método proposto pode detectar falha em linhas de forma exata e precisa, 
podendo ser utilizado em diferentes sistemas de distribuição com vários modos de configuração de aterramento.

De fato, métodos wavelet são capazes de realizar análises multi-resolução dos sinais, podendo melhorar o nível de detalhe no tempo ou freqüência de acordo com as necessidades, o que resulta também em excelentes filtros passa-alta, passabaixa, passa-faixas, etc, susbstituindo-se os tradicionais métodos de ajustes destes filtros pela análise de energia do espectro wavelet que se deseja investigar [86].

Um trabalho interessante sobre detecção de faltas de alta impedância em alimentadores de distribuição foi apresentado por [87]. Segundo os autores, a habilidade de detectar falta de alta impedância tem sido assunto de pesquisas e desenvolvimento por mais de 30 anos. Por volta de sete anos atrás, começaram a surgir no mercado produtos que podem ser seguramente utilizados para desenvolver esta função.

Segundo o grupo de trabalho da Comissão de Proteção de Sistemas de Potência do IEEE [88], falta de alta impedância é definida como aquela que não produz corrente de falta suficiente para ser detectada por relés de sobrecorrente convencionais ou fusíveis.

A falta de alta impedância típica ocorre quando um condutor é interrompido fisicamente e cai ao solo. A quebra do condutor geralmente resultará em queda das cargas supridas por aquele alimentador ou, possivelmente, por uma condição momentânea de sobrecorrente quando o condutor entra em contato rapidamente com um objeto solidamente aterrado. Uma vez ao solo, o sinal elétrico resultante é uma função da superfície de contato. Superfícies tais como o concreto, grama, sujeira, e superfícies úmidas produzem, em geral, uma falta de arco com correntes 
de falta RMS da ordem de 10 a 50 amperes, ao passo que superfícies secas como areia e asfalto produzem um nível de corrente baixo e constante.

Um tipo de falta de alta impedância relatada é quando o condutor não se rompe, mas entra em contato com objetos aterrados devido a uma falha do sistema de montagem do condutor, falha na isolação, ou um contato acidental com algum elemento externo, como um tronco de uma árvore. Essas faltas geralmente apresentam uma característica de sinal semelhante a de um condutor rompido ao solo; no entanto, a falta não será precedida por qualquer variação na corrente fundamental.

De acordo com [87], a detecção de faltas de alta impedância se dividem em duas categorias: detecção mecânica e a detecção elétrica. A detecção mecânica geralmente envolve alguma maneira de forçar o contato com um objeto aterrado para permitir que a proteção convencional de sobrecorrente opere.

São relatadas três técnicas elétricas de detecção de faltas de alta impedância. A primeira técnica mede o ângulo de fase da corrente de terceira harmônica com relação à tensão fundamental. O dispositivo calcula e armazena o fasor médio da corrente de terceira harmônica. Quando a falta ocorre, o novo fasor de corrente de terceira harmônica é vetorialmente subtraído do valor armazenado. Uma falta de alta impedância é enviada se a magnitude estiver acima do ajuste e se o ângulo coincidir com um valor pré-determinado para um condutor caído.

Um segundo método elétrico é apresentado quando se tem simplesmente um condutor aberto. A detecção de falta de alta impedância para este caso ocorre pela perda da tensão.

Finalmente, um terceiro método elétrico, relatado por [87] para faltas de alta impedância, é realizado por um sistema especialista de reconhecimento de padrões 
dos níveis harmônicos de energia das correntes em faltas com arco, denominado HiZ IED, o qual utiliza uma taxa de amostragem de 64 amostras por ciclo nas entradas de corrente alternada a fim de criar uma informação espectral usada nas análises das assinaturas. Técnicas de sistemas especialistas são empregadas para assegurar a segurança enquanto se mantém a confiabilidade.

O processo como um todo incorpora nove algoritmos, cada um desenvolvendo uma detecção específica ou função classificadora. A detecção de faltas de alta impedância requer entradas das correntes trifásicas e de terra através de transformadores de corrente. As entradas de tensão são utilizadas para aumentar a segurança e fornecer identificação suplementar de fase e não são necessárias para a detecção do arco.

Outros algoritmos principais de detecção são os de Energia e Aleatoriedade. O algoritmo de Energia se baseia no fato de que o arco causa transitórios de energia que são verificados ao longo de todo o espectro. Os valores de energia, calculados como o quadrado das componentes harmônicas e não harmônicas (exceto a fundamental), são integrados em valores harmônicos ímpares, pares, e não inteiros. Amostrando 64 amostras por ciclo tem-se o cálculo de componentes de freqüência até a $25^{a}$ harmônica. $O$ algoritmo de Energia monitora essas harmônicas calculadas para todas as correntes de fase e corrente de terra. Após estabelecer um valor de energia médio para um dado sinal, o algoritmo indica a presença de arco se ele detectar um aumento repentino e prolongado no valor daquela componente. 


\subsection{Aplicação de processamento digital de sinais em transitórios de faltas}

As ferramentas descritas no capítulo anterior foram utilizadas nos sinais armazenados de correntes das fases A, B, C, e corrente de neutro, e tensões das fases $A, B$ e $C$ de faltas oscilografadas no alimentador piloto, com o objetivo de se extrair as suas características, ao mesmo tempo em que se procurou um detector de transitório que melhor representasse a falta.

O primeiro sinal a ser analisado foi obtido a partir de uma falta de alta impedância, denominado ensaio I, onde uma das fases se rompe e toca o solo, sendo que a oscilografia foi realizada na subestação com uma janela de amostragem de 10 segundos. Os sinais foram analisados utilizando-se rotinas do Matlab e os resultados encontram-se registrados entre a Figura 4.1 e Figura 4.7.
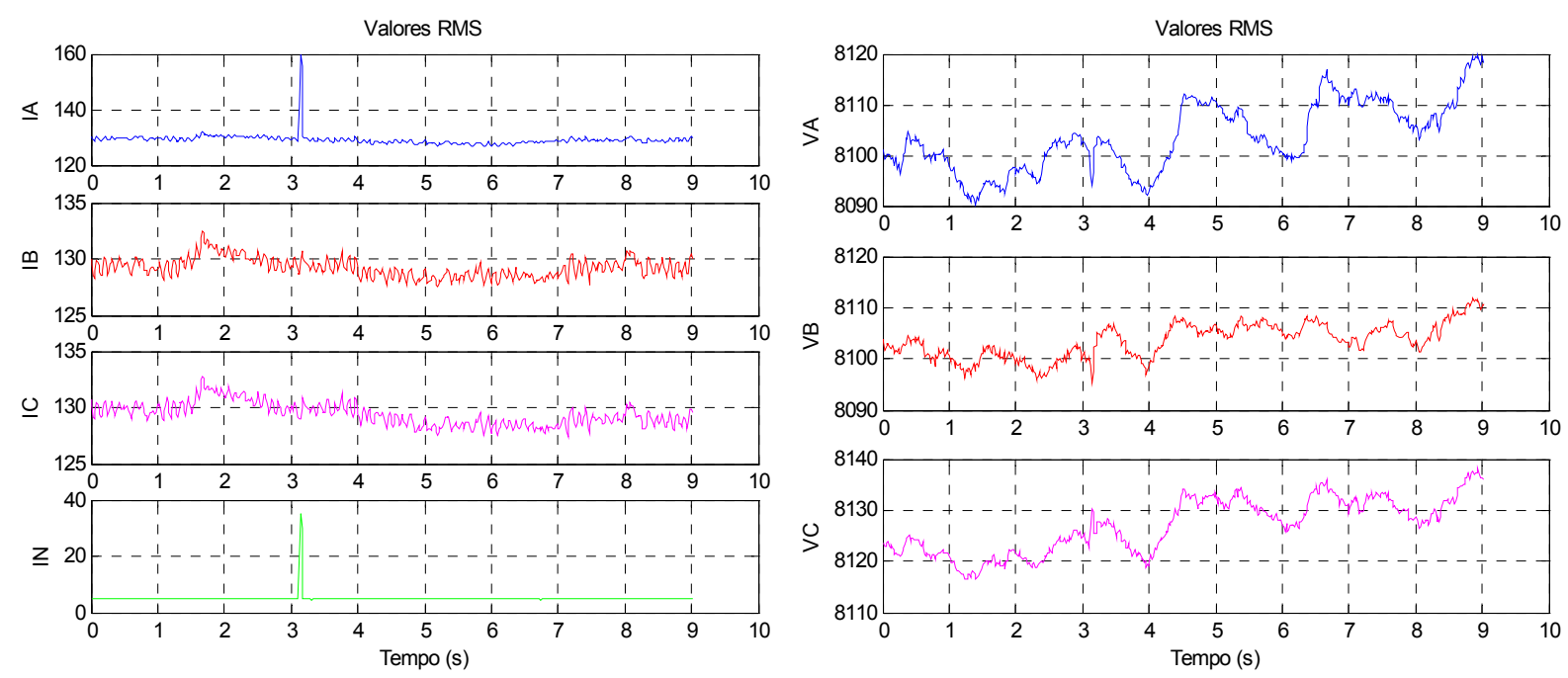

Figura 4.1 - Estatística RMS para correntes e tensões (ensaio I).

A estatística RMS aplicada aos sinais de corrente apresentou no momento da falta, valores de aproximadamente 160 amperes para a fase A e 35 amperes para a corrente de neutro, sendo os valores das correntes das fases B e C praticamente inalterados e com valor médio de 130 amperes. A detecção ocorreu no tempo de 3,2 
segundos, conforme os picos das correntes mostrados nas Figura 4.1. Observa-se que a variação percentual da corrente no momento da falta é de $23 \%$ para a fase $A$. Assim, a estatística foi eficaz para a detecção do transitório de curto-circuito utilizando os valores de corrente. Para as tensões, conforme mostra a Figura 4.1, não houve variação significativa nas formas de onda, embora possa se observar picos diferentes nas três tensões no instante 3,2 segundos, mas difícil de se identificar.

Observando os resultados da estatística CFAR para os sinais de corrente, constata-se na Figura 4.2 um pico na fase $A$, no instante da falta, de aproximadamente $3 \times 10^{13}$, significando uma variação de $58,7 \%$ do valor em regime contra uma variação de $23 \%$ para a estatística $R M S$.
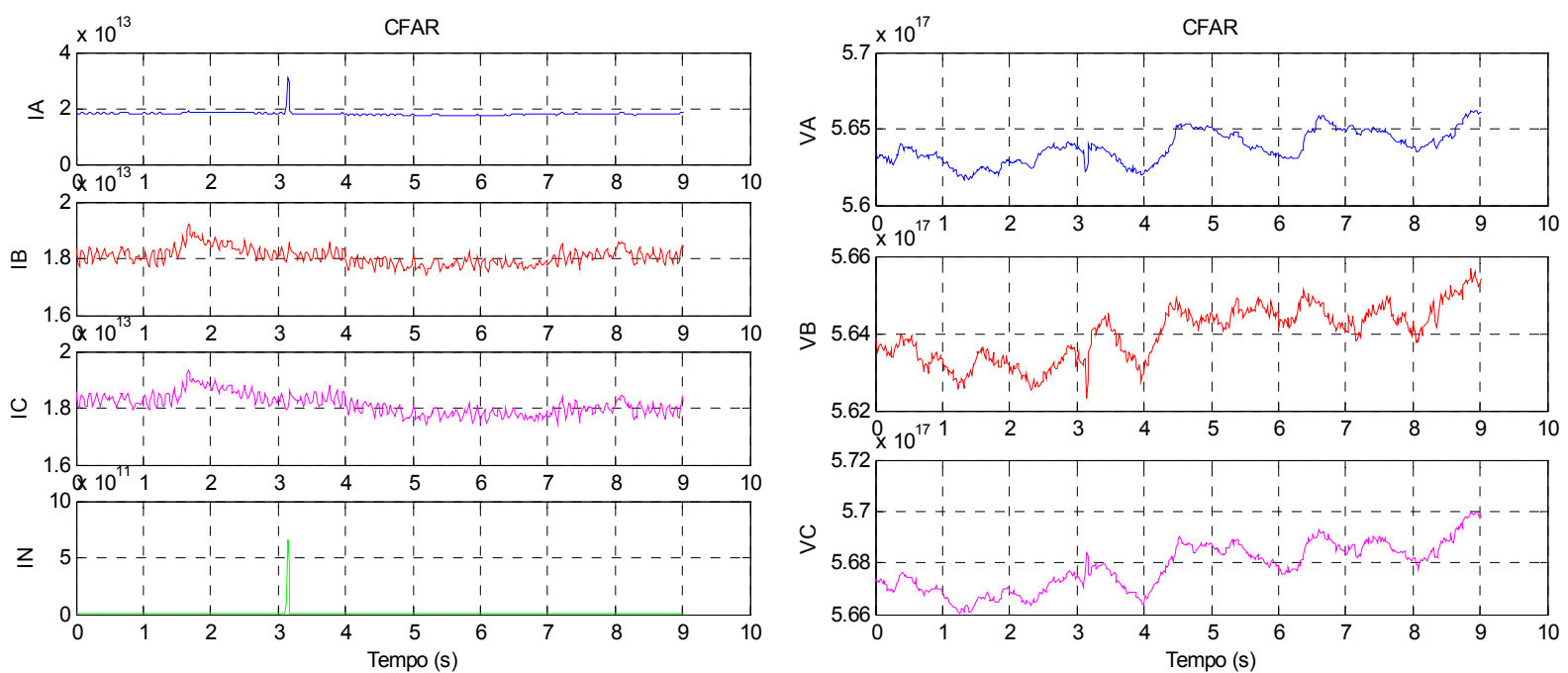

Figura 4.2 - Estatística CFAR para correntes e tensões (ensaio I).

Para a corrente de neutro, observa-se um pico de $7 \times 10^{11}$. Assim, pode-se afirmar que esta estatística apresentou uma sensibilidade muito grande quando comparada com a estatística RMS no tocante à detecção do transitório da corrente da fase A. Com relação aos resultados produzidos para os sinais de tensão, a estatística CFAR também não trouxe informação útil sobre a detecção. 
Do gráfico mostrado na Figura 4.3, observa-se que a estatística $M V D$ detectou o transitório para a fase $\mathrm{A}$, mas com uma baixa amplitude relativa ao sinal de regime, além de possuir uma relação sinal/ruído não muito satisfatória.
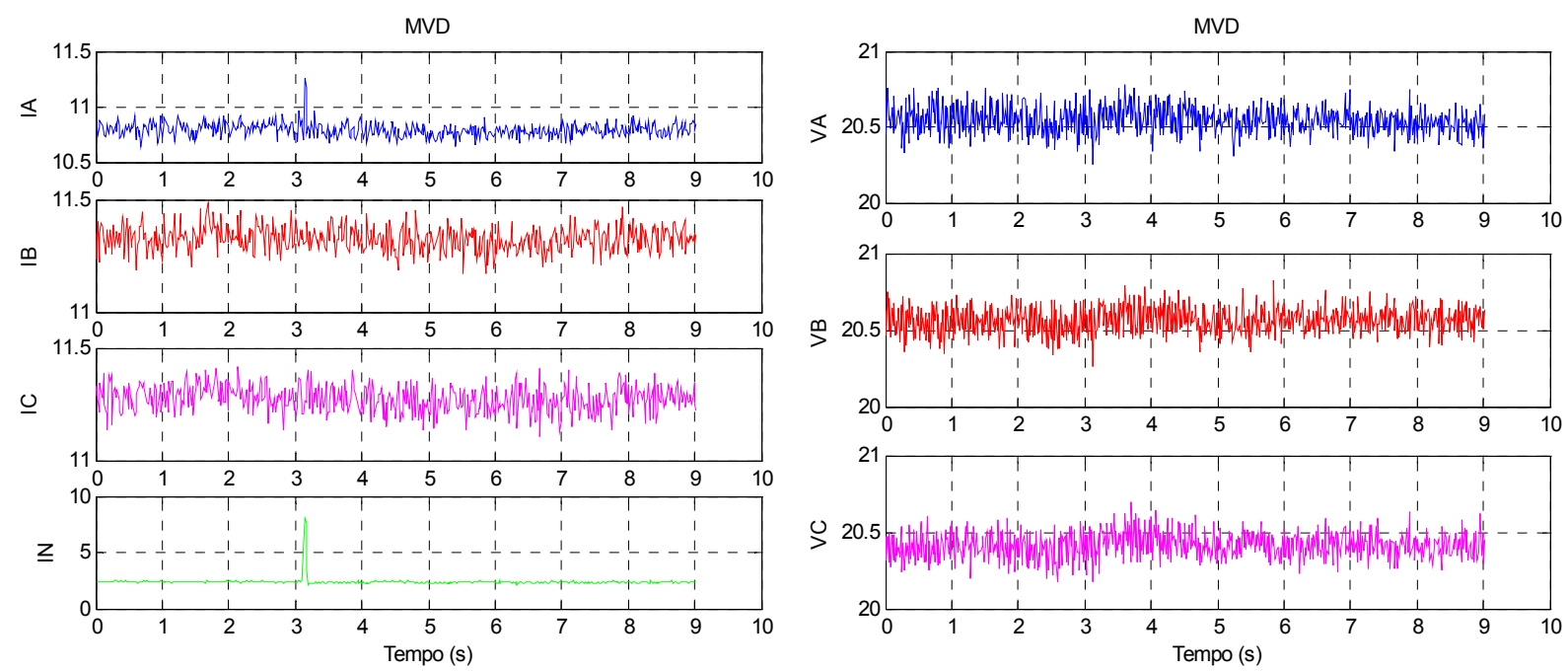

Figura 4.3 - Estatística MVD para correntes e tensões (ensaio I).

Por outro lado, a corrente de neutro apresentou uma variação significativa, mostrando a eficácia da técnica para a detecção da falta pela corrente de neutro. As correntes das fases B e C não sofreram variações significativas. Para os resultados advindos das tensões, observa-se na Figura 4.3 que não houve variação importante em nenhuma das fases, mostrando que a estatística $M V D$ não consegue distinguir os transitórios ocorridos e, portanto, se apresenta ineficaz para as tensões.

Os resultados registrados na Figura 4.4, oriundos da estatística $R O P$ para as correntes, mostram que a referida estatística detectou o transitório para a fase A e para a corrente de neutro, mas com amplitudes muito baixas, principalmente para a corrente da fase A. O mesmo ocorreu para as tensões, conforme pode ser observado na Figura 4.4, em que se pode constatar a ocorrência da falta apenas na fase A, com uma variação não significativa para propósitos de detecção. 

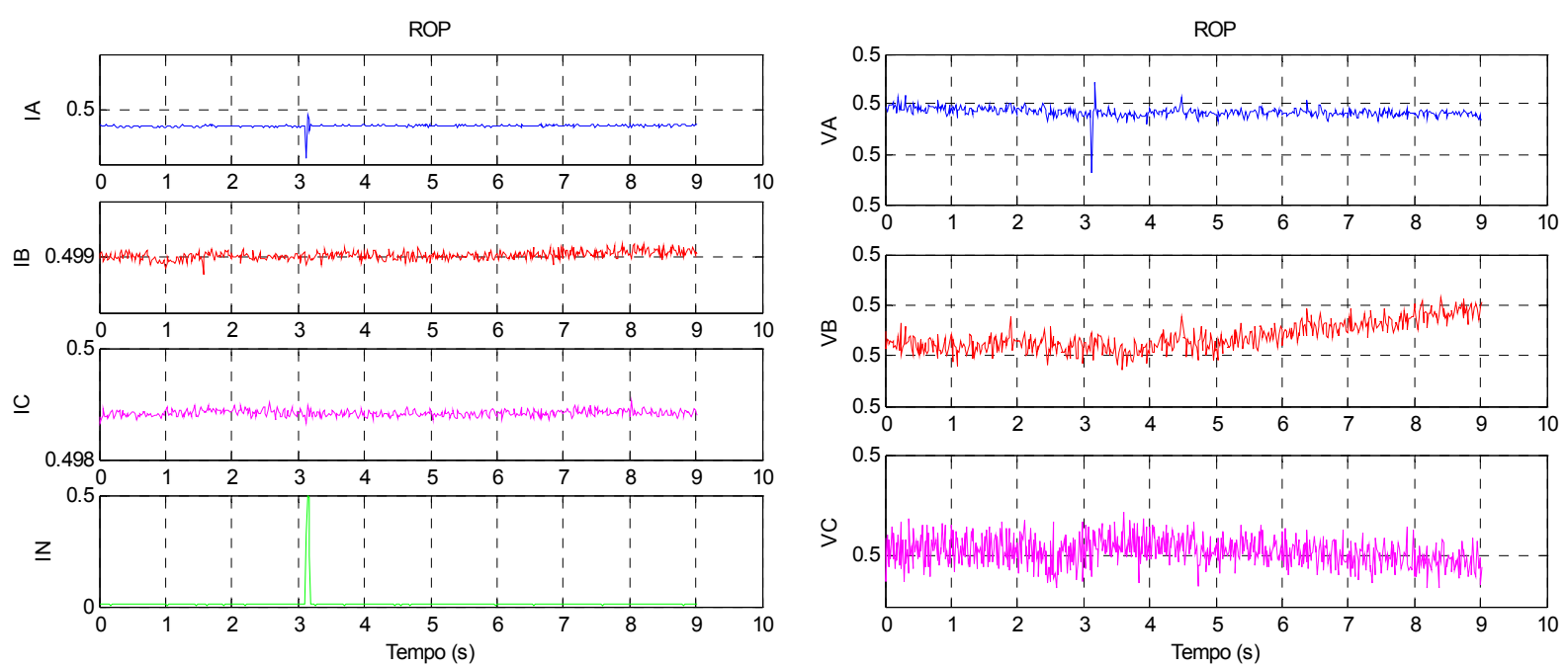

Figura 4.4 - Estatística ROP para as correntes e tensões (ensaio I).

A Autocorrelação, ilustrada na Figura 4.5, apresentou picos bem definidos nos sinais de corrente da fase A e corrente de neutro quando da falta; porém, deslocados significantemente com atraso em relação ao instante da ocorrência.
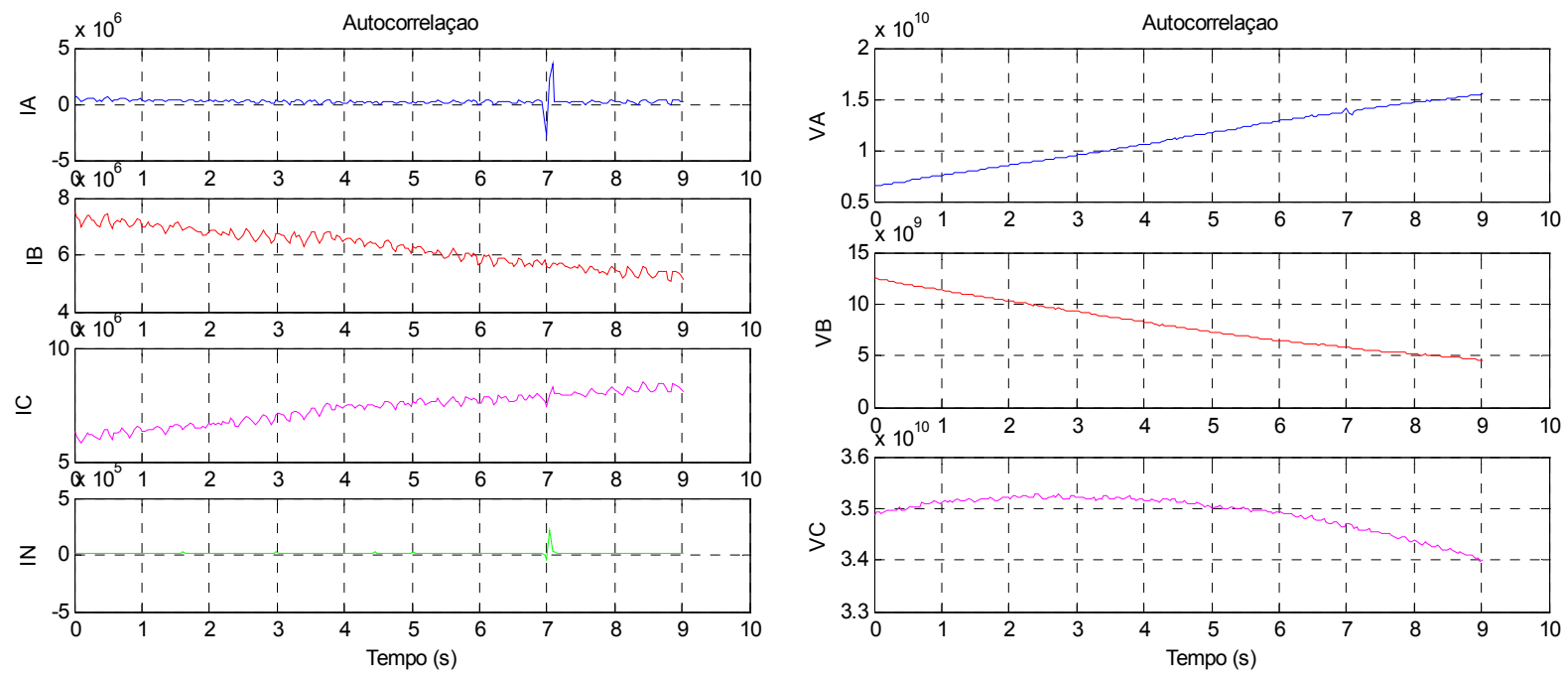

Figura 4.5 - Estatística Autocorrelação para correntes e tensões (ensaio I).

Isto pode ser explicado em função do número de amostras por cálculo da estatística, que foi de 1667 quando a taxa de amostragem foi de $100 \mathrm{kHz}$, significando a Autocorrelação do sinal a cada 16,67 ms. No entanto, os resultados produzidos para as tensões não trazem informações que possam ser utilizadas na detecção da falta estudada. 
A estatística de Kurtosis para as correntes revelou a detecção da falta para a fase A e corrente de neutro; porém, com amplitudes muito baixas, conforme pode ser observado na Figura 4.6.
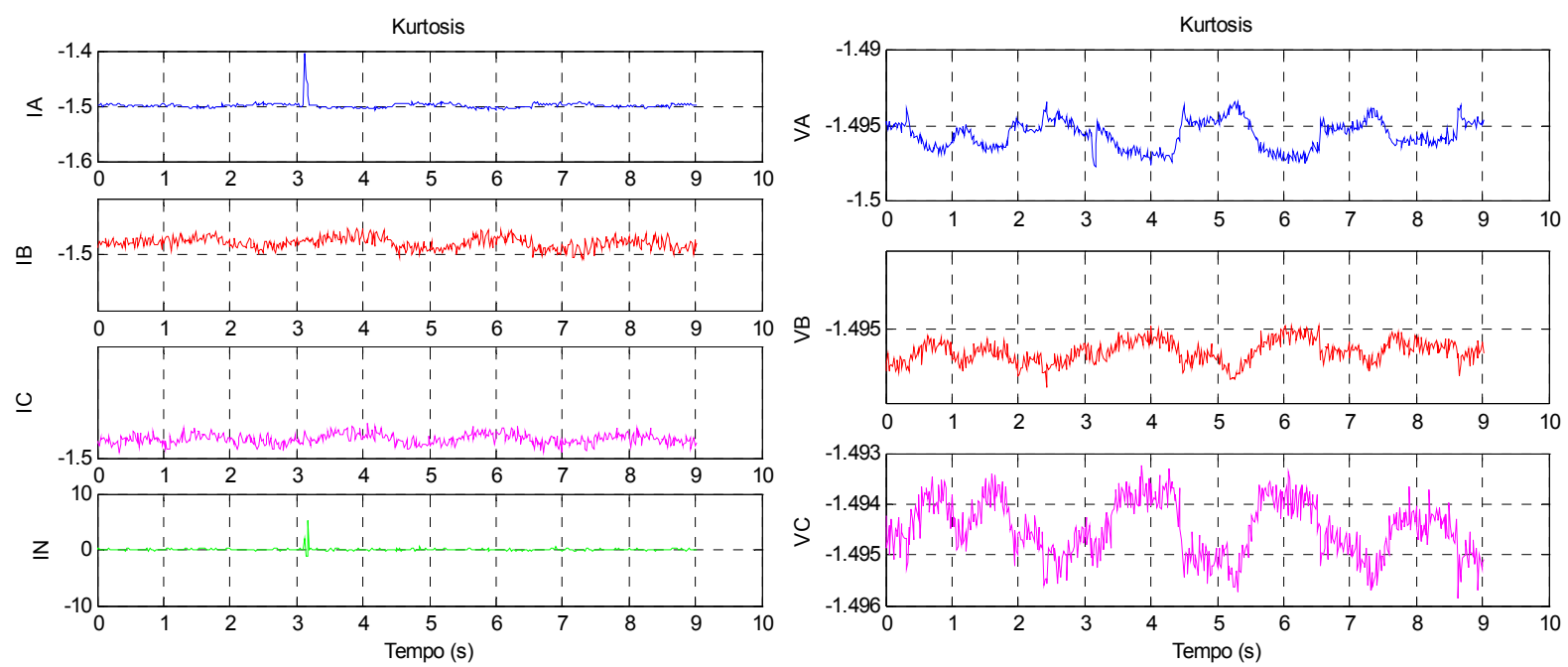

Figura 4.6 - Estatística Kurtosis para correntes e tensões (ensaio I).

Observa-se que as correntes da fase A, B, e C possuem valores de Kurtosis negativos, indicando uma distribuição normal plana, com uma cauda pouco acentuada, enquanto a corrente de neutro possui uma distribuição normal padrão em operação normal, com Kurtosis igual a zero. Os resultados para as tensões quando da aplicação de Kurtosis não revelaram informação útil sobre a ocorrência da falta conforme mostra a Figura 4.6.

A Figura 4.7 apresenta os resultados obtidos da estatística de Skewness para as correntes e tensões, em que se pode observar a detecção da falta tanto para a corrente da fase A como para a corrente de neutro. No entanto, o valor de pico observado para a corrente da fase A é bem pequeno, aproximadamente $-0,1$, enquanto que o valor de pico para a corrente de neutro é de aproximadamente $-2,0$. Assim, pode-se concluir que para a corrente de neutro, a estatística funcionou bem sensível para a detecção da falta. 

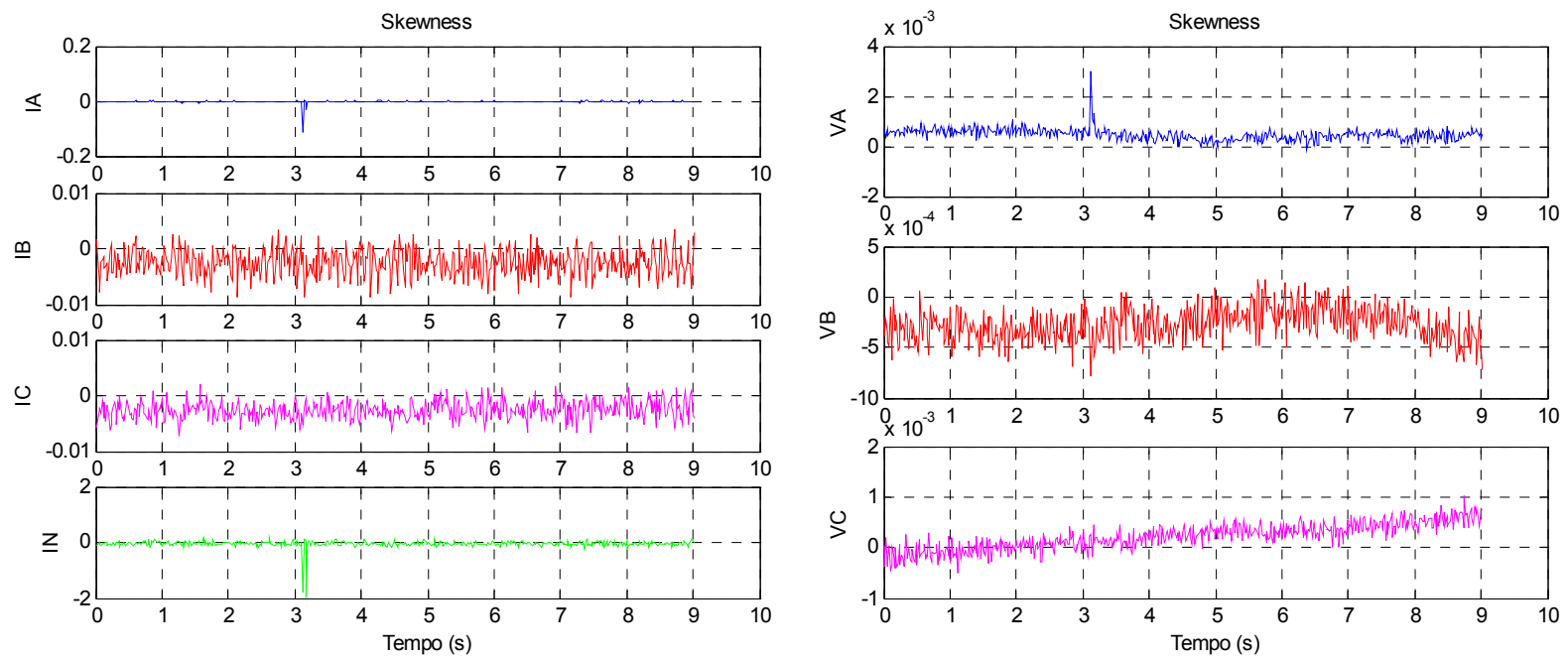

Figura 4.7 - Estatística Skewness para correntes e tensões (ensaio I).

Adicionalmente, observa-se que, no instante da aquisição dos dados, existia uma simetria das distribuições normais das correntes, sendo modificada apenas no momento da falta. Para as tensões, conforme mostra também a Figura 4.7, observase que apenas a tensão da fase $A$ indicou um pico de valor muito baixo no momento da falta, cerca de $3 \times 10^{-3}$, apresentando uma assimetria na distribuição da corrente apenas durante a falta.

O segundo sinal de falta a ser analisado, ensaio II, simulou-se um curtocircuito fase-fase, com uma janela de 10 segundos.

A estatística RMS para as correntes, mostrada na Figura 4.8, indica claramente a detecção da falta ensaiada. Observam-se para ambas as correntes da fases A e C uma amplitude de aproximadamente 1100 amperes no momento da falta. Adicionalmente, a corrente da fase B detectou um pico (no mesmo instante) de aproximadamente 175 amperes, e a corrente de neutro um pico de 7 amperes. De forma semelhante, os valores RMS de tensão apresentaram variações em que se pode claramente extrair a característica da falta, embora essas variações em termos percentuais relativas ao regime não sejam consideráveis $(\sim 6,5 \%$ fase $A, \sim 0,5 \%$ 
fase $B$, e $\sim 11,5 \%$ fase $C)$, os transitórios ficaram bem definidos, conforme mostra a Figura 4.8.
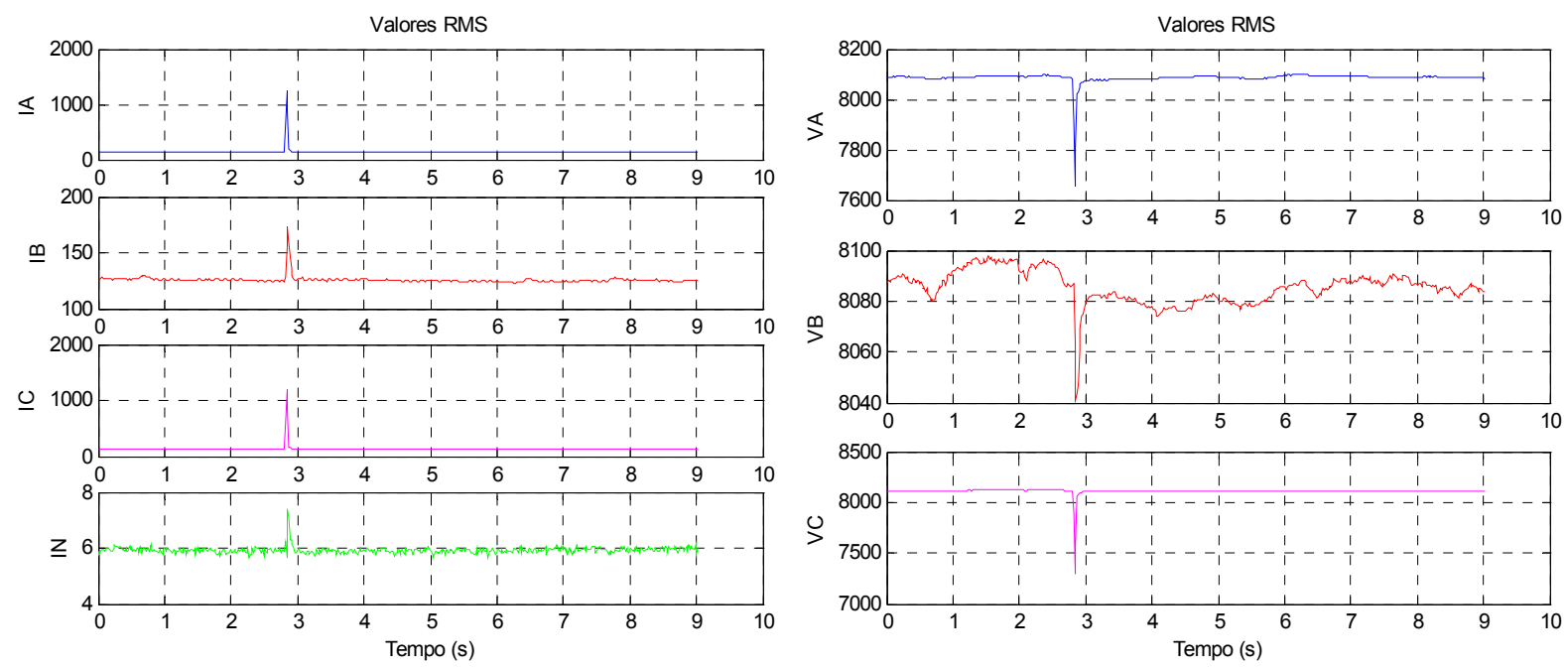

Figura 4.8 - Estatística RMS para correntes e tensões (ensaio II).

De maneira semelhante, a estatística CFAR para as correntes mostra que a mesma foi eficiente na detecção da falta simulada, sendo que para as fases $A$ e $C$ o valor CFAR atingiu um pico de cerca de $5 \times 10^{15}$ unidades, $3,9 \times 10^{13}$ unidades para a fase $B$, e $1,2 \times 10^{10}$ unidades para o condutor de neutro, conforme pode ser observado na Figura 4.9.

Para as tensões, os valores da CFAR se mostram também com picos bem evidentes no momento da falta, relativos ao decaimento das tensões. Estes decaimentos são praticamente iguais para as fases $A$ e $B$, em que se observa o valor da tensão em regime de aproximadamente $5,6 \times 10^{17}$, caindo para $5,55 \times 10^{17}$, ou seja, uma variação de apenas $1 \%$, enquanto que a tensão na fase C caiu de $5,6 \times 10^{17}$ para $4,3 \times 10^{17}$, representando uma variação considerável de $30 \%$. 

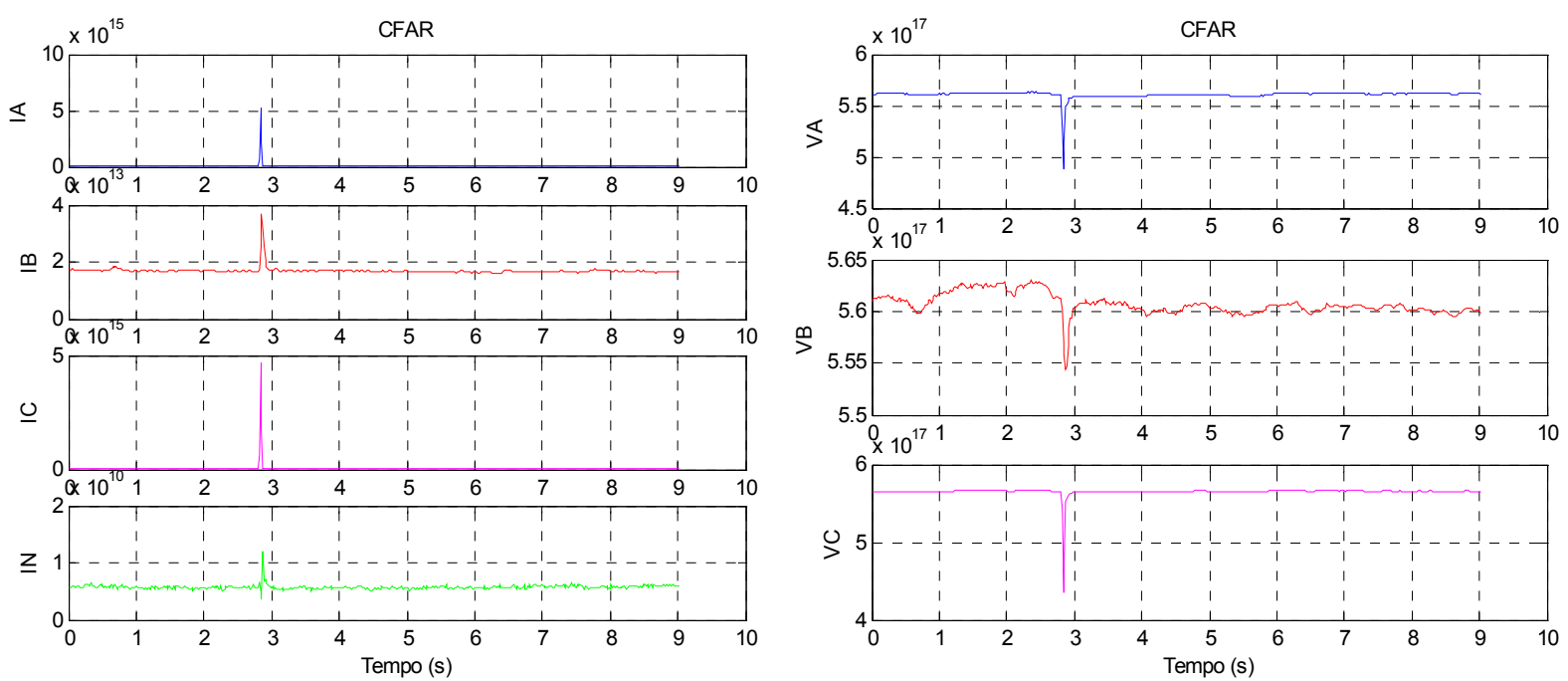

Figura 4.9 - Estatística CFAR para correntes e tensões (ensaio II).

Os resultados da estatística MVD mostrados na Figura 4.10 revelam que a mesma foi eficaz também na detecção da falta.
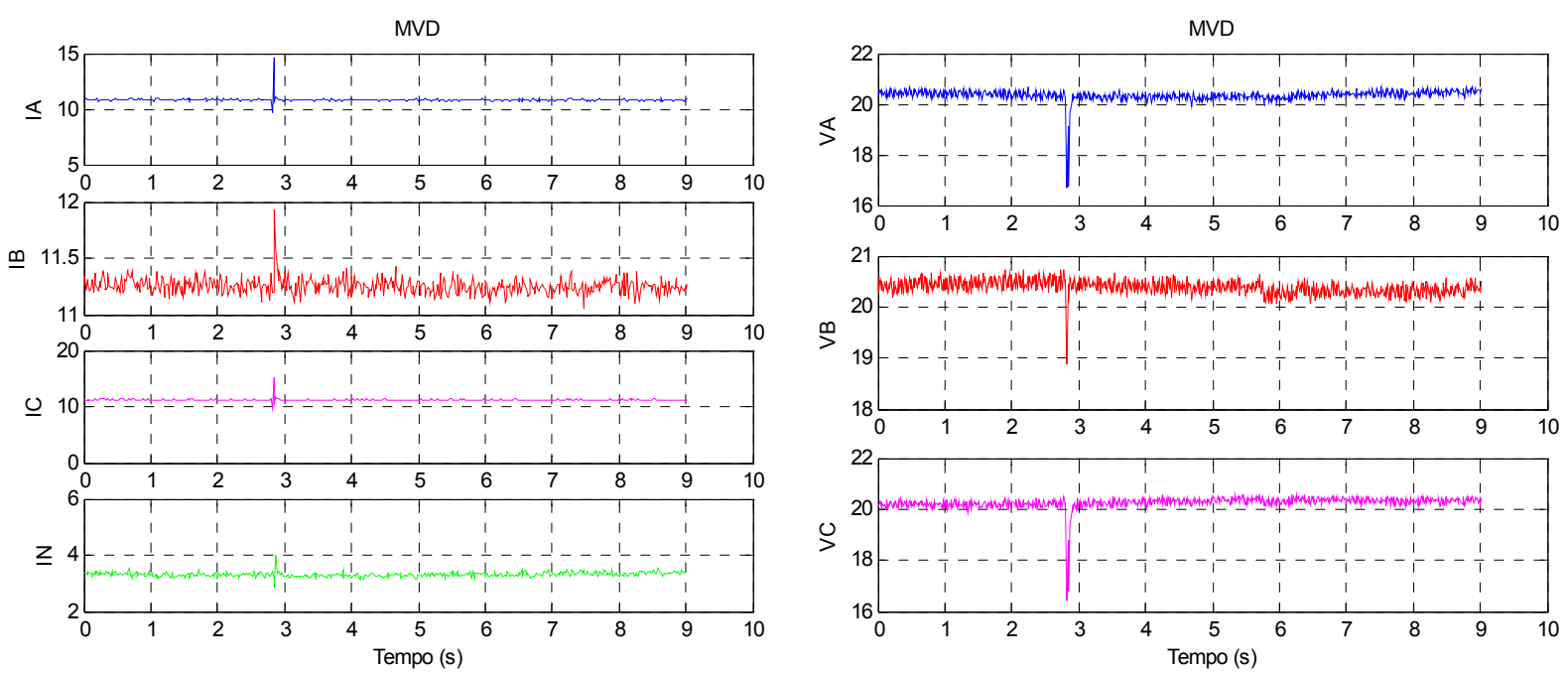

Figura 4.10 - Estatística MVD para correntes e tensões (ensaio II).

Observa-se para o valor $M V D$ da corrente da fase A um pico significativo de valor aproximado de 15 unidades, sendo uma variação percentual em relação à condição de regime de $25 \%$. Para a fase $B$, a variação percentual foi de apenas $4 \%$ e para a corrente de neutro de $14 \%$. Os valores MVD para as tensões também mostram com evidência o transitório da falta de curto-circuito fase-fase. Pode-se observar na Figura 4.10 que o valor $M V D$ da tensão para a fase $A$ variou de $20 \%$, 
para fase B de $8,5 \%$ e para a fase C de $24 \%$. Assim, esta estatística foi eficaz na detecção da falta de curto-circuito fase-fase ensaiada.

Na Figura 4.11 pode-se observar que a estatística $R O P$ foi eficaz na detecção do transitório de falta para as três correntes. No entanto, a variação percentual da corrente da fase A e fase C foi de $20 \%$, enquanto que a variação da fase $B$ foi de apenas $0,6 \%$. Para a corrente de neutro, a variação foi de 17 vezes a corrente de regime. Para as tensões, ilustrada também na Figura 4.11, observa-se ainda a detecção da falta em todas as fases, porém com uma variação percentual menor do que $1 \%$.
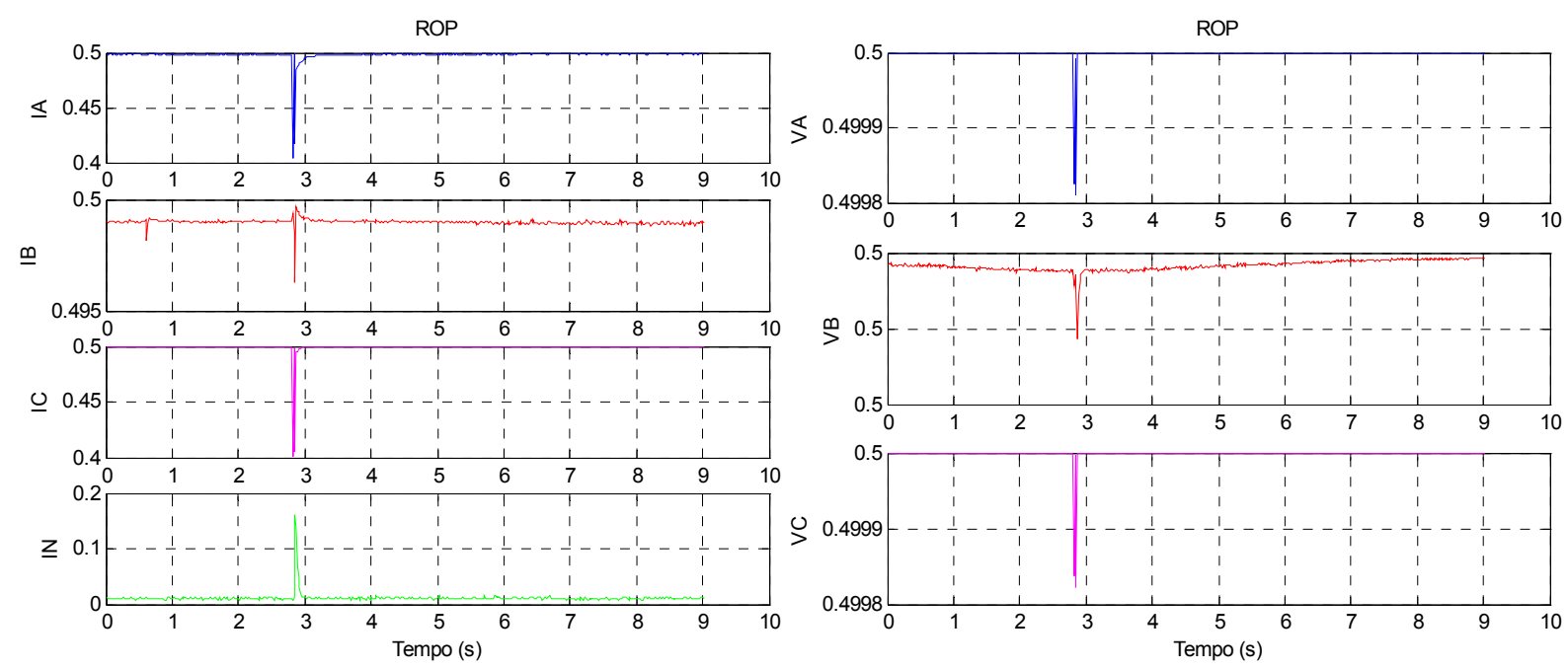

Figura 4.11 - Estatística ROP para correntes e tensões (ensaio II).

A estatística de Autocorrelação dos sinais de corrente apresentou bons resultados quanto à detecção da falta. Observa-se na Figura 4.12 um imenso valor percentual entre o regime e o máximo valor atingido pela estatística na detecção do transitório. Isto ocorreu para as fases A, B e corrente de neutro, embora esta última observa-se uma relação sinal/ruído bem maior, mas não comprometendo a sua eficácia. No entanto, o valor da Autocorrelação para a fase B no momento da falta foi próximo ao valor inicial do ensaio, não mostrando, portanto, um resultado desejável neste caso. Como mencionado várias vezes anteriormente, o instante de detecção 
ficou atrasado em função do valor que se utilizou para a Correlação entre os valores das amostras, o que pode ser corrigido utilizando-se valores bem menores. No caso dos valores da estatística para as tensões, não se observa utilidade nos resultados, ficando-se assim verificado a ineficácia dessa estatística para a detecção da falta quando da Autocorrelação dos sinais de tensão.
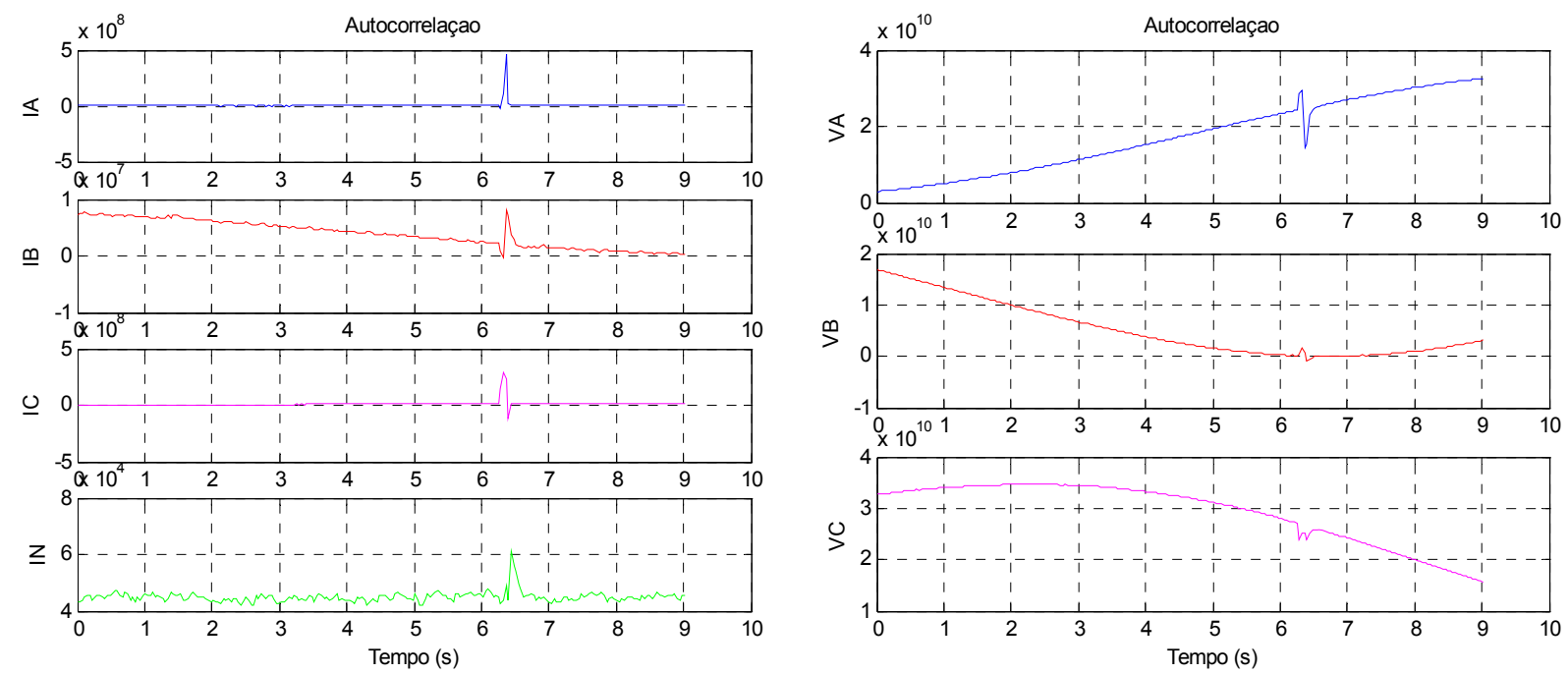

Figura 4.12 - Estatística Autocorrelação para correntes e tensões (ensaio II).

Os resultados advindos do processamento para a estatística de Kurtosis, conforme mostram a Figura 4.13, revelam que a mesma detectou bem o transitório de falta para as fases A, B e C.
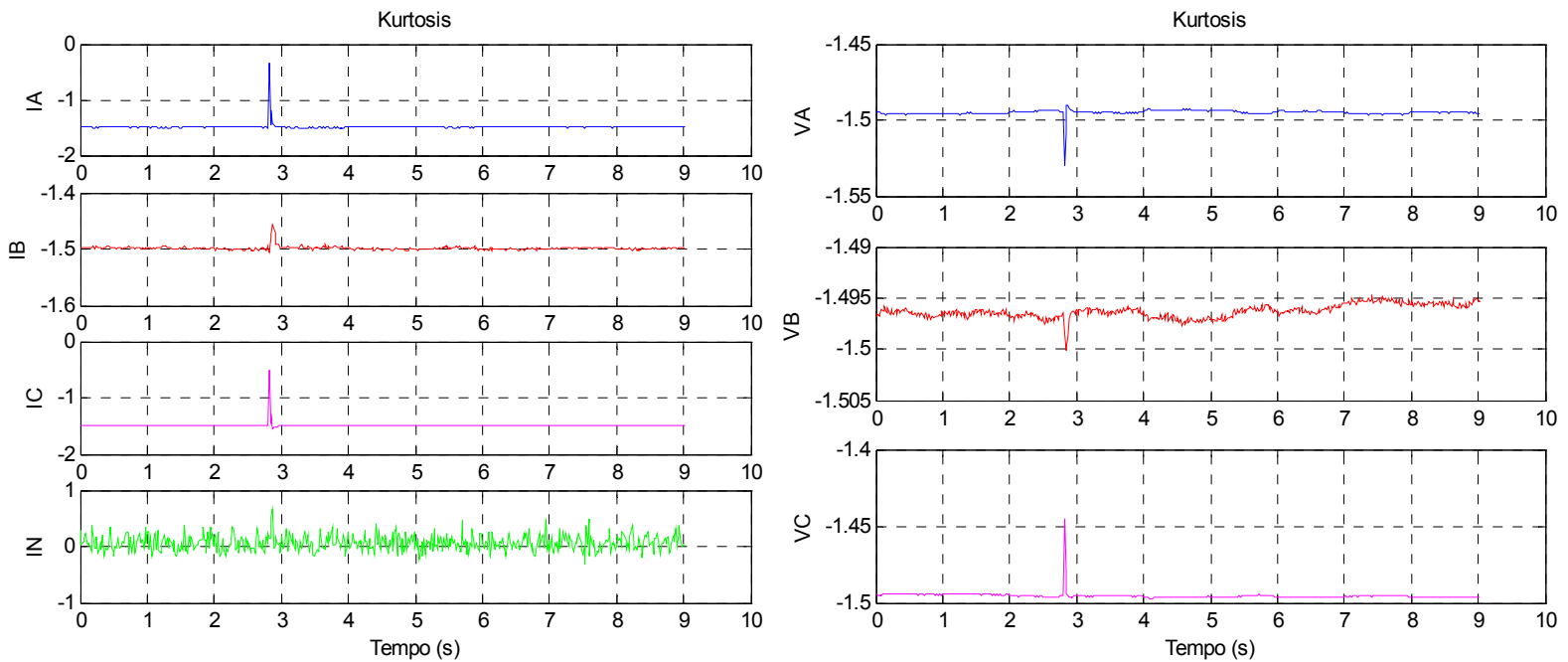

Figura 4.13 - Estatística Kurtosis para correntes e tensões (ensaio II). 
Observa-se uma variação de aproximadamente $100 \%$ do sinal da fase A e B quando da falta, e uma variação de apenas $2,6 \%$ para a fase B. Por outro lado, a corrente de neutro traz um pico no instante da falta, mas a sua relação sinal/ruído é muito ruim. Para as tensões, observam-se também variações que definem bem a falta, mas com valores percentuais muito baixos (menores que $3 \%$ ).

A estatística de Skewness mostrada na Figura 4.14, para os sinais de corrente revela que a mesma foi eficaz na detecção do transitório de falta de curtocircuito fase-fase. A variação percentual para os sinais obtidos para as fases A e C é de aproximadamente $100 \%$, enquanto que para a corrente de neutro é de $50 \%$. O sinal obtido para a fase B no instante da falta produziu uma variação percentual de aproximadamente $16 \%$. Os sinais da estatística de Skewness para as tensões mostram bem a extração da falta ocorrida, observando-se uma variação percentual de apenas $5 \%$ para a fase $A$ e de $3,5 \%$ para a fase $C$. No entanto, para a fase $B$, a variação percentual foi de $500 \%$.
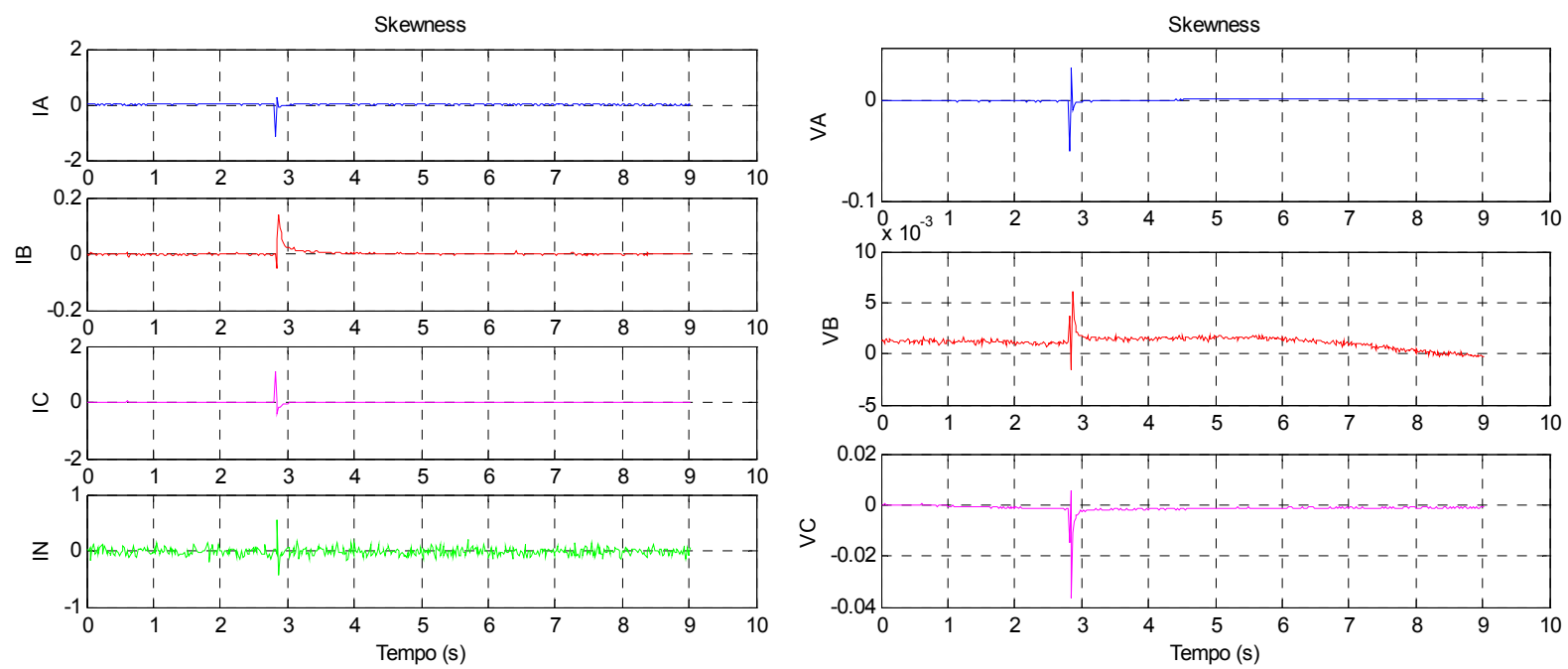

Figura 4.14 - Estatística Skewness para correntes e tensões (ensaio II).

Foram analisados dados provenientes de 16 oscilografias de faltas, ensaiadas no alimentador piloto, simulando as mais diversas situações de curto- 
circuito, seja ele de alta impedância com o terra ou franco. Pode-se destacar a performance das estatísticas RMS e CFAR na sua capacidade em detectar transitórios de corrente, e Skewness e $M V D$ na detecção dos de tensão. Na Figura 4.15 tem-se registrado o desempenho das estatísticas para o processamento dos sinais de corrente e na Figura 4.16 para os de tensão.

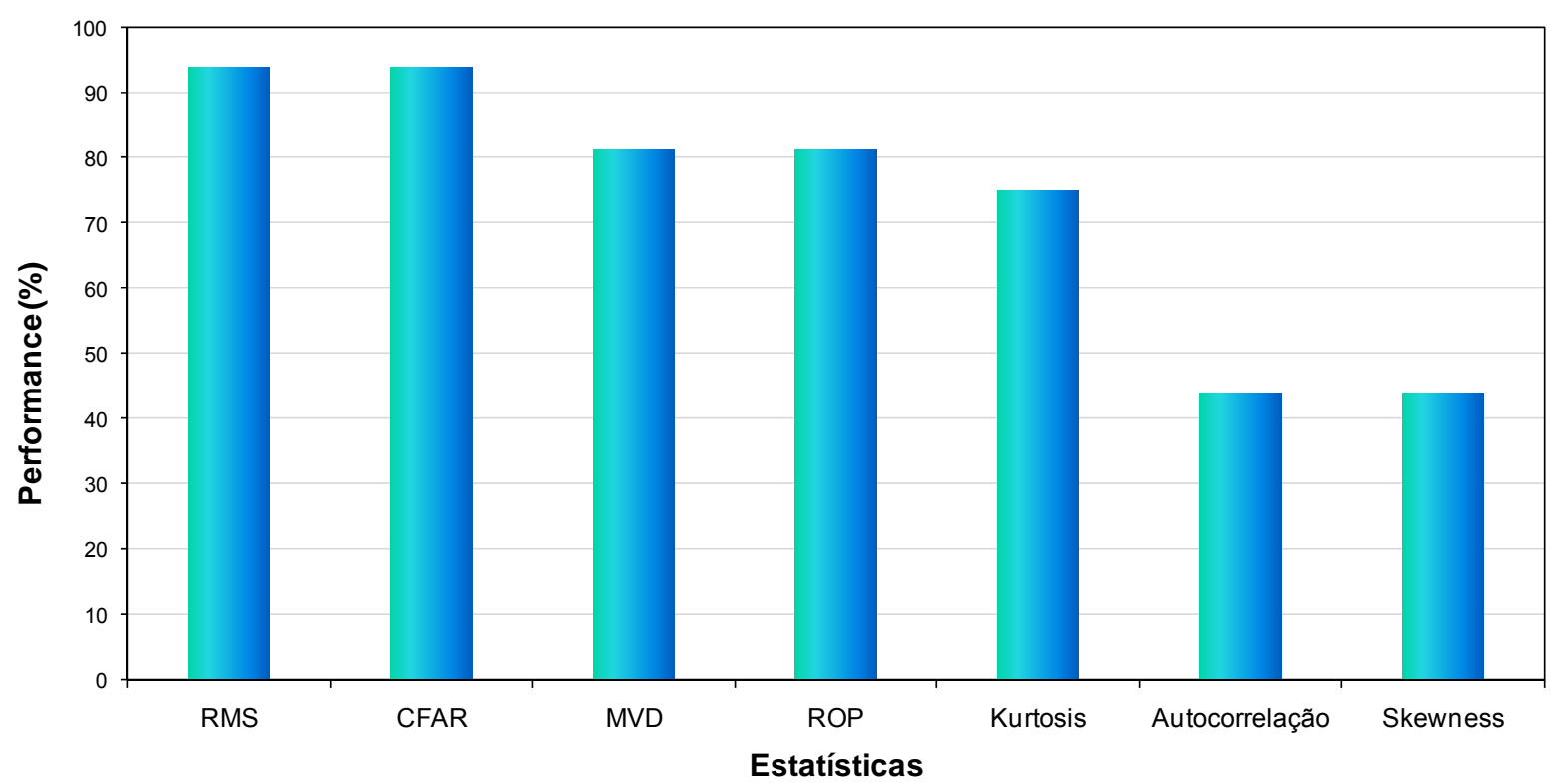

Figura 4.15 - Desempenho das estatísticas na detecção de transitórios de corrente.

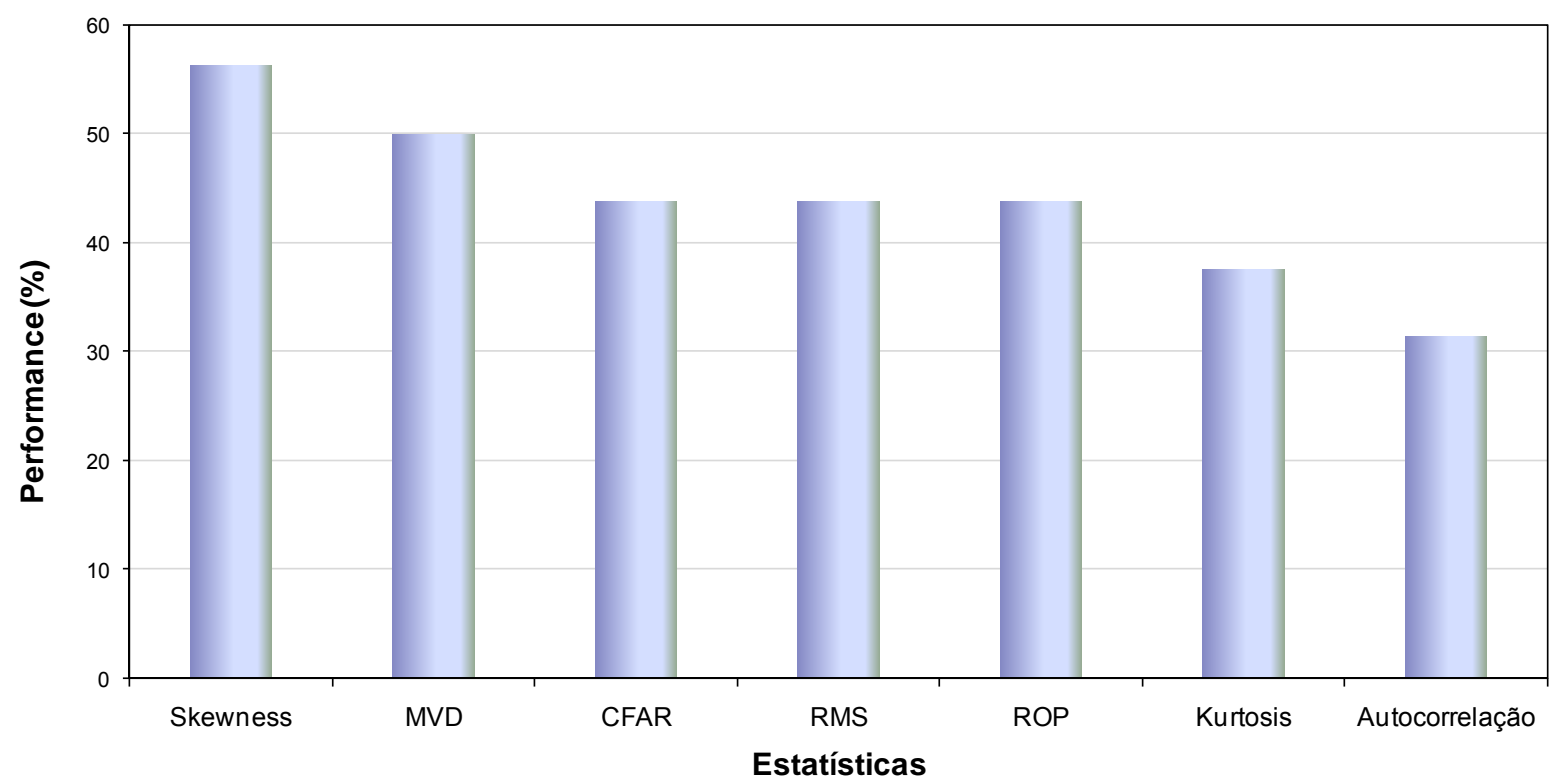

Figura 4.16 - Desempenho das estatísticas na detecção de transitórios de tensão. 
Apesar de algumas estatísticas apresentarem resultados inferiores a $50 \%$ na detecção, especialmente quando se analisa os transitórios de tensão, todas foram selecionadas para compor o sistema de identificação de transitório, pois tiveram ao menos uma detecção de caso bem sucedida, dentre os 16 avaliados, que representaram 16 situações distintas de falta. Fica evidente o caso, por exemplo, entre RMS e Skewness, onde o primeiro teve uma melhor performance detectando transitórios nos sinais de corrente, ao passo que o segundo se saiu melhor detectando aqueles de tensão.

\subsection{Aspectos metodológicos para identificação de faltas em sistemas de distribuição de energia elétrica}

Conforme se pode observar na Figura 4.17, o sistema de identificação de faltas é composto pelos módulos: Aquisição de dados, Pré-processamento, Identificação de transitório, Discriminador de faltas, Identificador de fase e Localizador de faltas.

O módulo "Aquisição de dados" tem por funcionalidade a adequação dos níveis de tensão e de corrente do sistema de distribuição de energia elétrica de maneira que os mesmos possam ser digitalizados e aquisitados.

Esses dados digitalizados são, por sua vez, processados e seus principais parâmetros são determinados por meio do módulo "Pré-processamento". Fazendose uso desses parâmetros, o módulo "Identificação de transitório" detecta quando um distúrbio se inicia.

Mediante uma identificação positiva de um transitório, em virtude de sua característica, o módulo "Discriminador de faltas" classifica o mesmo como sendo 
advindo de alterações de carga no sistema de distribuição ou proveniente de uma condição de falta.

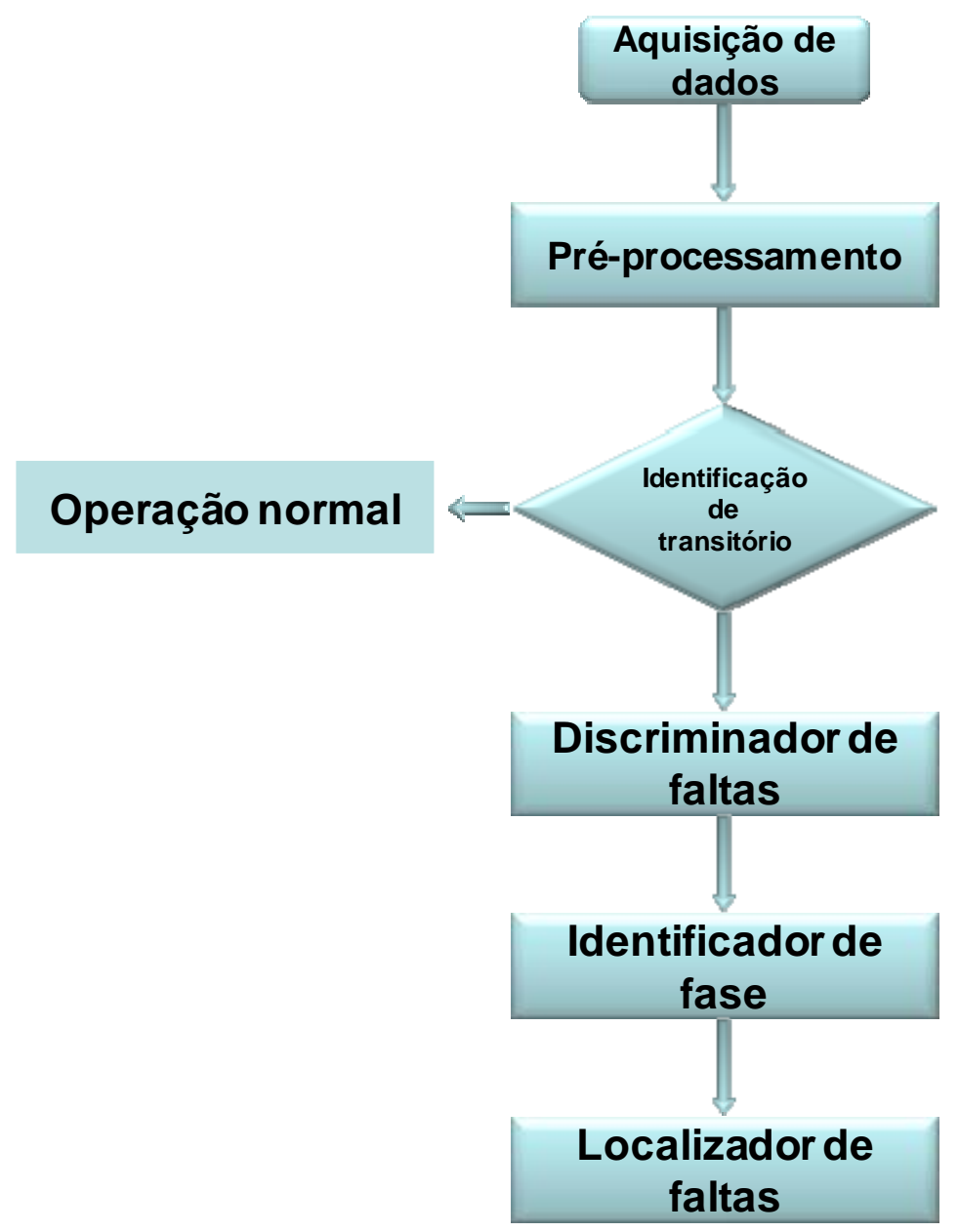

Figura 4.17 - Representação esquemática do sistema de identificação de faltas.

A identificação de uma condição de falta, por sua vez, desencadeia a operação do sistema "Identificador de fase" participante da falta. Por fim, tem-se o módulo "Localizador de faltas", responsável por fornecer a resposta mais provável do local da falta. 


\subsection{Sistema de aquisição de dados}

O sistema de identificação de faltas opera fazendo-se uso dos dados aquisitados do sistema de energia elétrica. Em princípio, esses dados são constituídos pelas três tensões de fase e pelas três correntes de linha. Considerando-se que o emprego de transformadores de corrente não é comum na medição da corrente de terra, essa grandeza é calculada tendo como resultado a corrente residual dos transformadores de corrente de fase, ou seja, o conjunto de dados aquisitados é composto por um total de seis entradas.

As leituras das variáveis elétricas são realizadas por meio de um oscilógrafo (Yokogawa, modelo 708G) que monitora as tensões (conexão direta ao barramento) e correntes (garras de corrente) do alimentador piloto, como pode ser observado nas Figura 4.18 e Figura 4.19.

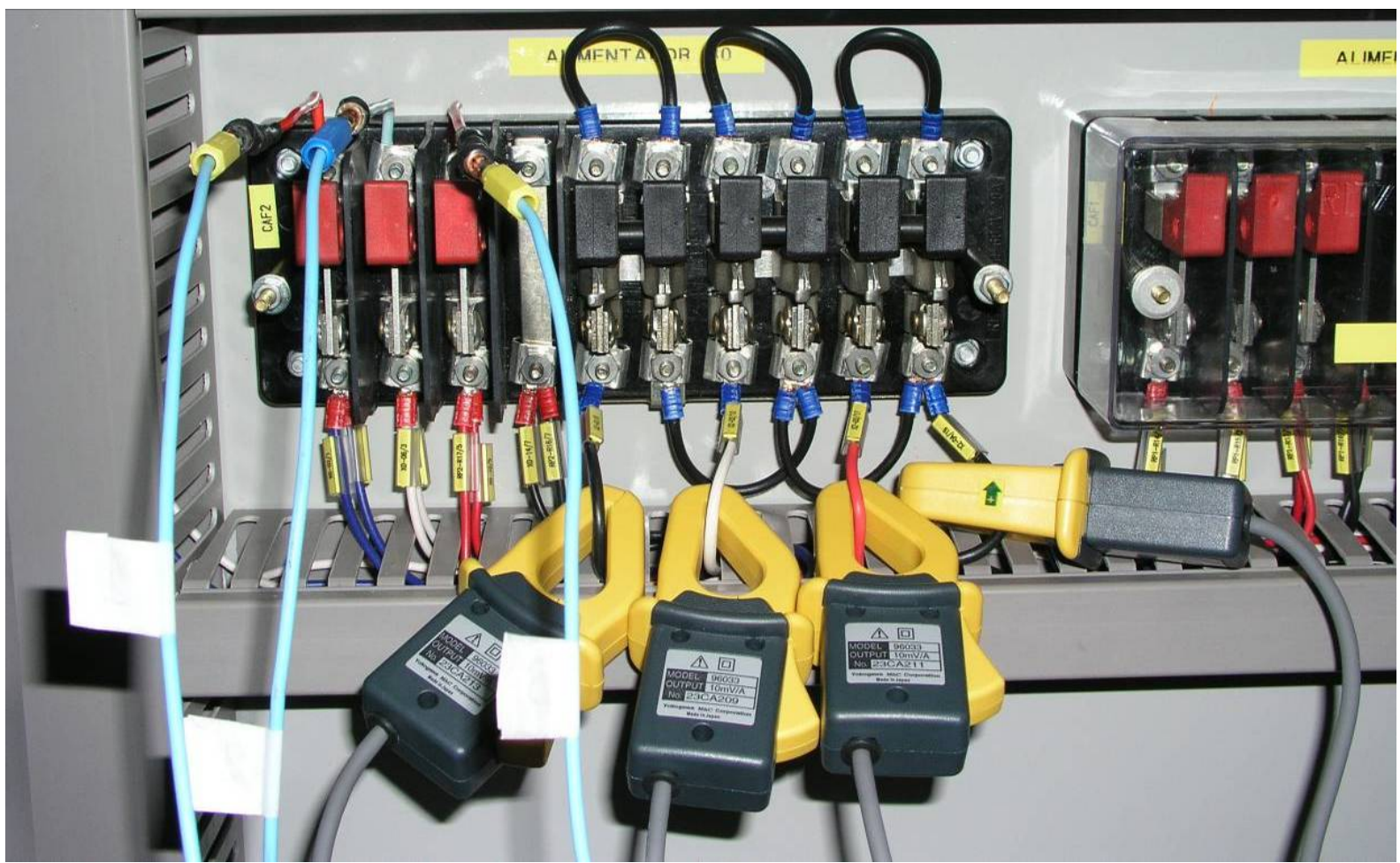

Figura 4.18 - Conexões de tensão e corrente para medição com oscilógrafo. 


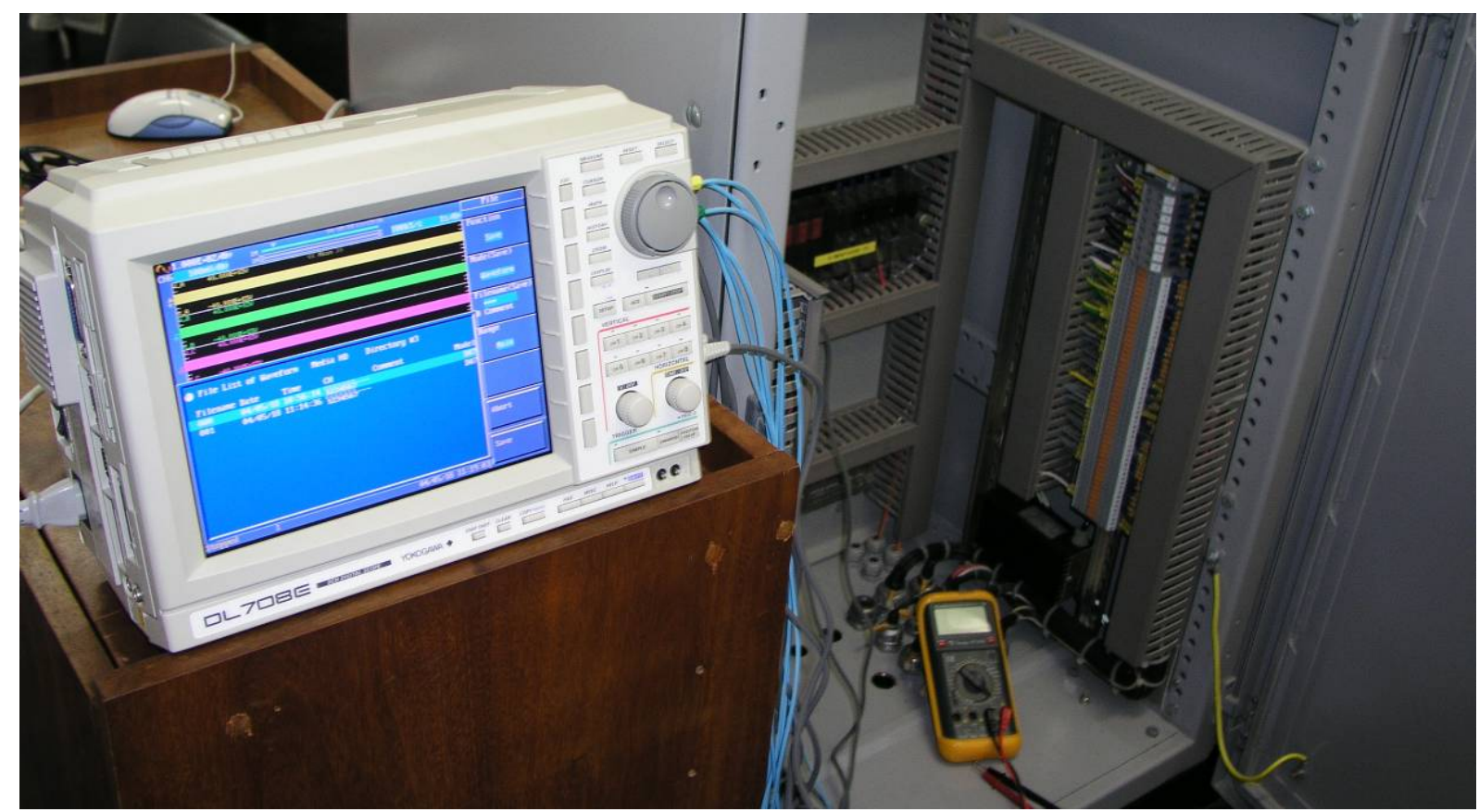

Figura 4.19 - Oscilógrafo utilizado na leitura das variáveis elétricas.

O oscilógrafo empregado possui uma grande capacidade de armazenamento e de velocidade de aquisição, podendo ser utilizados os 6 canais de forma simultânea e sem comprometimento de performance. As garras de corrente possuem uma resolução de $1 \mathrm{mV} / \mathrm{A}$.

\subsection{Módulos de tratamentos de faltas}

\subsubsection{Identificação de transitórios}

A identificação de transitórios permite constatar a existência de transitórios de corrente e tensão em sistemas de distribuição independente de sua origem. Essa identificação dará seguimento ao processo de identificação e classificação de faltas. Dessa forma, a identificação foi realizada de acordo com o diagrama de blocos apresentado na Figura 4.20. 


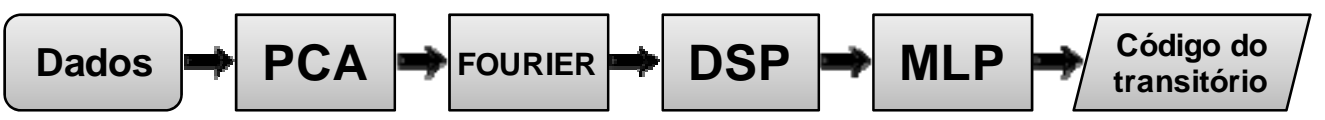

Figura 4.20 - Diagrama do módulo de identificação de transitórios.

Os sinais armazenados, representados por "Dados", são processados pela $P C A$, sendo assim realizada uma diminuição no espaço de variáveis, as quais serão apresentadas à uma análise de Fourier (representada por FOURIER) responsável por levantar o conteúdo harmônico dos sinais. Em seguida, as ferramentas de processamento digital de sinais, representadas por "DSP" são aplicadas e os resultados apresentados às redes neurais especializadas na identificação dos transitórios eletromagnéticos, representadas por "MLP”. A saída deste módulo é o código do transitório, que assume valor “-1" para condições normais de operação e "1" para transitórios.

\subsubsection{Discriminador de faltas}

Este bloco tem a função de identificar se o transitório é decorrente de uma falta ou de uma condição específica de operação do sistema, tais como, por exemplo, transitórios de energização de transformadores (inrush), transitórios de partida de motores, transitórios de rejeição de carga, dentre outros. A descriminação entre os transitórios foi realizada de acordo com o diagrama de blocos apresentado na Figura 4.21.

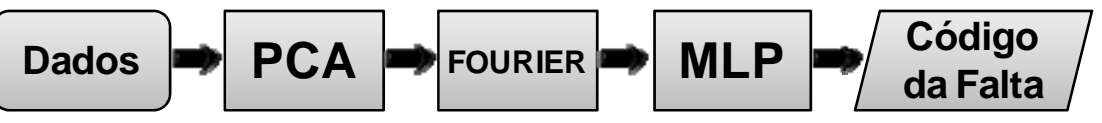

Figura 4.21 - Diagrama do módulo Discriminador de faltas. 
As três primeiras etapas são semelhantes ao módulo de Identificação de transitórios. A seguir, as informações são repassadas a uma rede MLP, responsável por fornecer o código da falta.

\subsubsection{Identificador de fase}

Este bloco tem a função de identificar a fase ou fases envolvidas na falta, bem como o plano de terra. Nesse caso, a identificação foi realizada por meio de uma rede neural perceptron multicamadas, representada por "MLP". A identificação de fase foi realizada de acordo com o diagrama de blocos apresentado na Figura 4.22 .

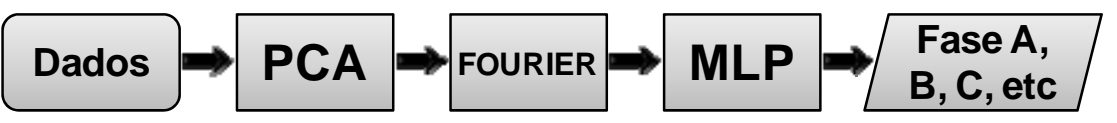

Figura 4.22 - Diagrama do módulo identificador de fase.

\subsection{Resultados de Simulações computacionais no alimentador piloto}

De forma a ilustrar a disposição geográfica do alimentador piloto estudado, apresenta-se na Figura 4.23 o mapa dos trechos primários desse alimentador. Em complemento, na Figura 4.24, apresenta-se a modelagem desse alimentador realizada por meio do toolbox SimPowerSystems do Matlab. Tal alimentador é denominado Rio Claro 30, localizado na subestação Rio Claro 3, na cidade de Rio Claro, estado de São Paulo. 


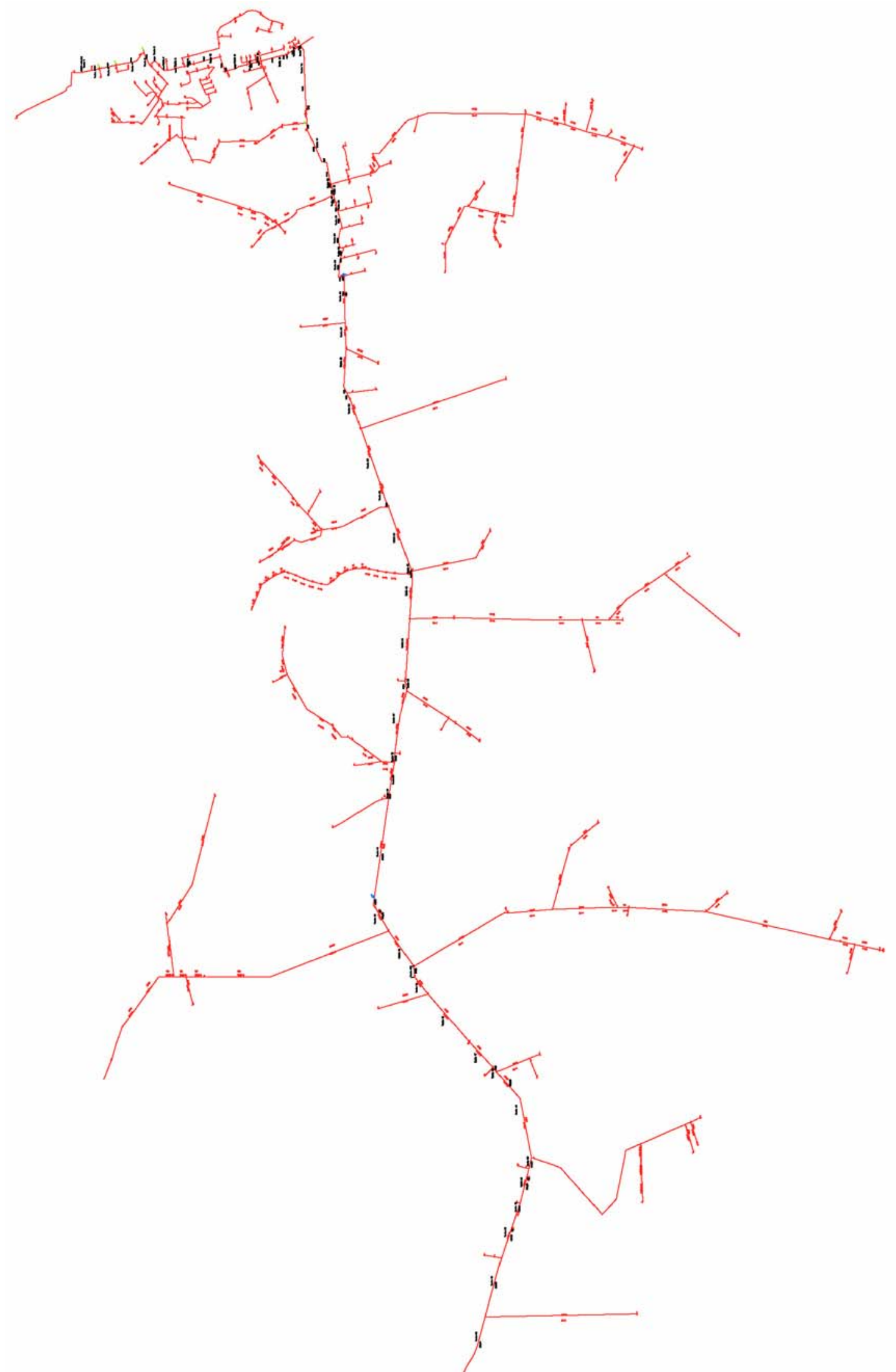

Figura 4.23 - Mapa dos trechos primários do alimentador piloto modelado. 


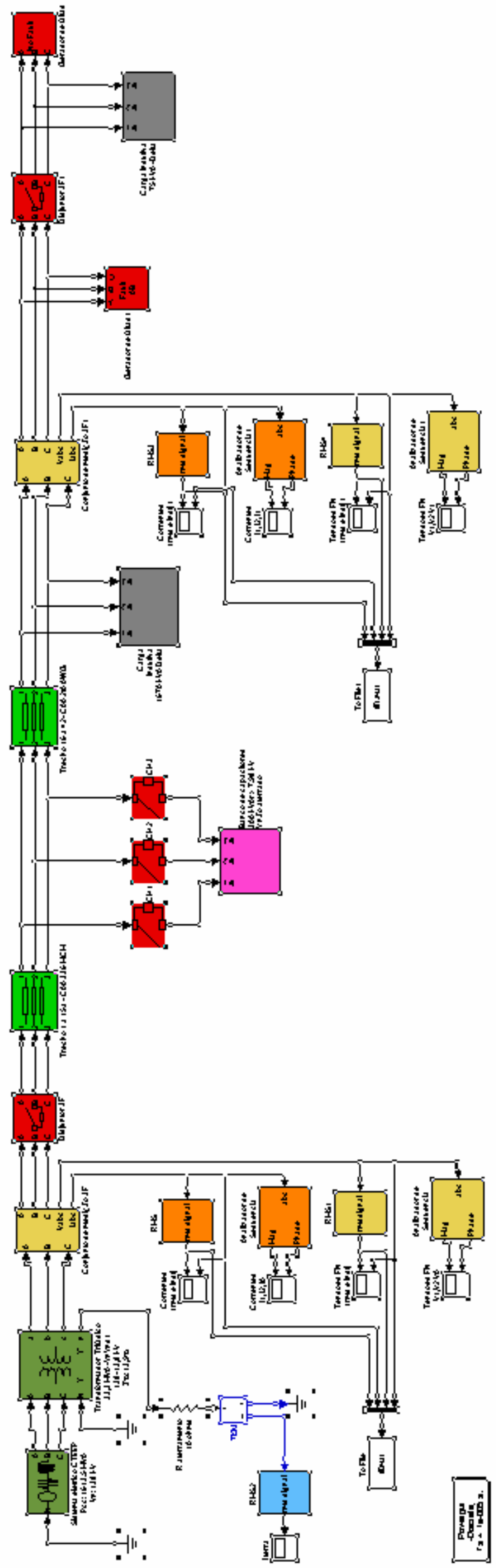

Figura 4.24 - Diagrama de blocos da modelagem no Matlab/Simulink do alimentador piloto. 


\subsubsection{Simulações de faltas fase-terra de alta impedância}

Foram simuladas um total de 100 condições de faltas do tipo fase-terra de alta impedância. Nessas simulações, a resistência de falta foi confinada de forma a possuir um mínimo de $100 \Omega$ e um máximo de $10 \mathrm{k} \Omega$. Em cada simulação realizada, o ponto de sua incidência foi alterado, de maneira que se permitisse a análise do comportamento das tensões e das correntes na subestação sob essas diferentes condições de falta. A fim de ilustrar os resultados obtidos por meio das simulações computacionais, apresenta-se, por meio da Figura 4.25, o destaque para as tensões e para as correntes no instante de início de uma falta fase-terra, com resistência de falta de $9877 \Omega$ incidente na fase $B$.
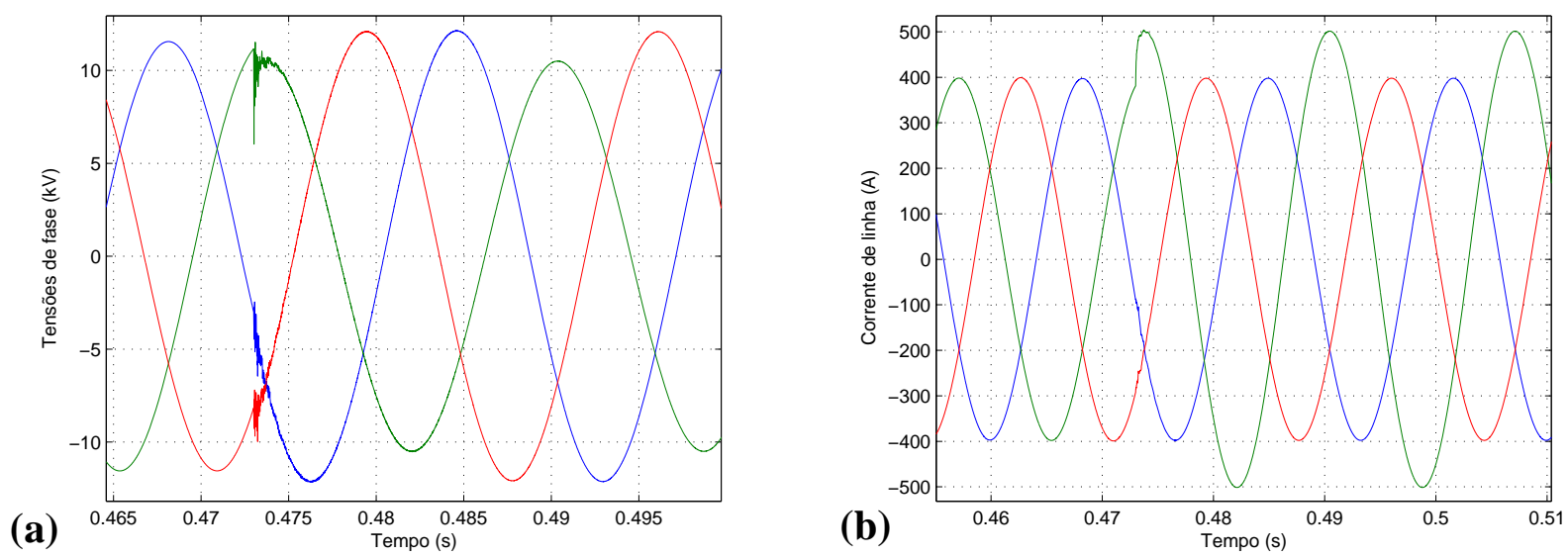

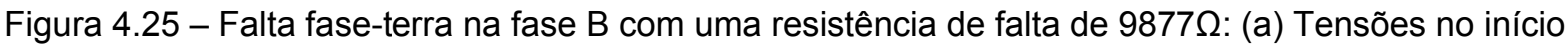
da falta; (b) Correntes no início da falta.

Uma análise preliminar das formas de onda de tensão e de corrente apresentadas por meio da Figura 4.25 permite verificar que as correntes das fases não participantes da falta sofrem pouca influência durante a falta. Por outro lado, as formas de onda de tensão são sensivelmente afetadas por componentes de alta freqüência no início da falta. Pode-se verificar, assim, que as formas de onda de tensão e corrente são afetadas de maneira diferente quando da incidência de uma 
falta fase-terra. Na Figura 4.26, apresenta-se os gráficos de tensão e de corrente para uma falta fase-terra com resistência de terra de $2714 \Omega$ incidente na fase $C$.

(a)

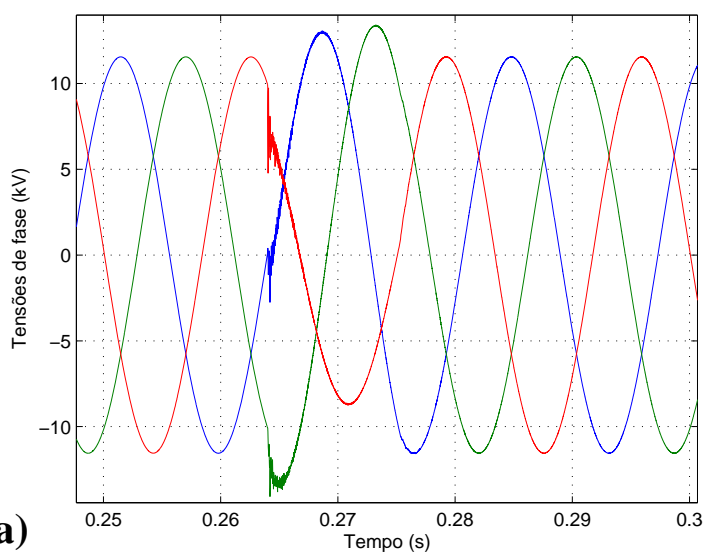

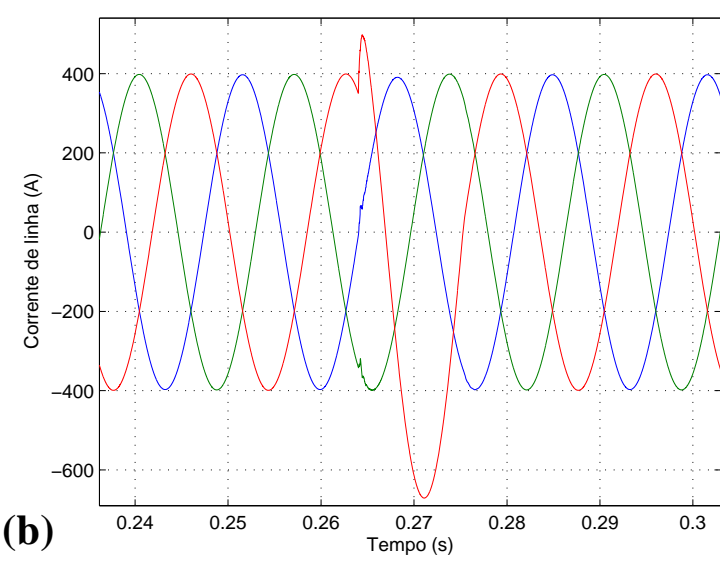

(b)

Figura 4.26 - Falta fase-terra na fase B com uma resistência de falta de $2714 \Omega$ : (a) Tensões no início da falta; (b) Correntes no início da falta.

A falta ilustrada graficamente por meio das formas de onda de tensão e de corrente na Figura 4.26 iniciou-se no instante de tempo de $264 \mathrm{~ms}$ e terminou no instante de tempo de $273 \mathrm{~ms}$, ou seja, uma duração total de $9 \mathrm{~ms}$. Em virtude de sua curta duração, pouco mais de meio ciclo da senóide, sistemas de proteção convencionais não atuam. No entanto, para o desenvolvimento de um sistema de identificação de faltas é interessante que essas ocorrências sejam identificadas e armazenadas a fim de constituir um histórico. A análise desse histórico pode indicar pontos, no sistema de distribuição, onde faltas intermitentes são identificadas e, dessa forma, ações preventivas podem ser adotadas, impedindo-se assim que tais faltas evoluam para condições de inoperância do sistema de distribuição de energia elétrica.

A Figura 4.27 apresenta as tensões e correntes de outra falta nesse mesmo nó; no entanto, com uma resistência de terra de $5149 \Omega$, com uma duração total de 514 ms, a qual é cerca de 31 ciclos de senóide. 
(a)

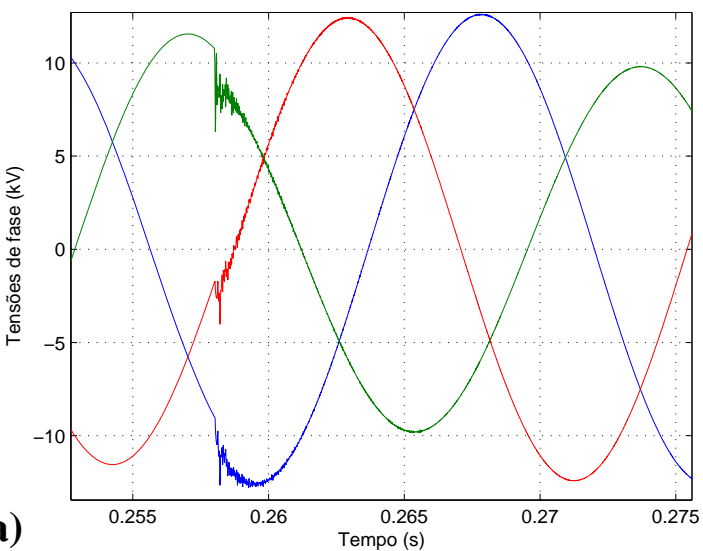

(b)

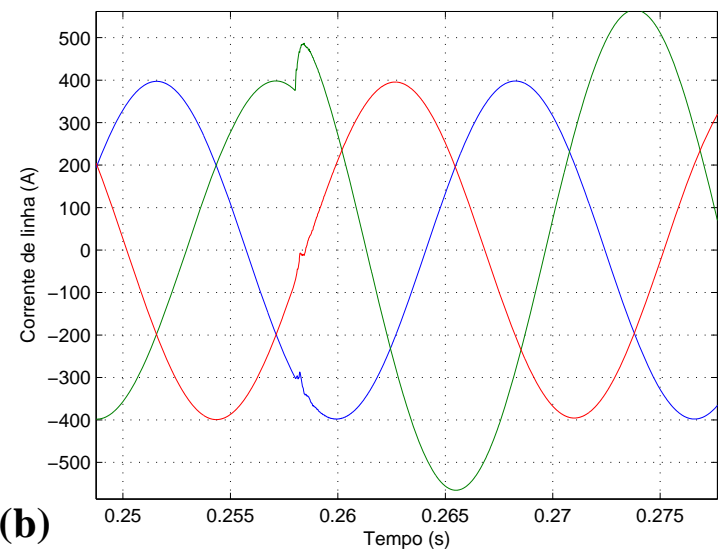

Figura 4.27 - Falta fase-terra na fase C com uma resistência de falta de $5149 \Omega$ : (a) Tensões no início da falta; (b) Correntes no início da falta.

Conforme se pode observar por meio dos gráficos da Figura 4.27, o aumento da resistência de falta faz com que a corrente registrada no início da falta seja inferior àquela observada na falta apresentada anteriormente. No entanto, a presença de componentes de alta freqüência nas tensões ainda se faz presente mesmo quando do aumento da resistência de falta.

A Figura 4.28 apresenta os gráficos de tensão e de corrente para uma falta fase-terra no final do alimentador, com uma resistência de terra de $1170 \Omega$, tendo-se a fase B como sendo a fase participante da falta.

Em virtude da relativa baixa resistência de falta, as correntes observadas na simulação destacada possuem amplitudes máximas superiores às correntes observadas nas simulações anteriormente apresentadas. No entanto, em virtude da distância entre o ponto de incidência da falta e a subestação, o distúrbio transitório nas tensões de fase se apresentaram de forma reduzida, porém, ainda perceptíveis. 
(a)

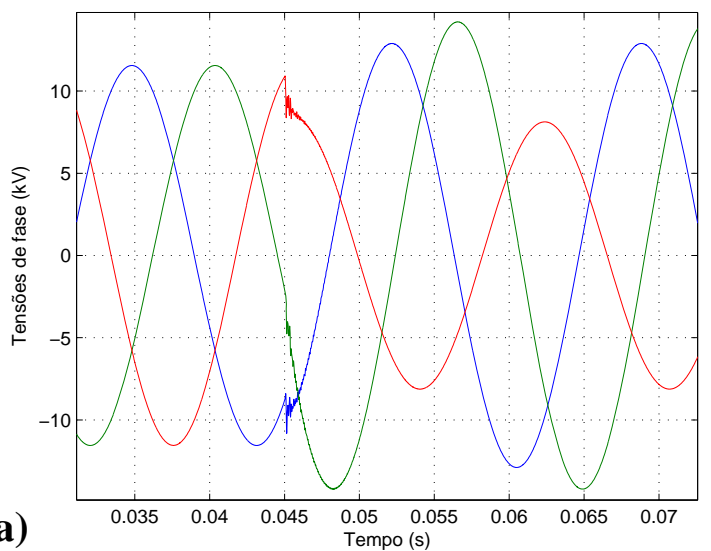

(b)

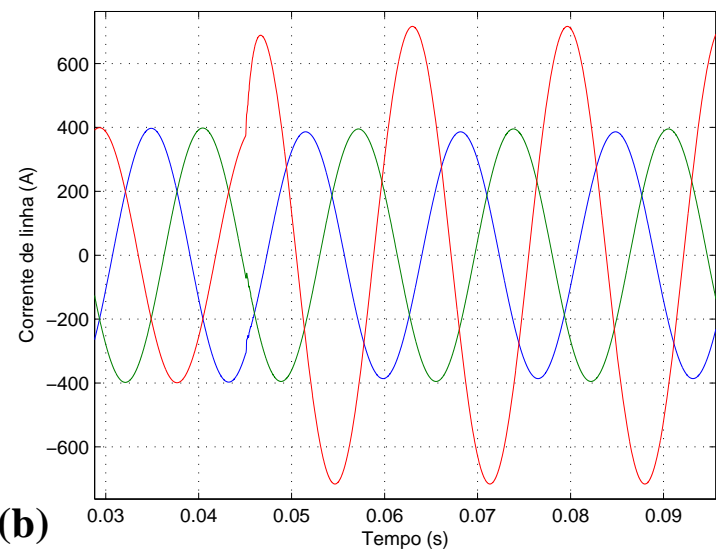

Figura 4.28 - Falta fase-terra na fase C com uma resistência de falta de $1170 \Omega$ : (a) Tensões no início da falta; (b) Correntes no início da falta.

Dessa forma, tem-se que os valores das correntes de linha são indicadores eficientes quanto da ocorrência de uma falta fase-terra, ao passo que os distúrbios transitórios nas tensões são bons indicadores para a estimação da distância de ocorrência da referida falta.

Complementando a apresentação dos resultados de simulação computacional para as faltas fase-terra, tem-se na Figura 4.29 os gráficos de tensão e de corrente para uma falta com resistência de contato ao terra de $8847 \Omega$, tendose a fase A como sendo a fase faltante.

(a)

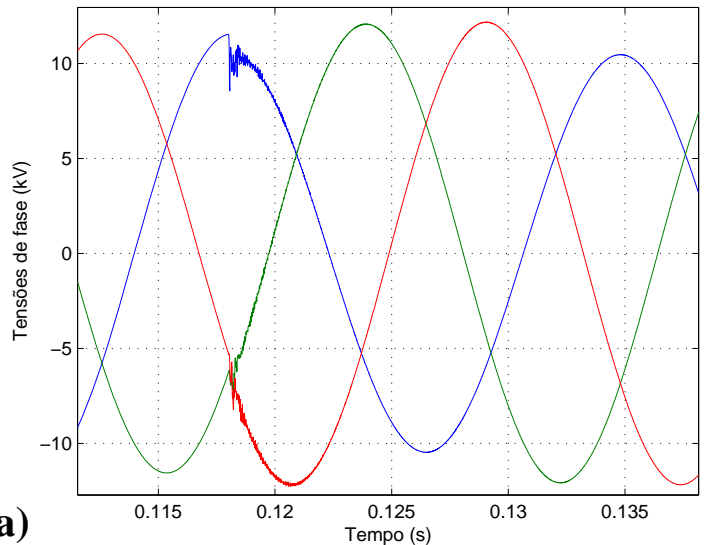

(b)

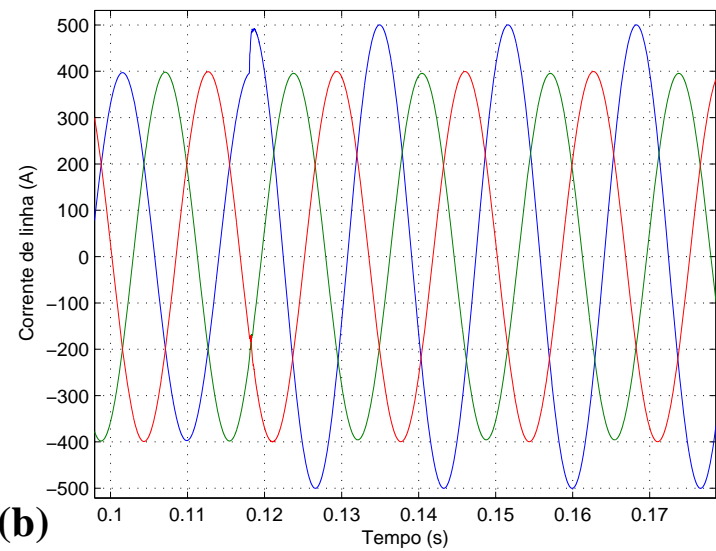

Figura 4.29 - Falta fase-terra na fase A com uma resistência de falta de $8847 \Omega$ : (a) Tensões no início da falta; (b) Correntes no início da falta. 


\subsubsection{Simulações computacionais referentes às faltas fase-fase}

Da mesma forma como realizado para as faltas fase-terra de alta impedância, foram realizadas 100 simulações para faltas fase-fase. Nessas simulações, o valor de $6 \Omega$ foi adotado como padrão para a resistência de contato entre os cabos. Dessa maneira, as variáveis que se alteraram de uma simulação para outra foi o ponto de ocorrência da falta, seu instante inicial e seu instante de extinção.

llustrando o comportamento das tensões e correntes no ponto de incidência da falta, tem-se na Figura 4.30 as formas de onda para tais grandezas quando da ocorrência de uma falta fase-fase próxima à subestação entre a fase $B$ e a fase $C$.
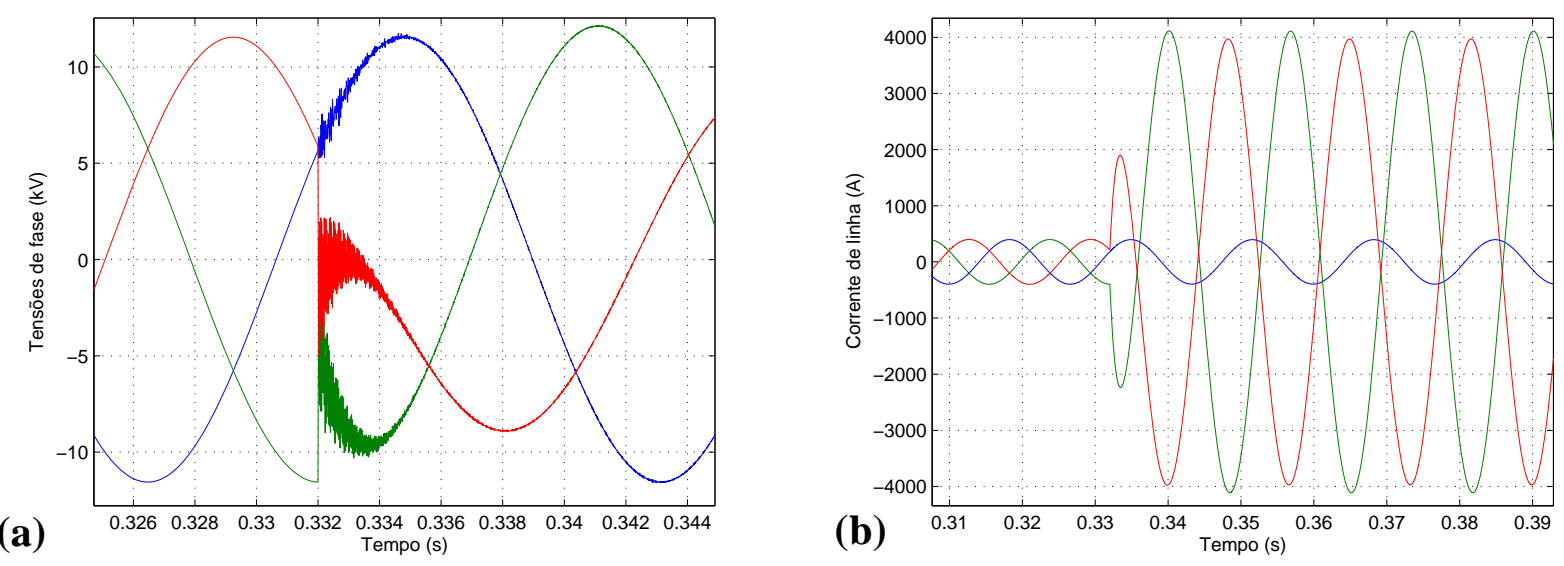

Figura 4.30 - Falta fase-fase entre a fase B e a fase C: (a) Tensões no início da falta; (b) Correntes no início da falta.

Conforme se verifica por meio dos gráficos da Figura 4.30, o distúrbio em freqüência observado nas formas de onda de tensão é mais expressivo do que aqueles verificados nas faltas fase-terra. Esse distúrbio é observado tanto nas tensões das fases participantes da falta, como na tensão da fase sã. Segundo estudos em literatura correlata, a magnitude das distorções nesse tipo de falta é 
decorrente, em parte, das grandes correntes registradas. Outro aspecto a ser verificado está correlacionado ao comportamento das correntes quando da perduração da falta. Mesmo sob influência da corrente de carga, a defasagem angular entre as correntes das fases faltosas fica próxima dos $180^{\circ}$. Além disso, em virtude das baixas resistências de contato verificadas nesse tipo de ensaio, as amplitudes das correntes de falta são significativamente superiores àquelas verificadas nas faltas fase-terra.

Na Figura 4.31 apresenta-se o comportamento temporal das tensões e correntes quando da ocorrência de uma falta fase-fase em um trecho próximo ao meio do alimentador modelado.

(a)

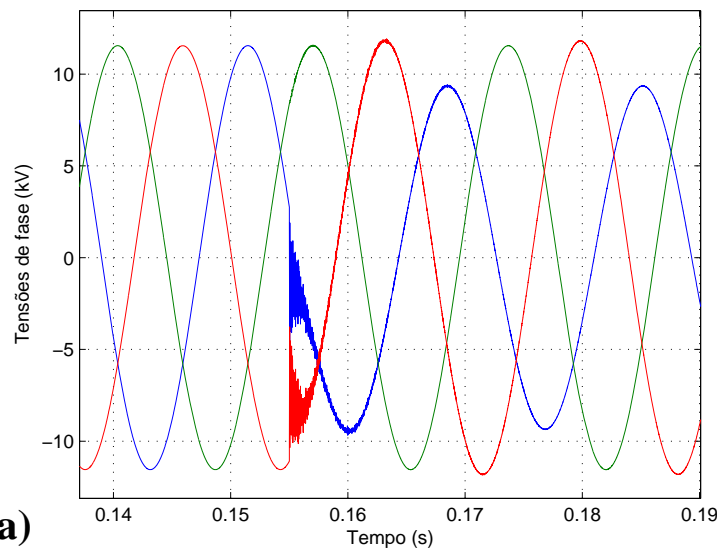

(b)

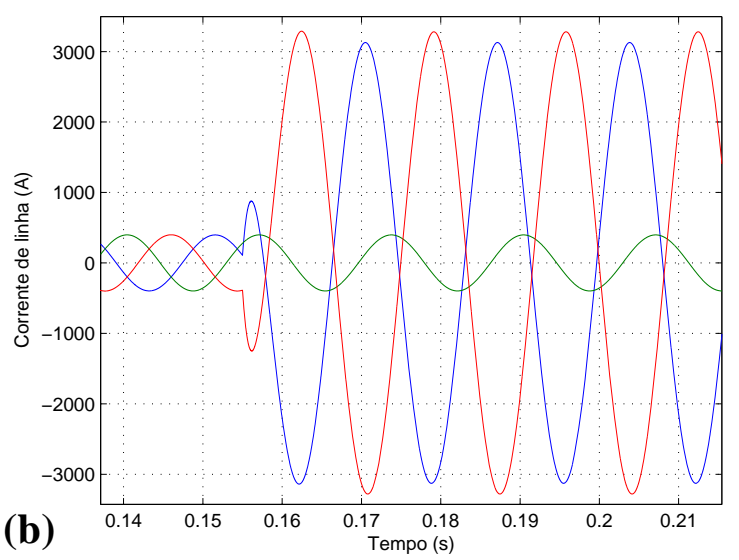

Figura 4.31 - Falta fase-fase entre a fase A e a fase B: (a) Tensões no início da falta; (b) Correntes no início da falta.

A análise visual do comportamento das tensões no instante de início da falta, ilustrada graficamente na Figura 4.31, permite verificar que os distúrbios apresentados são inferiores àqueles apresentados nos gráficos de tensão da Figura 4.30. Da mesma maneira, verifica-se que a amplitude das correntes observadas é sensivelmente inferior ao caso inicialmente apresentado nessa subseção. Assim, em virtude da maior impedância entre a subestação e o ponto de incidência de falta, tem-se tanto a atenuação dos distúrbios na tensão como a atenuação da máxima 
corrente de falta fase-fase possível de ser observada. No entanto, esses fatores atenuantes não se apresentam de forma efetiva quando da defasagem angular entre as correntes de falta, a qual permanece próxima a $180^{\circ}$. Além disso, não se observa variações expressivas na corrente da fase sã durante a falta.

Considerando-se os distúrbios de tensão e de corrente apresentados quando da incidência de faltas, torna-se pertinente uma análise dos distúrbios verificados quando da extinção da falta. Dessa forma, apresenta-se por meio da Figura 4.32 o comportamento das tensões de fase e das correntes de linha quando da extinção de uma falta fase-fase entre as fases B e C.
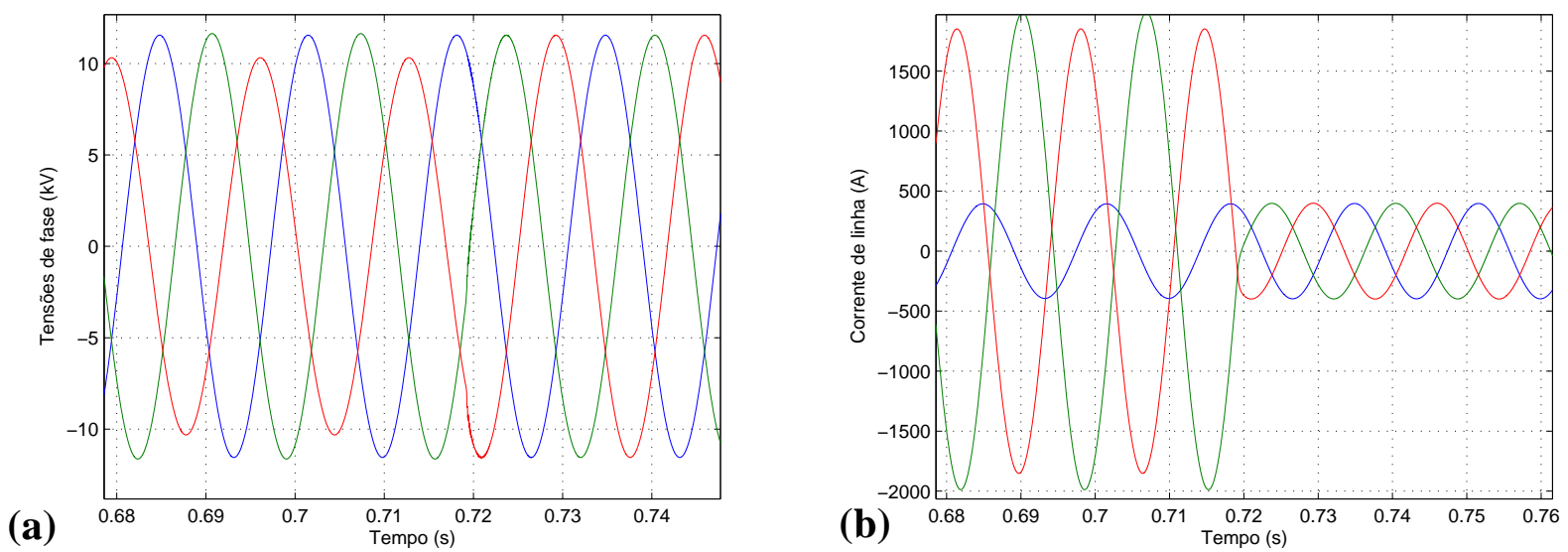

Figura 4.32 - Falta fase-fase entre a fase B e a fase C: (a) Tensões no término da falta; (b) Correntes no término da falta.

A falta apresentada na Figura 4.32 foi extinta no instante de tempo de 718 ms. Conforme se verifica nesses gráficos, a extinção de falta fase-fase não é acompanhada por distúrbios de alta freqüência. Contudo, os valores de tensão e de corrente retornam aos seus valores nominais verificados antes da incidência da falta.

As faltas fase-fase são influenciadas de maneira significativa pela distância entre a subestação e seus pontos de ocorrências. Ilustrando essa característica das faltas fase-fase, apresenta-se por meio da Figura 4.33 o comportamento temporal 
das tensões e das correntes para esse tipo de falta próximo ao término do alimentador.

(a)

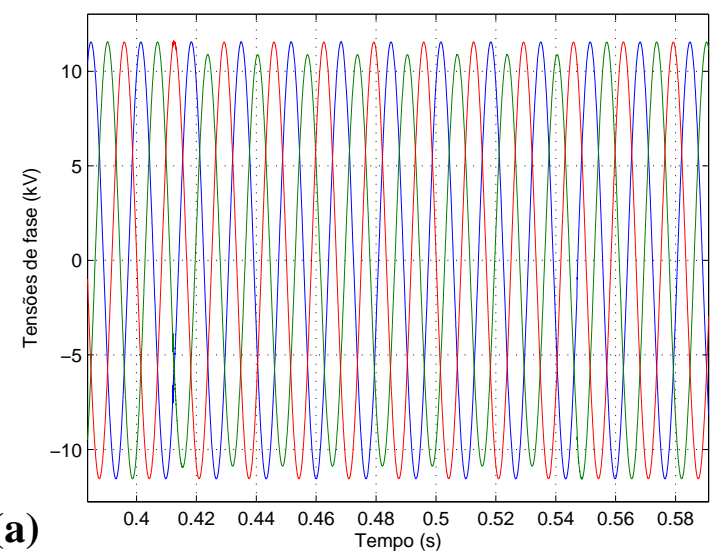

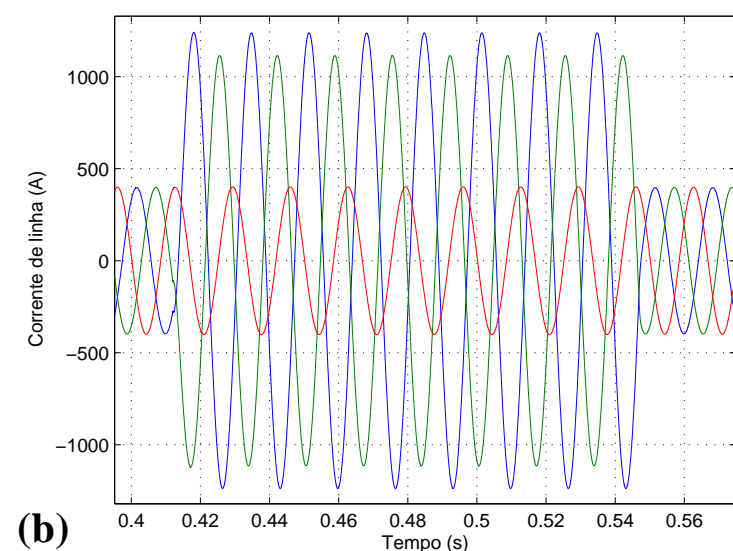

(b)

Figura 4.33 - Falta fase-fase entre a fase A e a fase C: (a) Tensões no início da falta; (b) Correntes no início da falta.

A corrente de falta observada na situação ilustrada graficamente na Figura 4.33 possui uma amplitude bem inferior às correntes de falta destacadas nos exemplos anteriores. Esse fato se deve ao aumento da impedância do ponto de falta, o qual ocorre em função da distância entre esse ponto e a subestação. Além da redução da amplitude da corrente, verifica-se uma acentuada redução dos distúrbios de alta freqüência verificados nas formas de onda de tensão. No entanto, a defasagem angular entre as correntes das fases faltosas é notável e permanece próximo de $180^{\circ}$, variando-se de forma mínima em função da distância entre o ponto da falta e a subestação.

Complementando a apresentação das simulações das faltas fase-fase, temse na Figura 4.34 o comportamento das tensões e correntes para uma falta fasefase em um dos ramais do alimentador modelado, o qual está localizado próximo ao meio do alimentador. 

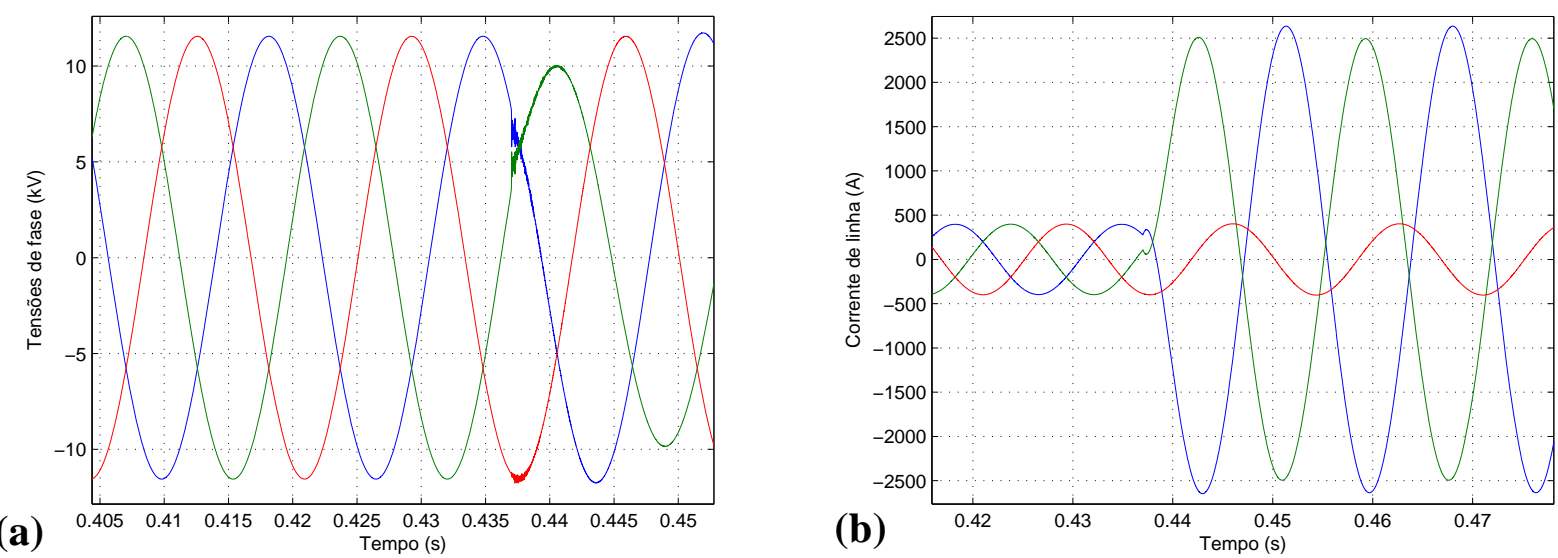

Figura 4.34 - Falta fase-fase entre a fase $\mathrm{A}$ e a fase C: (a) Tensões no início da falta; (b) Correntes no início da falta.

\subsubsection{Simulações computacionais referentes às faltas trifásicas}

A ocorrência de faltas trifásicas em sistemas de distribuição de energia elétrica, percentualmente, representa apenas uma pequena parcela do total de faltas observadas. No entanto, o sistema de identificação de faltas proposto tem como requisito necessário a correta identificação de todos os tipos de faltas, inclusive as faltas trifásicas. Dessa forma, foram realizadas simulações de curtos-circuitos trifásicos nos diversos trechos do alimentador padrão modelado computacionalmente. Nessa subseção, serão apresentados alguns dos resultados obtidos por meio dessas simulações, bem como serão tecidos comentários sobre suas características. Assim, por meio da Figura 4.35, apresenta-se os valores temporais das tensões de fase e das correntes de linha para uma falta trifásica incidente próxima à subestação. 
(a)

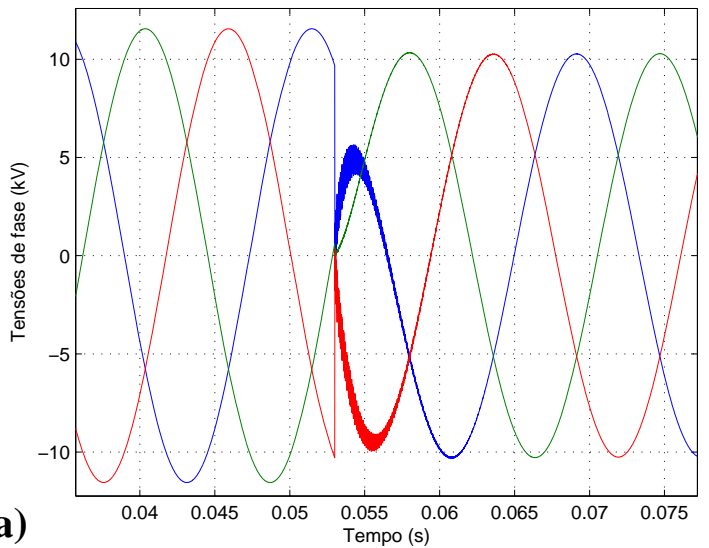

Figura 4.35 - Falta trifásica próxima à subestação: (a) Tensões no início da falta; (b) Correntes no início da falta.

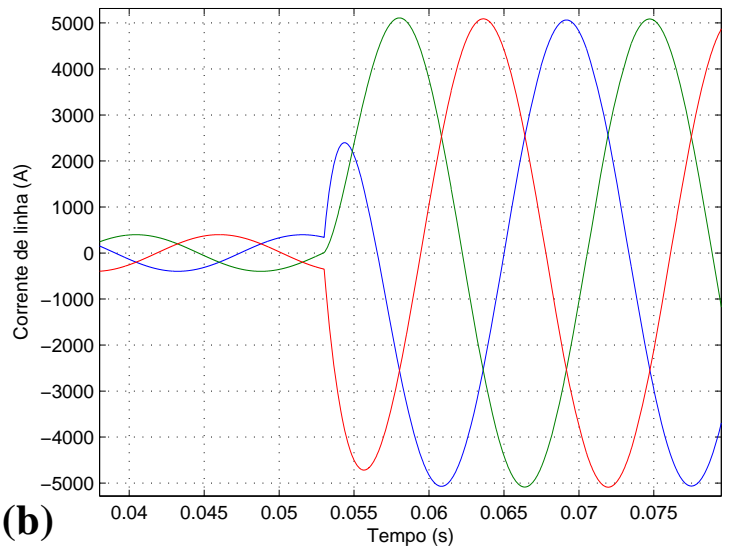

(b)

Os valores máximos de corrente, observados por meio dos gráficos da Figura 4.35, possuem magnitudes apreciáveis e superiores aos verificados nas faltas fase-fase no mesmo trecho do alimentador. Além disso, as defasagens angulares entre as correntes de falta não se alteram de forma significativa como observado nas faltas fase-fase, sendo que no caso das faltas trifásicas a defasagem angular entre as correntes permanece em $120^{\circ}$. Distúrbios oriundos de freqüências elevadas são também verificados nas tensões quando do início da falta, os quais se atenuam conforme a falta estabelece seu regime permanente.

Os valores das correntes de falta, nesse caso, também sofrem influência da distância entre o ponto de incidência da falta e a subestação. Esse fato pode ser comprovado observando-se as correntes de falta apresentadas por meio da Figura 4.36, as quais são referentes a uma falta trifásica simulada próxima ao meio do alimentador. 
(a)

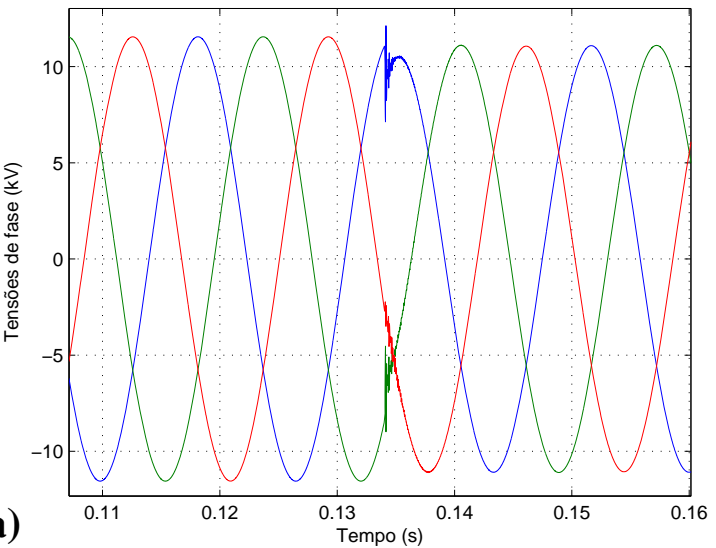

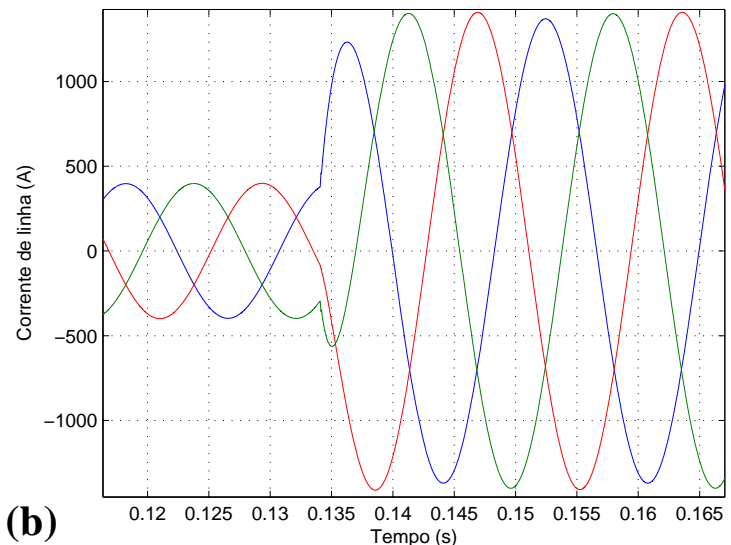

(b)

Figura 4.36 - Falta trifásica próxima ao meio do alimentador: (a) Tensões no início da falta; (b) Correntes no início da falta.

Conforme se pode verificar por meio dos gráficos apresentados na Figura 4.36, à medida que o ponto de falta se distância da subestação, os valores máximos da corrente de falta decaem de forma significativa. No entanto, os distúrbios de tensão ainda são observáveis, assim como o são para faltas próximas à subestação. O efeito do decaimento das correntes de falta para os curtos-circuitos trifásicos é acentuado conforme a distância entre o ponto de incidência da falta e à subestação aumenta. Como exemplo desse fenômeno, apresenta-se, por meio da Figura 4.37, os comportamentos instantâneos das tensões e correntes verificados na subestação quando da ocorrência de faltas trifásicas próximas ao término do alimentador.
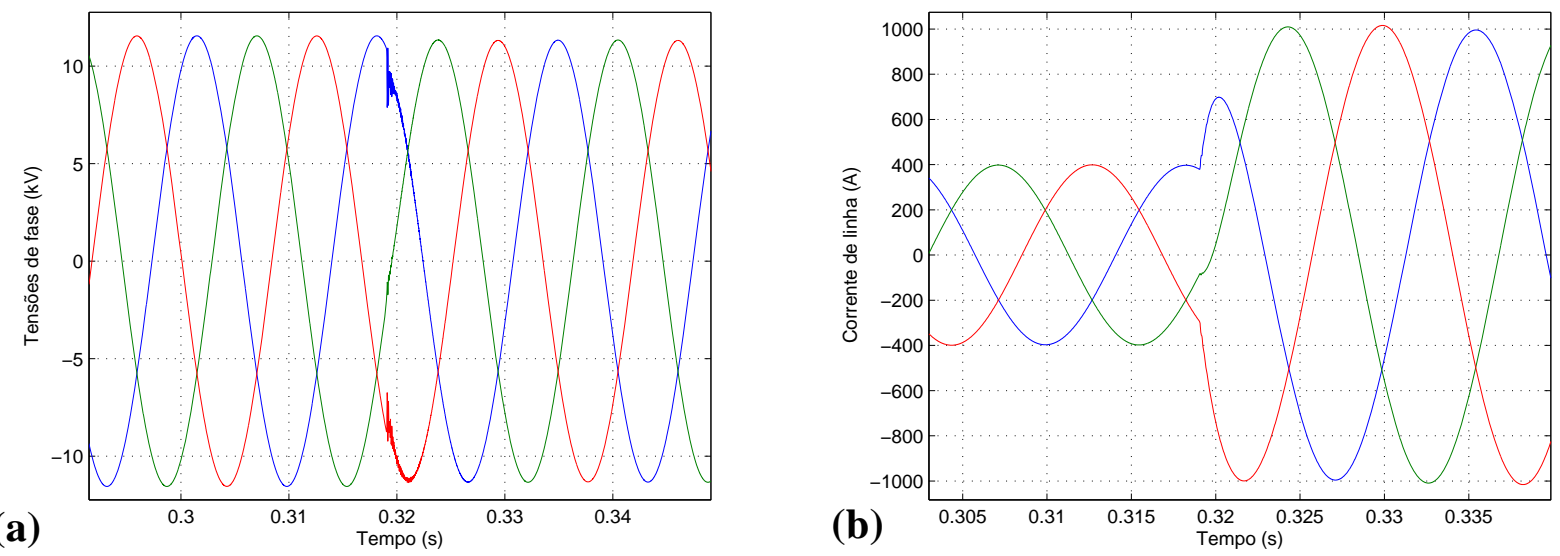

Figura 4.37 - Falta trifásica próxima ao término do alimentador: (a) Tensões no início da falta; (b) Correntes no início da falta. 
Assim como nas faltas fase-fase, distúrbios de alta freqüência não são observados no instante de extinção da falta. llustrando esse fato, apresenta-se por meio da Figura 4.38 o gráfico das tensões e das correntes no instante da extinção de uma falta trifásica próximo ao centro do alimentador.
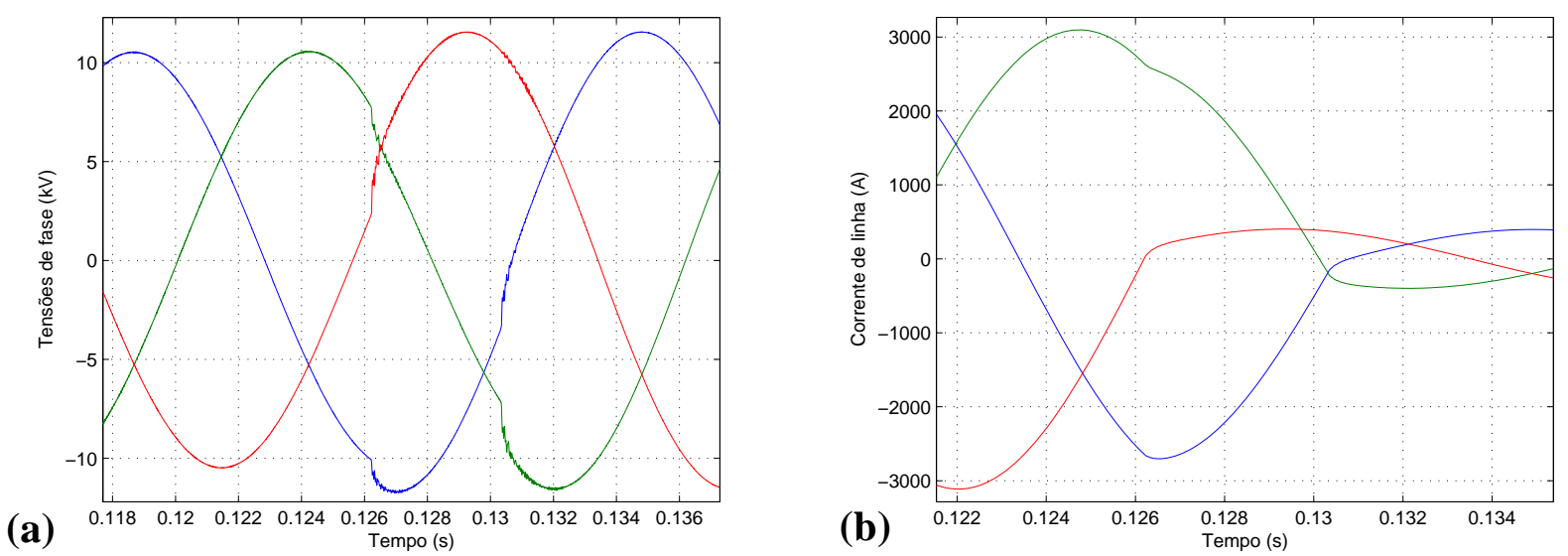

Figura 4.38 - Falta trifásica próxima ao centro do alimentador: (a) Tensões no término da falta; (b) Correntes no término da falta.

No entanto, apesar dos distúrbios observados ao término da falta serem pequenos, a aplicação de ferramentas dedicadas ao processamento digital de sinais pode contribuir às análises necessárias. Complementando a apresentação dos resultados computacionais obtidos por meio de simulações, apresentam-se na Figura 4.39 as formas de onda de tensão e de corrente para uma falta trifásica de pequena duração.

(a)

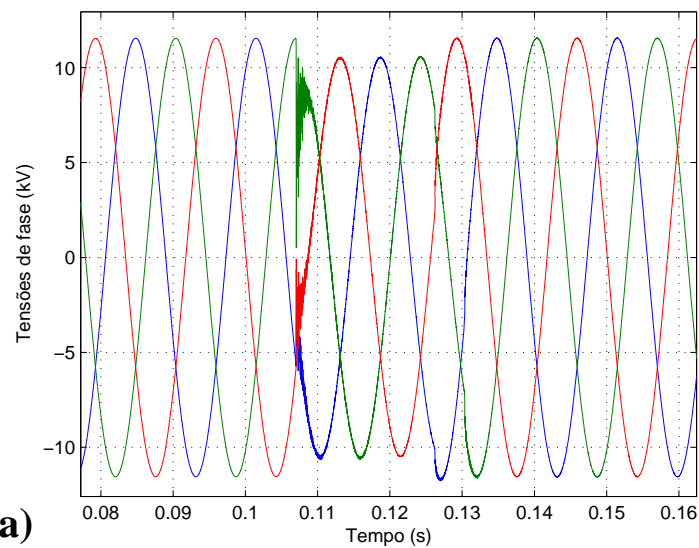

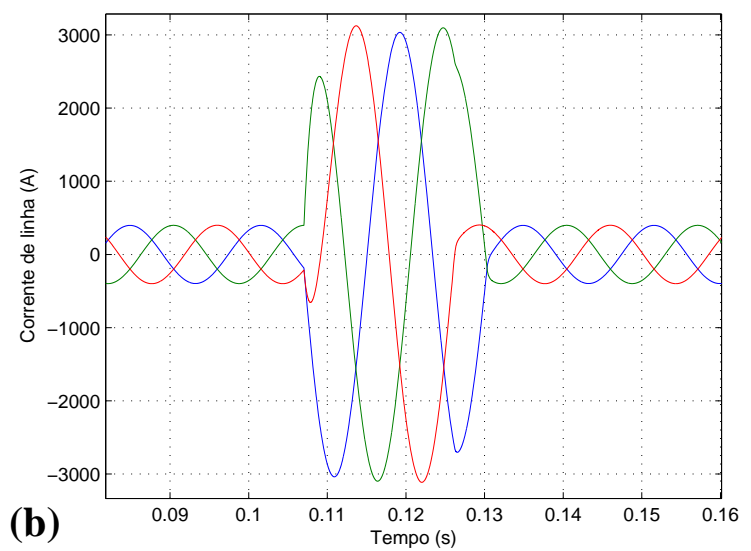

(b)

Figura 4.39 - Falta trifásica de curta duração: (a) Tensões no término da falta; (b) Correntes no término da falta. 


\subsubsection{Simulações computacionais referentes às faltas fase-fase com participação do terra}

As faltas fase-fase com participação do terra possuem um comportamento distinto daquele observado nas faltas fase-fase. A diferença comportamental surge devido à existência de uma resistência entre as fases e, também, entre as fases e o terra. Dessa forma, 100 simulações computacionais foram realizadas de maneira a refletir como a variação desses parâmetros e a posição de incidência da falta influencia no comportamento das tensões e das correntes na subestação, quando da ocorrência de faltas fase-fase com participação do terra.

$\mathrm{Na}$ Figura 4.40, apresenta-se as tensões de fase e as correntes de linha no início de uma falta fase-fase ao terra incidente próxima à subestação.

(a)

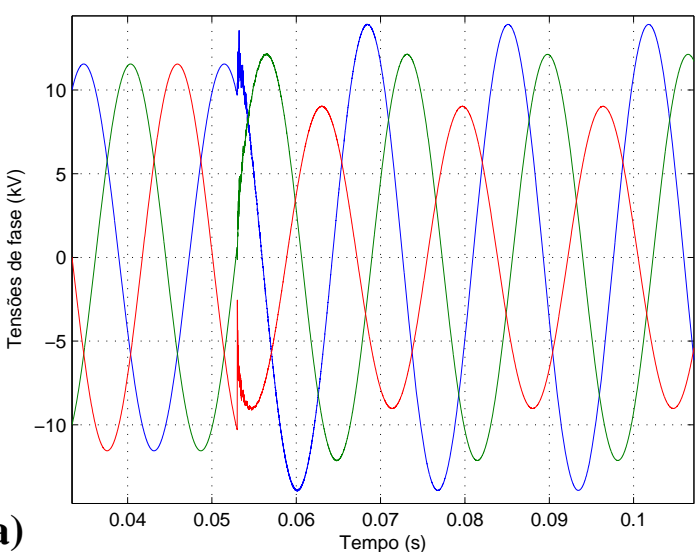

(b)

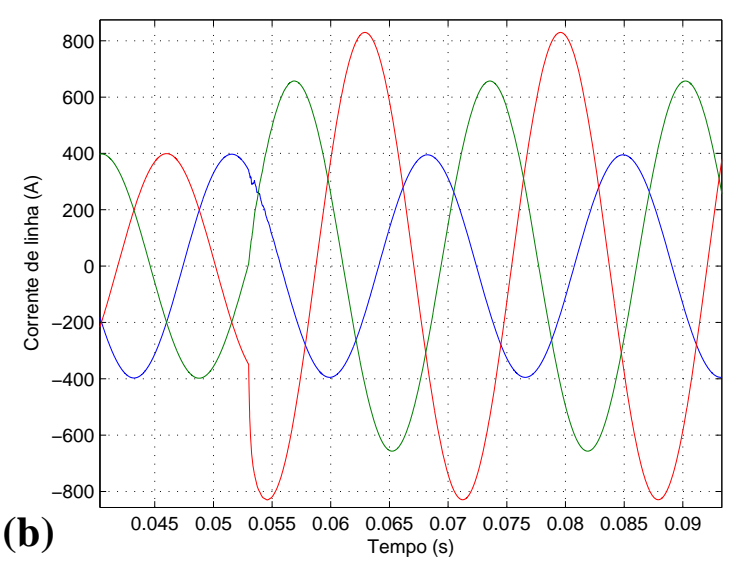

Figura 4.40 - Falta fase-fase ao terra próximo à subestação entre as fases B e C: (a) Tensões no início da falta; (b) Correntes no início da falta.

Conforme se pode verificar por meio dos gráficos apresentados na Figura 4.40 , as correntes das fases faltosas não se defasam de $180^{\circ}$ como observado nas faltas fase-fase. Isso se deve ao fato de que as resistências de falta para cada fase não são iguais e, portanto, o equilíbrio das correntes no instante de falta ocorre de 
outra forma. Contudo, os distúrbios nas tensões de fase no início da falta ainda se fazem presentes e se comportam de maneira distinta aos distúrbios verificados nas faltas fase-fase.

Além disso, o efeito da distância do ponto de incidência da falta à subestação se mostra presente nas tensões e correntes, conforme se verifica por meio dos gráficos de tensão e corrente, apresentados por intermédio da Figura 4.41, relativos a uma falta fase-fase ao terra próxima ao centro do alimentador.

(a)

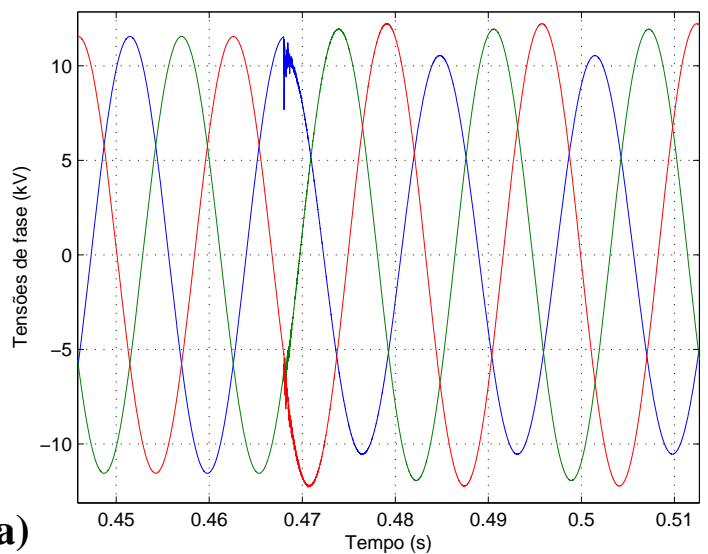

(b)

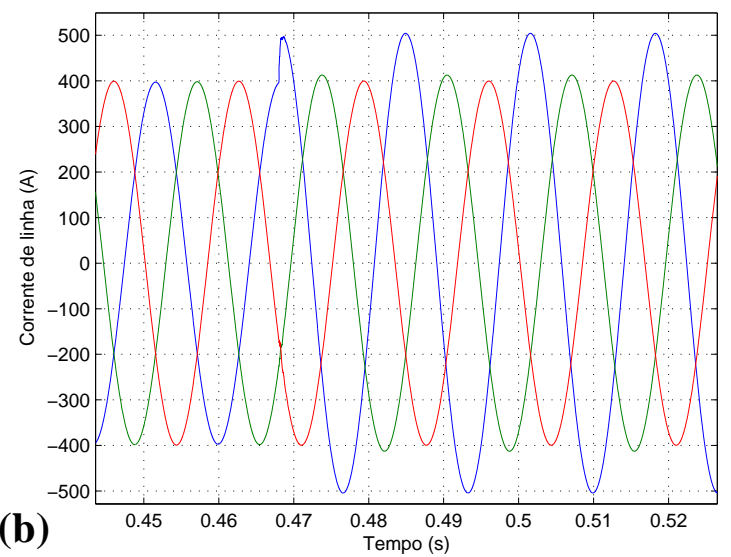

Figura 4.41 - Falta fase-fase ao terra próximo ao centro do alimentador entre as fases A e C: (a) Tensões no início da falta; (b) Correntes no início da falta.

Na Figura 4.41, tem-se os resultados da simulação computacional de uma falta fase-fase ao terra envolvendo as fases A e C. Nessa simulação, o valor da resistência entre a fase $\mathrm{A}$ e o terra foi de $927 \Omega$, ao passo que a resistência entre a fase C e o terra foi de $16919 \Omega$, ou seja, um valor de resistência de falta na fase C cerca de 18 vezes superior ao da fase A. Essa diferença nas resistências de falta fazem com que a defasagem angular entre as correntes de falta esteja próxima à defasagem nominal de $120^{\circ}$. Apesar da grande impedância de falta, ainda assim é possível verificar a existência de distúrbios de freqüência elevada na forma de onda de tensão, o que facilita na identificação do início da falta. 
O comportamento das correntes de falta para resistência de falta ao terra com valores menores pode ser verificado por meio dos gráficos da Figura 4.42.

(a)

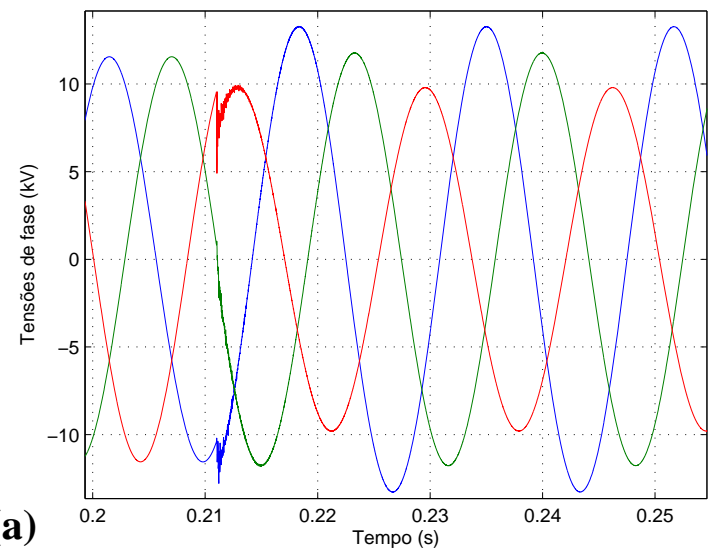

(b)

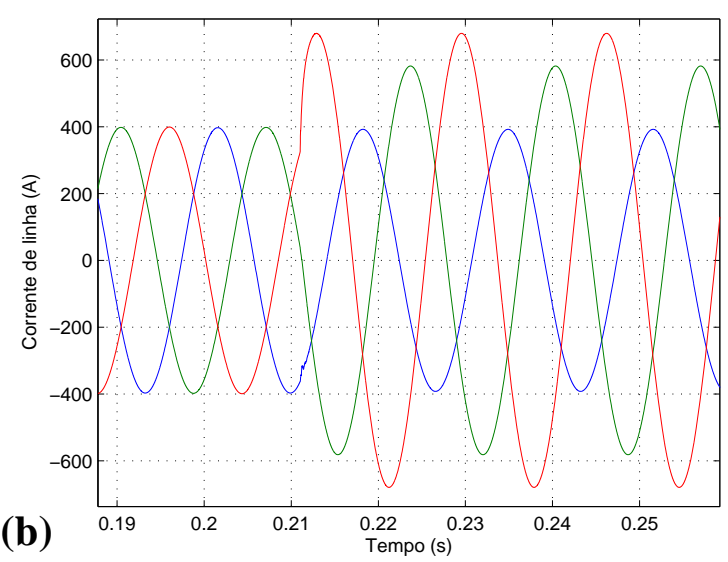

Figura 4.42 - Falta fase-fase ao terra próximo ao centro do alimentador entre as fases B e C: (a) Tensões no início da falta; (b) Correntes no início da falta.

Conforme se verifica por meio da Figura 4.42, as correntes das fases faltosas apresentam uma defasagem angular próxima à $120^{\circ}$. Dessa forma, verificase que as faltas fase-fase ao terra se portam como faltas fase-terra, ou seja, as correntes de falta não sofrem defasagem angular.

\subsubsection{Simulações computacionais referentes à entrada e saída de cargas}

O processo de entrada ou de saída de carga em um sistema elétrico pode, em virtude da carga, provocar transitórios elétricos nas tensões e nas correntes do alimentador. Esses transitórios, por sua vez, devem ser identificados como sendo decorrentes de alterações de carga no alimentador e não como sendo decorrentes de faltas. Dessa forma, o sistema especialista para identificação de faltas deve estar 
apto a distinguir os transitórios elétricos decorrentes de faltas daqueles advindos da alteração de cargas no sistema.

Assim, foram simuladas 100 condições de entrada e de saída de carga ao longo do alimentador piloto. Essas simulações, em conjunto com aquelas pertinentes às faltas e apresentadas nas subseções anteriores, constituem na base de dados para o desenvolvimento do sistema especialista dedicado à identificação de faltas. Ilustrando os resultados obtidos, apresenta-se por meio da Figura 4.43, as tensões e correntes relativas à simulação de saída de uma carga próxima à subestação.

(a)

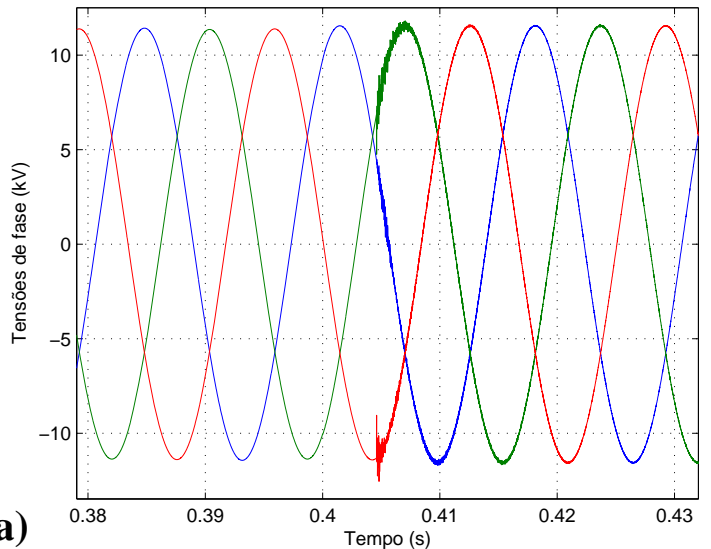

Figura 4.43 - Saída de carga próxima à subestação: (a)

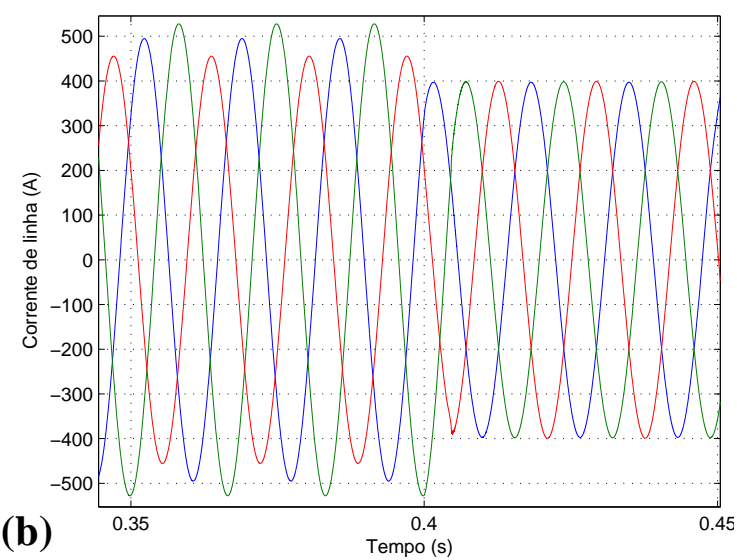

(b)

(a) Tensões no instante de saída de carga; (b) Correntes no instante de saída da carga.

Essas simulações abordaram, principalmente, situações envolvendo a saída e a entrada de cargas desequilibradas no sistema elétrico. $\mathrm{Na}$ simulação apresentada graficamente por meio da Figura 4.43, o desequilíbrio da carga pode ser observado por meio das amplitudes das correntes registradas antes do instante de retirada de carga, o qual ocorreu em 404 ms. Nesse instante, observam-se também distúrbios transitórios de alta freqüência na tensão da subestação. No entanto, tais distúrbios são sensivelmente inferiores àqueles observados quando da ocorrência de faltas. 
$\mathrm{Na}$ Figura 4.44 são apresentados os gráficos de tensão e de corrente obtidos na simulação de uma saída de carga próxima ao centro do alimentador.
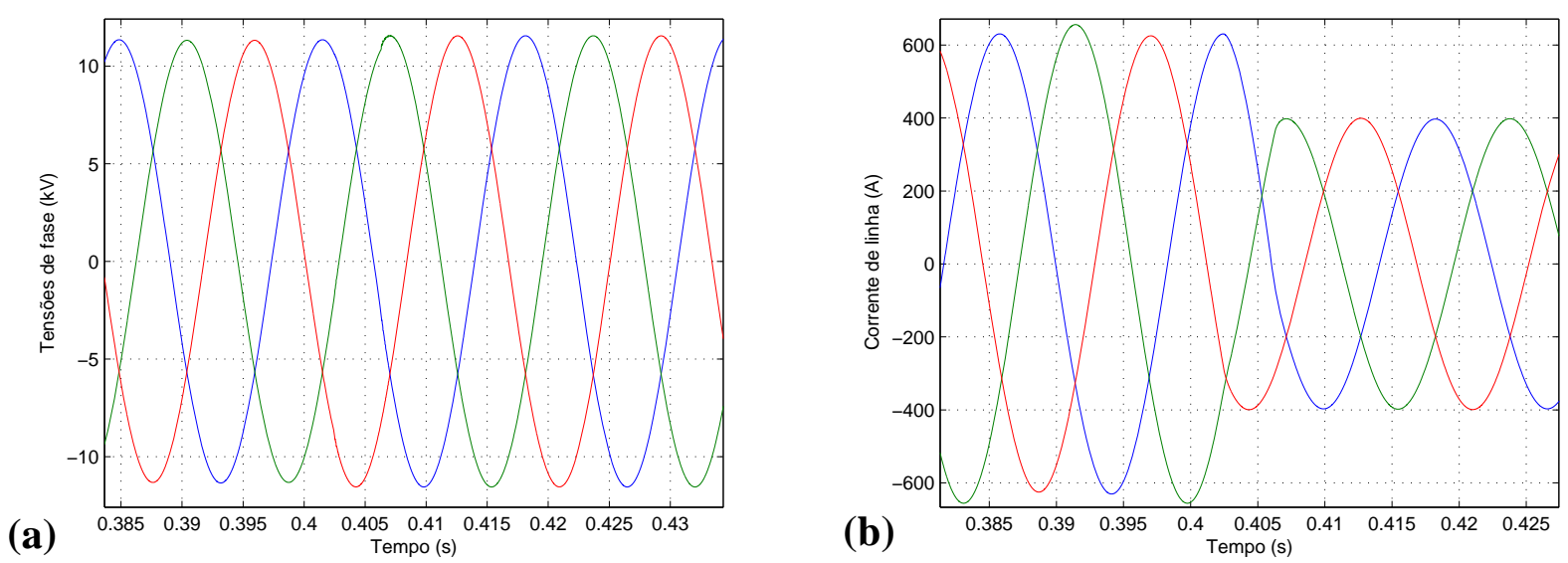

Figura 4.44 - Saída de carga próxima ao centro do alimentador: (a) Tensões no instante de saída de carga; (b) Correntes no instante de saída da carga.

Os resultados de simulação apresentados na Figura 4.44 ilustram, conforme se verifica por meio do gráfico das correntes, a saída de uma grande carga a qual o alimentador supria. Essa saída de carga se deu próximo ao centro do alimentador e, apesar de representar uma grande carga, não resultou em distúrbios transitórios apreciáveis nas tensões da subestação. Dessa forma, verifica-se que, nos processos envolvendo a saída de carga, a distância entre o ponto de saída de carga e a subestação influencia de forma significativa os distúrbios observados nas tensões de fase da subestação. Complementando os resultados observados quando da saída de carga no alimentador padrão modelado, apresenta-se por meio da Figura 4.45 as tensões e correntes observadas na subestação para uma situação de saída de carga próxima ao fim do alimentador. 
(a)

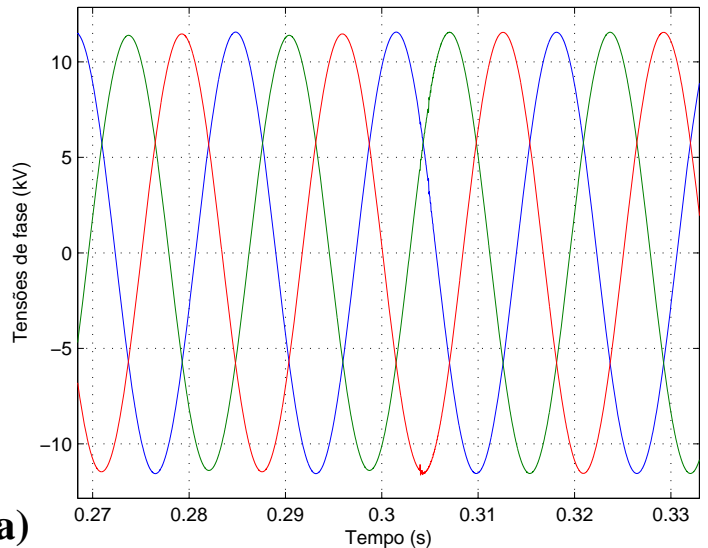

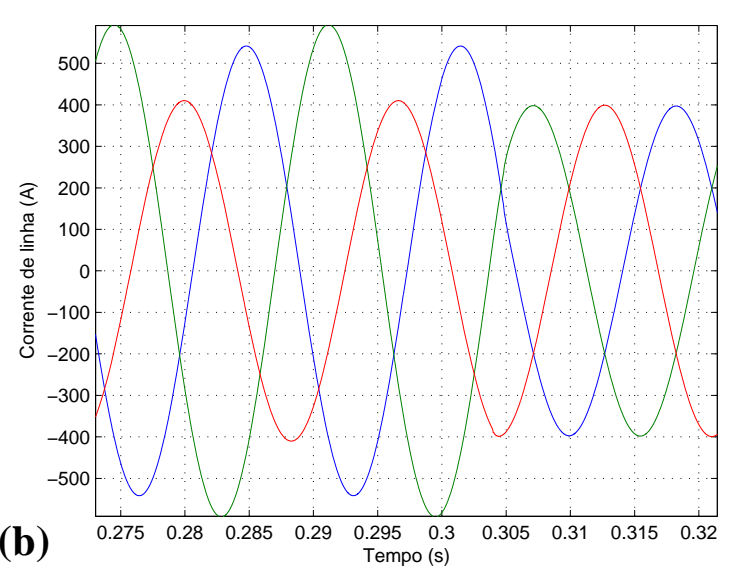

(b)

Figura 4.45 - Saída de carga próxima ao fim do alimentador: (a) Tensões no instante de saída de carga; (b) Correntes no instante de saída da carga.

Assim como para as condições de saída de carga, as situações de entrada de carga foram simuladas. Dessa forma, apresentam-se na Figura 4.46 as tensões e as correntes observadas na subestação quando da entrada de uma carga próxima à subestação.

(a)

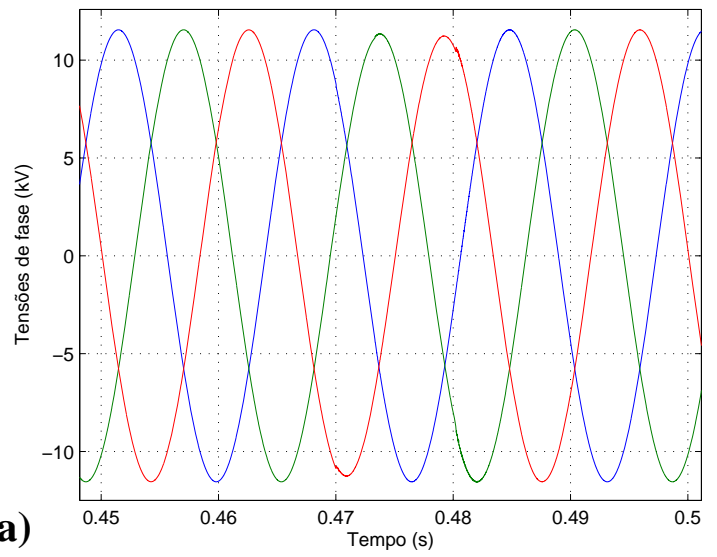

(b)

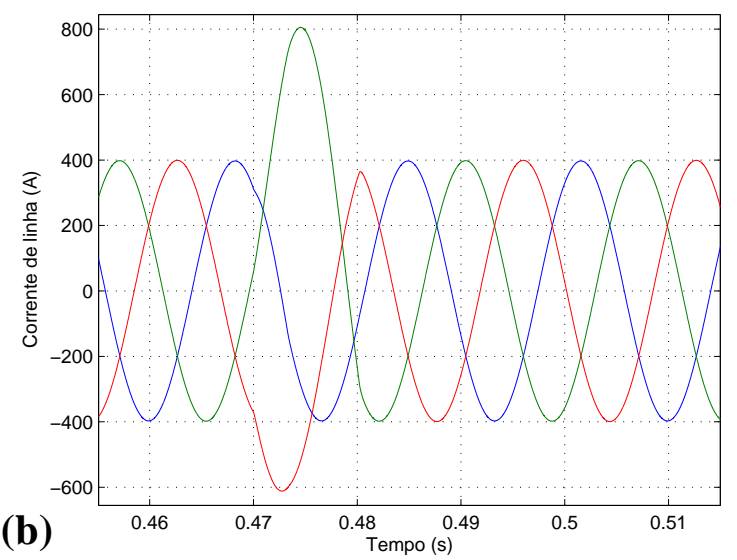

Figura 4.46 - Entrada de carga próxima à subestação: (a) Tensões no instante de entrada de carga; (b) Correntes no instante de entrada da carga.

Conforme se verifica por meio do gráfico das tensões da Figura 4.46, a entrada de carga, mesmo quando essa se dá próxima à subestação, não acarreta em distúrbios transitórios nas tensões. Contudo, observam-se alterações nas correntes de linha, as quais são ocasionadas pela necessidade de suprir a carga que fora inserida no sistema. Na Figura 4.47 é apresentado o comportamento das 
tensões e correntes na subestação para uma entrada de carga próxima ao centro do alimentador.

(a)

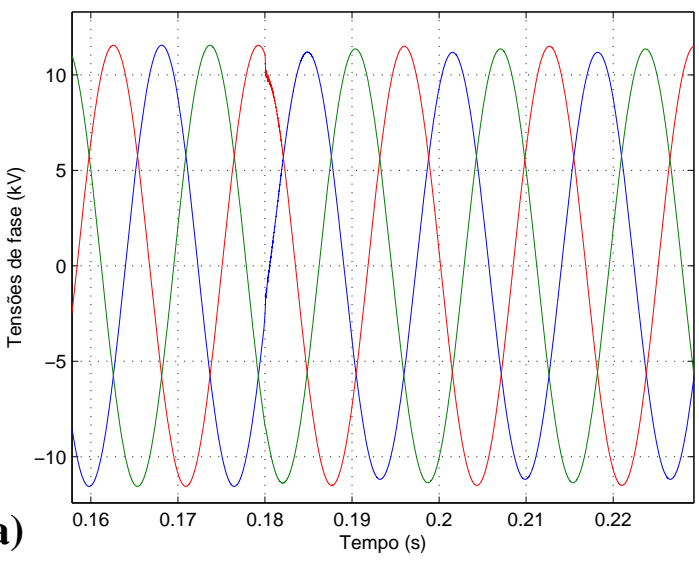

(b)

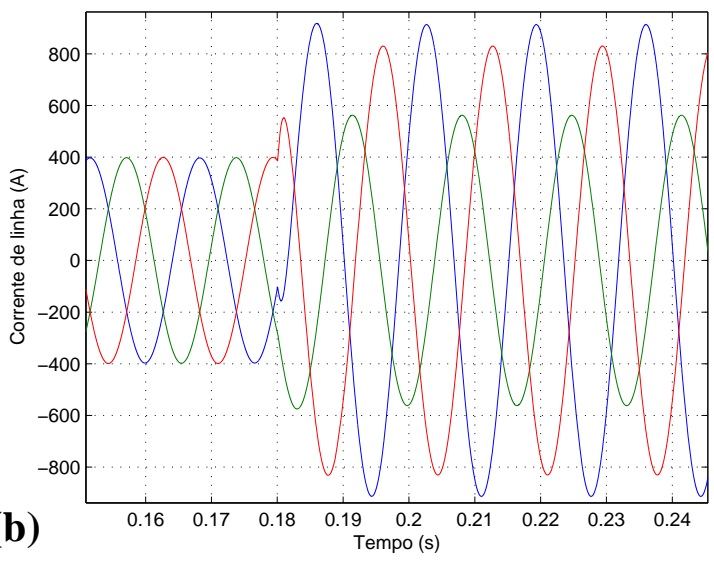

Figura 4.47 - Entrada de carga próxima ao centro do alimentador: (a) Tensões no instante de entrada de carga; (b) Correntes no instante de entrada da carga.

Por meio da análise do comportamento das correntes após a inserção de carga, apresentadas graficamente na Figura 4.47, verifica-se que a carga inserida possui um forte desequilíbrio. Esse desequilíbrio pode resultar em pequenos transitórios nas formas de onda de tensão da subestação. Por fim, apresenta-se na Figura 4.48 o comportamento temporal das tensões e das correntes para a entrada de uma carga próxima ao fim do alimentador.
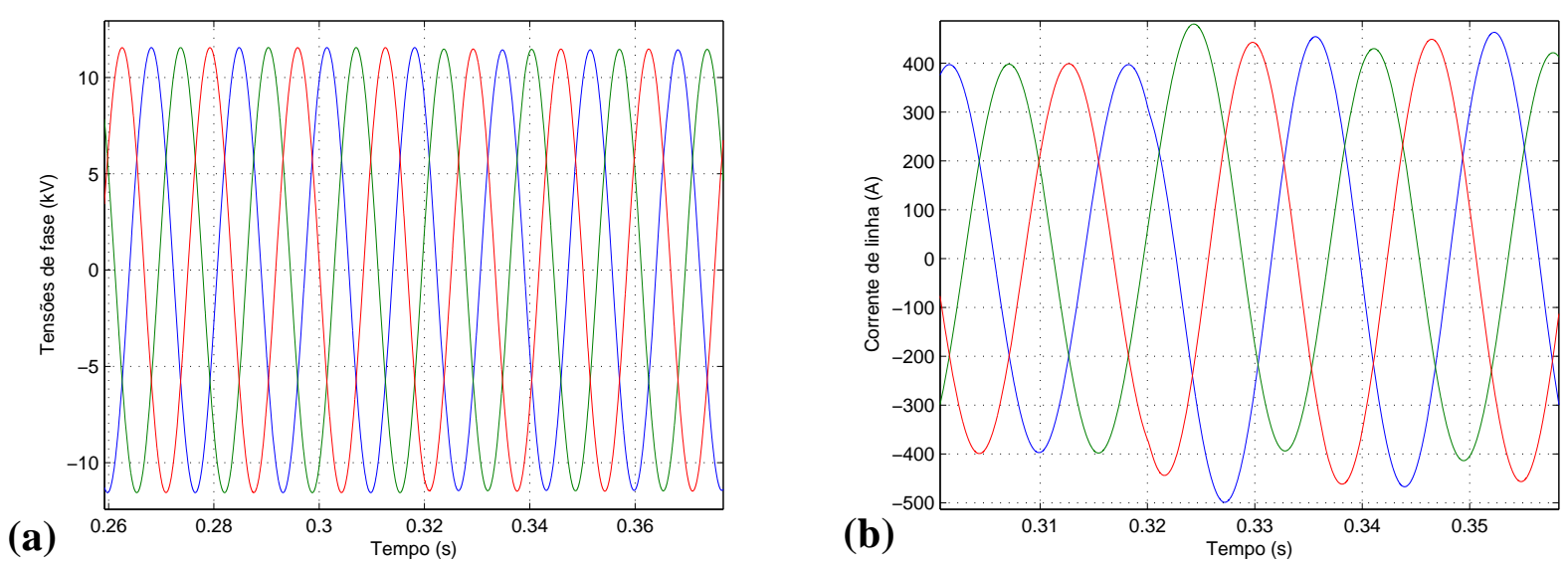

Figura 4.48 - Entrada de carga próxima ao fim do alimentador: (a) Tensões no instante de entrada de carga; (b) Correntes no instante de entrada da carga. 


\subsubsection{Resultados de simulação para o módulo de identificação de transitório}

O sistema de identificação de transitórios deverá identificar a ocorrência de um transitório elétrico a partir dos dados pré-processados das tensões e correntes oscilografadas na subestação. O módulo Identificador de transitórios faz uso dos parâmetros de Fourier, RMS, CFAR, MVD, ROP, Skewness, Kurtosis e Autocorrelação para identificar entre uma condição normal de operação e uma condição de transitório. Esta fase do processo é calculada de forma rápida, tendo em vista que as ferramentas utilizam a FFT para os cálculos.

Dentre os sistemas inteligentes testados para desempenhar a tarefa de identificação de transitório, aqueles que se destacaram em maior intensidade foram as redes neurais artificiais do tipo perceptrons multicamadas. Em virtude das simulações computacionais realizadas, verificou-se que as redes perceptrons com apenas uma camada escondida eram suficientemente capazes para desempenharem a funcionalidade de classificação almejada.

Dessa forma, a fim de escolher o número de neurônios para a camada oculta que resulte no melhor sistema para o módulo Identificador de transitórios, 4 redes neurais foram treinadas e testadas. A Tabela 4.1 apresenta os resultados obtidos para cada rede neural testada.

Tabela 4.1 - Resultados para a identificação de condições normais de operação e de transitórios para redes neurais com diferentes números de neurônios na camada oculta.

\begin{tabular}{|c|c|c|}
\hline $\begin{array}{c}\text { Número } \\
\text { de neurônios }\end{array}$ & $\begin{array}{c}\text { Desempenho para identificação } \\
\text { de condições normais de operação (\%) }\end{array}$ & $\begin{array}{c}\text { Desempenho para identificação } \\
\text { de transitórios (\%) }\end{array}$ \\
\hline 4 & 80,2 & 75,1 \\
\hline 6 & 86,6 & 95,4 \\
\hline 8 & 98,4 & 99,6 \\
\hline 10 & 97,3 & 99,3 \\
\hline
\end{tabular}


A rede neural que melhor identificou as condições normais de operação e de transitório foi aquela com 8 neurônios na camada oculta. Dessa forma, essa rede neural foi treinada com 5.689 padrões para treinamento, sendo que o desempenho deste processo pode ser acompanhado na Figura 4.49.

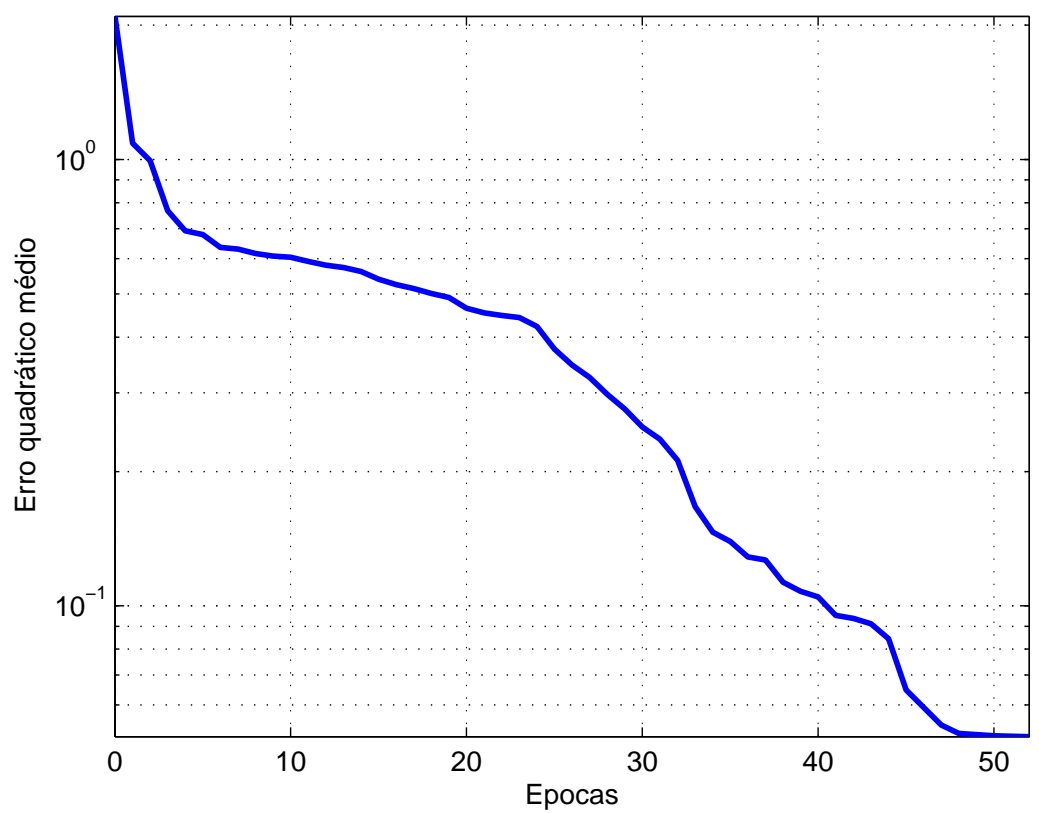

Figura 4.49 - Erro quadrático médio ao longo do treinamento do módulo de identificação de transitório.

O erro quadrático médio foi adotado como critério de parada por este representar de forma satisfatória o processo de aprendizado das redes neurais, frente aos padrões apresentados durante o processo de treinamento supervisionado.

Após o treinamento, a rede neural foi testada com todos os dados de simulação disponíveis, os quais totalizaram um montante de 28.443 padrões de entrada-saída. Esse montante de dados foi obtido por meio dos processos de simulação, sendo que o ajuste dos modelos fora realizado com sinais reais de faltas.

Na Figura 4.50 são apresentados os resultados fornecidos pela rede neural para 1000 padrões de testes escolhidos aleatoriamente entre os 28.443 padrões entrada-saída disponíveis. Nessa mesma figura, para fins de comparação, são 
também apresentados os resultados reais advindos das simulações computacionais do alimentador padrão.

Os valores apresentados na Figura 4.50 referem-se ou às condições normais de operação ou às condições transitórias. Dessa forma, ao longo do desenvolvimento do módulo identificador de faltas, associou-se o valor "-1" para as condições normais de operação e o valor "1" para as condições transitórias. Verificase por meio da Figura 4.50 que a rede neural desenvolvida foi capaz de identificar todas as condições normais de operação, bem como as condições transitórias de forma adequada e precisa.

(a)

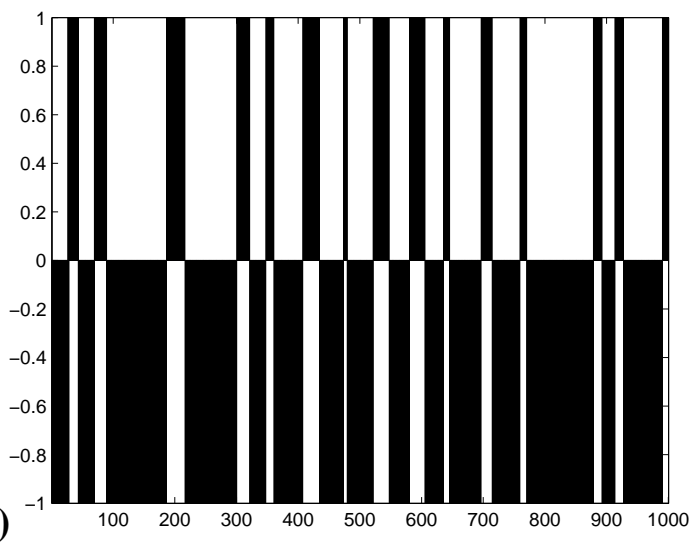

(b)

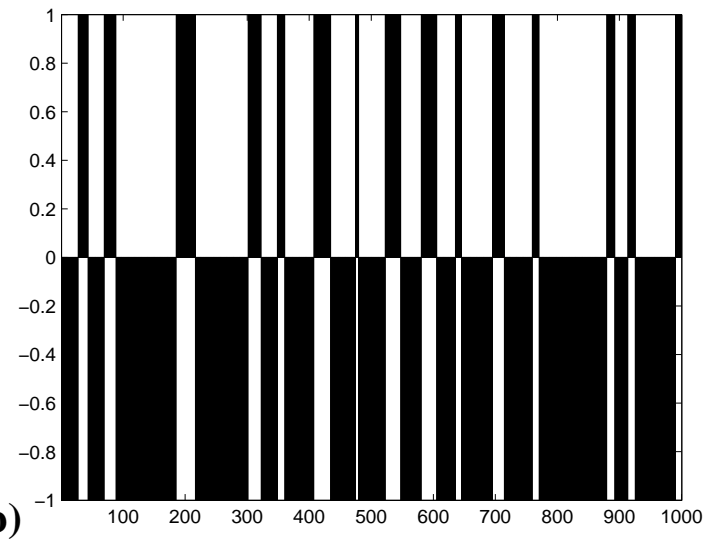

Figura 4.50 - Identificação de condições normais de operação e condições transitórias: (a) Resultados fornecidos pela rede neural; (b) Resultados desejados obtidos por meio de simulações do alimentador padrão.

\subsubsection{Resultados de simulação para o módulo discriminador de faltas}

É necessário classificar os transitórios como sendo oriundos ou de faltas ou de alterações na carga do sistema elétrico de distribuição de energia elétrica. Essa distinção é de fundamental importância, a fim de que o sistema identificador de faltas não forneça falsos alarmes quando da ocorrência de transitórios elétricos no sistema e, assim, uma maior robustez seja conferida ao sistema como um todo. 
Ao longo do desenvolvimento desse módulo do sistema de identificação de faltas, os melhores resultados foram obtidos com as redes perceptron multicamadas, com 2 camadas escondidas.

Uma vez que essa arquitetura fora escolhida para desempenhar a funcionalidade de discriminação de faltas, variaram-se seus parâmetros, tais como o número de neurônios em cada camada escondida e suas respectivas funções de ativação, até que se verificasse um bom desempenho referenciado pelo erro de discriminação.

Dessa forma, chegou-se a uma arquitetura neural com duas camadas ocultas, sendo que na primeira foram dispostos 4 neurônios e, na segunda camada escondida, dispuseram-se 6 neurônios. Tanto as camadas escondidas como a camada de saída foram parametrizadas tendo a função tangente sigmóide como sendo a função de ativação, sendo que o processo de treinamento desta rede pode ser acompanhado na Figura 4.51.

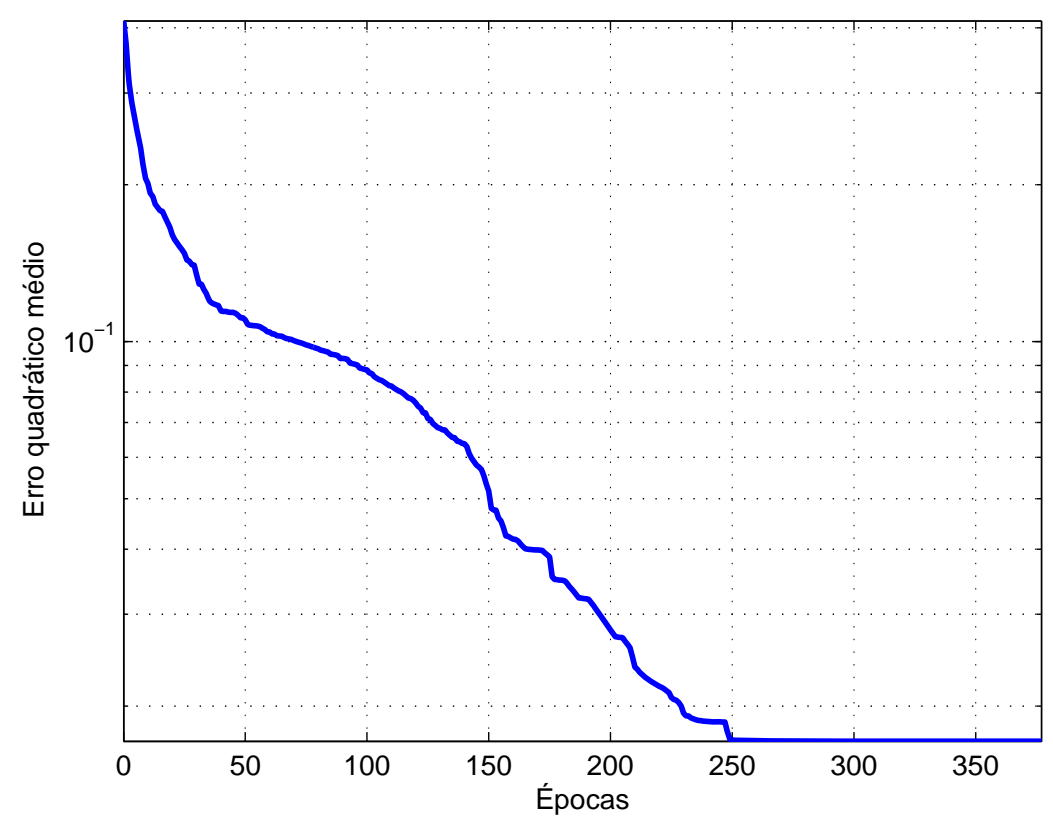

Figura 4.51 - Erro quadrático médio ao longo do treinamento do módulo discriminador de faltas. 
A fim de validar a rede neural desenvolvida para discriminação de faltas, a mesma foi testada com 28.443 padrões de entrada-saída disponíveis. A taxa de acerto foi de $98,2 \%$, sendo que os erros de discriminação observados se relacionaram às situações onde uma grande carga entra no sistema por um intervalo de tempo inferior a 10 ciclos de senóide. Visto que, tais situações não são rotineiras em um sistema de distribuição de energia elétrica, os resultados apresentados pelo módulo discriminador de transitórios são coerentes e eficazes quanto da realização de suas funcionalidades. Ilustrando os resultados obtidos, apresenta-se por meio da Figura 4.52 a classificação realizada pela rede para 1000 padrões escolhidos de maneira aleatória dentro de todo o conjunto disponível. Complementando, destacam-se também nessa figura os resultados reais obtidos por meio das simulações computacionais do alimentador padrão.

(a)

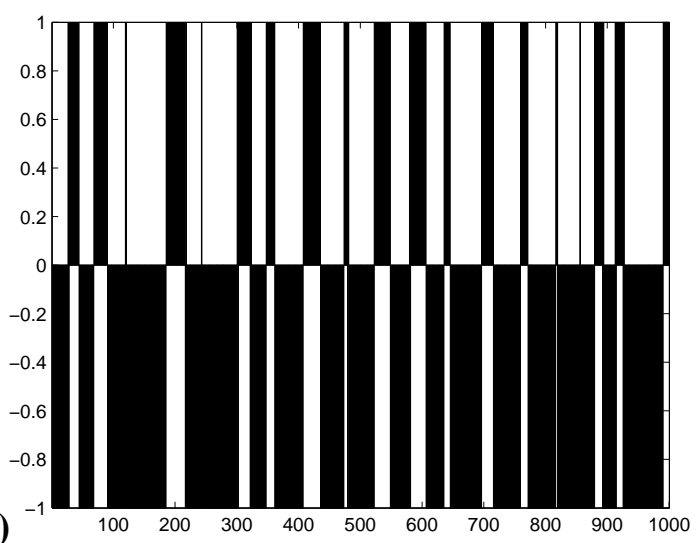

(b)

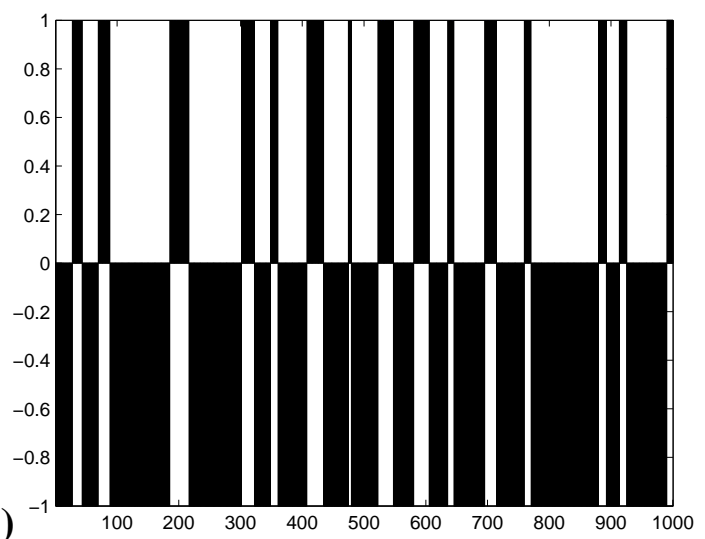

Figura 4.52 - Discriminador de transitórios: (a) Resultados fornecidos pela rede neural; (b) Resultados desejados obtidos por meio de simulações do alimentador padrão.

Nos gráficos da Figura 4.52, os valores indicados referem-se aos transitórios advindos de faltas, de maneira que o valor "-1" indica condições transitórias advindas da entrada ou da saída de carga. Da mesma maneira, o valor "1" é indicador de transitório proveniente de faltas. 


\subsubsection{Resultados de simulação para o módulo identificador de fase}

Frente à identificação de um transitório proveniente de falta, o sistema "Identificador de fase" começa a operar. O principal objetivo desse módulo é de identificar o tipo de falta que ocorreu, bem como fornecer dados sobre quais foram as fases faltosas e se houve ou não participação do terra na referida falta.

Em virtude deste módulo possuir muitas entradas, o emprego de redes neurais artificiais perceptrons de múltiplas camadas resulta em uma abordagem mais eficiente sob o ponto de vista computacional. Além disso, por meio dos resultados alcançados, verificou-se que essa arquitetura também é eficiente sob o ponto de vista da precisão dos resultados.

Dentre as parametrizações testadas, a arquitetura que apresentou os resultados mais expressivos foi aquela com 12 neurônios na primeira camada oculta e 20 neurônios na segunda camada oculta. Além disso, empregaram-se como funções de ativação nas camadas ocultas e na camada de saída a função tangente sigmóide, sendo que o processo de treinamento desta rede pode ser acompanhado na Figura 4.53. 


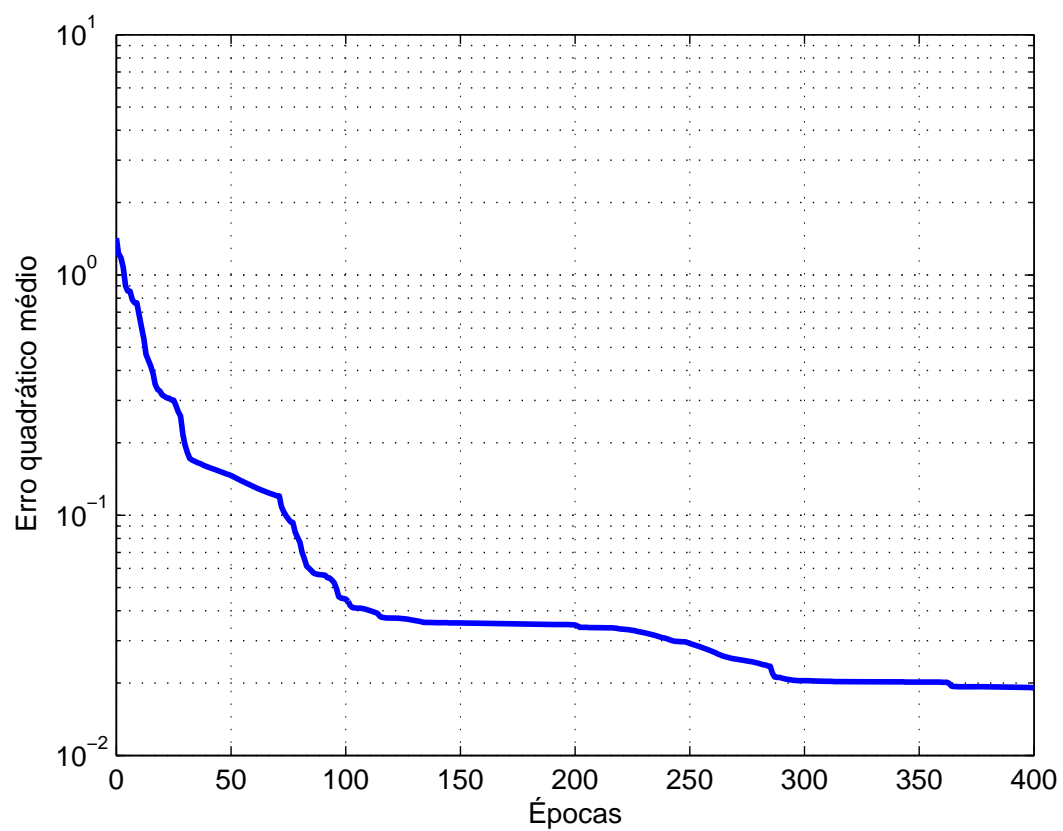

Figura 4.53 - Erro quadrático médio ao longo do treinamento do módulo identificador de fase.

Após seu treinamento, a rede neural foi testada para todos os dados disponíveis, fornecendo-se um erro percentual médio de $2,15 \%$. Ilustrando os resultados fornecidos pela rede neural, apresenta-se na Figura 4.54 o seu comportamento frente à identificação da Fase A para um total de 1000 padrões de teste, verificando-se ela foi capaz de identificar a maioria das faltas que tiveram a fase A como participante desse processo. A média de erro para a identificação da fase $A$ foi de $3,2 \%$.

$\mathrm{Na}$ Figura 4.55 apresentam-se os resultados fornecidos quando da identificação da fase B como participante do processo de falta. 
(a)
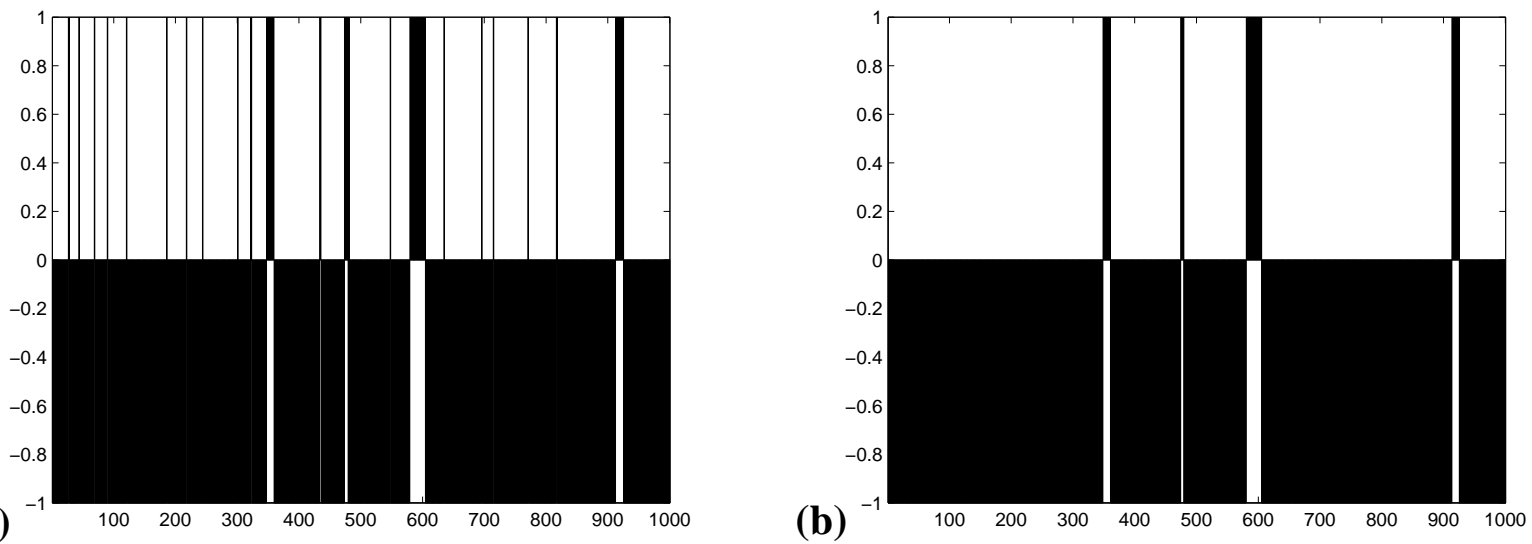

Figura 4.54 - Sistema identificador das fases participantes da falta com relação à Fase A: (a) Resultados fornecidos pela rede neural; (b) Resultados desejados obtidos por meio de meio de simulações do alimentador padrão.

(a)

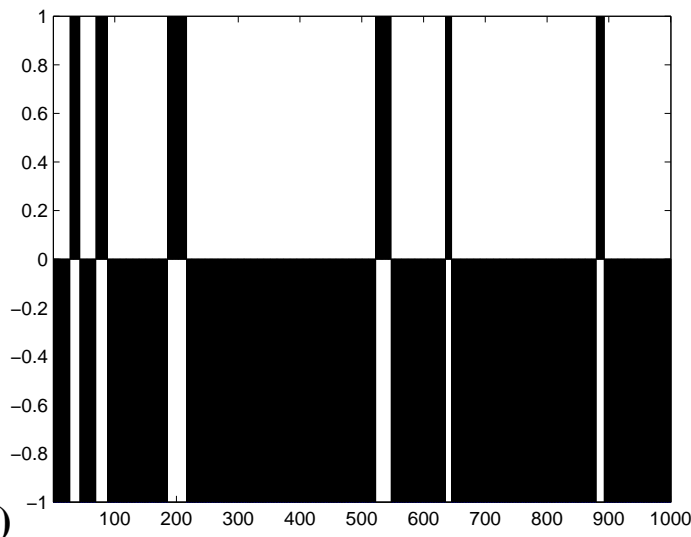

(b)

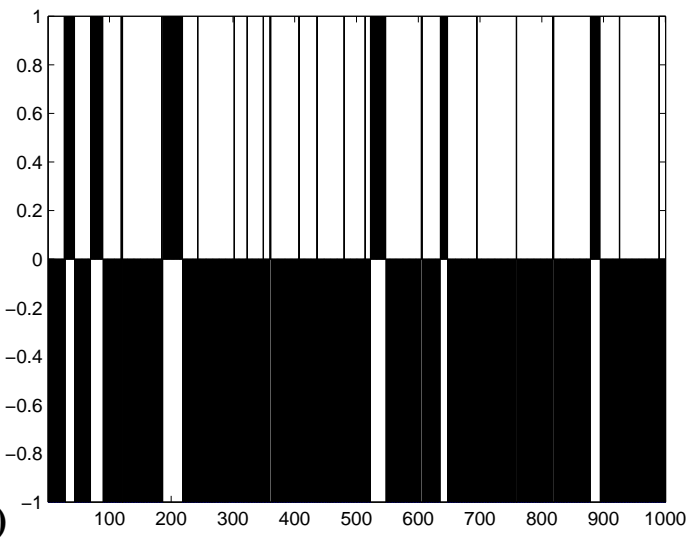

Figura 4.55 - Sistema identificador das fases participantes da falta com relação à Fase B: (a) Resultados fornecidos pela rede neural; (b) Resultados desejados obtidos por meio de simulações do alimentador padrão.

A análise dos resultados ilustrados na Figura 4.55 permite a verificação de que a rede neural foi capaz de identificar corretamente, na maioria dos casos, quando a Fase B participou do processo de falta. O erro percentual médio para essa saída foi de 3,4\%. Na Figura 4.56, apresenta-se os resultados fornecidos pelo sistema de identificação de faltas relativo à participação da Fase $\mathrm{C}$ no processo de falta. Diferentemente das demais fases, o erro percentual médio de identificação, para essa fase, ficou abaixo de $2 \%$. 
(a)

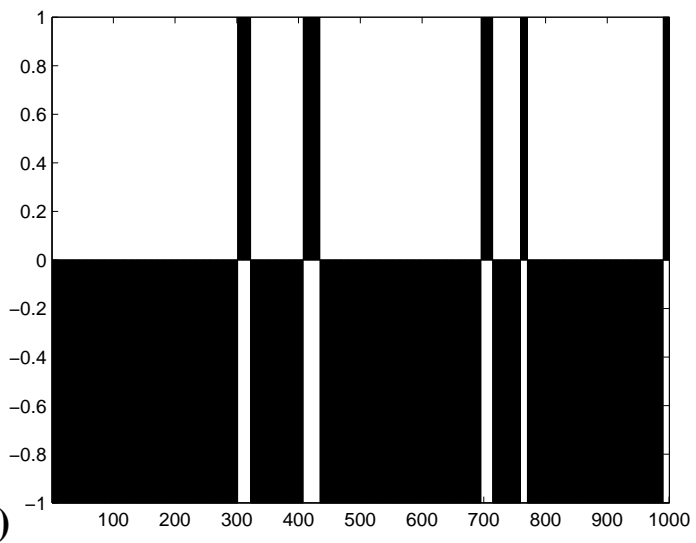

(b)

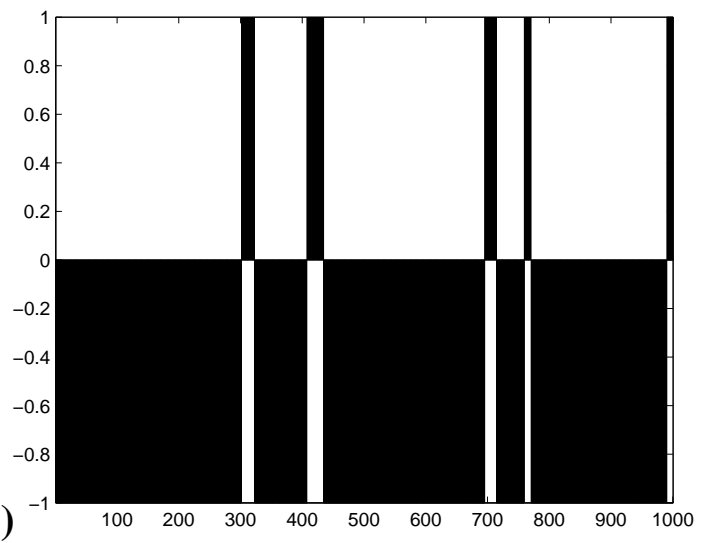

Figura 4.56 - Sistema identificador das fases participantes da falta com relação à Fase C: (a) Resultados fornecidos pela rede neural; (b) Resultados desejados obtidos por meio de simulações do alimentador padrão.

As situações que comprometeram a identificação para essa fase foram exclusivamente aquelas que se posicionaram na iminência da falta e nas situações posicionadas logo após sua extinção. A mesma característica observada para a fase C se observou para a identificação do terra como participante da falta. Ilustrando essa afirmação, apresenta-se por meio da Figura 4.57 os resultados fornecidos pela rede neural quanto da identificação do terra como participante do processo de falta.

(a)

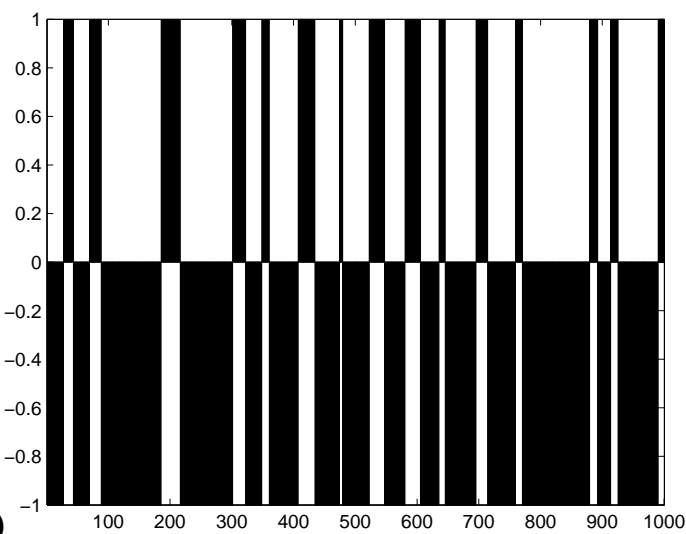

(b)

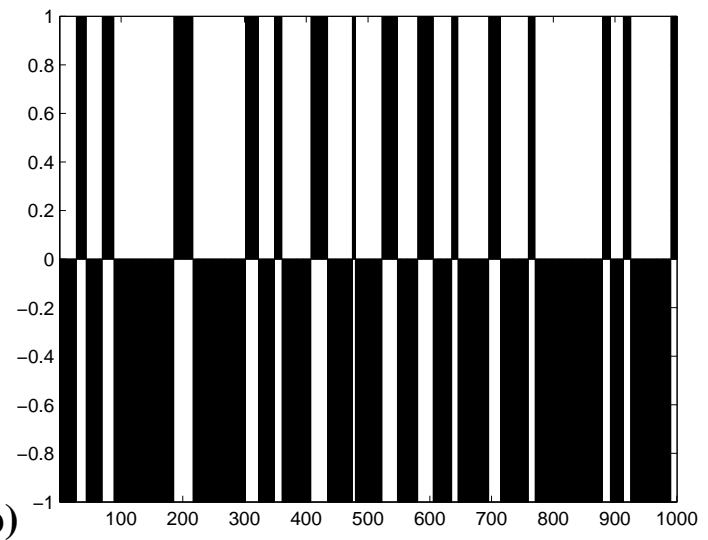

Figura 4.57 - Sistema identificador das fases participantes da falta com relação ao Terra: (a) Resultados fornecidos pela rede neural; (b) Resultados desejados obtidos por meio de meio de simulações do alimentador padrão. 


\section{Validação experimental das ferramentas de}

\section{localização de faltas}

Fazendo-se uso das evidências obtidas nas etapas anteriores dessa pesquisa, bem como de todas as ferramentas já desenvolvidas, a arquitetura do sistema especialista para localização de faltas proposto é composto por quatro módulos.

Os três primeiros módulos são dedicados à localização do ramal sob falta. Esses três módulos utilizam para sua operação dos dados de corrente e de tensão, os quais previamente são pré-processados pelas ferramentas de DSP: FFT, RMS, CFAR, MVD, ROP, Skewness, Kurtosis, Autocorretação e PCA, apresentadas anteriormente. Cada um desses módulos opera de maneira independente e fornecem como resposta o ramal do alimentador que sofrera uma provável falta. Dessa forma, têm-se três ramais candidatos para a ocorrência da falta. $\mathrm{O}$ quarto módulo tem por objetivo restringir a resposta final a um único ramal. Para isso, esse módulo utiliza-se dos sinais de tensão e de corrente pré-processados, da mesma maneira que os três módulos descritos anteriormente, bem como faz uso das respostas individuais desses módulos. Assim, esse quarto módulo trabalha de maneira a eleger qual das três respostas anteriores é a mais provável para ocorrência da falta.

A fim de ilustrar esquematicamente a arquitetura do sistema de localização de faltas, apresenta-se por meio da Figura 5.1 o interrelacionamento de cada um desses módulos. 


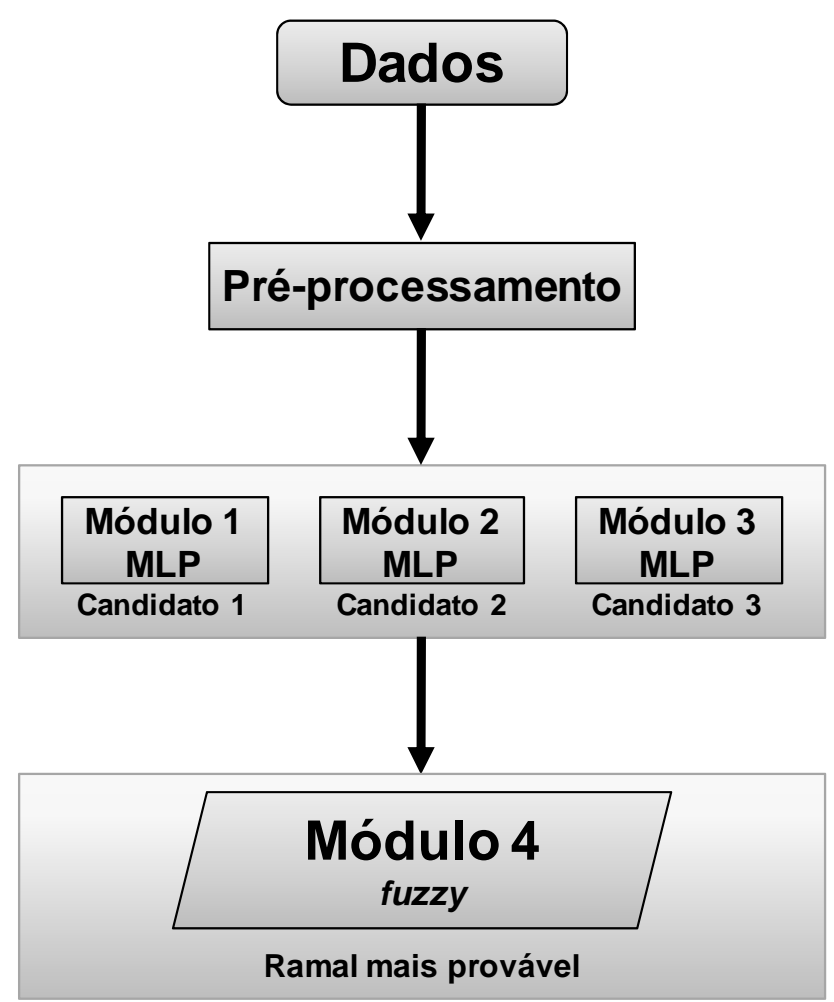

Figura 5.1 - Diagrama esquemático do sistema de localização de faltas.

A primeira tarefa realizada para a implementação do sistema especialista para localização de faltas foi a de constituir uma base de dados significativa de oscilografias de tensões e de correntes do alimentador sob condições diversas de faltas. Seguindo tais premissas, cerca de 2000 simulações computacionais foram realizadas. Essas simulações computacionais, abrangeram as faltas fase-terra, faltas fase-fase, fase-fase-terra e trifásicas, de forma igualitária. Além de refletirem essa variedade tipológica, as simulações realizadas foram parametrizadas de forma a traduzirem à base de dados a natureza aleatória que faltas de um sistema de distribuição de energia elétrica possuem. Assim, a cada simulação, os instantes de início e término da falta variaram, bem como as magnitudes das resistências de falta envolvidas na simulação. 


\subsection{Módulos para localização de faltas}

\subsubsection{Módulo 1 para localização de faltas}

O primeiro módulo para localização de faltas, ilustrado esquematicamente por meio da Figura 5.2, é constituído por 45 submódulos, os quais são responsáveis por informarem em qual ramal a falta ocorreu. Dessa maneira, é possível verificar que o alimentador padrão foi subdividido em 45 setores e, nesse primeiro módulo, foi desenvolvido um submódulo para cada um desses setores. Esses submódulos informam se a falta ocorreu ou não no setor o qual representam.

Em função da complexidade do problema de localização de faltas, o emprego de ferramentas advindas da inteligência computacional torna-se atrativa como alternativa para solução do mesmo. Assim, cada um dos 45 submódulos foram implementados por meio de redes neurais artificiais do tipo perceptrons multicamadas. Ilustrando a arquitetura desse módulo, tem-se por meio da Figura 5.2 o diagrama esquemático desse primeiro módulo. 


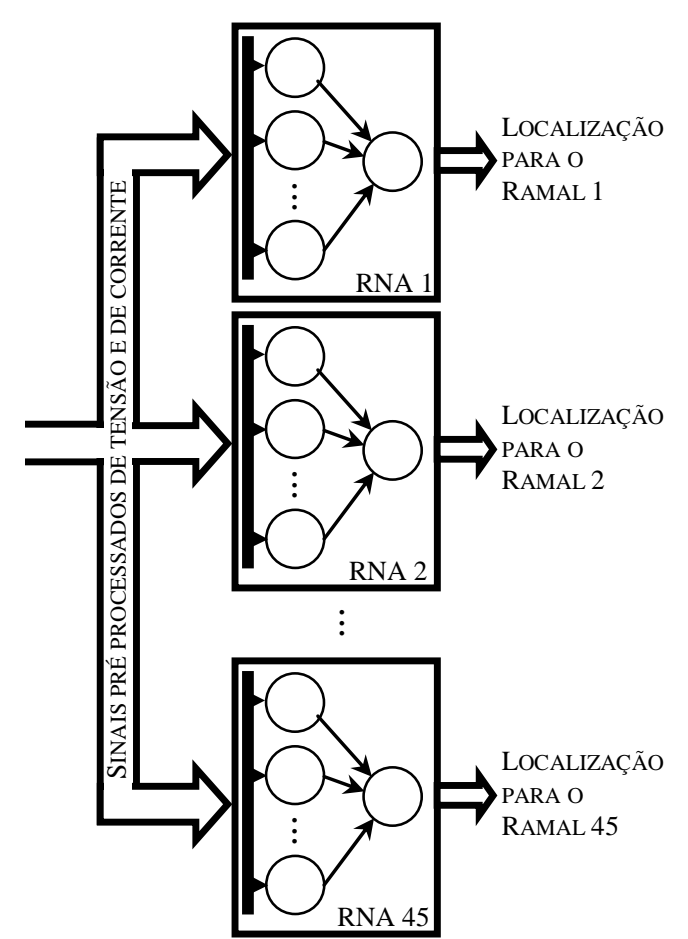

Figura 5.2 - Diagrama de funcionamento do Módulo 1 para localização de faltas.

\subsubsection{Módulo 2 para localização de faltas}

O segundo módulo, destacado no diagrama esquemático da Figura 5.3, primeiramente identifica em qual trecho primário do alimentador padrão a falta ocorreu e, a partir de uma tabela de interrelacionamento, determina a qual ramal o trecho primário identificado pertence. No entanto, em virtude do número de trechos primários existentes, cerca de 276 trechos, torna-se então necessário codificar cada um desses. Para isso, são necessários nove bits, os quais fornecem um total de 512 combinações possíveis. Dessa maneira, a implementação desse segundo módulo foi realizada por meio de nove redes neurais, conforme se destaca na Figura 5.3. 


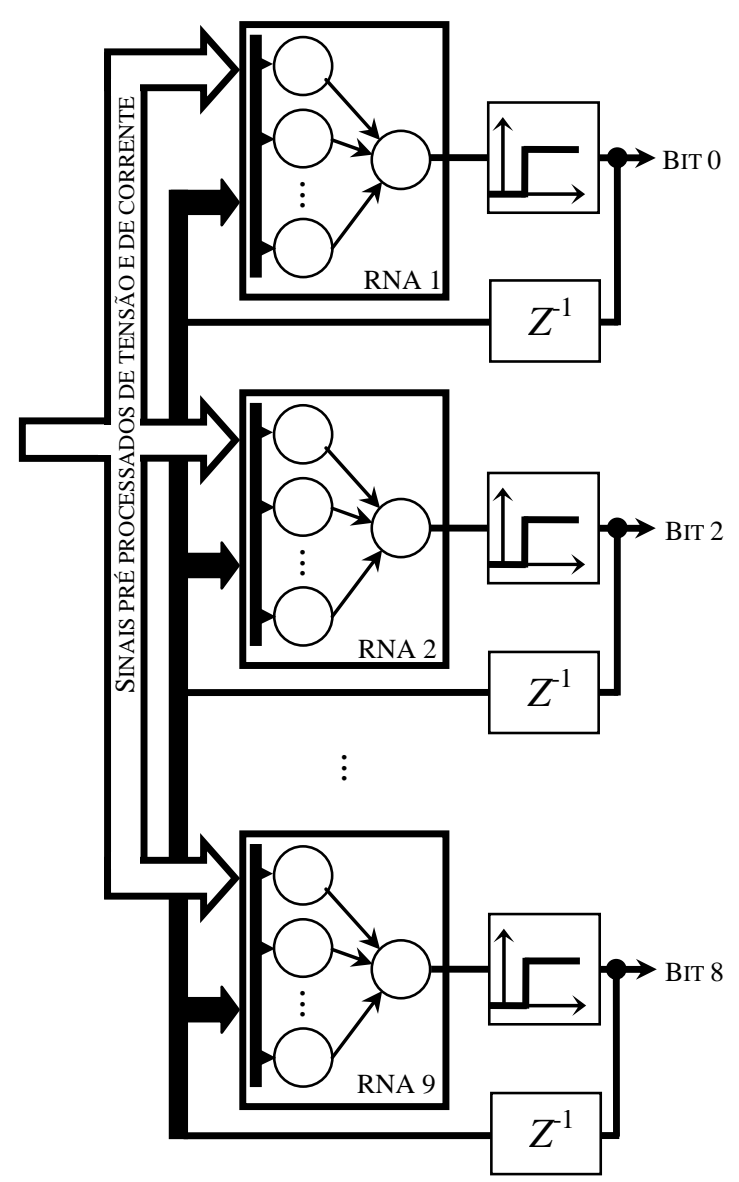

Figura 5.3 - Diagrama do Módulo 2 para localização de faltas.

De acordo com o diagrama esquemático da Figura 5.3, a estrutura computacional empregada para, a partir dos sinais pré-processados das tensões e das correntes, localizar qual dos trechos primários está sob falta é do tipo recorrente. Assim, na primeira iteração do processo de convergência, todos os bits são considerados como sendo nulos. Nas iterações seguintes, esses bits são ajustados àqueles valores observados nas saídas das redes neurais, ou seja, existe um processo de realimentação das saídas. Esse processo de convergência se repete até que não se observem alterações nas saídas das redes neurais artificiais. Dessa forma, tem-se como resposta o código do ramal que provavelmente está sob falta.

Conforme destacado anteriormente, a divisão dos 275 trechos foi realizada por meio de codificação binária em nove bits. Os ramais foram dispostos ordenadamente em função da distância em relação à subestação, sendo que o 
primeiro trecho considerado é aquele mais próximo da subestação e o último trecho corresponde ao mais distante. Assim, torna-se conveniente, durante o processo de codificação, o emprego do código de Gray. O código de Gray é caracterizado pela propriedade de que a variação de uma seqüência de bits para sua subseqüente ocorre em apenas um bit. Portanto, a distância euclidiana entre os códigos de dois trechos primários é proporcional à distância entre os mesmos fisicamente.

\subsubsection{Módulo 3 para localização de faltas}

O terceiro módulo para localização de faltas em sistemas de distribuição de energia elétrica foi idealizado de maneira similar ao implementado para o segundo módulo. Nesse terceiro módulo, representado pela Figura 5.4, ao contrário de se codificar cada um dos trechos primários, codificaram-se os ramais. No total são 45 ramais e, para uma codificação binária desses, faz-se necessário um total de 6 bits. 


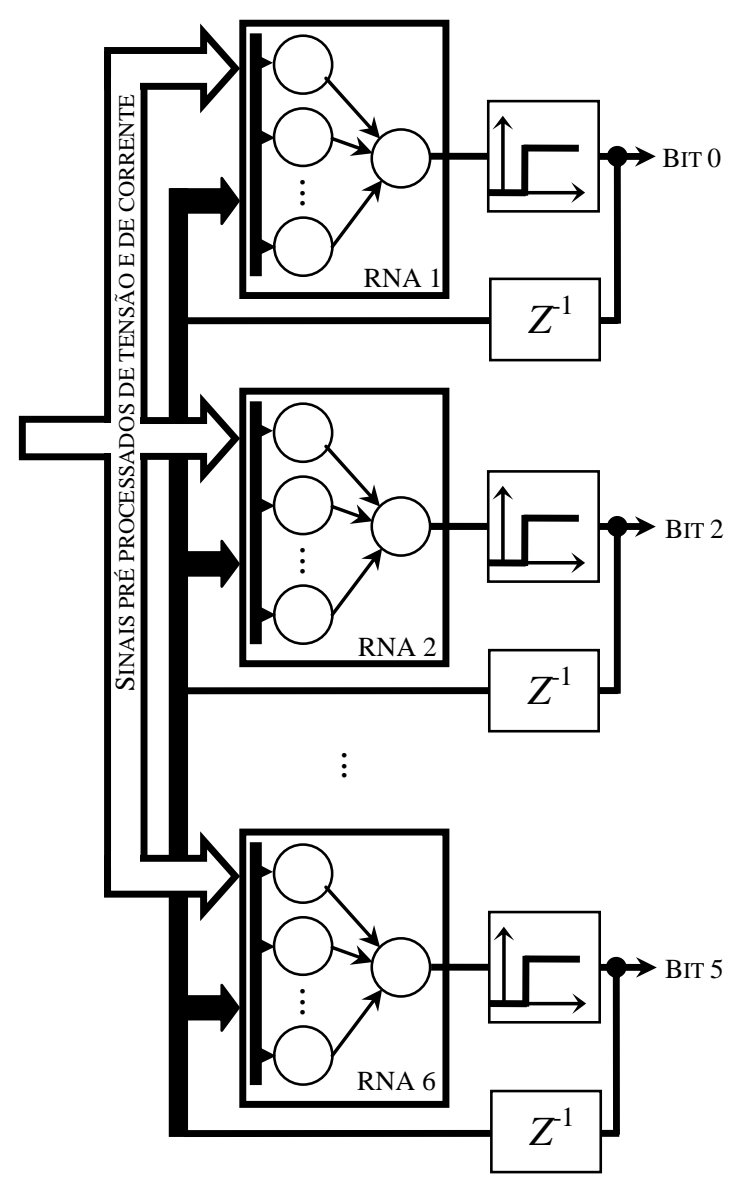

Figura 5.4 - Diagrama do Módulo 3 para localização de faltas.

\subsubsection{Módulo 4 para localização de faltas}

O quarto módulo constituinte do sistema especialista para localização de faltas em sistemas de distribuição de energia elétrica tem a finalidade de avaliar a resposta fornecida pelo Módulo 1, pelo Módulo 2 e pelo Módulo 3 a respeito de qual trecho primário foi alvo de ocorrência de uma falta. A referida avaliação considera a resposta fornecida por cada um dos sistemas, bem como analisa os sinais de tensão e de corrente pré-processados pelas ferramentas estatísticas de processamento de sinais, conforme ilustrado pela Figura 5.5. 


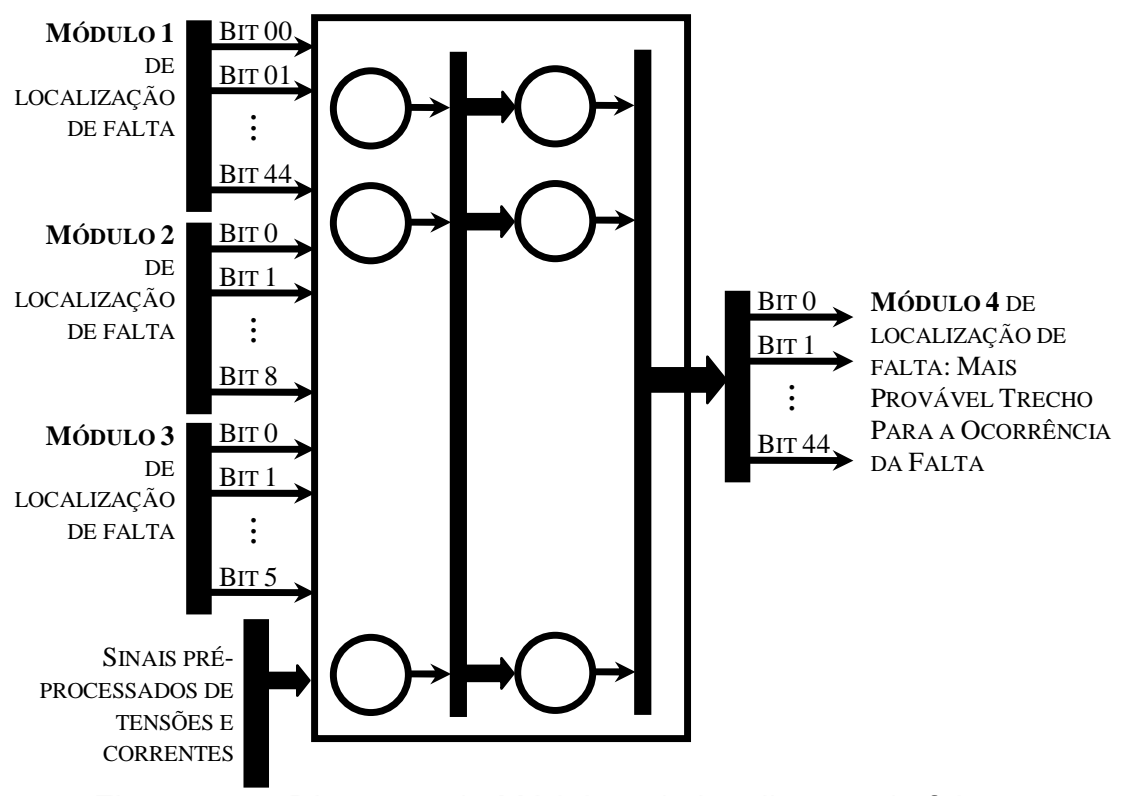

Figura 5.5 - Diagrama do Módulo 4 de localização de faltas.

Como resposta, esse módulo informa qual dos trechos é o mais provável para a ocorrência da falta.

\subsection{Resultados computacionais para treinamento das redes neurais dos módulos de localização de faltas}

\subsubsection{Resultados referentes ao Módulo 1}

Conforme apresentado anteriormente, esse primeiro módulo foi constituído por 45 redes neurais, onde cada uma dessas representa um determinado ramal do alimentador principal.

Assim, é possível verificar que o alimentador padrão foi subdividido em 45 setores e, nesse primeiro módulo, foi desenvolvido um submódulo para cada um desses setores. Esses submódulos informam se a falta ocorreu ou não no setor o qual representam. Após 480 treinamentos, verificou-se que a arquitetura de rede neural que melhor se enquadrava à realização dessa tarefa é a perceptron 
multicamadas. Além disso, empregaram-se redes com duas camadas escondidas, sendo que na primeira camada foram alocados seis neurônios e na segunda camada escondida dez foram os neurônios alocados.

A fim de que a melhor rede neural seja escolhida e de que a garantia de acerto global seja maximizada, todas as redes foram treinadas mais de uma vez. Dessa forma, para cada uma das redes neurais a serem treinadas, no mínimo 7 outras redes neurais foram especificadas. A cada nova rede gerada, a mesma era comparada com as anteriormente treinadas. Como parâmetro de comparação utilizou-se o erro relativo médio sobre o conjunto de teste. Como esse conjunto é constituído por dados que não participam do treinamento, as redes são comparadas pela sua capacidade de generalização. Quando não se observa uma melhor rede, por um determinado número de vezes, então se escolhe a melhor rede como sendo a vencedora e esta passa a ser treinada com o conjunto de dados completos a fim de melhorar ainda mais seu desempenho. Dessa maneira, verifica-se que o número de redes neurais testadas para cada submódulo pode variar. llustrando essa estratégia de treinamento, apresenta-se por meio da Figura 5.6, o erro relativo médio de todas as redes neurais treinadas para o primeiro submódulo. 


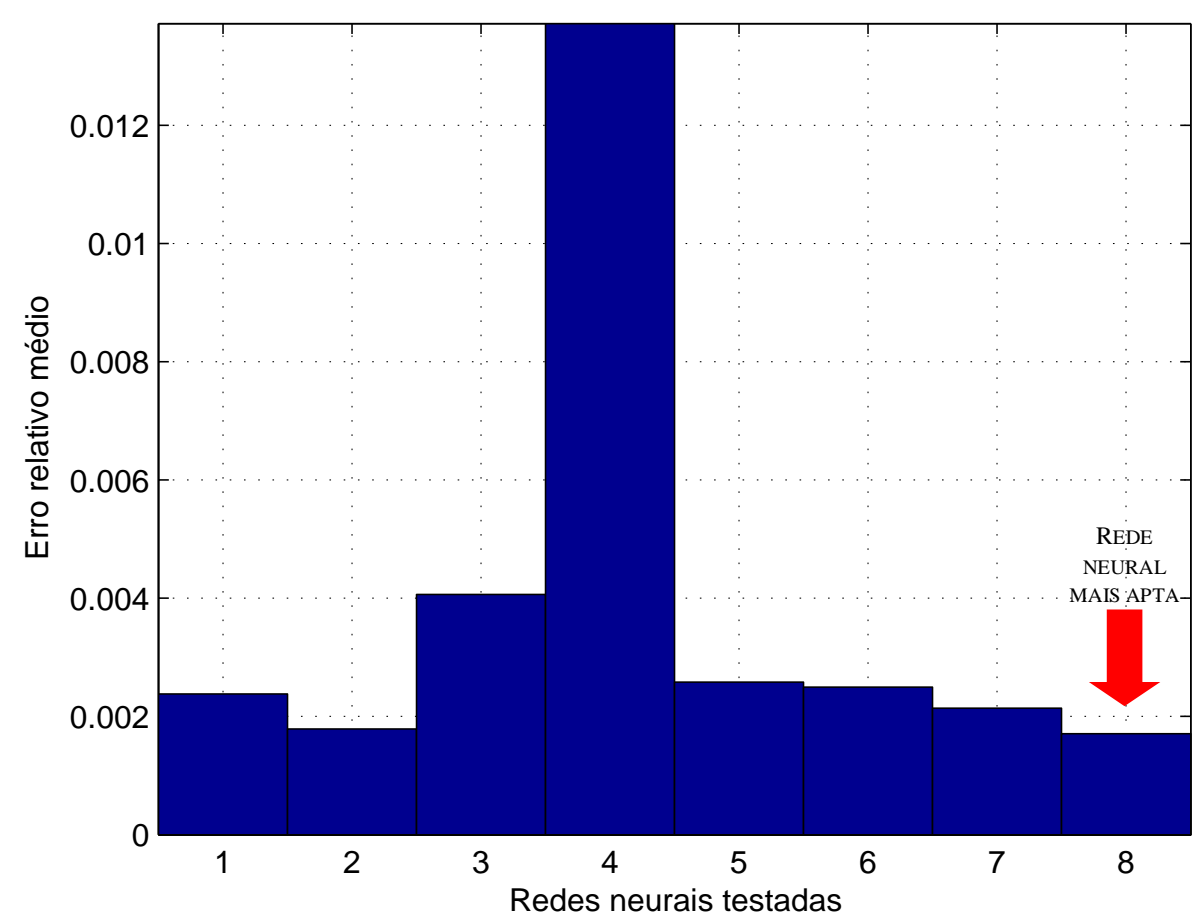

Figura 5.6 - Erro relativo médio das redes treinadas para o primeiro submódulo.

Conforme se pode verificar por meio da Figura 5.6, a determinação da melhor rede neural para o primeiro submódulo necessitou de oito tentativas, sendo que a rede mais apta forneceu um erro relativo médio de 0,0017 . Esse valor de erro foi aproximadamente dez vezes inferior àquele observado com a pior rede. Assim, verifica-se que esse procedimento de tentativa é importante a fim de se escolher uma rede neural adequada ao módulo em questão.

O gráfico de erro relativo médio do submódulo 2 e submódulo 3 são apresentados em conjunto por meio da Figura 5.7. 

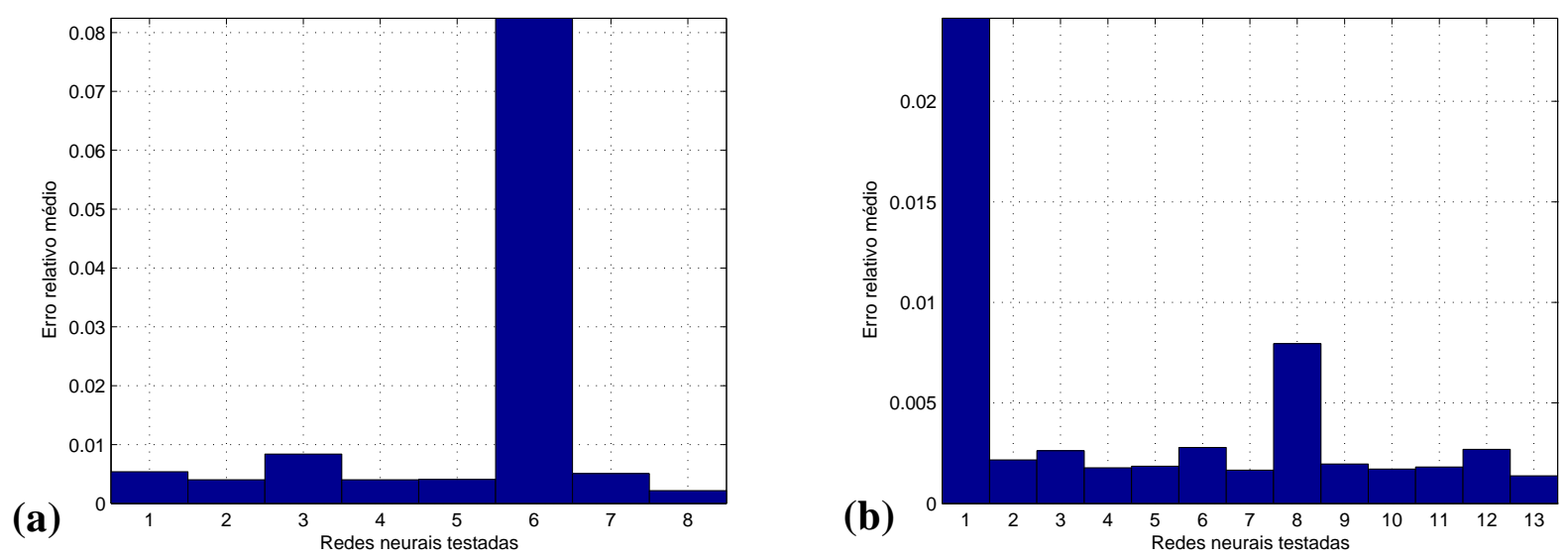

Figura 5.7 - Erro relativo médio das redes treinadas para o Módulo 1: (a) Submódulo 2; (b) Submódulo 3.

Conforme se verifica por meio dos gráficos da Figura 5.7, a determinação da melhor rede para o submódulo 2 necessitou do treinamento de 8 redes neurais, ao passo que para o submódulo 3 foram empregadas 13 redes neurais. Para o submódulo 2, o erro relativo médio em relação ao conjunto de teste foi de 0,0022 e, para o submódulo 3 , esse erro foi de 0,0014 . Prosseguindo com a apresentação dos resultados de treinamento para as redes neurais do primeiro módulo, tem-se na Figura 5.8 o gráfico dos erros relativos médios observados para o submódulo 4 e para o submódulo 5.

(a)

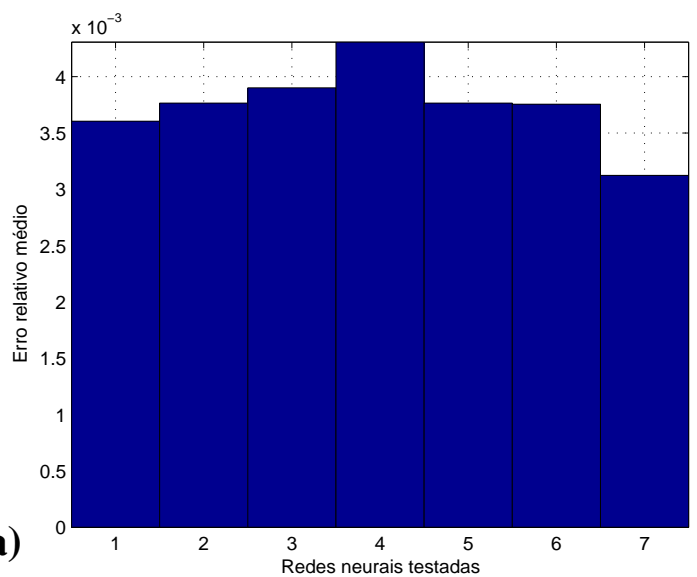

Figura 5.8 - Erro relativo médio das redes treinadas para o Módulo 1: (a) Submódulo 4; (b)

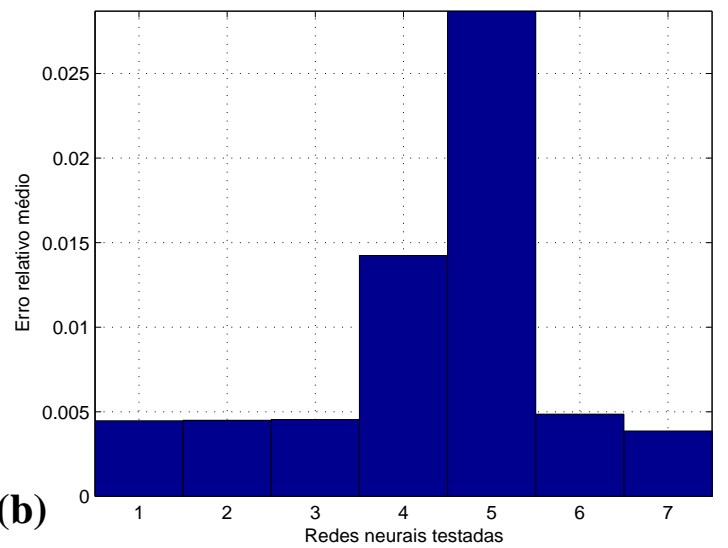

Submódulo 5. 
O menor erro relativo médio registrado para as redes neurais do submódulo 4 foi de 0,0031 e para o submódulo 5 fora de 0,0039. Em ambos os casos, a determinação do menor erro relativo médio utilizou sete redes neurais. Na Figura 5.9 apresentam-se os erros relativos médios para o submódulo 6 e para o submódulo 7 .

(a)

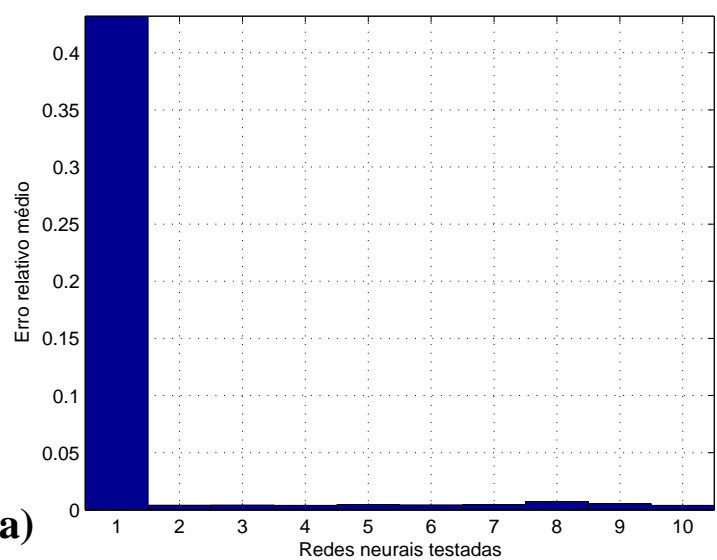

(b)

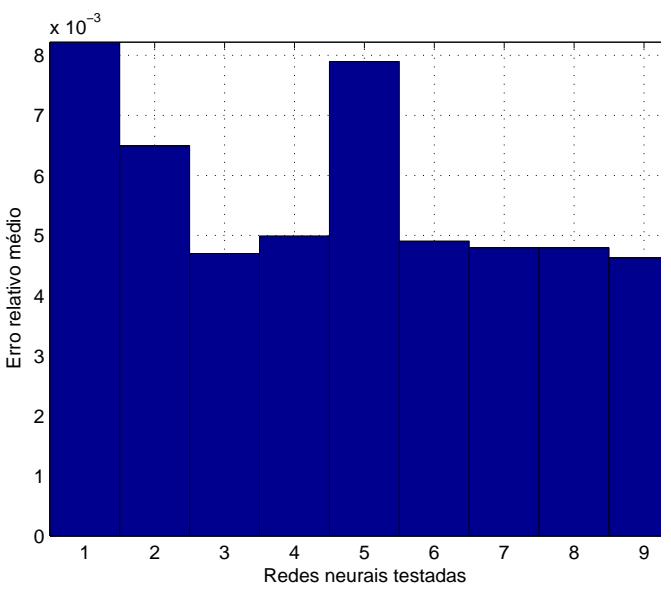

Figura 5.9 - Erro relativo médio das redes treinadas para o Módulo 1: (a) Submódulo 6; (b) Submódulo 7.

Pode-se observar por meio dos gráficos da Figura 5.9 que o número de redes neurais treinadas para o submódulo 6 e para o submódulo 7 foram de 10 e 9 redes, respectivamente. Esse processo de treinamento de redes conferiu ao submódulo 6 um erro relativo médio de 0,0038 e, para o submódulo 7, um erro de 0,0046. Para a implementação do submódulo 8 foi necessário o treinamento de 10 redes neurais, o que culminou em um erro relativo médio de 0,0016 . Os mesmos procedimentos foram realizados para os submódulos restantes, podendo-se assim condensar os resultados em forma tabular, os quais estão registrados na Tabela 5.1 . 
Tabela 5.1 - Redes neurais treinadas para submódulos do Módulo 1 de localização de faltas.

\begin{tabular}{|c|c|c|c|c|c|}
\hline Submódulo & $\begin{array}{l}\text { Redes } \\
\text { treinadas }\end{array}$ & $\begin{array}{c}\text { Erro } \\
\text { relativo } \\
\text { médio }\end{array}$ & Submódulo & $\begin{array}{l}\text { Redes } \\
\text { treinadas }\end{array}$ & $\begin{array}{c}\text { Erro } \\
\text { relativo } \\
\text { médio }\end{array}$ \\
\hline 1 & 8 & 0,0017 & 24 & 10 & 0,0004 \\
\hline 2 & 8 & 0,0022 & 25 & 9 & 0,0019 \\
\hline 3 & 13 & 0,0014 & 26 & 10 & 0,0073 \\
\hline 4 & 7 & 0,0031 & 27 & 9 & 0,0041 \\
\hline 5 & 7 & 0,0039 & 28 & 15 & 0,0025 \\
\hline 6 & 10 & 0,0038 & 29 & 9 & 0,0050 \\
\hline 7 & 9 & 0,0046 & 30 & 19 & 0,0072 \\
\hline 8 & 10 & 0,0016 & 31 & 11 & 0,0006 \\
\hline 9 & 13 & 0,0017 & 32 & 9 & 0,0024 \\
\hline 10 & 13 & 0,0030 & 33 & 13 & 0,0021 \\
\hline 11 & 14 & 0,0033 & 34 & 9 & 0,0064 \\
\hline 12 & 7 & 0,0004 & 35 & 11 & 0,0014 \\
\hline 13 & 9 & 0,0026 & 36 & 8 & 0,0031 \\
\hline 14 & 9 & 0,0015 & 37 & 11 & 0,0031 \\
\hline 15 & 13 & 0,0022 & 38 & 14 & 0,0029 \\
\hline 16 & 9 & 0,0028 & 39 & 18 & 0,0034 \\
\hline 17 & 9 & 0,0064 & 40 & 18 & 0,0043 \\
\hline 18 & 10 & 0,0051 & 41 & 8 & 0,0028 \\
\hline 19 & 7 & 0,0051 & 42 & 7 & 0,0035 \\
\hline 20 & 15 & 0,0014 & 43 & 10 & 0,0017 \\
\hline 21 & 9 & 0,0029 & 44 & 16 & 0,0048 \\
\hline 22 & 10 & 0,0036 & 45 & 10 & 0,0054 \\
\hline 23 & 7 & 0,0035 & & & \\
\hline \multicolumn{6}{|c|}{ Total de redes treinadas $=480$} \\
\hline
\end{tabular}

\subsubsection{Resultados referentes ao Módulo 2}

O segundo módulo para localização de faltas, ilustrado esquematicamente por meio da Figura 5.3, é constituído por 9 submódulos, os quais são responsáveis por informarem em qual trecho primário a falta ocorreu. Cada um desses submódulos representa um determinado bit na codificação dos trechos primários do alimentador padrão e, para o processo de localização de faltas, tais módulos fazem uso dos sinais de tensão e de corrente pré-processados, bem como utilizam os resultados dos demais módulos. Dessa maneira, cada módulo deve ser ajustado de forma conjunta, visto que as informações empregadas no seu processamento são oriundas tanto dos sinais de corrente e de tensão da falta como das informações 
fornecidas pelos demais submódulos, ou seja, esse módulo possui uma característica recorrente.

Por meio de inúmeras simulações computacionais, verificou-se que a arquitetura de rede neural que melhor se enquadrava à realização dessa tarefa é a perceptron multicamadas. Além disso, empregaram-se redes com uma única camada escondida, sendo que nessa camada foram alocados seis neurônios. De maneira similar ao que foi realizado no Módulo 1, cada rede foi treinada mais de uma vez, buscando-se maximizar a eficiência e a capacidade de generalização.

Ilustrando essa estratégia de treinamento, apresenta-se por meio da Figura 5.10 o erro relativo médio de todas as redes neurais treinadas para o primeiro submódulo.

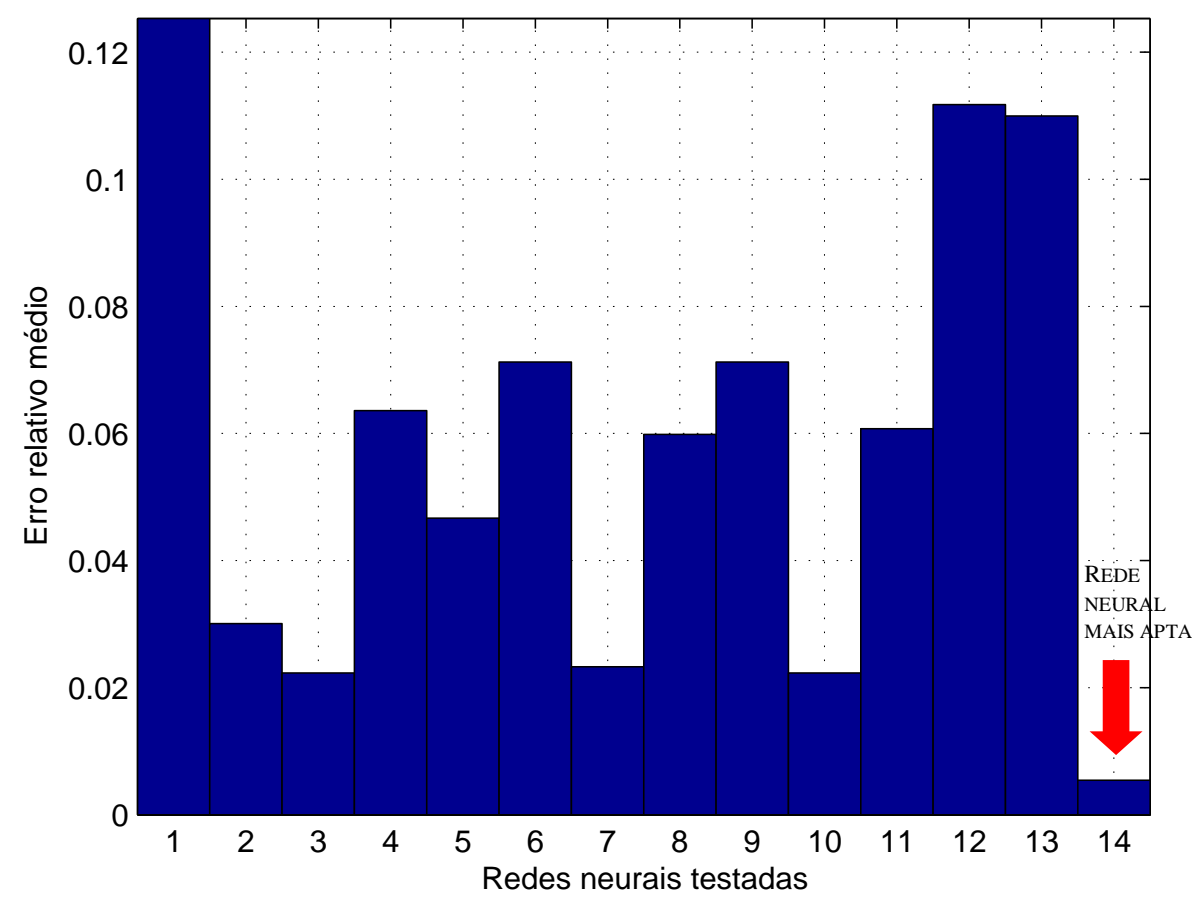

Figura 5.10 - Erro relativo médio das redes treinadas para o primeiro submódulo do módulo 2.

Semelhante ao realizado para o Módulo 1, todos os submódulos do Módulo 2 tiveram diversas redes treinadas e o ranking das melhores foi confeccionado tendo 
por base o erro relativo médio. Um resumo do processo de treinamento é apresentado na Tabela 5.2.

Tabela 5.2 - Redes neurais treinadas para submódulos do Módulo 2 de localização de faltas.

\begin{tabular}{|c|c|c|}
\hline Submódulo & $\begin{array}{c}\text { Redes } \\
\text { treinadas }\end{array}$ & $\begin{array}{c}\text { Erro } \\
\text { relativo } \\
\text { médio }\end{array}$ \\
\hline 1 & 14 & 0,0054 \\
\hline 2 & 20 & 0,0549 \\
\hline 3 & 19 & 0,0486 \\
\hline 4 & 15 & 0,0602 \\
\hline 5 & 14 & 0,0568 \\
\hline 6 & 17 & 0,0645 \\
\hline 7 & 23 & 0,0680 \\
\hline 8 & 16 & 0,0674 \\
\hline 9 & 13 & 0,0653 \\
\hline \multicolumn{2}{|c|}{ Total de redes treinadas $=\mathbf{1 5 1}$} \\
\hline \multicolumn{3}{|c}{} \\
\hline
\end{tabular}

\subsubsection{Resultado para o Módulo 3}

O terceiro módulo para localização de faltas, ilustrado esquematicamente por meio da Figura 5.4, é constituído por 6 submódulos, os quais são responsáveis por informarem em qual ramal do alimentador a falta ocorreu. Cada um desses submódulos representa um determinado bit na codificação desses ramais e, para o processo de localização de faltas, tais módulos fazem uso dos sinais de tensão e de corrente pré-processados, bem como utilizam os resultados dos demais módulos.

Dessa maneira, cada módulo deve ser ajustado de maneira conjunta, visto que as informações empregadas no seu processamento são oriundas tanto dos sinais de corrente e de tensão da falta como das informações fornecidas pelos demais submódulos, ou seja, esse módulo possui uma característica recorrente.

Novamente utilizou-se a estratégia de se treinar mais de uma vez as redes neurais dos módulos. Ilustrando essa estratégia de treinamento, apresenta-se por 
meio da Figura 5.11 o erro relativo médio de todas as redes neurais treinadas para o primeiro submódulo.

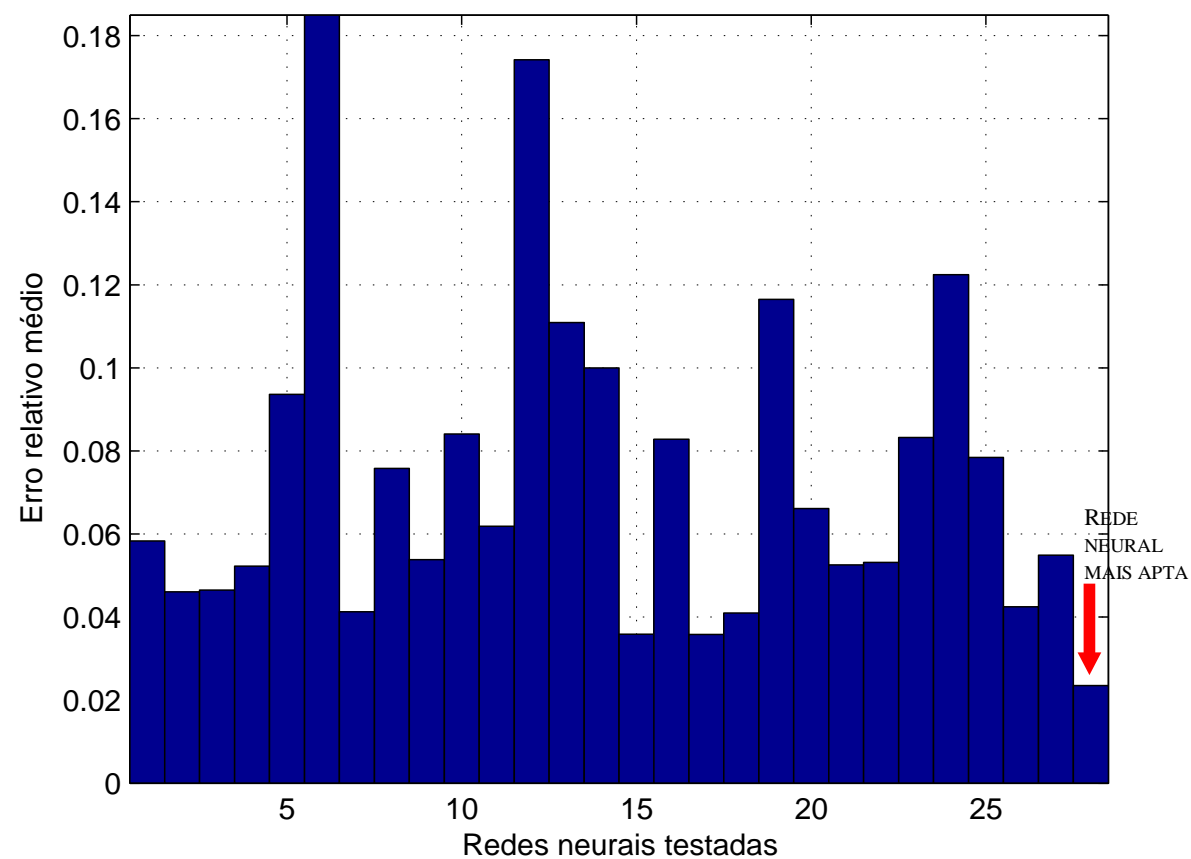

Figura 5.11 - Erro relativo médio das redes treinadas para o primeiro submódulo do Módulo 3.

Semelhante ao realizado para o Módulo 1 e 2, todos os submódulos do Módulo 3 tiveram diversas redes treinadas e o ranking das melhores foi confeccionado tendo por base o erro relativo médio. Um resumo do processo de treinamento é apresentado na Tabela 5.3.

Tabela 5.3 - Redes neurais treinadas para submódulos do Módulo 3 de localização de faltas.

\begin{tabular}{|c|c|c|}
\hline Submódulo & $\begin{array}{c}\text { Redes } \\
\text { treinadas }\end{array}$ & $\begin{array}{c}\text { Erro } \\
\text { relativo } \\
\text { médio }\end{array}$ \\
\hline 1 & 28 & 0,0235 \\
\hline 2 & 13 & 0,0275 \\
\hline 3 & 18 & 0,0481 \\
\hline 4 & 31 & 0,0496 \\
\hline 5 & 12 & 0,0455 \\
\hline 6 & 29 & 0,0480 \\
\hline \multicolumn{3}{|c|}{ Total de redes treinadas $=131$} \\
\hline
\end{tabular}


Nessa seção serão destacados diversos outros resultados computacionais obtidos por meio do sistema especialista, principalmente em relação ao Módulo 1 de localização, sendo que para os demais os resultados são similares. Conforme destacado anteriormente, o primeiro módulo para localização de faltas fora constituído por 45 submódulos, cada um dos quais responsáveis por localizar em qual dos ramais a falta ocorreu.

$\mathrm{Na}$ seqüência, apresentam-se por meio das Figuras 5.12 a 5.21 os resultados obtidos e aqueles desejados para a operação dos 10 primeiros módulos, sendo que é possível se constatar que a localização fornecida pelas submódulos diferem em alguns trechos dos resultados desejados.

Isto ocorre devido à saída da rede neural não ter sido normalizada. Assumese o valor representado por "1" como corresponde às situações de falta e "0" para não falta. Adotou-se tal postura de não normalização da saída da rede para que valores que estivessem fora da faixa de normalização sejam representativos da qualidade da resposta do sistema. Mais especificamente, os valores em "1" ou "0" representam situações onde a saída da rede apresentou resultados com grande certeza. Já os valores que divergem de "1" ou "0" possuem imprecisões frente à qualidade de resposta.

De maneira geral, pode-se afirmar que os resultados de localização dos submódulos foram satisfatórios dentre os $11 \times 10^{4}$ padrões avaliados; porém, cabe-se ressaltar que, mesmo se tratando de um alimentador de pequeno porte, a representação por 45 ramais é bastante simplificada frente ao nível de detalhamento que ainda é possível conferir, empregando-se para tal finalidade outras ferramentas de simulação de circuitos elétricos. 

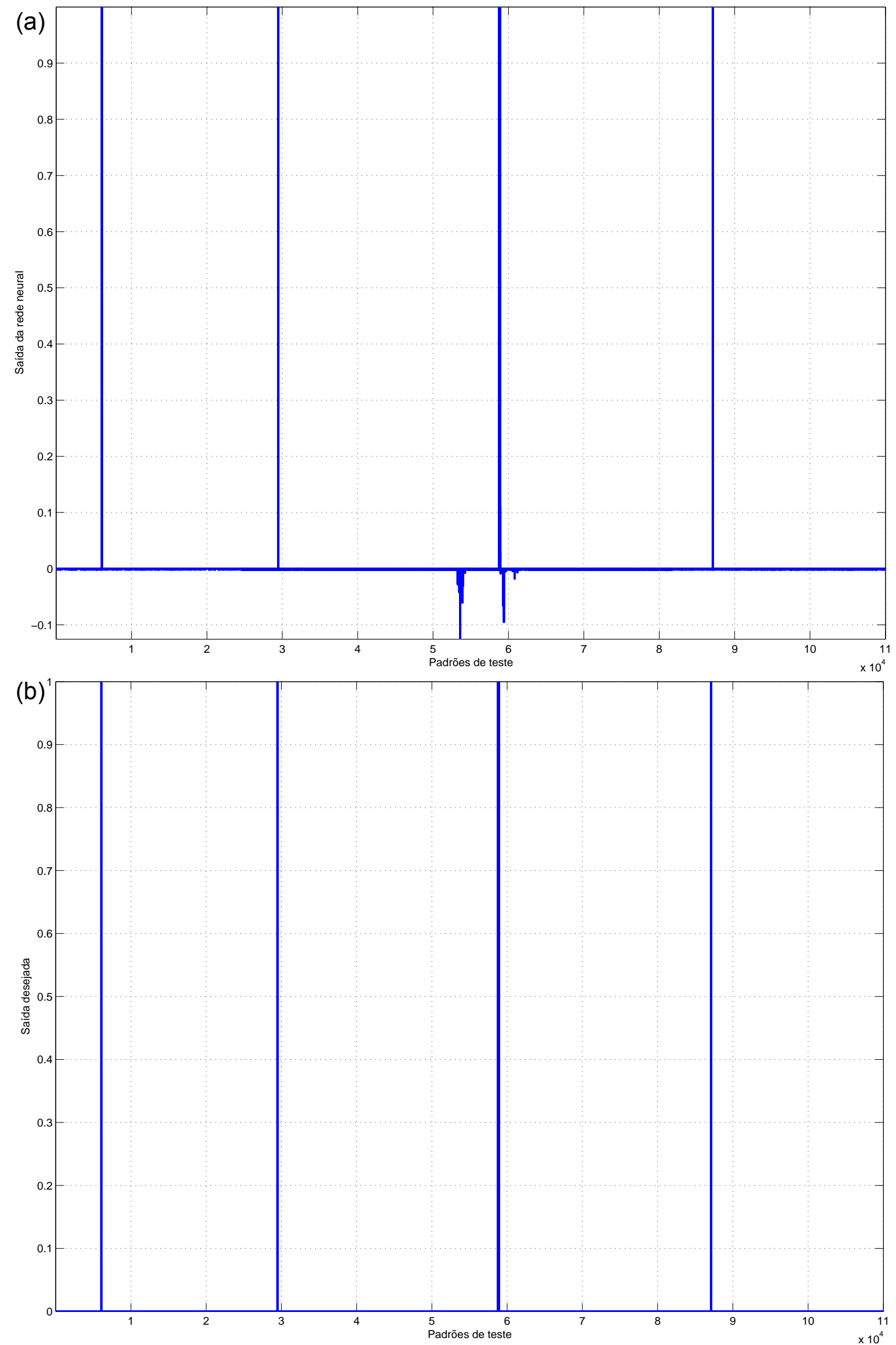

Figura 5.12 - Resultados de simulação para o submódulo 1 do Módulo 1: (a) Resultados fornecidos pelo submódulo; (b) Resultados desejados. 

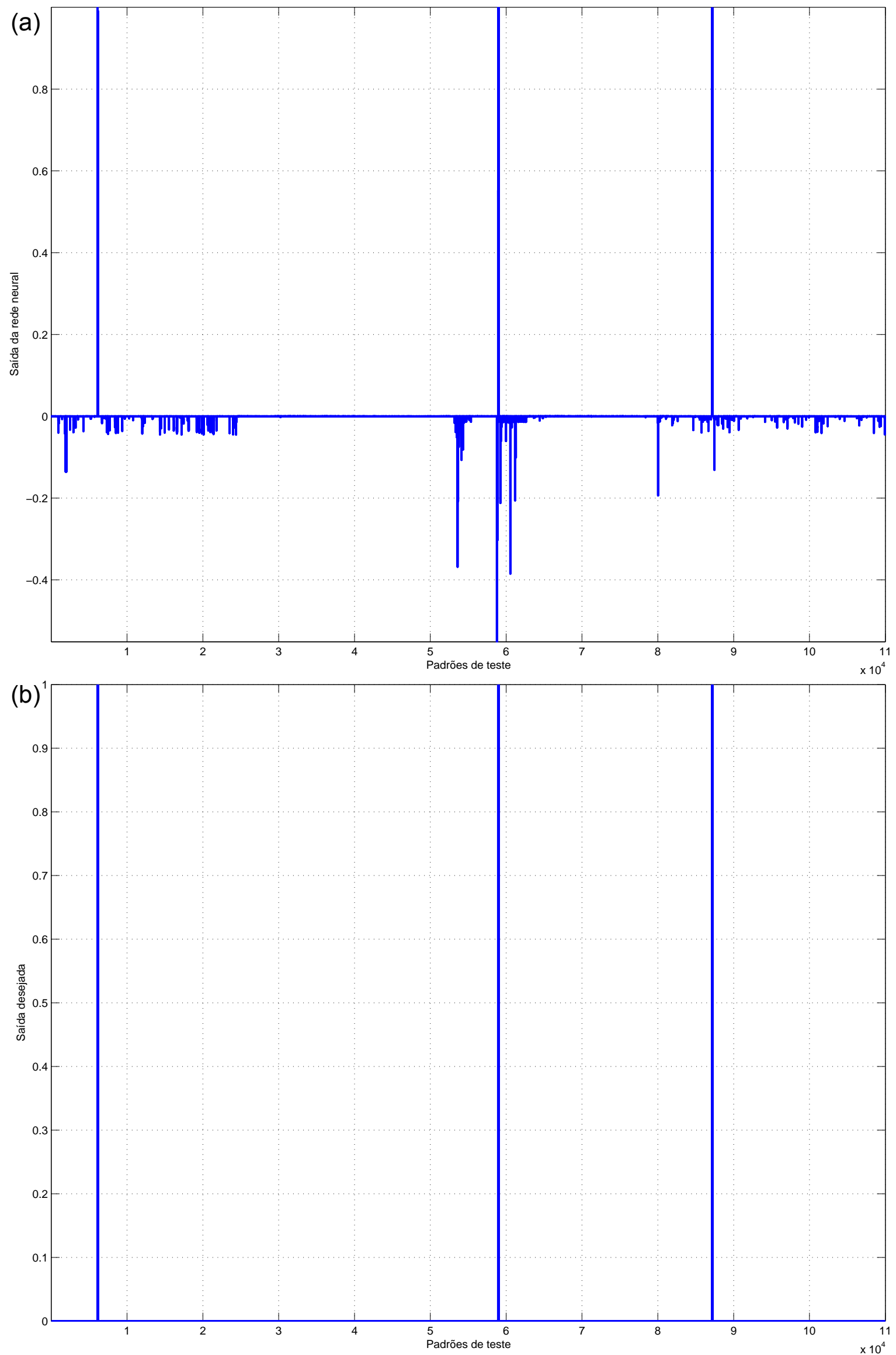

Figura 5.13 - Resultados de simulação para o submódulo 2 do Módulo 1: (a) Resultados fornecidos pelo submódulo; (b) Resultados desejados. 

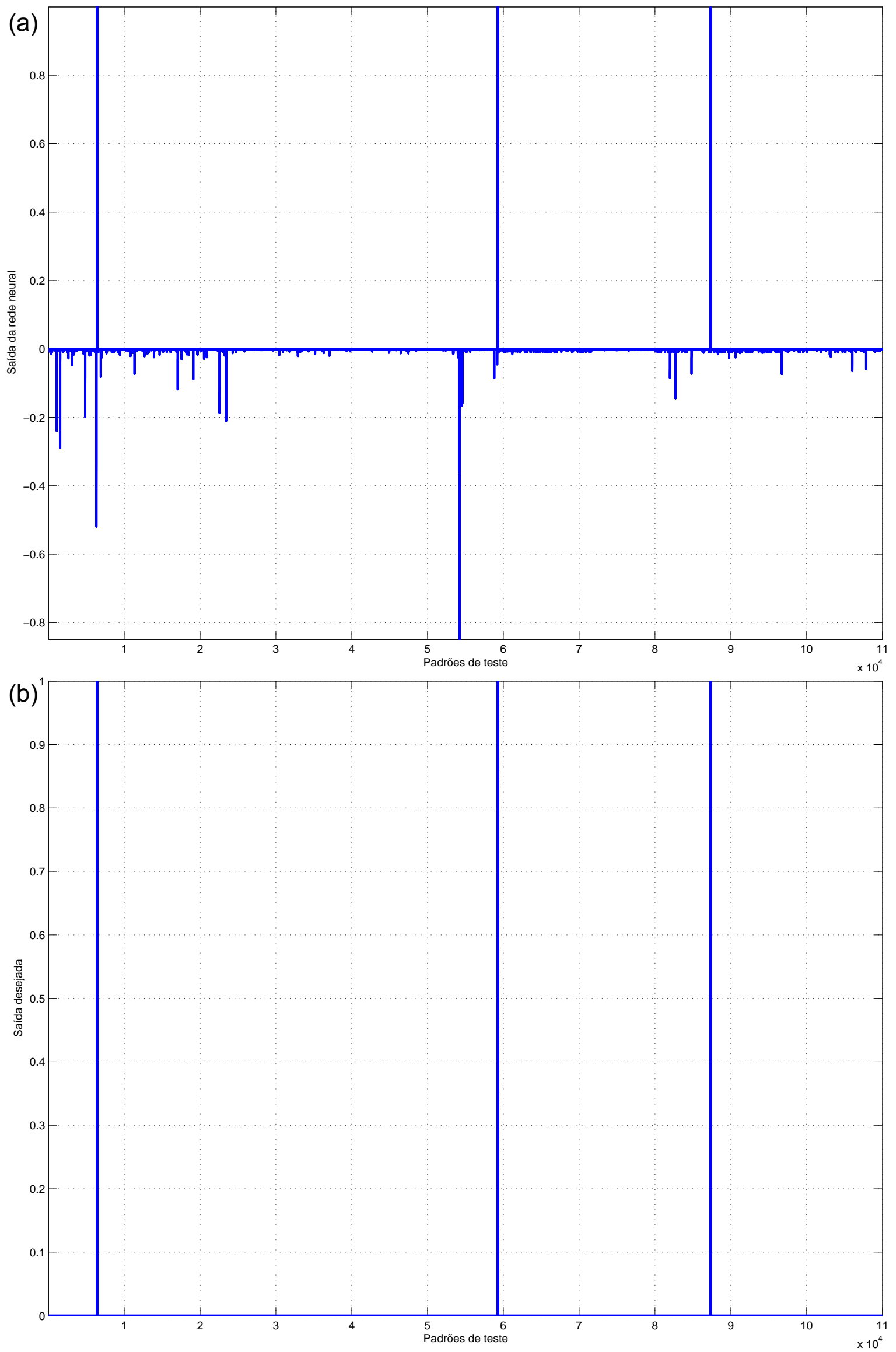

Figura 5.14 - Resultados de simulação para o submódulo 3 do Módulo 1: (a) Resultados fornecidos pelo submódulo; (b) Resultados desejados. 

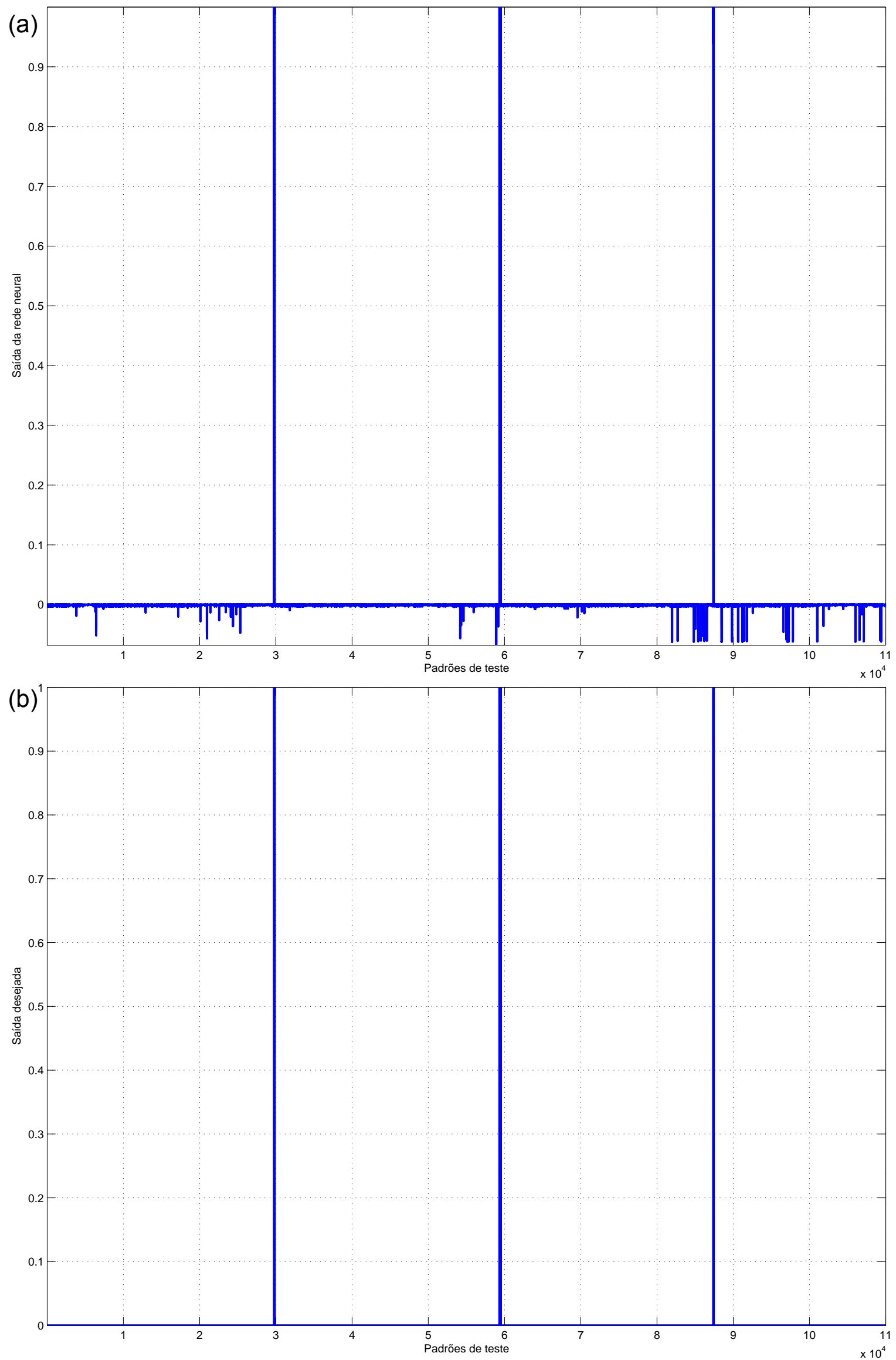

Figura 5.15 - Resultados de simulação para o submódulo 4 do Módulo 1: (a) Resultados fornecidos pelo submódulo; (b) Resultados desejados. 

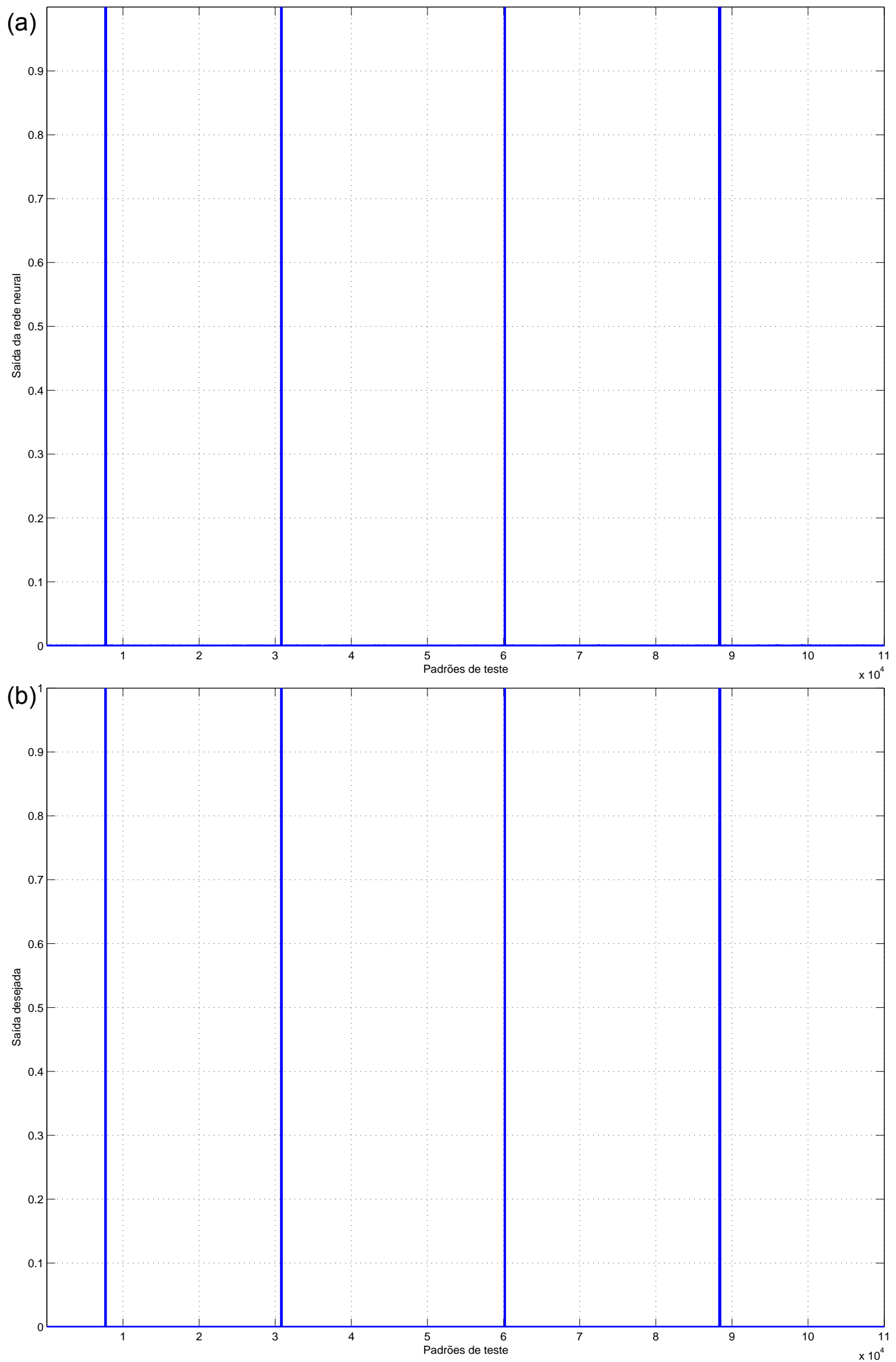

Figura 5.16 - Resultados de simulação para o submódulo 5 do Módulo 1: (a) Resultados fornecidos pelo submódulo; (b) Resultados desejados. 

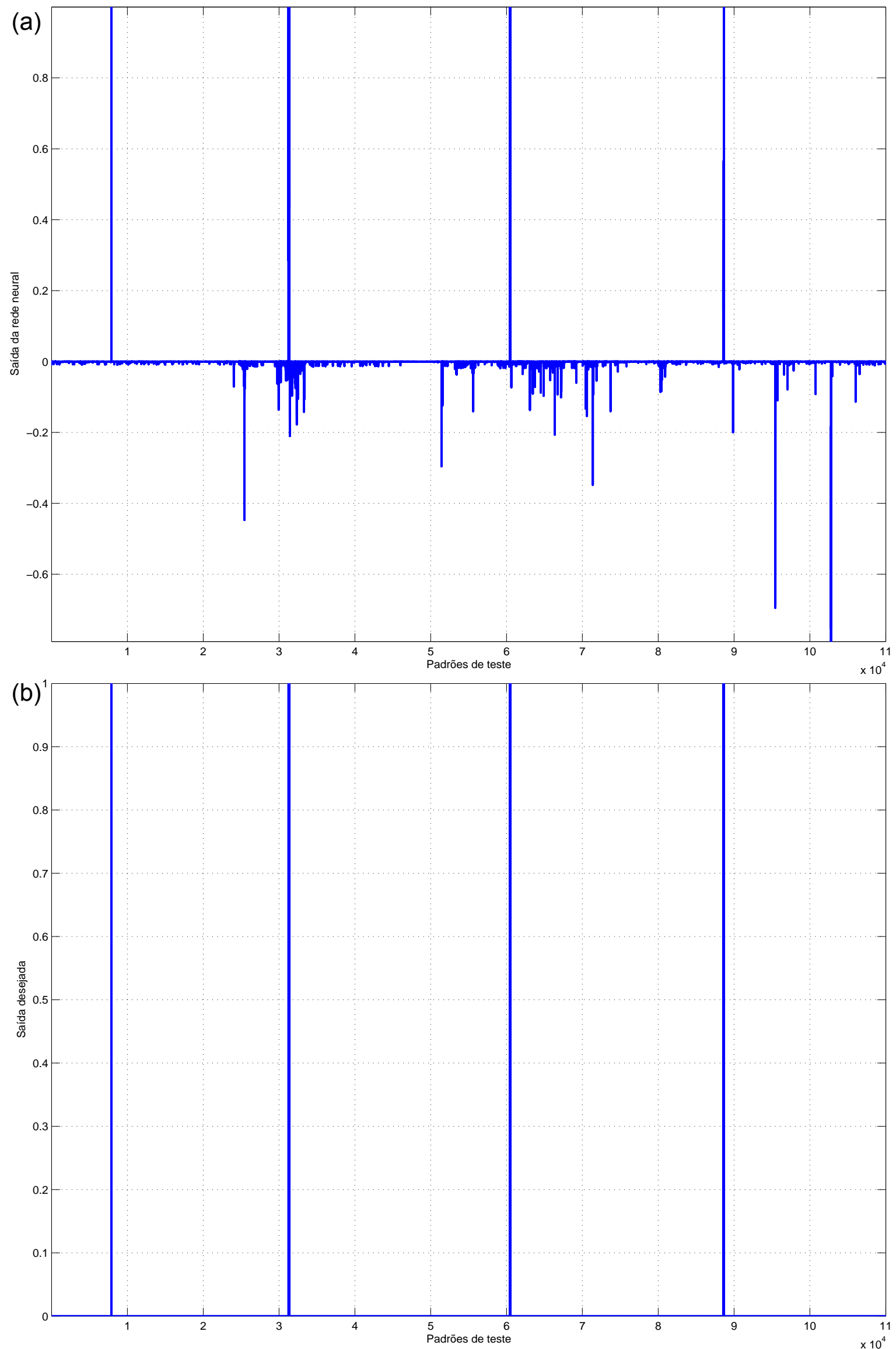

Figura 5.17 - Resultados de simulação para o submódulo 6 do Módulo 1: (a) Resultados fornecidos pelo submódulo; (b) Resultados desejados. 
168
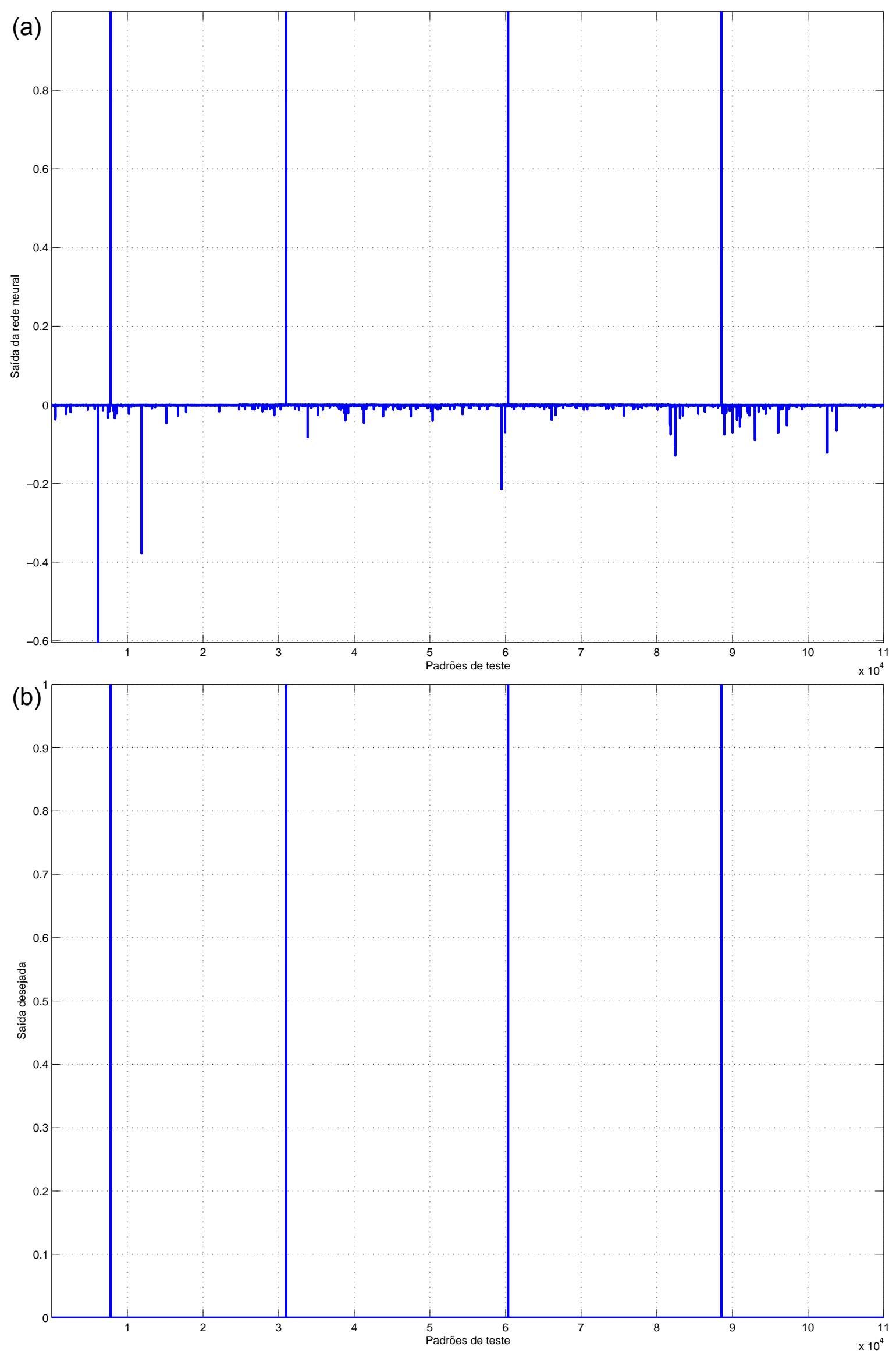

Figura 5.18 - Resultados de simulação para o submódulo 7 do Módulo 1: (a) Resultados fornecidos pelo submódulo; (b) Resultados desejados. 

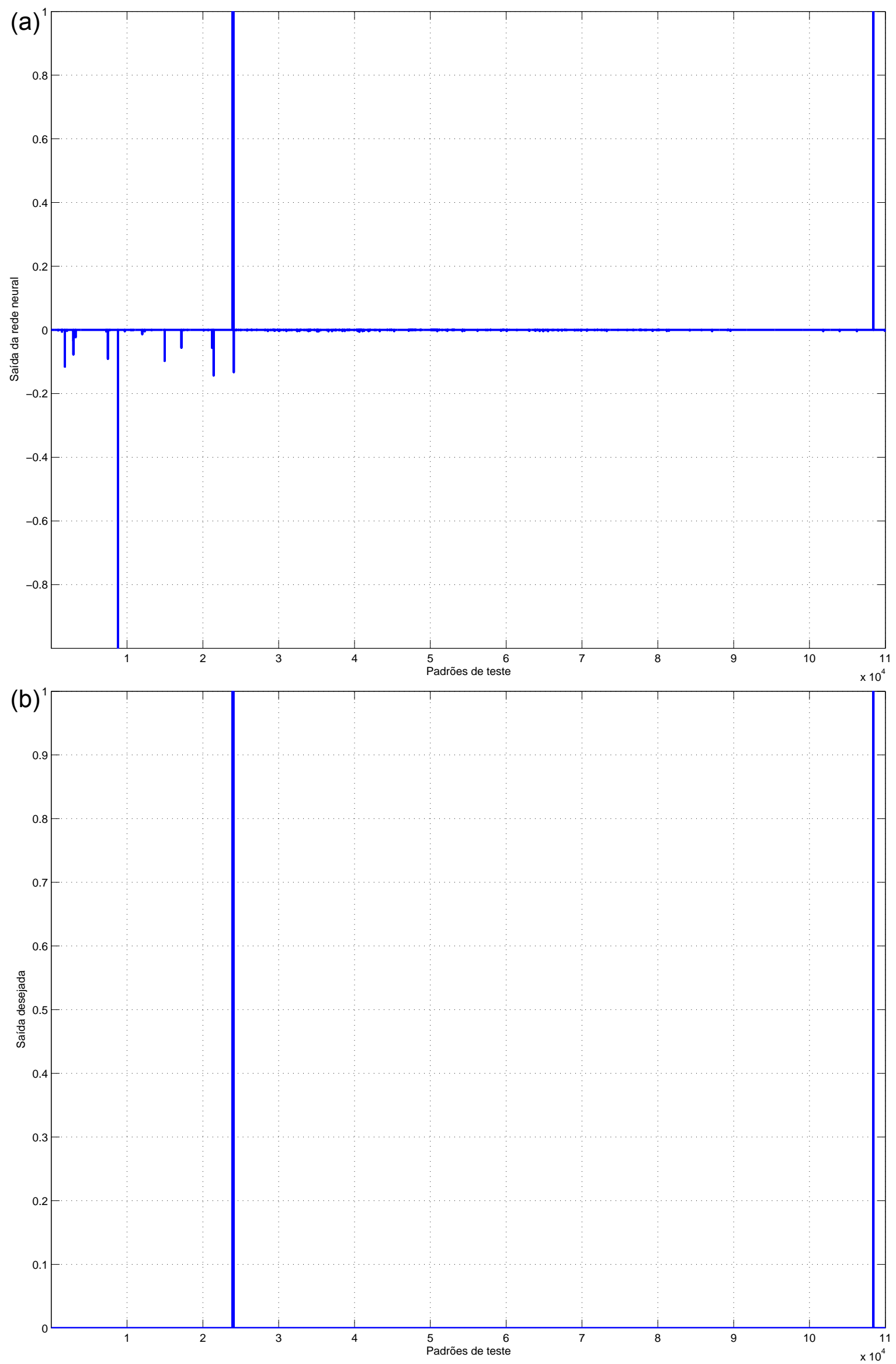

Figura 5.19 - Resultados de simulação para o submódulo 8 do Módulo 1: (a) Resultados fornecidos pelo submódulo; (b) Resultados desejados. 
(a)
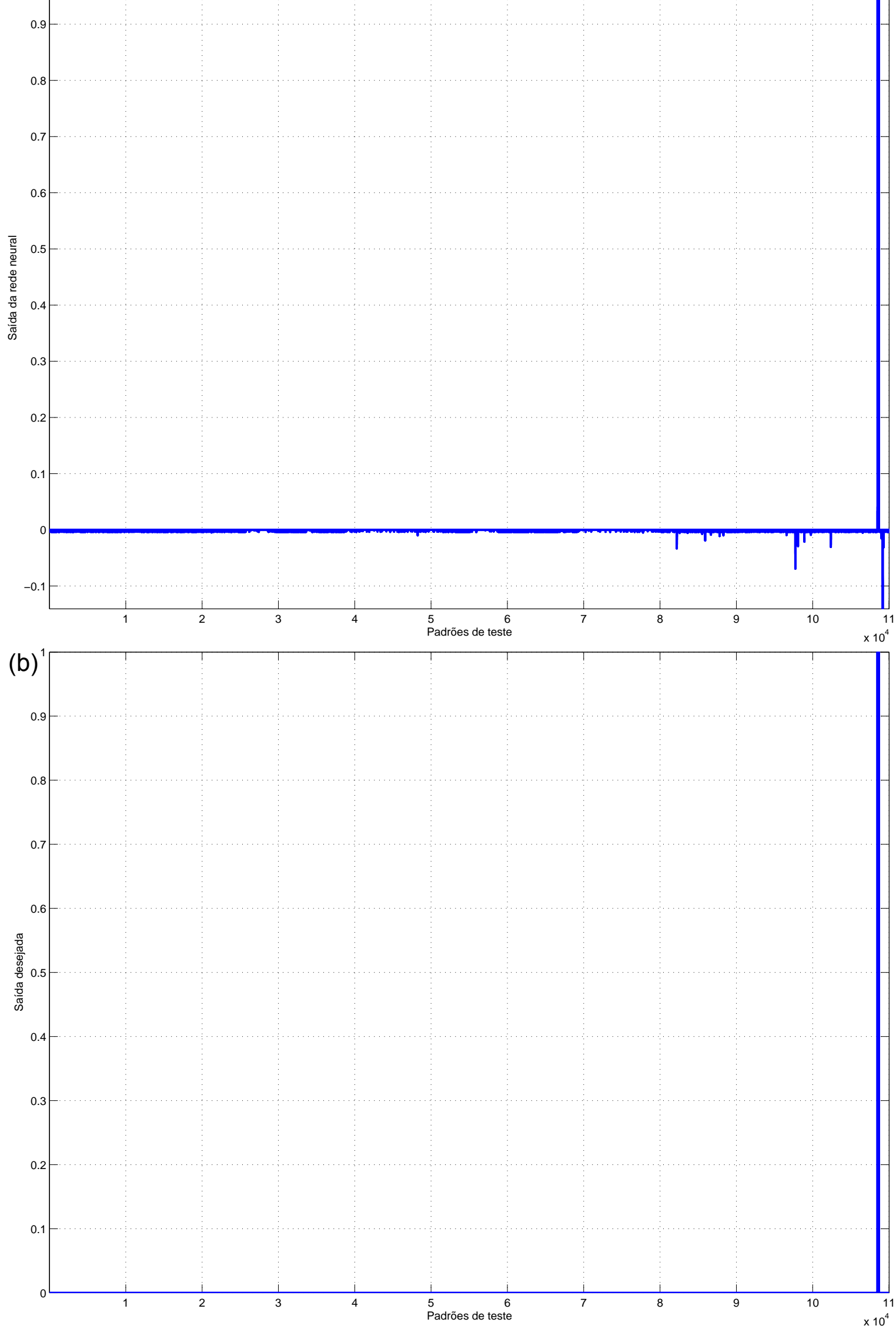

Figura 5.20 - Resultados de simulação para o submódulo 9 do Módulo 1: (a) Resultados fornecidos pelo submódulo; (b) Resultados desejados. 

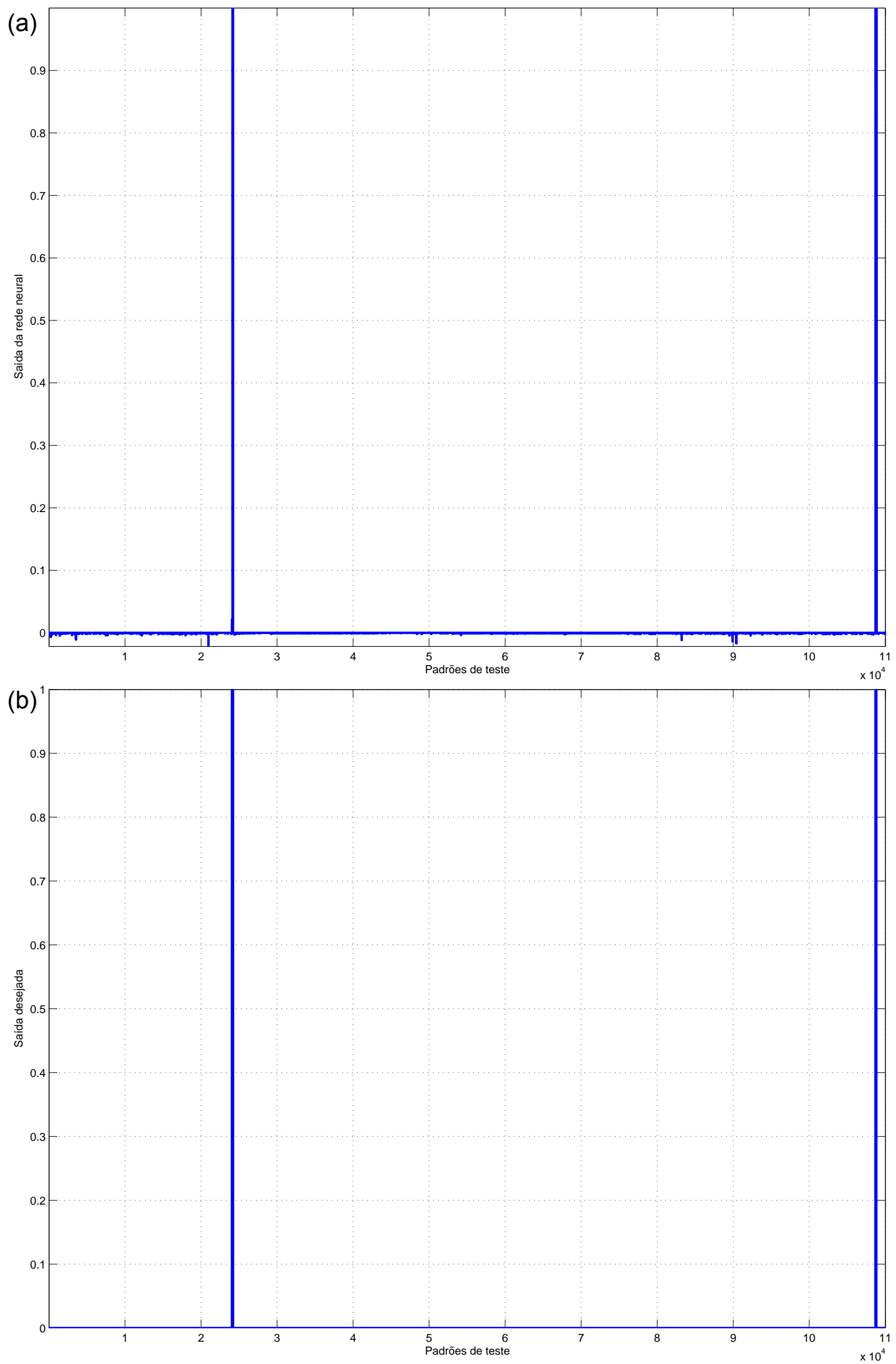

Figura 5.21 - Resultados de simulação para o submódulo 10 do Módulo 1: (a) Resultados fornecidos pelo submódulo; (b) Resultados desejados. 
Para a validação do Módulo 4 de localização, 21 situações de faltas foram apresentadas, sendo que as mesmas foram obtidas a partir de oscilografias de tensões e correntes da subestação do alimentador piloto. Dentre os dados disponíveis, foram escolhidos aqueles mais representativos do que realmente acontece no alimentador piloto, que seriam faltas de alta impedância (fase-terra).

Para avaliar a performance do sistema de localização de faltas, os ramais apontados pelo mesmo foram confrontados com os reais e o erro percentual da distância entre os mesmos foi contabilizado, como pode ser observado na Figura 5.22 .

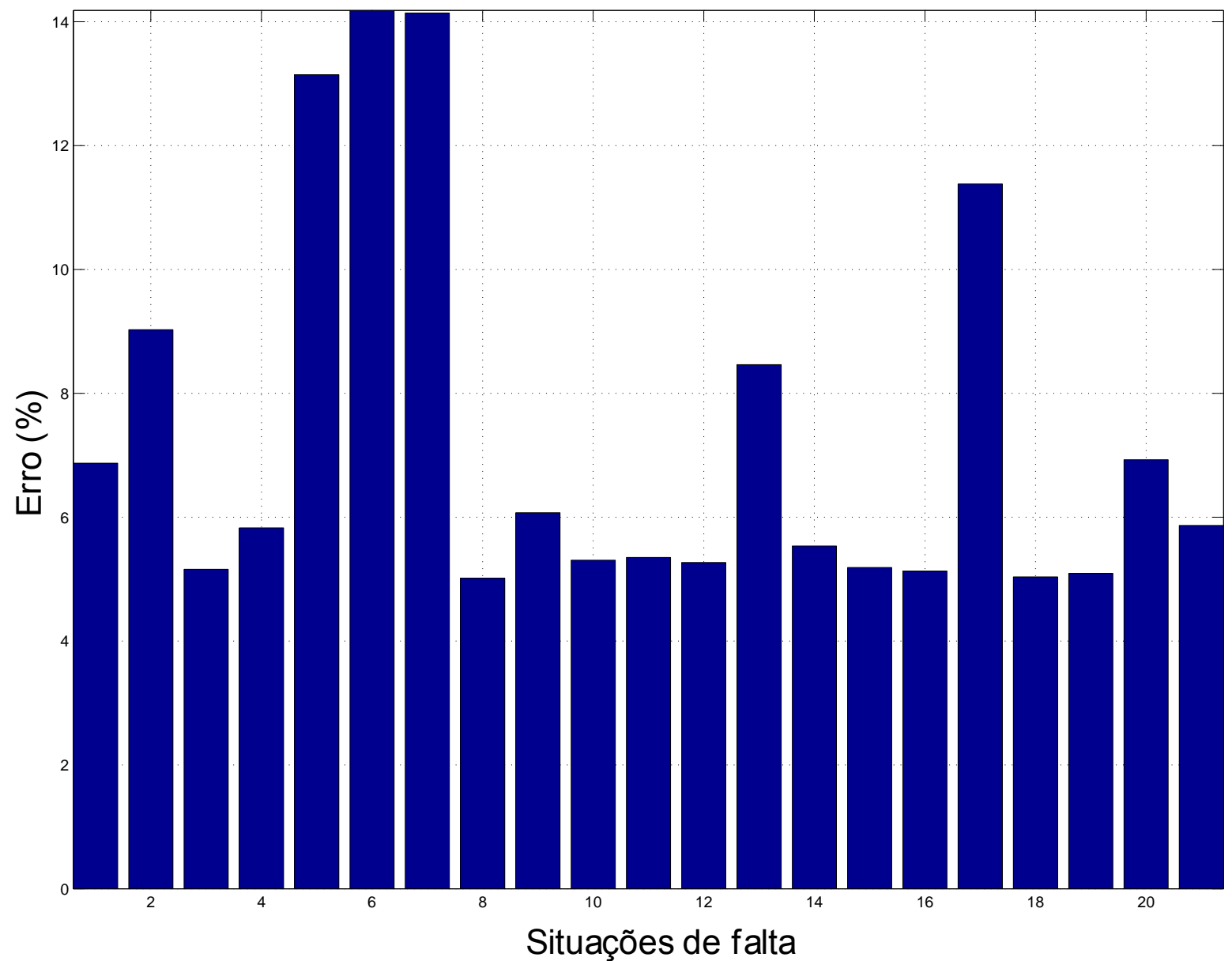

Figura 5.22 - Resultados de validação do módulo 4 de localização de faltas. 
É possível verificar por meio da Figura 5.22 que os erros de localização encontram-se entre $5 \%$ e pouco mais que $14 \%$, sendo a média em torno de $7 \%$. Tais erros são considerados aceitáveis frente aos benefícios de se possuir uma informação sobre o local da falta; porém, mais uma vez destaca-se que resultados melhores ainda podem ser conquistados com a representação mais detalhada do alimentador, permitindo-se então uma maior divisão dos trechos primários. 



\section{Monitoramento à distância do alimentador}

\section{piloto}

O sistema inteligente de localização de faltas é formado por dispositivos de aquisição (oscilógrafo) e de processamento de sinais (computador). O computador de suporte dos módulos de identificação e localização de faltas, que é instalado na subestação piloto, além de processar as informações adquiridas pelos dispositivos de aquisição de sinais, irá também realizar a manutenção de um banco de dados local, que abrigará as informações processadas sobre os transitórios armazenados.

O banco de dados será compatível com a tecnologia SQL (Structured Query Language), largamente utilizada nos mais diversos setores industriais e acadêmicos. Tais informações deverão ficar disponíveis aos operadores do COD para auxiliar a tomada de decisão frente a um desligamento não programado.

Neste capítulo serão apresentados os aspectos motivadores para a escolha da tecnologia de banco de dados visando o monitoramento à distância do alimentador piloto.

\subsection{Procedimento para tratamento de faltas em sistemas de distribuição}

Quando da ocorrência de uma interrupção não programada, procedimentos são tomados pela companhia que administra o circuito afetado a fim de restaurar a alimentação dos clientes no mais rápido possível. Neste contexto, pode-se destacar 
a ação primordial de dois grupos de equipes: operadores do COD e as equipes de manutenção.

As equipes de manutenção são as responsáveis por fazer a inspeção e remover o defeito da rede, sendo que elas respondem às diretivas comandadas pelo operador do COD. Apesar de ser consenso o fato de que uma interrupção precisa ser rapidamente tratada para que os consumidores possam ser restabelecidos, determinados aspectos necessitam ser cuidadosamente levados em conta pelo operador do COD antes de realizar os despachos das equipes. Tais aspectos envolvem o conhecimento do circuito em questão, apuração de informações vindas de call centers, equipes disponíveis e suas capacitações para tratar do problema em questão.

Para tais considerações, o operador utiliza geralmente um sistema computadorizado que possui dois monitores, conhecido como Dual Monitor, semelhante ao representado na Figura 6.1.

Em tais telas encontram-se informações vindas do sistema SCADA, contendo status de chaves, valores de tensões, correntes, potências, etc., além de informações referenciadas das equipes de manutenção, documentos relacionados aos circuitos e bases de dados do call center. 


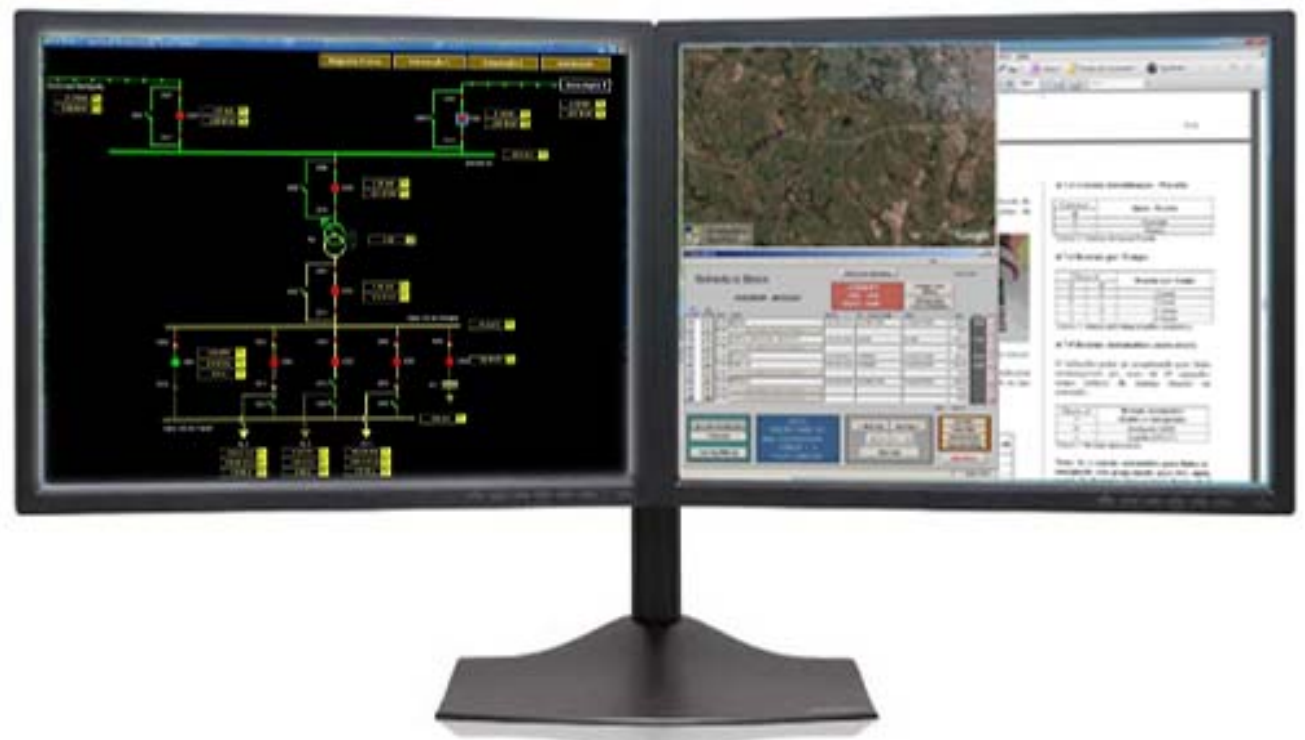

Figura 6.1 - Exemplo de dual monitor utilizado pelo operado do COD.

À medida que um desligamento é reconhecido, o operador inicia os procedimentos de restabelecimento a partir do respectivo guia de restabelecimento. Este documento possui informações valiosas sobre o circuito em questão, identificando pontos de manobra, localização de elementos sinalizadores de faltas, chaves e outros elementos de proteção, além de seqüências padronizadas de operações de acordo com cada tipo de desligamento.

Portanto, antes de acionar as equipes de manutenção, o operador faz uma varredura sobre as informações mais importantes do alimentador, recorrendo-se ao SCADA e do call center, se houver necessidade, a fim de setorizar as ações de restabelecimento.

Para que o operador tenha de pronto acesso todos os recursos para iniciar o tratamento de faltas, encontra-se à sua disposição uma ferramenta computacional, que possui um formato de gerenciador de base de dados, ou como é conhecido pelos operadores, SGD. Tal software aglutina o status das equipes disponíveis, gerencia os guias de restabelecimento e apresenta as informações do call center, 
sendo que sua função primordial é concentrar todas as informações que possam ser empregadas em situações de desligamento.

Assim, os operadores estão muito familiarizados com procedimentos de busca, inserções, edições e exclusões em bases de dados, tendo-se em vista que o SGD fornece todos os meios que ele precisa para dar prosseguimento ao restabelecimento.

A proposta de um sistema que trate de forma automatizada os procedimentos de identificação e localização de faltas comumente é associado a ferramentas georeferenciadas que emitem alertas aos operadores do COD, as quais mostram os possíveis locais da falta. Entretanto, uma ressalva precisa ser levada em conta no desenvolvimento deste tipo de sistema para auxílio da tomada de decisão em determinados cenários, tais como em que o operador encontra-se gerenciando muitas outras ocorrências ao mesmo tempo.

Neste caso, ele encontra-se em contato com várias equipes, lendo diversos guias de restabelecimento e buscando novas informações sobre o desligamento. De fato, os operadores entrevistados para o desenvolvimento desta pesquisa de doutorado argumentaram que a disponibilização de alarmes visuais, automatizados, a respeito de faltas no sistema de distribuição acaba por comprometer o nível de concentração, sendo que a disponibilização de medidas em que eles estejam mais familiarizados seria as mais adequadas.

Fora também levantado que tais sistemas de alarmes automatizados seriam interessantes em circuitos com elevado grau de automatização, onde setores defeituosos seriam automaticamente isolados para que o maior número de consumidores pudesse ser energizado antes mesmo de uma equipe inspecionar a rede. Tal nível de automatismo não era vislumbrado no alimentador piloto, assim 
como em outros circuitos brasileiros, tendo-se em vista a grande extensão média de nossas redes de distribuição.

Levando em consideração estes aspectos, foram escolhidas ferramentas que pudessem proporcionar ao operador o menor nível possível de perturbação, mas que ao mesmo tempo pudessem apresentar informações importantes sobre faltas ocorridas nos circuitos.

Esta estratégia envolveu a escolha de um sistema de comunicação bastante confiável e difundido, o TCP/IP, além de ferramentas de banco de dados que os operadores já possuíam grande experiência. Um relevante detalhe observado é que o sistema responsável por identificar e localizar as faltas no alimentador piloto estaria sempre executando suas ferramentas; porém, apenas no momento considerado oportuno pelo operador do COD é que estas informações seriam avaliadas para sua tomada de decisão.

Cabe ressaltar que o sistema de detecção de faltas não é responsável por ações realizadas em dispositivos de proteção ou mesmo manobras, ficando-se então a cargo do operador realizar tais operações.

A seguir serão então apresentados os aspectos envolvendo o sistema de comunicação e de base de dados escolhidos para a comunicação à distância do alimentador piloto.

\subsection{Sistema de bases de dados SQL}

O banco de dados SQL é estruturado na forma de tabelas e representa um paradigma de armazenamento de informações, com acesso a registros do tipo aleatório. A vantagem deste tipo de base de dados é permitir uma rápida indexação 
do conteúdo dos seus registros, sem a necessidade de se percorrer todos os ponteiros até chegar ao destino desejado [89].

Na Figura 6.2 é apresentado um exemplo de uma estrutura de base de dados em tabela, onde se podem encontrar um cadastro exemplo de um sistema de divulgação, que utiliza as categorias Impresso, CD-Rom, Internet e Outro. Cada campo deste está relacionado a um código, que pode ser um número gerado automaticamente pelo sistema ou uma representação particular que seja desejada pelo desenvolvedor.

\begin{tabular}{|c|c|c|c|}
\hline & codigodedivulgacao & nomedadivulgacao & $\Delta$ \\
\hline \multirow[t]{4}{*}{ 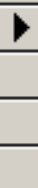 } & & 1 Impresso & \\
\hline & & CD-Rom & \\
\hline & & 3 Internet & \\
\hline & & Outro & $\vec{v}$ \\
\hline
\end{tabular}

Figura 6.2 - Exemplo de base de dados em tabela.

A grande vantagem de se empregar bases de dados fundamentadas em SQL é a facilidade de relacionamento entre campos, permitindo-se uma atualização dinâmica das informações à medida que é preciso expandir ou modificar a estrutura da base de dados. O relacionamento entre tabelas consiste em uma das etapas mais criteriosas para a confecção de uma base de dados, pois é a partir do sucesso da ação de conexão entre as tabelas é que resulta uma base de dados extremamente eficiente.

Um exemplo da aplicação do relacionamento da tabela de dados apresentada na Figura 6.2 pode ser encontrado na Figura 6.3. 


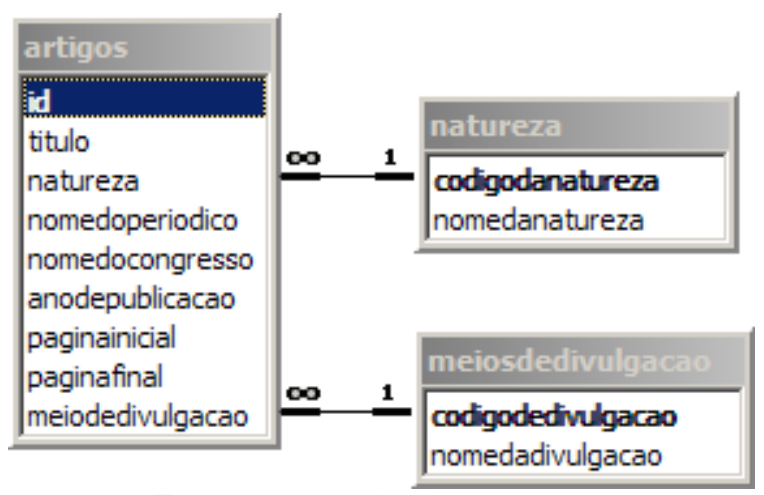

Figura 6.3 - Exemplo de relacionamento entre tabelas.

É possível observar que a tabela artigos possui relacionamento com duas outras tabelas, "natureza" e "meiosdedivulgacao". Tais tabelas relacionadas à tabela "artigos" são chamadas de complementares, pois elas armazenam informações tipadas para os campos em específico na tabela principal, podendo ser atualizadas dinamicamente, fornecendo-se mais opções de informações e preenchimento para o usuário.

Quando os relacionamentos entre tabelas começam a assumir grandes proporções, por exemplo aquele representado na Figura 6.4, além de massivo volume de dados, é preciso o emprego de bases de dados que melhor acondicionam este tipo de situação, sendo que uma das mais difundidas é a SQL. 


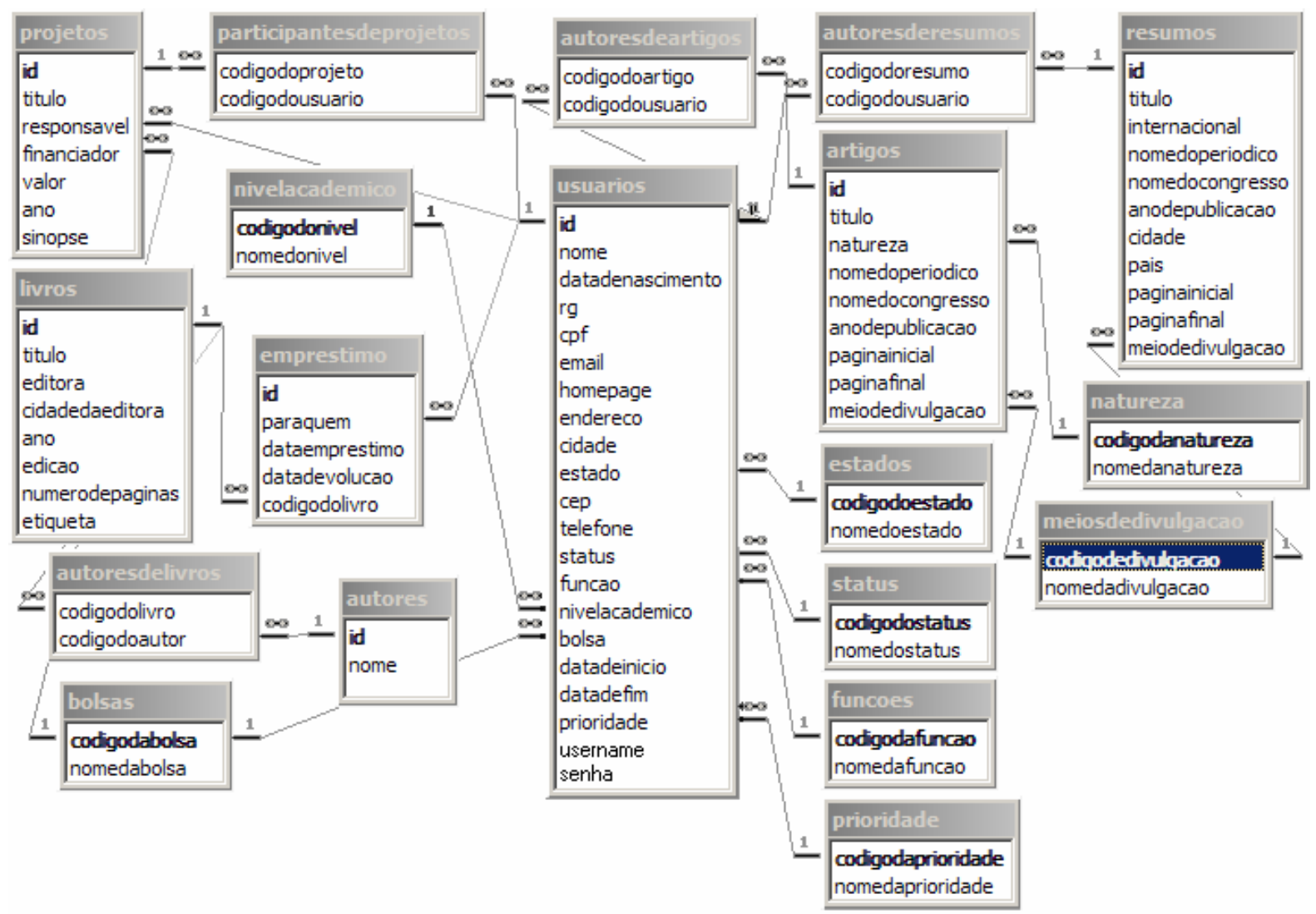

Figura 6.4 - Exemplo de relacionamento entre tabelas com massivas conexões.

Apesar da visualização em modo de estrutura representada nas Figura 6.3 e Figura 6.4, a SQL emprega linhas de comando para retornar buscas nas bases de dados. Estas linhas de comando, conhecidas por cláusulas ou queries SQL, podem ser empregadas tanto no desenvolvedor universal de $S Q L$ quanto em outras bases de dados fundamentadas na estrutura SQL.

Na Figura 6.5 tem-se um exemplo de uma cláusula SQL utilizada para retornar uma consulta a uma base de dados de nomes e informações sobre pesquisadores de um laboratório.

\begin{tabular}{|lrr|}
\hline SELECT usuarios.nome, usuarios.email, usuarios.homepage, funcoes.nomedafuncao, & \\
nivelacademico.nomedonivel FROM nivelacademico INNER JOIN (funcoes & INNER JOIN usuarios & ON \\
funcoes.codigodafuncao=usuarios.funcao) & ON \\
nivelacademico.codigodonivel=usuarios.nivelacademico & WHERE & usuarios.status=1 \\
usuarios.nivelacademico=1 ORDER BY usuarios.nome" & AND & \\
\hline
\end{tabular}

Figura 6.5 - Exemplo de cláusulas SQL. 
Por possuir documentação e funcionalidades já bem difundidas, a $S Q L$ possibilita, por exemplo, o emprego em outras linguagens de programação que permitem até mesmo a edição gráfica, seja ela por meio de ambientes voltados para web ou mesmo por ambientes de programação profissionais. Além disso, é ainda possível a realização de diversos serviços sobre as bases de dados a partir de ferramentas disponibilizadas pelos próprios fabricantes dos servidores de bancos de dados SQL.

A listagem das informações da base de dados, por esta ser de acesso aleatório, depende fortemente da coesão entre os termos da cláusula SQL, já que os acessos são realizados diretamente nos ponteiros dos registros apontados para serem lidos.

Para uma eficiente avaliação do local da falta, os campos considerados chaves, a serem localmente armazenados na base de dados que suportará as informações vindas dos sistemas inteligentes de localização de faltas, são os seguintes:

- Índice do registro de transitório.

- Índice seqüencial do registro na tabela de dados.

- Código da subestação.

- Código do alimentador.

- Estampa de tempo do registro oscilográfico.

- Tipo de falta.

- Distância da falta.

- Resistência de falta.

- Número total de possibilidades para a confiabilidade.

- Código da confiabilidade.

- Grau de acerto da confiabilidade. 


\subsection{Modelo de comunicação fundamentado em redes ethernet}

A subestação piloto onde o sistema de localização de faltas foi instalado e validado possui um sistema de comunicação fundamentado em redes ethernet. O tipo de rede ethernet, juntamente com as rotinas de protocolos TCP/IP, fornece a combinação de comunicação mais difundida e eficiente na história da comunicação de dados. Trata-se de uma rede de topologia barramento, onde as informações são propagadas por difusão, ou seja, os dados ficam disponíveis no barramento, porém, apenas o destinatário pode abri-lo.

Justamente pelo seu grande êxito, inúmeras companhias de energia estão adotando os modelos de comunicação ethernet para fornecer conectividade às suas subestações, e assim realizar downloads de informações oscilográficas, bem como status e sinais de alertas de dispositivos, além de realizar operações remotamente.

Outra substancial razão para a adoção de redes ethernet em comunicações entre os centros de operação da distribuição e as subestações se deve à grande estruturação em camadas das redes, que diminuem consideravelmente o índice de bits perdidos durante as transações. Este tipo de rede permite a integração de diversos módulos de serviços, uma vez que possuem dispositivos de aglutinação de hosts mais customizados. Na Figura 6.6 é possível visualizar o exemplo de uma rede de computadores do tipo ethernet contendo diversos dispositivos, ou hosts, com funcionalidades diferenciadas. 


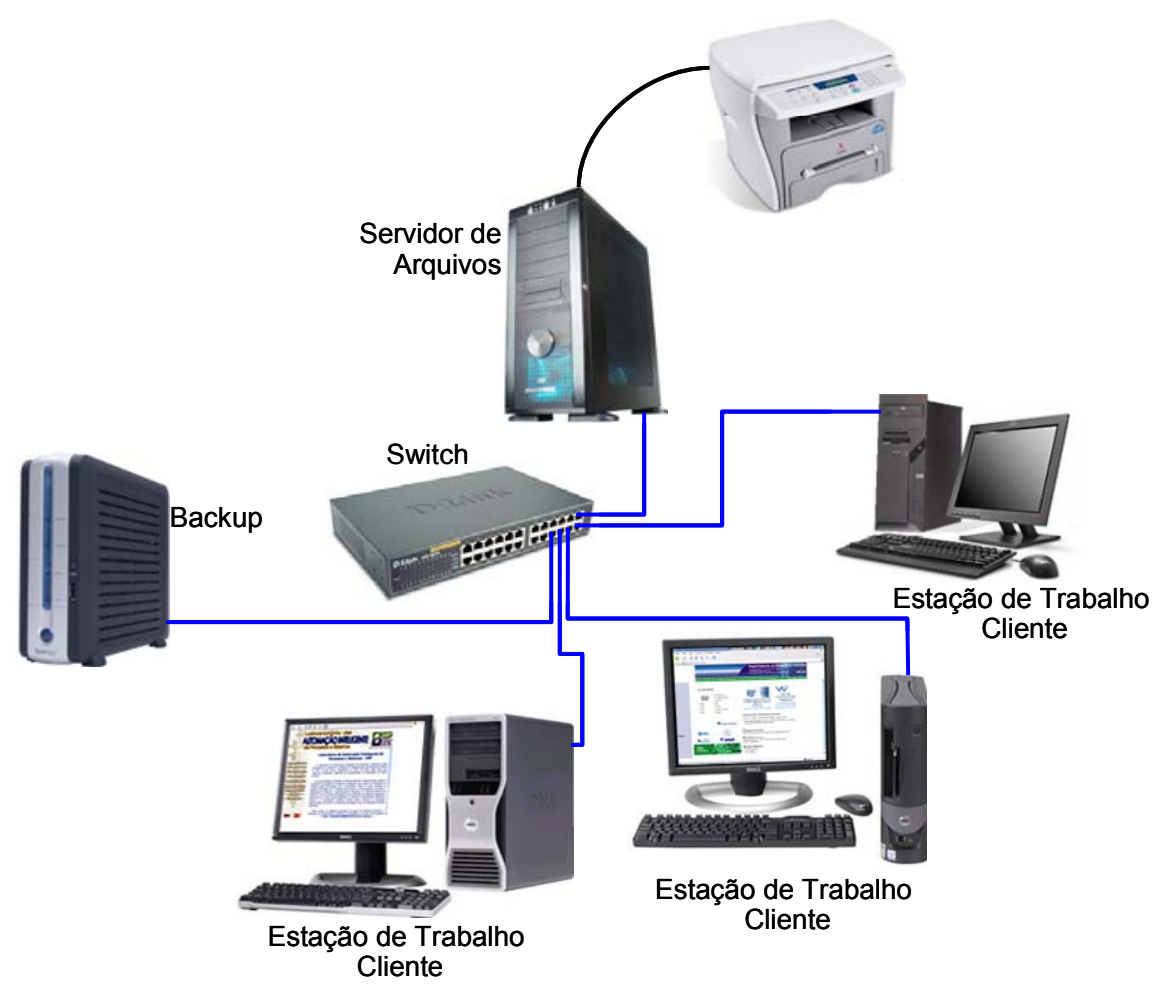

Figura 6.6 - Exemplo de rede ethernet com diversos hosts.

Da Figura 6.6 se pode destacar o Switch, dispositivo responsável por concentrar e aumentar o número possível de hosts que podem ser utilizados na rede. Este dispositivo conecta os diversos computadores, impressoras, servidores, etc, na rede ethernet, permitindo que os dados (na forma de difusão) fiquem disponíveis para todos os membros da rede. Para que os dados sejam transmitidos da subestação, que contem o sistema de localização de faltas, até o centro de operação da distribuição onde as informações serão processadas, existem à disposição dos engenheiros diversos meios de comunicação.

Atualmente, vem ganhando bastante espaço os meios envolvendo a cobertura digital de dados via celular, com o padrão GSM de transmissão de informações. Esta tecnologia possui um grande potencial de aplicação, principalmente envolvendo o sincronismo entre dispositivos localizados ao longo do alimentador e os concentradores de informações na subestação. Outro meio que também apresenta boas características para essa comunicação são as linhas 
privativas de comunicação de dados, que permitem o tráfego tanto de voz e dados em formato digital.

Estas duas tecnologias são extremamente diferenciadas em banda disponível, disponibilidade e custo de implementação, e sua penetração dentro do cenário de sincronismo remoto entre subestações ainda é tímido, principalmente em locais relativamente afastados dos centros urbanos.

Esta é uma das razões para as companhias distribuidoras de energia adotar o meio de comunicação via satélite, pois apesar dos elevados custos envolvidos e à limitação de banda de transmissão, este sistema possui uma disponibilidade muito superior às demais alternativas, o que representa um artifício estratégico para a operação em tempo real dos dispositivos envolvendo a distribuição de energia.

Na Figura 6.7 tem-se um exemplo da utilização da comunicação via satélite para transmissão de dados.

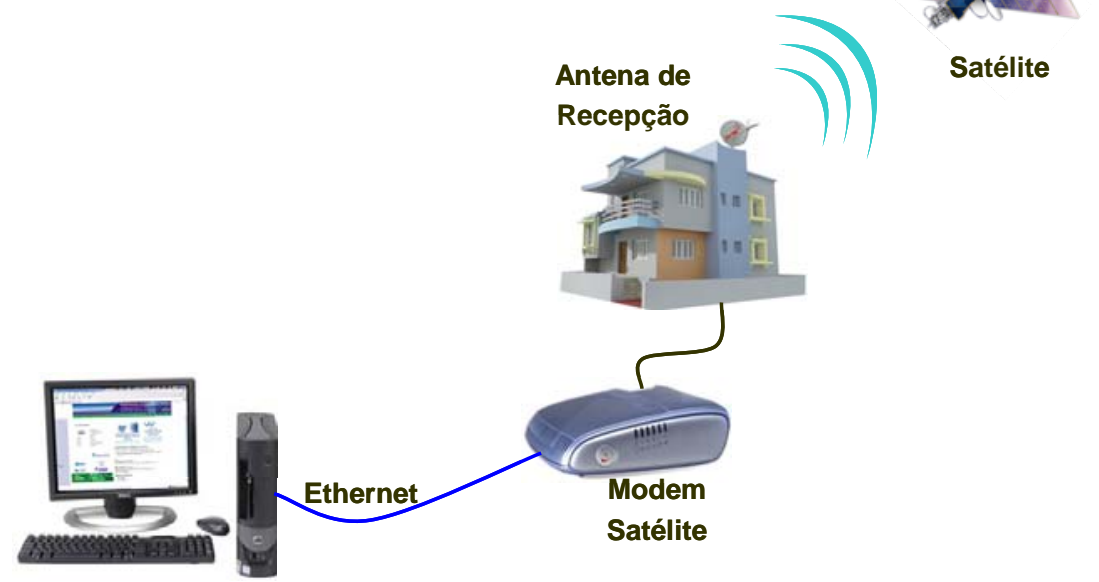

Figura 6.7 - Exemplo de comunicação via satélite.

A comunicação é realizada por meio de um Modem Satélite, responsável por converter os sinais vindos do Satélite em órbita, transferindo-se os dados para a central de distribuição de informações, que pode ser um Switch, um Hub ou mesmo um servidor de dados. Conectado ao Modem Satélite encontra-se uma antena, 
responsável por alinhar a visada do sinal e amplificar o mesmo, para que seja possível o estabelecimento do link de comunicação. O sinal é enviado do Satélite para o Modem Satélite e, assim, é possível estabelecer redes de comunicação com outras redes separadas por grandes distâncias. Os dados podem inclusive trafegar de um satélite para outro até chegar ao seu destino final, pois o número de canais disponíveis por dispositivo é limitado. Para cobrir a maior área possível do globo é, portanto, preciso uma massiva rede de satélites geoestacionários.

Este tipo de sistema de comunicação é atualmente considerado um dos mais caros entre os disponíveis. Isso porque se avalia o custo por bit transmitido e, como a banda disponível via satélite possui limitações, a taxa de bit transmitido acaba sendo a principal desvantagem desta tecnologia.

Apesar de existirem diversas bandas de freqüências disponíveis para a transmissão via satélite, as mesmas variam de $9.6 \mathrm{kbits} / \mathrm{s}$ à $496 \mathrm{kbits} / \mathrm{s}$, sendo esta última obtida quando se utilizam as antenas do tipo "Pizza", que trabalham em velocidade próximas das bandas largas comercialmente usadas via rede de telefonia.

Mesmo possuindo limitações de banda e alto custo de implementação, este tipo de aplicação é a mais recomendada e utilizada para serviços de tempo real, principalmente porque o satélite pode cobrir áreas onde a rede de telefonia não tem suporte. Considerando-se que os dados vindos das subestações em sua maioria trafegam em formato texto, tem-se um grande aproveitamento do link de comunicação, mesmo este sendo de velocidade de $9.6 \mathrm{kbits} / \mathrm{s}$.

Outro ponto positivo da comunicação via satélite é a grande rede de satélites de comunicação geoestacionários disponíveis para transmissão de dados, deixando este tipo de serviço robusto. Assim, mesmo com custos mais elevados, a 
comunicação sendo realizada via satélite é o meio mais confiável e controlável para acessar as informações dos dispositivos da subestação e enviá-los ao centro de distribuição.

\subsection{Estratégia de comunicação à distância do alimentador piloto}

O sistema de localização de faltas desenvolvido nesta pesquisa encontra-se em funcionamento em um computador do tipo PC, que foi instalado na subestação piloto. Após a ocorrência de um transitório, as informações elétricas serão processadas neste computador local para a determinação de característica de faltas. Caso positivo, ou seja, uma falta foi constatada, todos os mecanismos responsáveis por determinar o local da falta serão realizados e os resultados para o auxílio à tomada de decisões serão armazenados em um banco de dados neste computador local. Este PC estará conectado à rede ethernet da subestação por meio de um cabo de rede, que interliga o centro de distribuição de dados, Switch ou Hub, até o Modem Satélite.

Por meio da comunicação via satélite, bidirecional, com uma antena localizada no centro de operação da distribuição e outra na subestação, será então possível acessar esta base de dados através de cláusulas de banco de dados a fim de realizar operações nesta.

Tais cláusulas se resumem em comandos no formato texto e tráfego de informações também em formato texto, o que não onera o link de comunicação, mesmo com as bandas mais estreitas disponíveis para a transmissão de dados. Esta estratégia de comunicação permite que, a partir de qualquer ponto da rede ethernet do centro de operação da distribuição, seja possível acessar a rede ethernet das 
subestações e realizar o download das informações da base de dados de localização de faltas, usando-se como meio de transmissão a comunicação via satélite.

Na Figura 6.8 encontra-se um diagrama esquemático de como funciona o sistema de localização de faltas e também o preenchimento da base de dados de faltas.

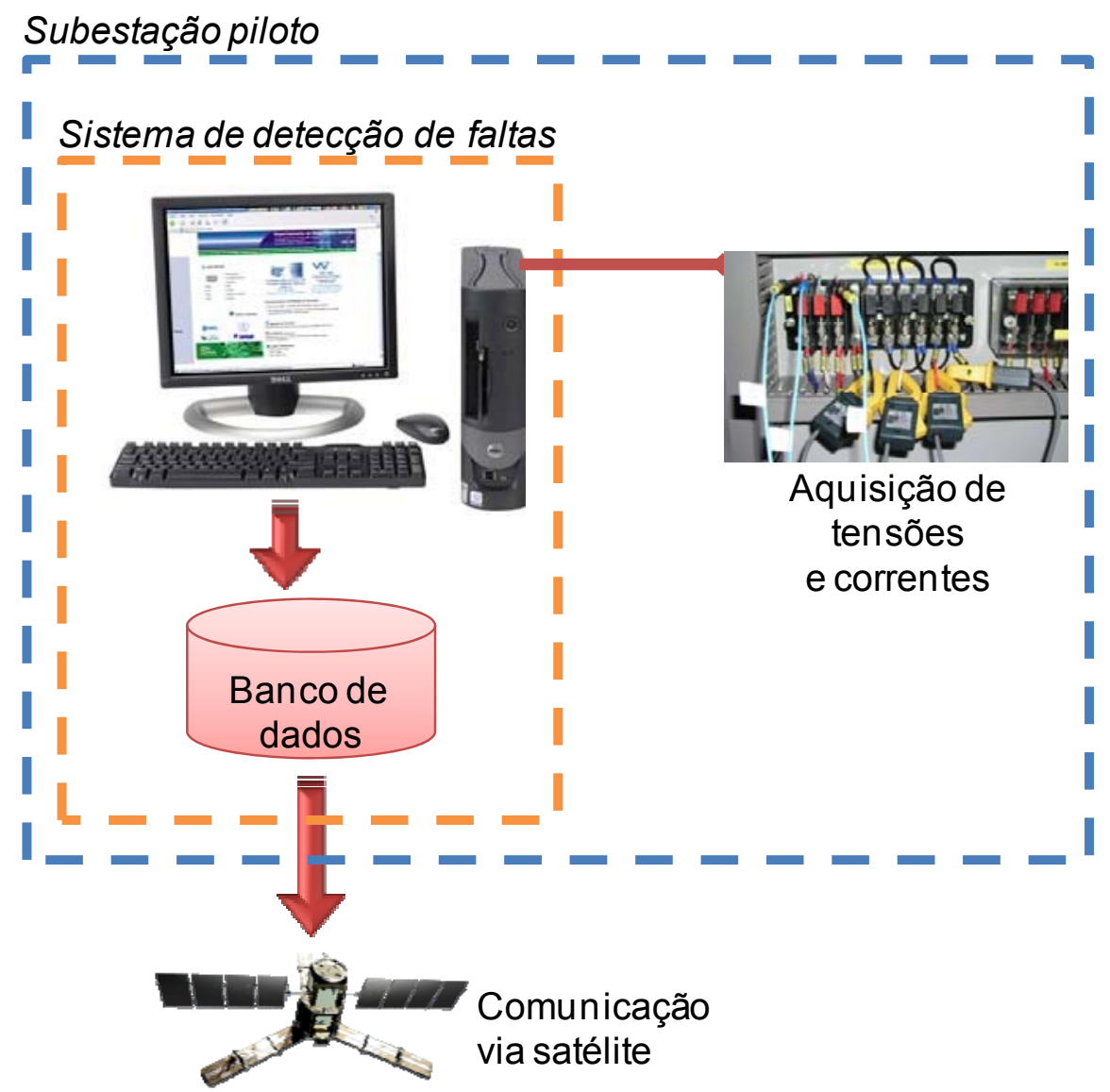

Figura 6.8 - Sistema de localização de faltas instalado na subestação.

Cada evento relacionado a uma falta gera um registro com 11 colunas. À medida que estes eventos vão populando a base de dados, como no exemplo da Figura 6.9, é preciso se definir os procedimentos de sincronismo com um servidor no centro de operação, para que as informações fiquem disponíveis para todos. 


\begin{tabular}{|c|c|c|c|c|c|c|c|c|c|c|c|}
\hline & $?$ id & subestacao & alimentador & est_tempo & tipo_falta & distancia_falta & resistencia_falta & tot_ert_contabil & indice_confiabil & cod_confi_inf & grau_acerto_confiabil \\
\hline \multirow[t]{6}{*}{ 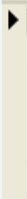 } & 1 & RCT & 30 & 2009-06-02 23:35:00 & 1 & 5.000000 & 20.000000 & 2 & 95 & 23 & 95.000000 \\
\hline & 2 & RCT & 30 & 2009-06-02 23:35:05 & 1 & 5.000000 & 20.000000 & 3 & 94 & 23 & 92.000000 \\
\hline & 3 & RCT & 30 & 2009-06-02 23:36:01 & 1 & 5.000000 & 50.000000 & 1 & 96 & 23 & 98.000000 \\
\hline & 4 & RCT & 30 & 2009-06-02 23:37:00 & 1 & 6.000000 & 20.000000 & 4 & 95 & 14 & 95.000000 \\
\hline & 5 & $\mathrm{RCT}$ & 30 & 2009-06-02 23:37:05 & 2 & 2.000000 & 20.000000 & 2 & 94 & 25 & 99.000000 \\
\hline & 6 & RCT & 30 & $2009-06-0223: 37: 50$ & 1 & 2.000000 & 20.000000 & 2 & 94 & 25 & 99.000000 \\
\hline
\end{tabular}

Figura 6.9 - Exemplo de base de dados contendo registros de faltas.

A base local que se encontra na subestação, por meio dos campos "subestacao" e "alimentador", identifica as informações específicas da subestação e alimentador em que o sistema de aquisição de localização de faltas está instalado. Como o sistema precisa ser modular para a instalação em outras subestações, é preciso então este código de identificação.

Mediante a ocorrência de um desligamento, tais informações precisam ser acessadas para a correta tomada de decisão visando o restabelecimento do sistema. Como estratégia de acesso, deve-se então utilizar a rede ethernet e realizar o sincronismo entre as informações das bases locais (nas subestações) e a base central localizada no centro de operação da distribuição.

Nas máquinas utilizadas no sistema de localização de faltas deverá ser instalado um servidor de base de dados da família SQL. Tais servidores funcionarão como Escravos. A base de dados central que se encontra no centro de operação da distribuição também deverá possuir um servidor de banco de dados $S Q L$ e este funcionará como Mestre.

Quanto à operação do sincronismo, duas estratégias podem ser adotadas, sendo uma manual e outra automatizada. No sincronismo manual, fica então disponível no PC localizado no centro de operação um aplicativo que, mediante um desligamento, permite ao operador efetuar um sincronismo entre a base de dados da subestação afetada pela falta (Escrava) e a base de dados Mestre. Cada servidor Escravo, portanto, deverá possuir um identificador de IP para que seja possível o 
sincronismo apenas da subestação desejada. Este tipo de estratégia é orientada a eventos e pode ser utilizada tanto em situações de desligamento como em estudos periódicos sobre a ocorrência de faltas.

Já o sincronismo automático visa manter a base de dados Mestre a mais atualizada possível em relação a todas as subestações que venham a ser utilizadas como pilotos, para que o tráfego de informações quando da ocorrência de um desligamento seja o mínimo possível, sendo também direcionado aos últimos eventos. Este sincronismo por meio de replicação está presente na maioria dos mecanismos de gerenciamento de bases de dados e deverá ser executado periodicamente pela equipe de tecnologia de informação, de tal modo que quando da necessidade real de uma busca, o operador tenha dados sempre atualizados.

A replicação deverá afetar todas as subestações pilotos; assim, de tempos em tempos, as mesmas irão solicitar uma sincronia com a base de dados.

Os passos padrões para se adotar o mecanismo de replicação MestreEscravo variam para cada gerenciador de base de dados; porém, é possível definir os seguintes critérios em modelos SQL:

1. Primeiramente, é preciso a criação de um usuário no servidor Mestre, com prioridades de replicação;

2. O usuário criado em 1 precisará possuir direitos de replicação na base de dados que se deseja sincronizar no servidor Mestre;

3. A este servidor mestre deve ser atribuído o id $=0$, pois ele será o centralizador dos recursos;

4. Deve-se habilitar o log de registros binários e a atualização por meio do log para os servidores Escravos, junto ao servidor Mestre. Por meio deste recurso é que se habilitará a sincronização;

5. É preciso após estes passos reiniciar o servidor Mestre; 
6. Em cada servidor Escravo deve ser atribuído um id $>0$, para que este compreenda que a hierarquia começa no servidor de id $=0$, que neste caso é o servidor Mestre;

7. Em cada servidor Escravo é preciso definir o IP para onde o serviço de replicação deverá apontar. No caso o IP do servidor Mestre;

8. É preciso realizar a mudança de status (Mestre para Escravo) em cada um dos servidores Escravos, especificando-se o usuário de replicação criado em 1, a senha deste e também o IP de destino do servidor Mestre;

9. Após estes procedimentos, é preciso reiniciar os servidores Escravos para que se inicie a sincronização.

De forma resumida, tem-se na Figura 6.10 a tela do Software "MySQL Front", de uso gratuito, onde é possível visualizar a conexão entre as duas bases de dados sendo iniciada.

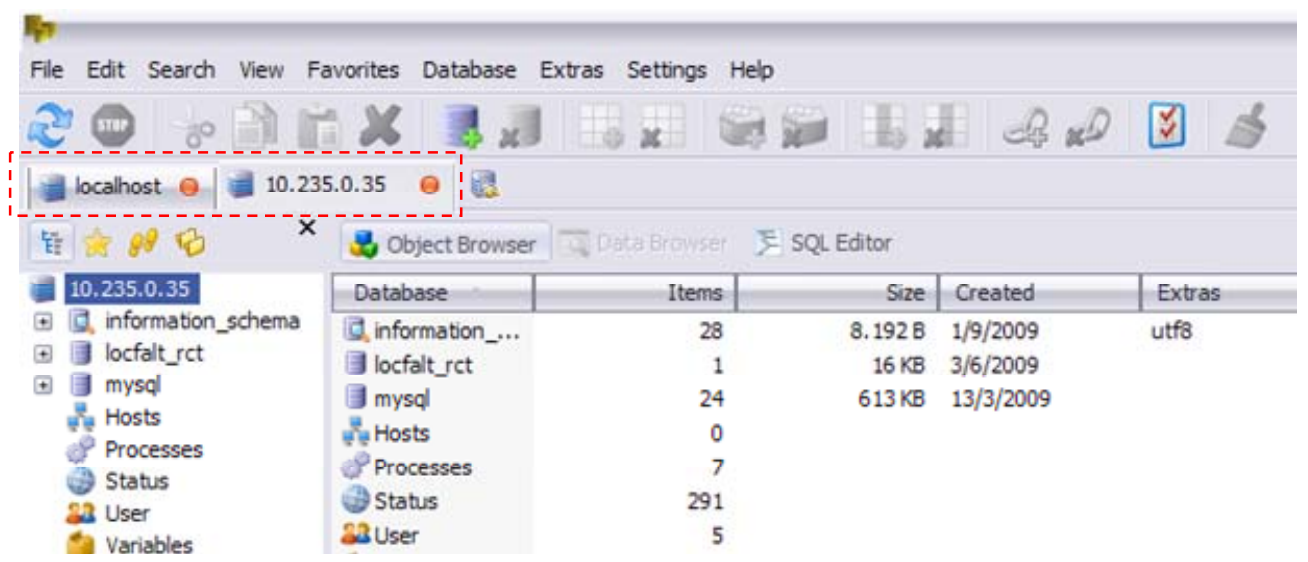

Figura 6.10 - Tela do software MySQL Front contendo as conexões para as bases de dados.

O dispositivo representado pelo IP "10.235.0.35" corresponde ao computador localizado na subestação e o "localhost" à máquina que irá receber os dados remotos. O software "MySQL Front" possui suas próprias ferramentas de sincronismo, com diversas funcionalidades otimizadas para transmissão em baixa velocidade. Na Figura 6.11 tem-se a representação do passo anterior ao do 
sincronismo, onde as bases locais (lado direito) e remotas (lado esquerdo) estão representadas.

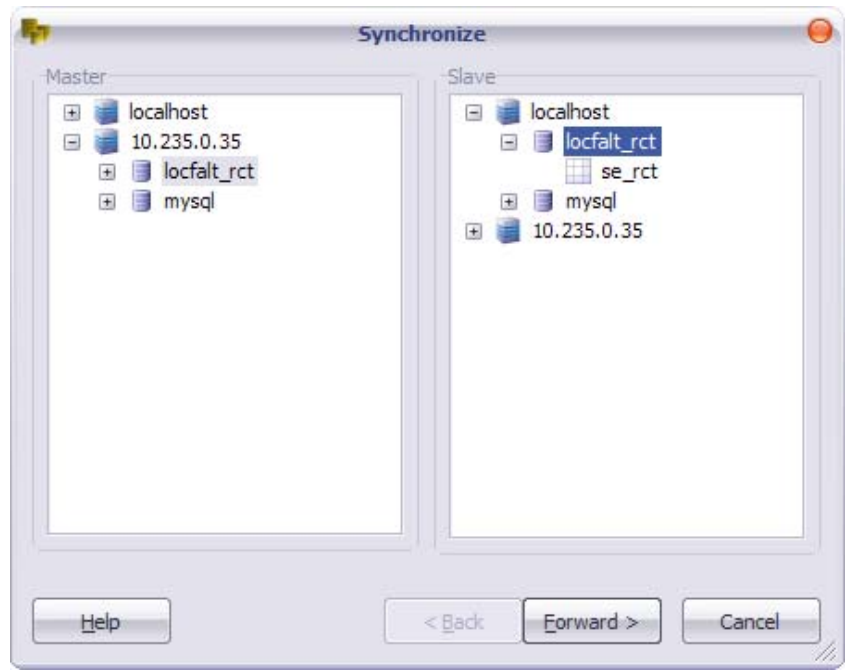

Figura 6.11 - Tela do software MySQL Front precedente ao sincronismo.

O próximo passo permite a configuração avançada das opções de sincronismo, sendo representada pela Figura 6.12.

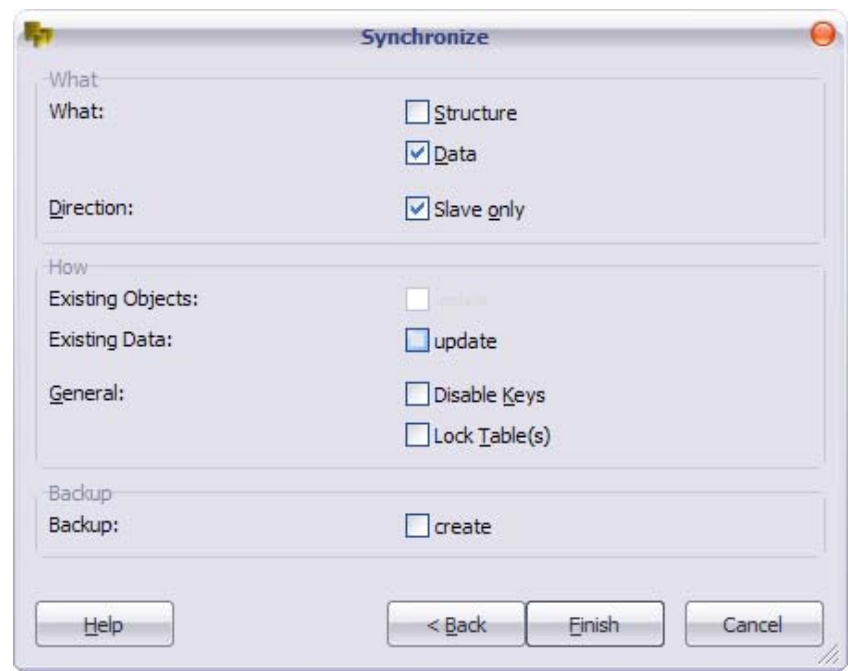

Figura 6.12 - Tela do software MySQL contendo as configurações avançadas de sincronismo.

As opções "Data" e "Slave only" quando selecionadas, assim com as demais não selecionadas, permitem o sincronismo rápido dos dados existentes na subestação, atualizando os registros mais novos da máquina remota para a máquina local. A transferência de 7 registros contendo dados de faltas pode ser exemplificada 
na Figura 6.13, onde menos de um segundo foi gasto para o download das informações, sendo esta informação omitida pelo software.

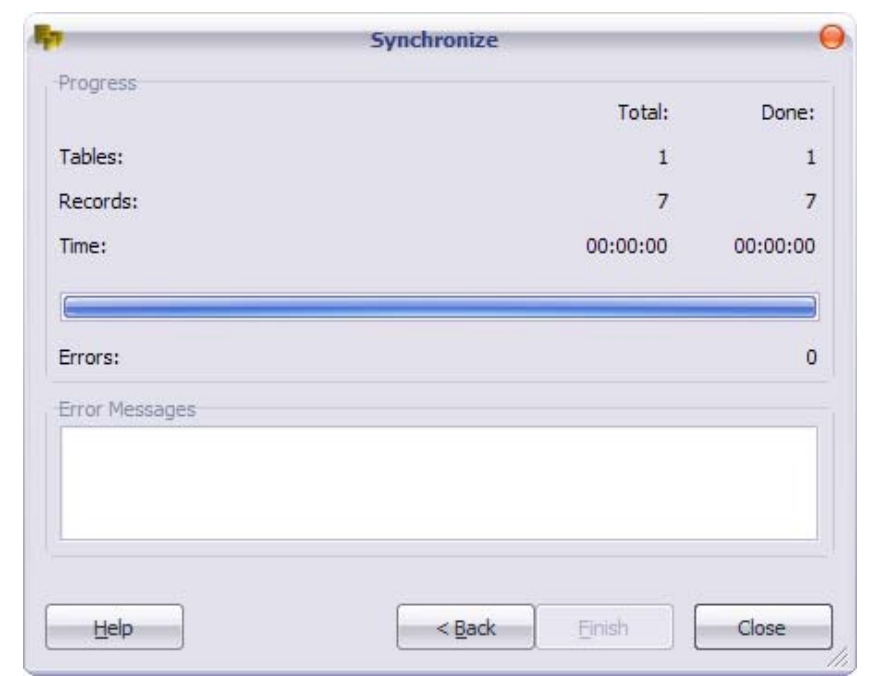

Figura 6.13 - Tela do software MySQL contendo a conclusão do sincronismo.

Este mecanismo permite que as informações das subestações selecionadas para monitoramento com o sistema de detecção de faltas fiquem disponíveis via rede ethernet para todos os hosts pertencentes a esta rede e, assim, é possível realizar os processos de tratamento destes registros de faltas no auxílio à tomada de decisão, ou mesmo em estudos periódicos de proteção.

Na tela da Figura 6.14 tem-se o comparativo entre as bases sincronizadas. 


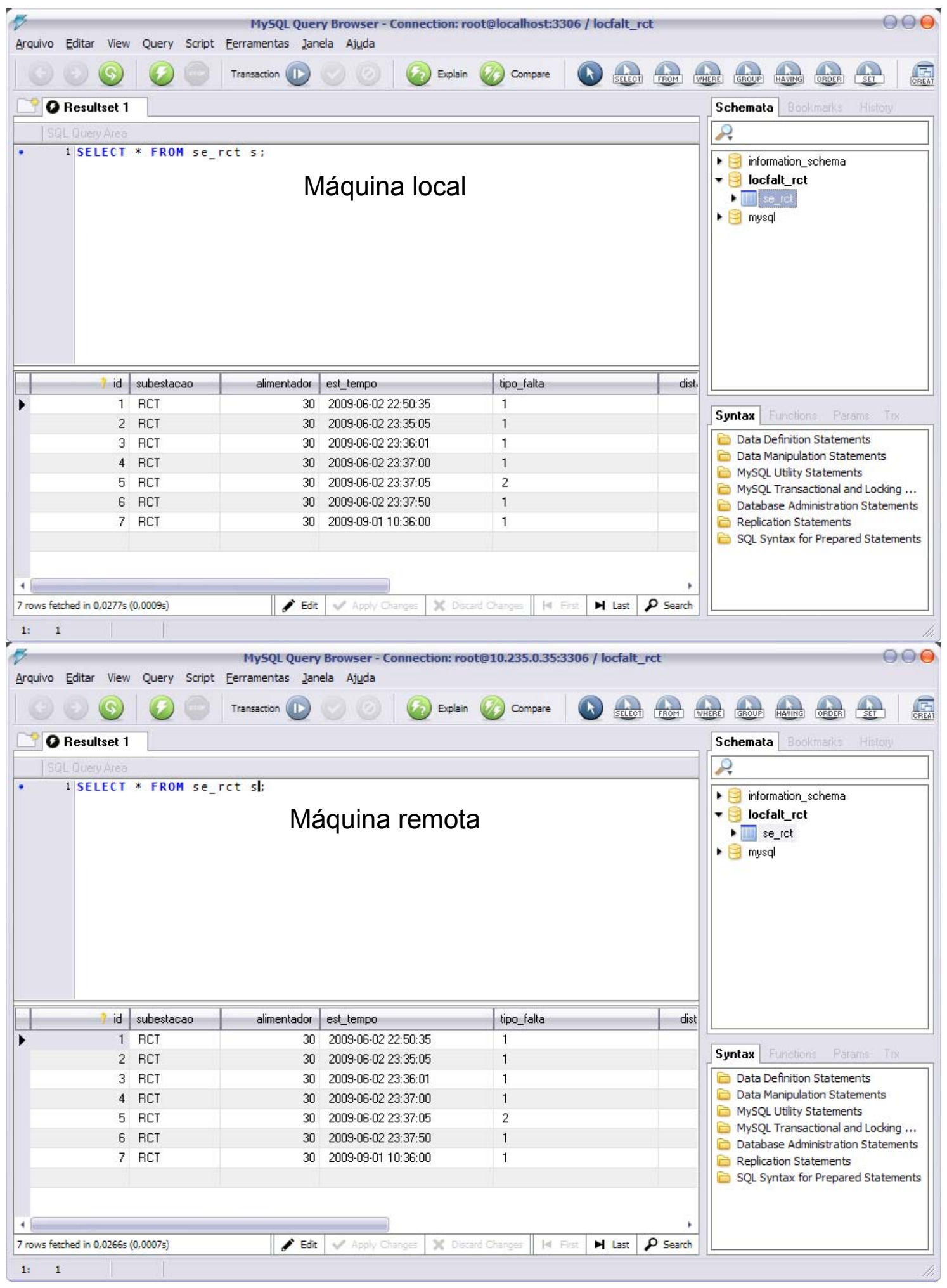

Figura 6.14 - Comparativo entre bases sincronizadas. 



\section{Conclusões e trabalhos futuros}

Esta tese contempla todos os aspectos envolvendo os processos de identificação e localização de faltas, que podem ser aglutinados no termo detecção de faltas, realizado durante o projeto de doutorado.

Da pesquisa em base de dados científicas e técnicas, pode-se constatar o empenho de pesquisadores de vários países em solucionar o problema de localização de faltas em linhas de distribuição. De fato, o problema é complexo e apresenta inúmeros desafios, principalmente quanto à generalidade da ferramenta a ser desenvolvida, frente as mais variadas situações de carga e faltas inerentes ao sistema de distribuição brasileiro.

Destaca-se aqui as ferramentas inteligentes como sendo as mais presentes na literatura científica, pois o seu grande potencial de aplicação já vem sendo empregado com sucesso em diversos outros setores relacionados aos sistemas elétricos de potência. Fica também evidente na pesquisa correlata que apenas a utilização de uma ferramenta inteligente não é capaz de suprir as necessidades de fenômenos faltosos nos sistemas de distribuição elétrico brasileiro, o que reforça ainda mais a proposta desta pesquisa em desenvolver uma ferramenta híbrida, que realiza combinações entre sistemas inteligentes e ferramentas de processamento de sinais, a fim de localizar com precisão o local da falta.

Os resultados obtidos, advindos do exaustivo processamento dos sinais coletados de corrente e tensão em sinais de faltas, permitiram analisar cada uma das estatísticas empregadas com relação a sua eficiência e sensibilidade para cada tipo de falta. 
Dentre os estudos envolvendo as ferramentas de processamentos de sinais, mais especificamente as ferramentas estatísticas, destaca-se a CFAR na determinação de condições de faltas, frente às outras ferramentas avaliadas.

O sistema de localização de faltas desenvolvido, fundamentado em módulos, permite um maior encadeamento das tarefas de identificação de transitórios com a tarefa de discriminação dos mesmos e, por fim, com a tarefa de identificação das fases participantes da falta. A robustez é garantida, pois, a eventual falha em um dos módulos citados pode ser contornada pelos módulos que seguem a este.

Além de uma arquitetura modular e robusta sob o ponto de vista da ocorrência de falhas, o sistema inteligente para identificação de faltas foi implementado fazendo-se uso de ferramentas, comprovadamente eficientes, dedicadas à realização do pré-processamento dos sinais de tensão e de correntes provenientes de sinais de faltas. Essas ferramentas operam sobre os referidos sinais de maneira a lhes extrair características que particularizem e diferenciem condições de falta das demais condições normais de operação.

A eficiência conjunta das ferramentas de pré-processamento é garantida pelo fato de que parte dessas realizam suas inferências no domínio do tempo, enquanto as demais inferem resultados manipulados no domínio da freqüência. Assim, o conjunto de ferramentas empregadas é capaz de, em conjunto, fornecer informações e características em ambos os domínios destacados.

Outra atividade que recebe destaque é a implementação propriamente dita e a simulação do sistema especialista para localização de faltas em linha de distribuição de energia elétrica. O referido destaque se dá em virtude de que eventuais limitações no processo de localização, possam ser corrigidas tanto no âmbito metodológico como no contexto do sistema especialista em si. A partir dos 
procedimentos metodológicos definidos no Capítulo 3, pôde-se treinar e ajustar as diversas arquiteturas de sistemas inteligentes, principalmente aquelas baseadas em redes neurais artificiais, visando o reconhecimento e localização dos trechos que ocorreram as faltas.

Complementarmente, cada um dos módulos constituintes foi desenvolvido e ajustado a fim de que seus resultados fossem coerentes aos desejados. A análise desses resultados possibilitou, então, verificar que a arquitetura proposta e a metodologia de desenvolvimento são plenamente adequadas à implementação do sistema especialista para identificação e classificação de faltas em sistemas de distribuição de energia elétrica.

O modelo de comunicação adotado para o sincronismo entre a subestação e o centro de operação da distribuição utiliza meios largamente difundidos tanto no âmbito acadêmico como industrial, o que propicia uma infinidade de recursos disponíveis.

Finalmente, destaca-se a grande vantagem de se utilizar as associações de bases de dados SQL e o sincronismo por meio de comunicação satélite frente à grande presença destas tecnologias nas empresas distribuidoras de energia elétrica.

Como trabalhos futuros, a evolução desta pesquisa de doutorado poderá ser direcionada para as seguintes frentes investigativas:

i) Avaliação e incorporação de outros paradigmas de sistemas inteligentes, os quais sejam mais voltados para a otimização, tais como as técnicas baseadas nos algoritmos genéticos ou enxame de partículas.

ii) Expansão das funcionalidades dos sistemas especialistas híbridos já desenvolvidos, a fim de se contemplar também aspectos que permitam identificar padrões relacionados com estudos de qualidade de energia. 
iii) Formulação de estratégias para os sistemas híbridos especialistas que permitam identificar se as faltas de alta impedância estão relacionadas diretamente com algum dispositivo defeituoso presente na linha de distribuição, tais como isoladores e pára-raios. 


\section{Referências bibliográficas}

[1] $\mathrm{CHO}, \mathrm{N}$.; HÁ, B., "The results of the field test in distribution automation system for the Korea Utility". Proceedings of Power System Technology POWERCON '98, vol.1, pp. 48-52, 1998.

[2] ZAHRA, F.; JEYASURYA, B.; QUAICOE, J.E., "High-speed transmission line relaying using artificial neural networks". Electric Power Systems Research, no. 53, pp. 173-179, 2000.

[3] GRANADOS-LIEBERMAN, D.; ROMERO-TRONCOSO, R.J.; OSORNIORIOS, R.A.; GARCIA-PEREZ, A.; CABAL-YEPEZ, E., "Techniques and methodologies for power quality analysis and disturbances classification in power systems: a review. IET Generation, Transmission \& Distribution, vol. 5, no. 4 , pp. 519-529, 2011

[4] ANEEL, "Procedimentos de Distribuição de Energia Elétrica no Sistema Elétrico Nacional (PRODIST) - Módulo 8 - Qualidade da Energia Elétrica". Retificação 1, 62 pp., 2010.

[5] TANG, Y.; WANG, H.F.; AGGARWAL, R.K.; JOHNS, A.T., "Fault indicators in transmission and distribution systems". Proceedings of Electric Utility Deregulation and Restructuring and Power Technologies, pp. 238-243, 2000.

[6] CHUNJU, F.; HUARONG, C; WEIYONG, Y., "Application of six-sequence fault components in fault location for joint parallel transmission line". Tsinghua Science \&Technology, vol. 10, no. 2, pp. 247-253, 2005.

[7] YAOZHONG, G., "New types of protective relaying and fault location - Theory and technique". Xi'an Jiao Tong University Press, 1996.

[8] MIRZAI, M.A.; AFZALIAN, A.A., "A Novel Fault-Locator System; Algorithm, Principle and Practical Implementation". IEEE Transactions on Power Delivery, vol. 25, n. 1, pp. 35-46, 2010.

[9] CHOI, M.S.; LEE, S.J.; LEE, D.S., "A new fault location algorithm using direct circuit analysis for distribution systems". IEEE Transactions on Power Delivery, vol. 19, no. 1, pp. 35-41, 2004.

[10] LUO, S.; KEZUNOVIC, M.; SEVICK, D.R., "Locating faults in the transmission network using field measurements, simulation data and genetic algorithm". Electric Power Systems Research, vol. 71, pp. 169-177, 2004.

[11] POURAHMADI-NAKHLI, M.; SAFAVI, A.A., "Path Characteristic FrequencyBased Fault Locating in Radial Distribution Systems Using Wavelets and Neural Networks". IEEE Transactions on Power Delivery, vol. 26, no. 2, pp. 772-781, 2011. 
[12] TAG ELDIN, E.S.M., "Fault location for a series compensated transmission line based on wavelet transform and an adaptive neuro-fuzzy inference system". IEEE Electric Power Quality and Supply Reliability Conference, pp. 229-236, 2010.

[13] MARTINS, L.S.; MARTINS, J.F.; FERNÃO PIRES, V.F.; ALEGRIA, C.M., "A neural space vector fault location for parallel doublé-circuit distribution lines". Electrical Power \& Energy Systems, vol. 27, 225-231, 2005.

[14] MAHANTY, R.N.; GUPTA, P.B.D. "Application of RBF neural network to fault classification and location in transmission lines". IEE Proceedings on Generation, Transmission and Distribution, vol. 151, no. 2, pp. 201-212, 2004.

[15] ZABORZSKY, J.; WHANG, K.; PRASAD, K., "Fast contingency evaluation using concentric relaxation". IEEE Transactions on Power Apparatus and Systems, vol. PAS-99, no. 1, pp. 28-36, 1980.

[16] ELMENDORF, F.; MCGRANAGHAN, M.; DAI, Z., "Next-Generation Power Information System". CIRED 2009 - 20th International Conference and Exhibition on Electricity Distribution, 6 pp., 2009.

[17] KO, Y.S.; KANG, T.K.; PARK, H.Y.; KIM, H.Y.; NAM, H.S., "The FRTUBased Fault-Zone Isolation Method in the Distribution Systems". IEEE Transactions on Power Delivery, vol. 25, no. 2, pp. 1001-1009, 2010.

[18] BUTLER, K.L.; MOMOH, J.A., "A neural net based approach for fault diagnosis in distribution networks". IEEE Power Engineering Society, vol. 2, pp. 1275-1278, 2000.

[19] SARLAK, M.; SHAHRTASH, S.M., "High impedance fault detection using combination of multi-layer perceptron neural networks based on multiresolution morphological gradient features of current waveform". IET Generation, Transmission \& Distribution, vol. 5, no. 5, pp. 588-595, 2011.

[20] LIU, W.H.E.; ZHONG, W., "A Fuzzy set method for fault location identification in power distribution systems". Proceedings of the 35th IEEE Conference on Decision and Control, vol. 2, pp. 2208-2212, 1996.

[21] JARVENTAUSTA, P.; VERHO, P.; PARTANEN, J., "Using Fuzzy Sets to Model the Uncertainty in the fault location process of distribution networks". IEEE Transactions on Power Delivery, vol. 9, no. 2, pp. 954-960, 1994.

[22] DEPEW, A.C.; PARSICK, J.M.; DEMPSEY, R.W.; BENNER, C.L. RUSSELL, B.D.; ADAMIAK, M.G.; "Field experience with high-impedance fault detection relays". 59th Annual Conference for Protective Relay Engineers, vol. 1, pp. 1-6, 2006.

[23] MORA-FLOREZ, J.; ESTRADA-CARDONA, N.; MORALES-ESPANA, G., "Single phase fault location in power distribution systems using statistical analysis". 2008 IEEE/PES Transmission and Distribution Conference and Exposition: Latin America, pp. 1-5, 2008. 
[24] ZADEH, L.A., "Fuzzy sets". Information and Control, vol. 8, pp. 29-44, 1965.

[25] ZADEH, L.A. "Outline of new approach to the analysis of complex systems and decision". IEEE Transactions on Systems, Man and Cybernetics, vol. 3, pp. 28-44, 1973.

[26] MCCULLOCH, W. S.; PITTS, W. "A logical calculus of the ideas immanent in nervous activity". Bulletin of Mathematical Biophysics, vol. 5, pp. 115-133, 1943.

[27] ROSENBLATT, F., "Principles of Neurodynamics and the Theory of Brain Mechanisms". Spartan Books, Washington, DC, 1959.

[28] WIDROW, B.; HOFF, M.E., "Adaptive switching circuits". Proceedings of IRE WESCON Convention Record, pp. 96-104, 1960.

[29] MINSKY, M.L.; PAPERT, S.A., "Perceptrons: An Introduction to Computational Geometry". The MIT Press, Cambridge, Massachusetts, 1969.

[30] HOPFIELD, J.J., "Neural network and physical systems with emergent collective computational abilities". National Academy of Sciences of the U.S.A., vol. 79, pp 2554-2558, 1982.

[31] RUMELHART, D.E.; HINTON, G.E.; WILLIAMS, R.J., "Learning internal representations by error propagation". Parallel Distributed Processing, vol. 1, chap. 8, MIT Press: Cambridge, Massachusetts, 1986.

[32] FROLOV, A.A.; DUFOSSE, M.; BENSMAIL, S.; OUEZDOU, F.B., "Biologically inspired neural network approach to manipulator movement control". Proceedings of the IEEE ICRA '02, vol. 4, pp. 3876-3881, 2002.

[33] PETROVIC, I.; BAOTIC, M.; PERIC, N., "Model structure selection for nonlinear system identification using feedforward neural networks". Proceedings of the IEEE-INNS-ENNS International Joint Conference on Neural Networks, vol. 1, pp. 53-57, 2000.

[34] NAKAYAMA, K.; HIRANO, A.; SAKAI, T., "An adaptive nonlinear function controlled by kurtosis for blind source separation". Proceedings of the International Joint Conference on Neural Networks, vol. 2, pp. 1234-1239, 2002.

[35] KING, D.; FLANAGAN, C.; LYONS, W.B.; LEWIS, E., "An optical fibre water sensor utilizing signal processing techniques and artificial neural network pattern recognition". Proceedings of IEEE Sensors, vol. 2, pp. 1374-1378, 2002.

[36] GROSSMANN, A.; MORLET, J., "Decomposition of hardy functions into squared integrable wavelets of constant shape". SIAM J. Math. Analysis, vol. 15, pp. 723-736, 1984. 
[37] MALLAT, S., "A theory for multiresolution signal decomposition: The wavelet representation". IEEE Transactions on PAMI, vol. 11, no. 7, pp. 674-693, 1989.

[38] DAUBECHIES, I., "The wavelet transform, time-frequency localization and signal analysis". IEEE Transactions on Information Theory, vol. 36, no. 5, pp. 961-1005, 1990.

[39] DAUBECHIES, I., "Ten Lectures on Wavelets". CBMS-NSF Regional Conference Series in Applied Mathematics, Philadelphia, Pennsylvania, 1992.

[40] SMITH, S.W., "The Scientist and Engineer's Guide to Digital Signal Processing". Second Edition, California Technical Publishing, San Diego, California, 1999.

[41] OPPENNHEIM, A.V.; WILLSKY, A.S., "Signals \& Systems". Second Edition, Prentice Hall, 1998.

[42] LYONS, R.G., "Understanding digital signal processing". AddisonWesley,Massachusetts, 1997.

[43] GRANT, P.M., "Digital signal processing - Part 1: Digital filters and the DFT". Electronics \& Communications Engineering Journal, pp. 13-21, 1993.

[44] CHEN, C.H., "Seismic and underwater waveform analysis". Handbook of Pattern Recognition and Image Processing, Academic Press, New York, pp. 527-544, 1986

[45] VAN ECK, T.; AHLBOM, L.G., "Automatic event detection applied to single channel seismic records". IEEE International Conference on Acoustics, Speech and Signal Processing, pp. 1894-1897, 1982.

[46] BODENSTEIN, G.; PRAETORIUS, H.M., "Feature extraction from the electro-encephalogram by adaptive segmentation". Proceedings of IEEE, vol. 65, no. 5, pp. 642-652, 1977.

[47] NUTTALL, A., "Detection performance of power-law processors for random signals of unknown localtion, structure, extent, and strength". NUWC-NPT Tech, Rep., Newport, RI, 10751, 1994.

[48] WANG, Z.; WILLETT, P., "All-purpose and plug-in power-law detectors for transient signals". IEEE Transactions on Signals Processing, vol. 49, no. 11, pp. 2454-2466, 2001.

[49] NUTTALL, A., "Performance of power-law processors with normalization for random signals of unknown structure". NUWC-NPT Tech. Rep., Newport, RI, $10760,1997$.

[50] PROAKIS, J.G.; MANOLAKIS, D.G., "Digital Signal Processing: Principles, Algorithms, and Applications". Third Edition, Prentice Hall, 1996. 
[51] COOLEY, J.; TUKEY, J., "An algorithm for the machine calculation of complex Fourier Series”. Math. Comput., vol. 19, no. 90, pp. 297-301, 1965.

[52] WANG, Z., WILLETT, P., WEBSTER, J., AGUIAR, P.R., "Improved wheel/workpiece contact detection during grinding via AE". Abrasives Magazine, USA, pp.7- 13, 1999.

[53] CHEN, B.; WILLETT, P.; STREIT, R., "A test of overdispersion in a data set with application to transient detection". Proceedings of the 1998 CISS, Princepton, NJ, March 1998.

[54] LIU, J.B., "Monitoring the precision machining process: Sensors, signal processing and information analysis", Ph.D. Thesis, University of California at Berkeley, USA, 1991.

[55] PRESS W.H.; FLANNERY, B.P.; TEUKOLSKY, S.A.; VETTERLING, V.T., "Numerical Recipes in C : The Art of Scientific Computing". Cambridge University Press; 2nd edition, 994 pp., 1993.

[56] HU, Q.; WANG, R.; ZHAN, Y., "Research of Fault Diagnosis Distinguishing Technology Based on PCA-Neural Network". ICICIC 07 - International Conference on Innovative Computing, Information and Control, 4 pp., 2008.

[57] JOTA, F.G.; JOTA, P.R.S., "High-impedance fault identification using a Fuzzy reasoning system". IEE Proceedings - Generation, Transmission and Distribution, vol. 145, no. 6, pp. 656-661, 1998.

[58] EBRON, S.; LUBKEMAN, D.L.; WHITE, M., "A neural network approach to the detection of incipient faults on power distribution feeders". IEEE Transactions on Power Delivery, vol. 5, no. 2, pp. 905914, 1990.

[59] KO, J. H.; SHIM, J. C.; C. WAN RYU; PARK, G.; YIM, W. Y., "Detection of high impedance faults using neural nets and chaotic degree". Proceedings of Energy Management and Power Delivery, vol. 2, pp. 399-404, 1998.

[60] BUTLER, K.L.; MOMOH, J.A.; SOBAJIC, D.J., "Field studies using a neuralnet-based approach for fault diagnosis in distribution networks". IEE Proceedings - Generation, Transmission and Distribution, vol. 144, no. 5, pp. 429-436, 1997.

[61] BUTLER, K.L.; MOMOH, J.A., "Robust features selection scheme for fault diagnosis in as electric power distribution system". CCECE/CCGEl' 93, pp. 209-213, 1993.

[62] ULRYCH, T.; BISHOP, T., "Maximum entropy spectral analysis and autoregressive". Rev. Geophysics and Space Physic, vol. 13, pp. 183-200, 1975.

[63] AKAIKE, H., "Fitting autoregressive models for prediction". Annals Inst. Statist. Math., vol. 21, pp. 243-247, 1969. 
[64] CHEN, W.H.; LIU, C.W.; TSAI, M.S., "On-line fault diagnosis of distribution substations using hybridcause-effect network and Fuzzy rule-based method". IEEE Transactions on Power Delivery, vol. 15, no. 2, pp. 710-717, 2000.

[65] MAGNAGO, F.H.; ABUR, A., "A new fault location technique for radial distribution systems based on high frequency signals". IEEE Power Engineering Society Summer Meeting, vol. 1, pp. 426-431, 1999.

[66] GAOUDA, A.M.; KANOUN, S.H.; SALAMA, M.M.A.; CHIKHANI, A.Y. "Wavelet-based signal processing for disturbance classification and measurement". IEE Proceedings on Generation, Transmission and Distribution, vol. 149, no. 3, pp. 310-318, 2002.

[67] KARIMI, M.; MOKHTARI, H.; IRAVANI, M.R., "Wavelet based on-line disturbance detection for power quality applications". IEEE Transactions on Power Delivery, vol. 15, no. 4, pp. 1212-1220, 2000.

[68] CHAN, D.; WAI, T.; YIBIN, X., "A novel technique for high impedance fault identification". IEEE Transactions on Power Delivery, vol. 13, no. 3, pp. 738744, 1998.

[69] MARTINS, L.S.; MARTINS, J.F.; PIRES, V.F.; ALEGRIA, C.M., "The application of neural networks and Clarke-Concordia transformation in fault location on distribution power systems". IEEE Transactions on Power Delivery, vol. 4, no. 2, pp. 2091-2095, 2002.

[70] FARIA, J.A.B., "Application of Clake's Transformation to the modal analysis of asymmetrical single-circuit three-fase line configuration". ETEP European Transaction on Electrical Power, vol. 10, pp. 225-231, 2000.

[71] LEHTONEN, M.; MATSINEN, A.; ANTILA, E.; KURU, J., "An advanced model for automatic fault management in distribution networks". 2000 IEEE Power Engineering Society Winter Meeting, vol. 3, pp. 1900-1904, 2000.

[72] TANNLUND, P.; BJORKMAN, G., "An advanced distribution automation system experience from application development and project implementation". Proceedings of Power System Technology - PowerCon 2000, vol.1, pp. 127-132, 2000.

[73] CHOI, T.; KOH, I.S.; KIM, B.H.; SONG, W.S.; JANG, W.S., "PC-based remote control and fault location system for distribution line". 1999 IEEE Power Engineering Society Winter Meeting, vol. 2, pp. 1085-1090, 1999.

[74] CHO, N.; HA, B., "The results of the field test in distribution automation system for the Korea Utility". Proceedings of Power System Technology POWERCON '98, vol.1, pp. 48-52, 1998.

[75] BORGHETTI, A.; BOSETTI, M.; NUCCI, C.A.; PAOLONE, M.; ABUR, A., "Integrated Use of Time-Frequency Wavelet Decompositions for Fault Location in Distribution Networks: Theory and Experimental Validation". IEEE Transactions on Power Delivery, vol. PP, n. 99, pp. 1-8, 2010. 
[76] MORA, J.J.; CARRILLO, G.; PEREZ, L., "Fault Location in Power Distribution Systems using ANFIS Nets and Current Patterns". 2006 IEEE/PES Transmission \& Distribution Conference and Exposition: Latin America, pp. 16, 2006.

[77] FRIEDLANDER, B.; PORAT, B., "Detection of transient signals by the Gabor representation". IEEE Transactions on Acoustics, Speech, and Signal Processing, vol.37, no. 2, pp. 169-174, 1989.

[78] SANTOSO, S.; POWERS, E.J.; GRADY, W.M.; HOFMANN, P., "Power quality assessment via wavelet transform analysis". IEEE Transactions on Power Delivery, vol. 11, no. 2, pp. 924-930, 1996.

[79] MO, F.; KINSNER, W., "Wavelet modeling of transients in power systems". WESCANEX 97: IEEE Communications, Power and Computing, pp. 132-137 1997.

[80] CHEN, J.; KINSNER, W.; HUANG, B., "Power System Transien Modelling and Classification". IEEE Canadian Conference on Electrical \& Computer Engineering, vol.1, pp. 184-189, 2002.

[81] MAKI, Y.; LOPARO, K.A., "A neural-network approach to fault detection and diagnosis in industrial processes". IEEE Transactions on Control Systems Technology, vol. 5, no. 6, pp. 529-541, 1997.

[82] JIN, J.; SHI, J., "Automatic feature extraction of waveform signals for inprocess diagnostic performance improvement". Journal of Intelligent Manufacturing, vol. 12, pp. 257-268, 2001.

[83] GREENWOOD, A., "Electrical Transients in Power Systems". John Wiley \& Sons Inc, 1991.

[84] McEACHERN, A., "Handbook of Power Signatures". Published by Basic Measuring Instruments.

[85] LIANG, J.; YUN, Z.; LIU, F., "A method of fault line detection in distribution systems based on wavelets". International Conference on Power System Technology, PowerCon 2002, vol. 4, pp. 2635-2639, 2002.

[86] HERNÁNDEZ, O.C.M.; ENJETI, P.N., "A fast detection algorithm suitable for mitigation of numerous power quality disturbances". IEEE Transactions on Industry Applications, vol. 41, n. 6, pp. 1684-1690, 2005.

[87] ADAMIAK, M.; WESTER, C.; THAKUR, M.; JENSEN, C., "High impedance fault detection on distribution feeders". GE Industrial Systems, Publication \# HizFeeder,

http://www.geindustrial.com/industrialsystems/pm/products/HiZ/papers.htm.

[88] TENGDIN, J.; WESTFALL, R.; STEPHAN, K., "High Impedance Fault Detection Technology", Report of PSRC Working Group D15 http://www.pes-

psrc.org/Reports/High_Impedance_Fault_Detection_Technology.pdf. 
[89] PAUCAR, V.L.; DE SOUSA, O.S., JR.; ALMEIDA, I.O.; RIDER, M.J.; BEDRINANA, M.F.; SANTOS, J.H., "Software development with computer graphics, distributed data base and OOP for deregulated power systems analysis". LESCOPE-04 - Large Engineering systems Conference on Power Engineering, pp. 198-202, 2004. 